
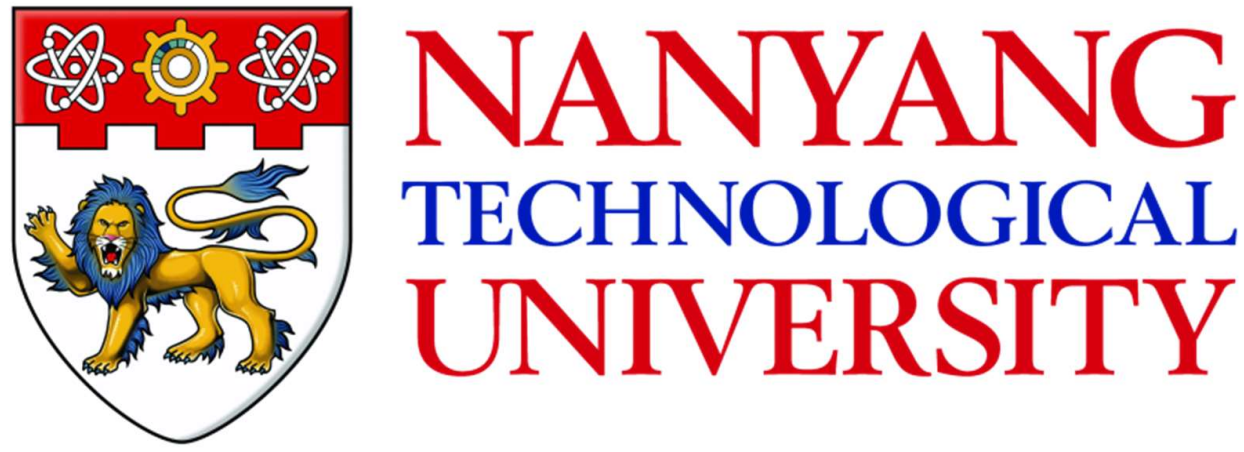

DEVELOPMENT OF COPPER NANOPARTICLES FOR LOW TEMPERATURE DIE-ATTACH APPLICATIONS

NG MEI ZHEN

SCHOOL OF MATERIALS SCIENCE AND ENGINEERING 


\title{
DEVELOPMENT OF COPPER NANOPARTICLES FOR LOW TEMPERATURE DIE-ATTACH APPLICATIONS
}

\author{
NG MEI ZHEN \\ SCHOOL OF MATERIALS SCIENCE AND \\ ENGINEERING
}

\begin{abstract}
A thesis submitted to the Nanyang Technological University in partial fulfilment of the requirement for the degree of Doctor of Philosophy
\end{abstract}




\section{Abstract}

Copper nanoparticles ( $\mathrm{Cu}$ NPs) that are passivated with thin layers of amine-based organic materials is studied as a low temperature die attach material. Due to the high surface energy of these $\mathrm{Cu}$ NPs, they need a protection layer to prevent spontaneous fusion. However, it is important to have these passivation layers removed for effective sintering. Since these layers prevent fusion, the $\mathrm{Cu}$ NPs will have high electrical resistance before any thermal sintering. Therefore, a fast and effective technique has been developed based on observation of electrical resistance measurements during sintering of $\mathrm{Cu}$ NPs when subjected to different sintering parameters. Based on the change in electrical resistance, a sintering model of the Cu NPs used in this study has been developed. It was observed that the onset temperature of volatilization and onset temperature of fusion are closely related to the final microstructures of the sintered $\mathrm{Cu}$ NPs. For good fusion of these $\mathrm{Cu}$ NPs, the passivating layers and the organic materials that are present in the $\mathrm{Cu}$ NPs paste must be effectively and completely removed. Any presence of passivating materials will hinder the fusion of $\mathrm{Cu}$ NPs that leads to low neck growth.

Though it was reported that a higher heating rate is beneficial for the $\mathrm{Cu}$ NPs to achieve a denser sintered layer, it is not necessary for the case in this study. If the passivating layers are not removed completely when subjected to higher heating rates, the fusion of the $\mathrm{Cu}$ NPs is poor and it will lead to lower shear strength. In addition, based on the electrical resistance measurements, it is observed that when the onset temperature of volatilization is high, it will lead to a higher fusion temperature and the degree of necking between $\mathrm{Cu}$ NPs will be high. To leverage on the effect of high heating rates, fast and complete removal of all organic materials within the layer must be carried out. However, this usually would not happen when the heating rate is too fast and/or the peak sintering temperature is $<200^{\circ} \mathrm{C}$ unless sintering is done under a reactive atmosphere. Therefore, to remove the amine-based passivation layers 
faster, formic acid vapor is introduced into the sintering furnace. When formic acid vapor is used, it reacts with the amines-based passivation layers to separate them from the $\mathrm{Cu}$ NPs surfaces. Hence the fusion of $\mathrm{Cu}$ NPs will occur. Since the reaction is faster than sintering in N2 ambient, more fusion was observed and the increase in shear strength was significantly higher when formic acid vapor was introduced only at $200^{\circ} \mathrm{C}$ instead of throughout the sintering process. This again shows that fusion of $\mathrm{Cu}$ NPs at $200^{\circ} \mathrm{C}$ is possible only when the passivation layers are effectively and completely removed. The thermal stability and the level of oxidation of the sintered $\mathrm{Cu}$ NPs joint after 1000 hours of isothermal annealing at $150^{\circ} \mathrm{C}$ in air have demonstrated the potentiality of this material to be used to replace current solder materials.

Lastly, application of $\mathrm{Cu}$ NPs paste was demonstrated for high power LEDs and compared directly with commercially available AuSn solder. The electrical, mechanical and optical properties of the LEDs modules bonded with $\mathrm{Cu}$ NPs are comparable or even better than those LED modules that were bonded with AuSn solders. Moreover, the peak sintering temperature of $\mathrm{Cu} N P s$ is $40^{\circ} \mathrm{C}$ lower than $\mathrm{AuSn}$ reflow temperature. Thus, this material has the potential to lower the overall thermal budget that eventually will reduce the overall manufacturing cost. 


\section{Acknowledgements}

I would like to express my sincere gratitude to my thesis advisor Prof. Gan Chee Lip for all the guidance, opportunities and support throughout my $\mathrm{PhD}$ studies. I would also like to thank the inventor of CuantumFuse $^{\mathrm{TM}}$, Dr Alfred A. Zinn for this fascinating material that gives me the opportunities to explore and learn more about the world of nanoparticles and having the chance to visit his lab to work with him and his wonderful team.

Many thanks to all those people that have provided technical and nontechnical help and support along the way. I would not have survived this far without all of your generous help.

Lastly, I would also like to thank my family and all my besties (you know who you are) who are always there to encourage and give me their utmost support throughout all these while. 


\section{Table of Contents}

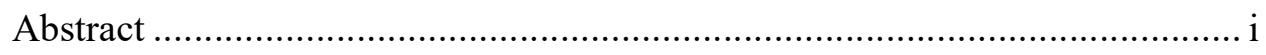

Acknowledgements ............................................................................

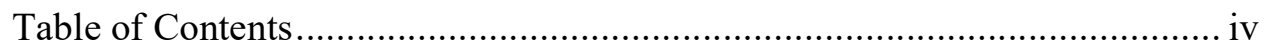

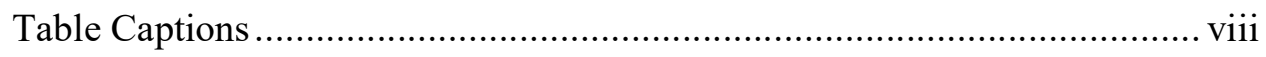

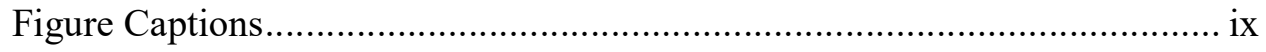

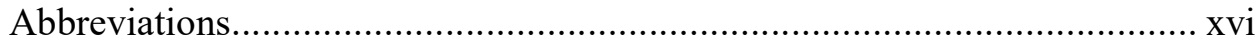

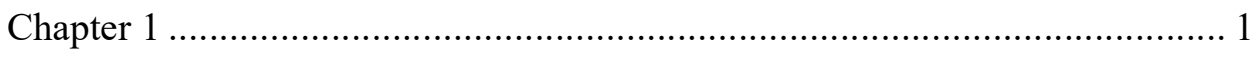

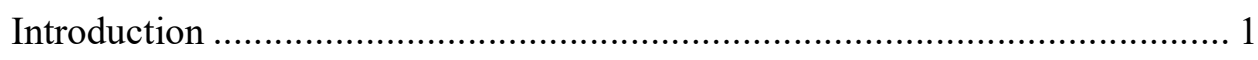

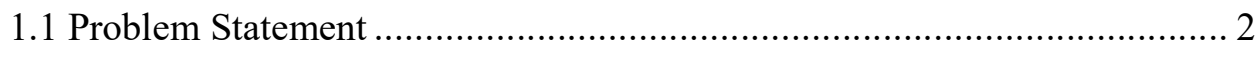

1.2 Objective and Scope........................................................................ 3

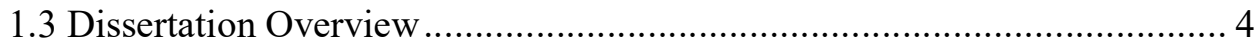

1.4 Findings and Outcomes/Originality .............................................. 6

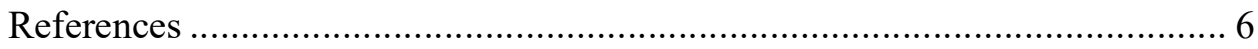

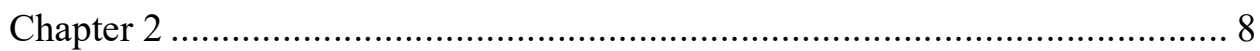

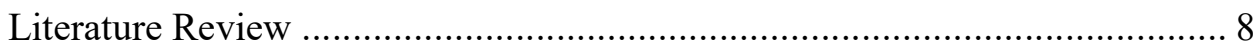

2.1 Overview of interconnects ................................................................ 9

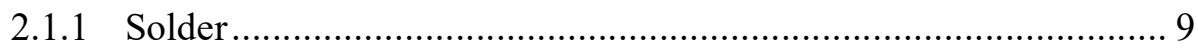

2.1.2 Copper Pillar Bumps .................................................... 12

2.1.3 Electrically Conductive Adhesives (ECAs) ............................ 13

2.1.4 Die attach materials for high temperature applications ............... 14

2.1.4.1 Requirements for High Temperature Die Attach Materials 13

2.1.4.2 Metallic Nano-sized Materials....................................... 15

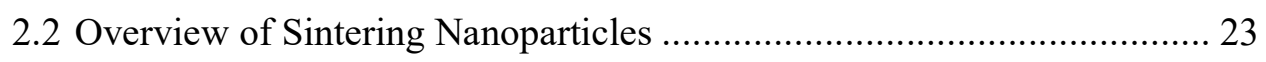

2.2.1 Sintering Mechanism ......................................................... 23

2.2.2 Challenges of Nanomaterial Sintering ................................... 26

$2.3 \mathrm{Nano} \mathrm{Cu}$ Sintering and its Thermal Stability ...................................... 29

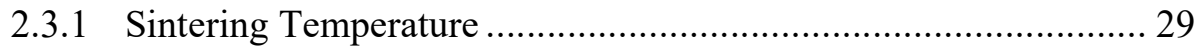

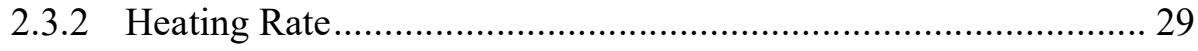


2.3.3 Sintering Time 30

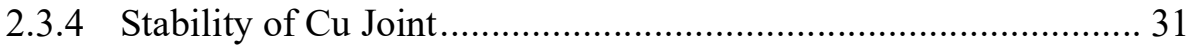

2.4 Sintering Behavior of $\mathrm{Cu}$ NPs and Removal of Organic Materials.......... 31

2.4.1 Removal of solvent and capping layers ................................... 32

$2.5 \mathrm{PhD}$ in Context of literature ............................................................... 34

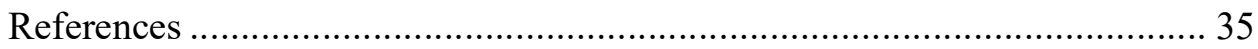

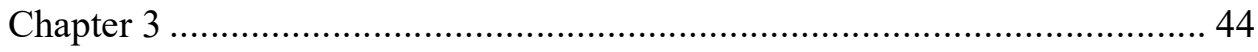

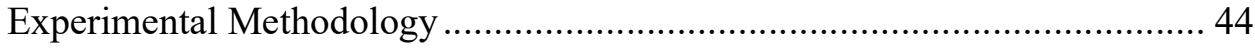

3.1 Rationale for Selection of Methods ................................................. 45

3.2 Post-Processing and Sample Preparation of $\mathrm{Cu}$ NPs .............................. 46

3.2.1 Washing of as-synthesized Cu NPs ......................................... 46

3.2.2 Sample Preparation for Electrical Resistance Studies................. 47

3.2.3 Sample Preparation for Bonding Applications .......................... 48

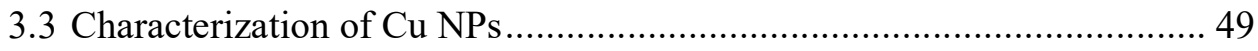

3.3.1 Thermal gravimetric analysis (TGA) ................................... 49

3.3.2 Differential Scanning Calorimetry (DSC) ............................. 51

3.3.3 In-situ electrical resistance measurements................................. 52

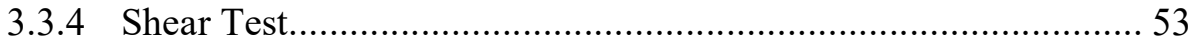

3.3.5 Field Emission Scanning Microscopy with Focused Ion Beam

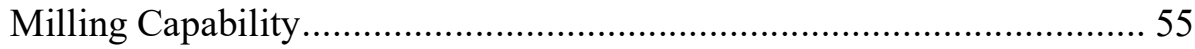

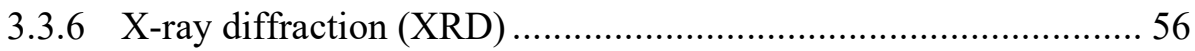

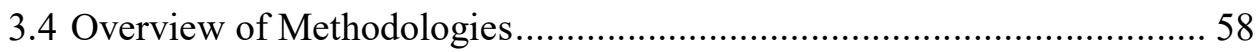

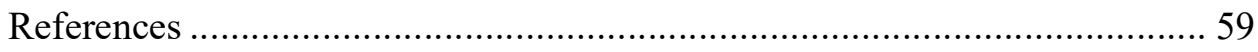

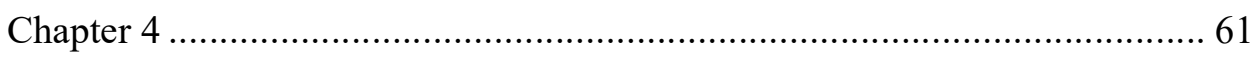

Sintering and Densification Behavior of Nano-sized Copper Particles.......... 61

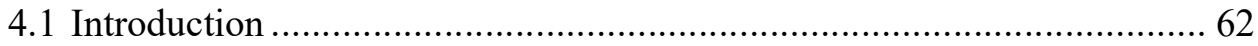

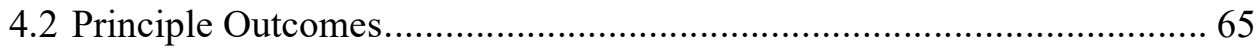

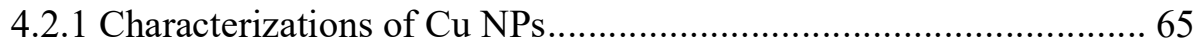

4.2.1.1 In-situ Electrical Resistance Measurement....................... 66

4.2.1.2 Particle growth and electrical resistance measurements ... 70

4.2.2 Sintering Process of Cu NPs .............................................. 73 


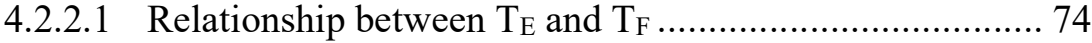

4.2.2.2 Relationship between Heating Rates and Volatilization ... 75

4.2.2.3 Microstructure evolution of $\mathrm{Cu}$ NPs at Different Heating Rates

4.2.2.4 Further Growth and Densification during Isothermal

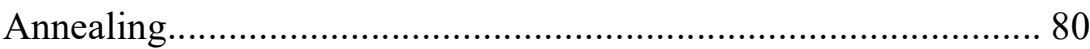

4.2.2.5 Determining the Dominant Sintering Mechanism ........... 86

4.2.3 Stability of Passivating Ligands under Acidic Environment ........ 91

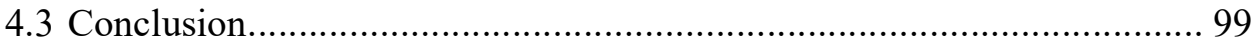

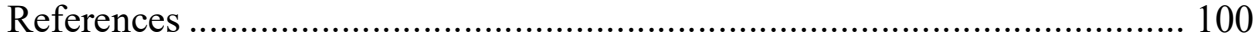

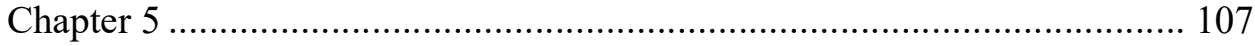

Influence of Sintering Parameters on Bond Strength of Cu NPs ................ 107

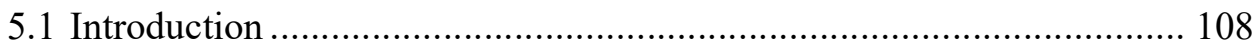

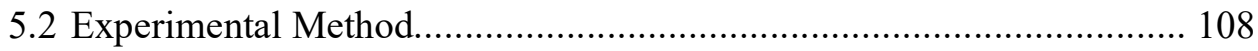

5.2.1 Bonding and characterizations of fused $\mathrm{Cu}$ NPs ..................... 108

Influence of Sintering Parameters on Bond Strength of $\mathrm{Cu}$ NPs ................ 109

5.3.1 Effect of Heating Rate ........................................................ 109

5.3.2 Effect of Bonding Temperature.......................................... 114

5.3.3 Effect of Applied Pressure .................................................... 117

5.3.4 Effect of Bonding Environment ........................................ 125

5.3.5 Relationship between Microstructure, Porosity and Bond Strength 126

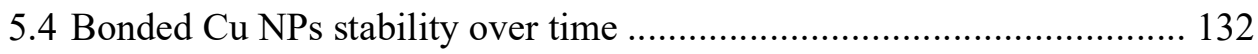

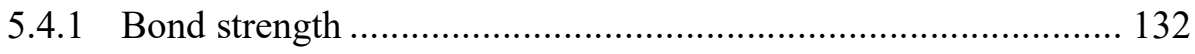

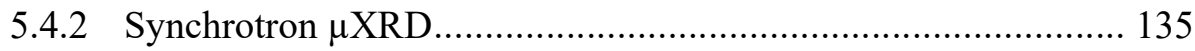

5.4.2.1 Relationship of Shear strength with (111) FWHM........ 137

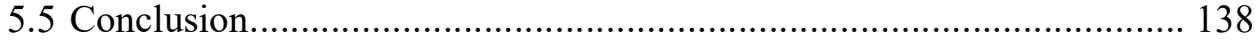

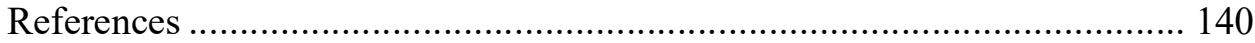

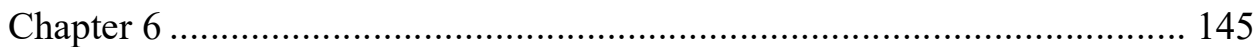

$\mathrm{Cu}$ NPs as Interface Materials for High Power LEDs ............................ 145

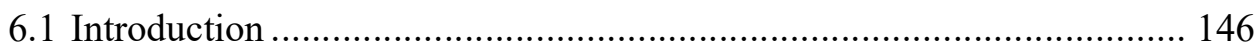


6.2 Experimental Methods .............................................................. 147

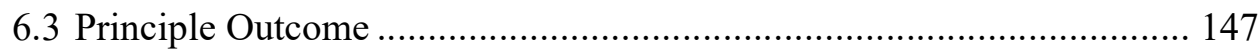

6.3.1 Overview of $\mathrm{Cu}$ NPs as a LEDs die attach material.................. 147

6.3.1.1 Mechanical Measurements ........................................ 149

6.3.1.2 Electrical Measurements .......................................... 150

6.3.1.3 Optical Measurements........................................... 153

6.3.1.4 Thermal Resistance Comparison ............................... 154

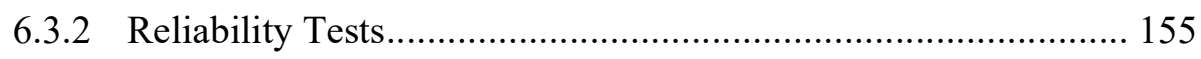

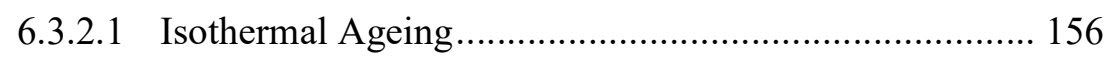

6.3.2.2 Thermomechanical Reliability................................ 162

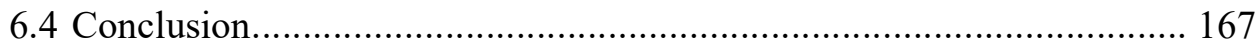

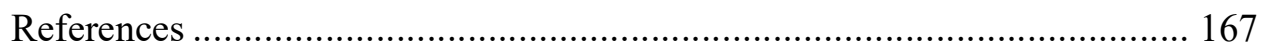

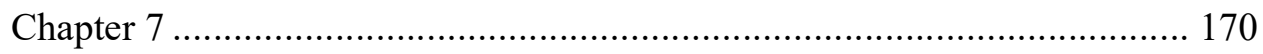

Discussion and Future Work ................................................................ 170

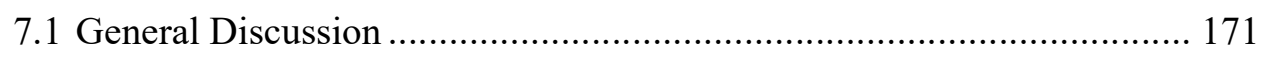

7.1.1 Understanding $\mathrm{Cu}$ NPs Sintering Mechanism Through In-Situ Electrical Resistance Measurement .................................................... 171

7.1.2 Enabling Low Temperature Bonding Using $\mathrm{Cu}$ NPs ................ 173

7.1.3 $\mathrm{Cu}$ NPs Bonding Application in High Power LEDs Die Attach.. 174

7.2 Reconnaissance work not included in main chapters .......................... 176

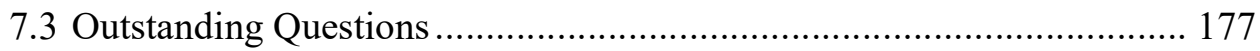

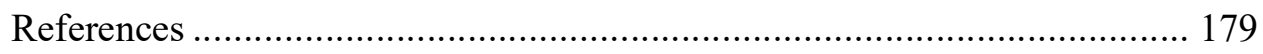

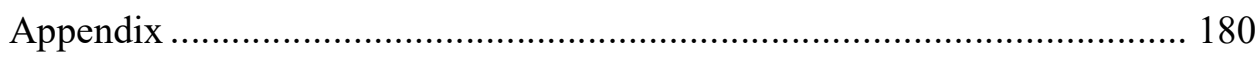




\section{Table Captions}

Table 2.1 Important Properties of Solder Alloy ....................................... 10

Table 2.2 Exponents for different sintering mechanisms [48] ..................... 20

Table 2.3 Values of m, $\mathrm{n}$ and $\mathrm{H}$ for Equation 2.3 [68].............................. 25

Table 5.1 Relative intensity of aged $\mathrm{Cu}$ NPs......................................... 136

Table 6.1 Shear strength of LED modules bonded with Cu NPs and AuSn

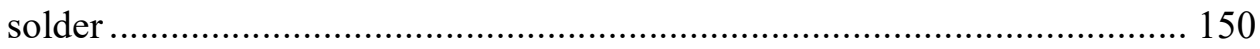

Table 6.2 Electrical resistance of LED modules bonded with Cu NPs and AuSn

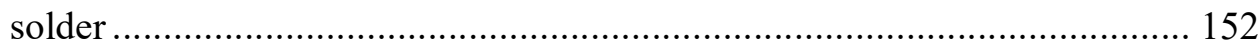

Table 6.3 CTE of materials across the entire LED module [12] ................. 164 


\section{Figure Captions}

Figure 2.1 Fractured Flip Chip Joint [5] ............................................. 11

Figure 2.2 Example of squashed bump due to over bonding [20] ................ 13

Figure 2.3 Schematic diagram and cross-sectioned FESEM of nanowires

bonded with Sn-based solder

Figure 2.4 Top view of $\mathrm{Cu}$ nanowires bundles after removing of the AAO

template

Figure $2.5 \mathrm{~T}_{\mathrm{m}} / \mathrm{T}_{\mathrm{MB}}$ ratio with particle diameter

19

Figure 2.6 Schematic diagram of the different sintering mechanism for a twoparticle model 25

Figure 2.7 Difference between agglomeration and aggregation of nanoparticles during sintering 27

Figure 2.8 Schematic diagram of rate of densification as a function of temperature 28

Figure 3.1 Schematic diagram of the post-processing of $\mathrm{Cu}$ nanoparticles before sintering 46

Figure 3.2 Picture of the simple Electrical Test Structures........................ 47

Figure 3.3 Schematic diagram of a TGA …........................................ 50

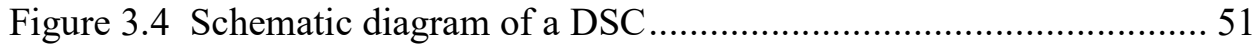

Figure 3.5: Shear test setup ......................................................... 53

Figure 3.6 Schematic diagram of the shear test setup.............................. 55

Figure 3.7 Cross-sectioned SEM image of a sintered $\mathrm{Cu}$ NPs layer .............. 56

Figure 3.8 Schematic diagram of Bragg's law [8] .................................. 57

Figure 4.1 TEM image of Cu NPs used (b) Zoomed-in image of a Cu NP (c) Schematic diagram of how the ligands are attached on $\mathrm{Cu}$ NPs 64 
Figure Captions

Figure 4.2 TGA and electrical resistance curves of $\mathrm{Cu}$ NPs heated from $25^{\circ} \mathrm{C}$

to $300^{\circ} \mathrm{C}$ 66

Figure 4.3 FESEM image and schematic illustration of $\mathrm{Cu}$ NPs before sintering

Figure 4.4 Schematic illustration of the regularly arranged $\mathrm{Cu}$ NPs 68

Figure 4.5 FESEM image and schematic illustration of $\mathrm{Cu}$ NPs after volatilization and onset of neck growth at $150^{\circ} \mathrm{C}$ 70

Figure 4.6 FESEM image and schematic illustration of subsequent neck growth of $\mathrm{Cu}$ NPs at $300^{\circ} \mathrm{C}$ when heated at $10^{\circ} \mathrm{C} / \mathrm{min}$..... 70

Figure 4.7 Fused $\mathrm{Cu}$ NPs sizes as a function of temperature and the corresponding change in electrical resistance.

Figure 4.8 (a) FESEM images of microstructure evolution (Scale $500 \mathrm{~nm}$ ), and (b) Schematic diagram of the $\mathrm{Cu}$ nanoparticles at different stages of sintering 73

Figure 4.9 Heat flow and change in electrical resistance of $\mathrm{Cu}$ NPs as a function of temperature 76

Figure 4.10 In situ electrical resistance for $\mathrm{Cu}$ nanoparticles heated at different rates to $200^{\circ} \mathrm{C}$ 78

Figure 4.11 Microstructure changes of $\mathrm{Cu}$ sintered at (a) $7^{\circ} \mathrm{C} / \mathrm{min}$ (b) $17^{\circ} \mathrm{C} / \mathrm{min}$ (c) $30^{\circ} \mathrm{C} / \mathrm{min}(\mathrm{d}) 40^{\circ} \mathrm{C} / \mathrm{min}$ (Scale: $500 \mathrm{~nm}$ ) 80

Figure 4.12 Resistance as a function of isothermal annealing duration for different heating rate samples 83

Figure 4.13 Microstructure evolution during isothermal annealing of $\mathrm{Cu}$ particles that were previously heated up at different heating rates (Scale bar in white: $500 \mathrm{~nm}$ ). 86

Figure 4.14 Experimental results and proposed model prediction of resistance as a function of time (a) $7^{\circ} \mathrm{C} / \mathrm{min}$ (b) $17^{\circ} \mathrm{C} / \mathrm{min}$ 
Figure Captions

Figure 4.15 Experimental results and proposed model prediction of resistance as a function of time (a) $30^{\circ} \mathrm{C} / \mathrm{min}$ (b) $40^{\circ} \mathrm{C} / \mathrm{min}$ 89

Figure 4.16 Schematics diagram of Cu NPs microstructure evolution after (a) complete removal, (b) incomplete removal of organic materials.

Figure 4.17 XRD of sintered $\mathrm{Cu}$ NPs film at $300^{\circ} \mathrm{C}$ 92

Figure 4.18 in situ electrical resistance measurements during heat up at $40^{\circ} \mathrm{C} / \mathrm{min}$ under $\mathrm{N}_{2}$ and formic acid 92

Figure 4.19 Changes in $T_{F}$ when $\mathrm{HCOOH}$ vapor is introduced with a heating rate of $40^{\circ} \mathrm{C} / \mathrm{min}$.

Figure 4.20 Microstructure evolutions of $\mathrm{Cu}$ NPs (a) under conventional $\mathrm{N}_{2}$ sintering profile (b) under high heating up rate with $18.125 \mathrm{M} \mathrm{HCOOH}$ vapor (Scale bar: $500 \mathrm{~nm}$ )

Figure 4.21 Microstructure of $\mathrm{Cu}$ NPs sintered under (a) $\mathrm{N}_{2}\left(17^{\circ} \mathrm{C} / \mathrm{min}\right)$ (b) 18.125M Formic Acid Vapor $\left(40^{\circ} \mathrm{C} / \mathrm{min}\right)$ 96

Figure 4.22 $\mu$ XRD for samples heated under (a) $\mathrm{N}_{2}$ (b) Formic acid 97

Figure 4.23 Schematic diagrams showing the sintering behavior under (a) $\mathrm{N}_{2}$ and (b) Formic acid

Figure 5.1 Schematic diagram of how the passivating layers on the $\mathrm{Cu}$ NPs escape under (a) covered and (b) uncovered structure

Figure 5.2 FESEM images of un-sintered Cu NPs. (a) Top view, (b) Cross sectioned and (c) Zoom in of the bonded layer

Figure 5.3 Shear strength of sintered $\mathrm{Cu}$ NPs joints at different heating rate 112

Figure 5.4 Microstructure of $\mathrm{Cu}$ NPs joint at ramping rate of (a) $7^{\circ} \mathrm{C} / \mathrm{min}$ (b) $17^{\circ} \mathrm{C} / \mathrm{min}$ (c) $30^{\circ} \mathrm{C} / \min (\mathrm{d}) 40^{\circ} \mathrm{C} / \mathrm{min}$ (Scale Bar: $500 \mathrm{~nm}$ ). 113

Figure 5.5 Microstructures evolution of Cu NPs bonded at (a) $200^{\circ} \mathrm{C}$ (b) $250^{\circ} \mathrm{C}$ (c) $300^{\circ} \mathrm{C}$ for $0-20 \mathrm{~min}$ (scale bar: $1 \mu \mathrm{m}$ ) 
Figure Captions

Figure 5.6 Shear Strength as a function of isothermal duration at $200^{\circ} \mathrm{C}, 250^{\circ} \mathrm{C}$ and $300^{\circ} \mathrm{C}$ 117

Figure 5.7 Porosity of $\mathrm{Cu}$ NPs layer with respect to time for samples bonded at $200^{\circ} \mathrm{C}, 250^{\circ} \mathrm{C}$ and $300^{\circ} \mathrm{C}$.

Figure 5.8 Schematic diagram of bonding without and with bonding pressure exerted

Figure 5.9 Schematic diagram of deformation between $\mathrm{Cu}$ NPs

Figure 5.10 Relationship between shear strength and porosity as a function of bonding pressure 124

Figure 5.11 FESEM images of fracture surfaces and cross sectioned of sintered $\mathrm{Cu}$ joints at (a) $0 \mathrm{MPa}$ (b) $1 \mathrm{MPa}$ (c) $3 \mathrm{MPa}$ (d) $5 \mathrm{MPa}$ (Scale bar of $500 \mathrm{~nm}$ )

Figure 5.12 Cross-sectioned FESEM images of sintered $\mathrm{Cu}$ with and without pressure. 126

Figure 5.13 Shear Strength of $\mathrm{Cu}$ NPs joint under $\mathrm{N}_{2}$ and Formic Acid 127

Figure 5.14 Microstructures of the sintered Cu NPs under (a) $\mathrm{N}_{2}$ and (b) formic acid vapor

Figure 5.15 in-situ Electrical resistance measurements under $\mathrm{N}_{2}$ and formic acid vapor environment.

Figure 5.16 Schematics illustration of densification at (a) $200^{\circ} \mathrm{C}$ and (b) $300^{\circ} \mathrm{C}$ (Scale bar: $1 \mu \mathrm{m}$ )

Figure 5.17 Failure types and locations (a) Type 1: Propagate along weakly bonded $\mathrm{Cu}$ NPs (b) Type 2: Does not propagate easily along $\mathrm{Cu}$ NPs due to strong bonding

Figure 5.18 Shear strength of sintered Cu NPs under isothermal ageing at $150^{\circ} \mathrm{C}$ for 1000 hours 
Figure Captions

Figure 5.19 Microstructure evolutions of bonded $\mathrm{Cu}$ layers during ageing test from $0-1000$ hours (Scale bar: $500 \mathrm{~nm}$ ) 135

Figure 5.20 XRD patterns of $\mathrm{Cu}$ NPs (a) before (b) after ageing for 1000 hours

Figure 5.21 Graph of shear strength and line width (FWHM) as a function of ageing time.

Figure 6.1 As-reflow single-chip LED module 148

Figure 6.2(a) Overview of the LED module bonded with (a) Cu NPs paste with (b) Zoom-in view of the bonded layer; (c) AuSn solder with (d) Zoom-in view of the bonded layer (scale $10 \mu \mathrm{m}$ ). 149

Figure 6.3 FESEM cross-sectioned image of $\mathrm{Cu}$ NPs on the LED die after shear test

Figure 6.4 Schematic diagram of the electrical resistance measurement setup of LED module. 152

Figure 6.5 Photoluminescence spectra of Cu NPs and AuSn die-attach LEDs operated at $3 \mathrm{~V}$ at room temperature. 153

Figure 6.6 Measured temperature with time for Cu NPs and AuSn LED samples 155

Figure 6.7 Shear Strength of Cu NPs LED die after $1000 \mathrm{hrs}$ of thermal aging 156

Figure 6.8 Microstructural changes of $\mathrm{Cu}$ NPs bonded onto LED 158

Figure 6.9 Microstructures of Cu NPs (a) just after sintering, (b) after 1000 hours at $200^{\circ} \mathrm{C}$ 158

Figure 6.10 Fracture surfaces of LED dice and substrate after (a) 250 hours (30 $\mu \mathrm{m}$ scale) (b) 1000 hours of isothermal ageing at $200^{\circ} \mathrm{C}(100 \mu \mathrm{m}$ scale $) \ldots . . .159$ Figure 6.11 Schematic diagram of crack propagation through Cu NP layer . 159 
Figure Captions

Figure 6.12 Electrical resistance of $\mathrm{Cu}$ NPs with Au LED from $0-1000 \mathrm{hrs}$ of isothermal ageing test

Figure 6.13 Photoluminescence spectra of Cu NPs on Au metallization of a white light LED (blue + phosphor) operated at $3 \mathrm{~V}$ at room temperature for different ageing period

Figure 6.14 Shear strengths of $\mathrm{Cu}$ NPs bonded LEDs after thermal cycling. 163

Figure 6.15 FESEM images of Cu NPs LED modules after (a) 100 cycles, (b) 200 cycles, (c) 300 cycles (Scale: $20 \mu \mathrm{m}$ ) 164

Figure 6.16 Voids were present at the bonding interface between $\mathrm{Cu}$ NPs and (a) Ag, and (b) Au metallization after sintering.... 166

Figure 6.17 (a) FESEM image of sheared surface of an as-bonded LED chip (b) Zoomed-in on the "islands" of sintered Cu NPs clusters. 166

Figure 7.1 Color change during bonding under (a) N2 (b) Formic Acid...... 176 


\section{Abbreviations}

DSC Differential Scanning Calorimetry

EDS Energy Dispersive X-ray Spectroscopy

FESEM Field Emission Scanning Electron Microscopy

TEM Transmission Electron Microscopy

TGA Thermogravimetric Analysis

XRD X-ray Diffraction 


\section{Chapter 1}

\section{Introduction}

Die attach materials are used as a bonding material between a die and a substrate. They play a key role in the performance and reliability of the overall microelectronics package. Some of the common die attach materials are gold alloys, solders and polymeric adhesive pastes or films. Recently, the development of gallium nitride (GaN) and silicon carbide (SiC) for high power electronics in automotive, aerospace, high-brightness light-emitting diodes (HBLEDs) and sensor technology has led to a surge in the demand for lead-free soldering material that is able to meet the high temperature electronics requirements. Hence, several new die attach materials are in development. Among them are the metallic nanoparticles (NPs) such as $A u, A g$ and $C u$ that have gained tremendous interest in this field. This is attributed to its high electrical and thermal conductivity, low elastic modulus that enables good thermo-mechanical reliability, its ability to be processed at lower temperatures due to their high surface energies and yet able to operate at high temperatures. However, though the metallic nanomaterials found in literatures are similar, the synthesis technique, the size and size distribution of NPs, and the capping layers are very much different. Hence, this thesis will investigate the feasibility of a chemically synthesized $\mathrm{Cu} N \mathrm{~N}$ s to be used as a die attach material in high power electronics, and at the same time develop ways to study such materials in general. 


\subsection{Problem Statement}

High-power semiconductor devices currently represent one of the highest growth sectors of any semiconductor technology, with many key applications including motor control, high-brightness light-emitting diodes (HBLEDs), solar concentrator cells, and radio-frequency (RF) and microwave circuits used in radar and telecommunications equipment. From a packaging perspective, there are a number of common requirements for all these high-power applications. They must be able to handle high electrical currents, possess a higher melting point than the operating temperature, able to dissipate large amounts of heat, manage thermal expansion-induced stresses for high reliability, and this must all be accomplished at low cost. The problem with current conventional soldering materials, such as Tin-Silver-Copper (SAC), is that it has a low working temperature as it melts at a low eutectic temperature of $217^{\circ} \mathrm{C}$. Therefore, they are not suitable as the $\mathrm{SiC}$ power transistor die attach because the melting temperature of the solder is much lower than the potential application temperature of $>250^{\circ} \mathrm{C}$ [1]. Thus, lead-tin ( $\mathrm{PbSn}$ ) solder, typically $\mathrm{Pb} 90 \mathrm{Sn} 10$ which has a liquidus temperature of $302^{\circ} \mathrm{C}$, is still commonly used for power semiconductors. Another advantage of this material is its high ductility and acceptable thermal conductivity. However, due to its high $\mathrm{Pb}$ content, it has negative effects on health and the environment. To overcome this problem, AuSn or AuSi solders are the best alternatives. Both types of solders have high melting temperatures, good thermal and electrical conductivities. However, the major drawback for both of these materials is their cost. In addition, when compared with other low temperature solders, AuSn and AuSi have lower ductility and require a higher die attach temperature, making thermal coefficient of expansion (TCE) stress an issue. When AuSn solders are used on $\mathrm{Cu}$ lines, the formation of irregularly ( $\mathrm{Au}, \mathrm{Ni}$ ) Sn intermetallic on $\mathrm{Cu}$ lines can lead to lower mechanical strength.

With all these problems stated above, it is important to develop and understand the next alternative material to be used in interconnects and die attach material technology, especially for high power electronics applications. This new material must be able to process at low temperature $\left(\leq 200^{\circ} \mathrm{C}\right)$, has a high melting point after processing $\left(>300^{\circ} \mathrm{C}\right)$, good mechanical strength, high electrical and 
thermal conductivities. The compatibility, i.e. good wetting and little or no intermetallic formation, with common metallization such as copper, silver, gold or nickel is necessary. In addition, it must not be too expensive and be able to be integrated into the current processing system with minimum or no changes required. It is well-known that nanoparticles have a higher surface energy than bulk form due to its higher surface area to volume ratio. As a result, metallic nanoparticles can be fused at a much lower temperature. Therefore, if copper nanoparticles can be used as a paste similar to the solder paste currently adopted in the die attach technology, it can have the excellent properties of a bulk copper such as high electrical and thermal conductivities after reflow (i.e. sintering), yet maintain a low processing temperature as that used currently in the solder reflow process. Furthermore, with $\mathrm{Cu}$ NPs as a die attach material, it can potentially improve the joint's bond strength as no IMCs would be formed within the joint that would lower the bond strength. Hence reliability can be improved as compared to current solder materials.

\subsection{Objective and Scope}

The objective of this study is to understand a new lead-free nanomaterial for die attach technology by studying the processing-microstructure-property relationship, which is the low temperature sintering of copper nanoparticles paste. The scope of this project will cover the processing procedure of the assynthesized copper nanoparticles paste to suit the current surface mount technologies such as syringe-dispensing and screen/stencil-printing. Detailed study on its physical sintering mechanism such as removal of organic materials, fusion and densification of the nanoparticles at different processing parameters will be carried out. Microstructure evolutions with various changes in sintering parameters and long-term joint stability after sintering will also be studied. Finally, the feasibility of adopting this material as a die attach material for commercially available LEDs dies and substrate will be studied and benchmarked against the high temperature AuSn solder. The mechanical, electrical and optical properties of the sintered $\mathrm{Cu}$ NPs joints will be analyzed through the bonded joint. Lastly, reliability testing such as thermal ageing and thermal cycling will also be done to understand the potential failure mechanisms. 


\subsection{Dissertation Overview}

This thesis addresses the issues and challenges of today's materials used in the interconnect and die attach technology. In addition, this thesis also investigates and discusses about a new viable material, copper nanoparticles paste, that can be used in the current and future interconnect and die attach technology.

Chapter 1 provides a rationale for the research and outlines the goals and scope.

Chapter 2 reviews the literature concerning the types of interconnect and die attach technology and their limitations and challenges towards current and future electronics devices. The development of future interconnects and die attach materials such as copper pillars, copper pillar bumps and metallic nanoparticles to be used as the next solder materials, will be discussed. With the introduction of $\mathrm{Cu}$ pillar and $\mathrm{Cu}$ pillar bumps, it does help to solve certain issues such as stand-off height and shorting between solder bumps due to smaller pitch. However, high processing temperature in the previous and formation of intermetallic in the latter pose some challenges for them to be adopted. Hence the development of metallic nanoparticles paste comes into the picture. These metallic nanoparticles are able to form connecting paths based on the principle of sintering that has been very well developed, especially for ceramics materials. However, due to its small diameter, it has a high surface energy that enables these metallic nanoparticles to be sintered at low temperature. Till date, there are not much studies on $\mathrm{Cu}$ nanoparticles. One of the reasons being its tendency to oxidize easily that affects its electrical properties. Hence this chapter will also be looking into the current studies on $\mathrm{Cu}$ nanoparticles and areas that have yet to be studied but worth the attention.

Chapter 3 discusses the experimental methodology used in this entire study. First, the post-processing procedures of the synthesized $\mathrm{Cu}$ nanoparticles needed to be carried out to suit specific applications are explained. Some of the characterization techniques used to study the thermal properties of copper nanoparticles before sintering includes thermal gravimetric analysis (TGA) and differential scanning calorimetry (DSC). Microstructures evolution based on changes in electrical resistance during sintering are studied in detail using FieldEffect Scanning Electron Microscopy (FESEM) coupled with Focused-Ion 
Beam (FIB) milling capability. Energy dispersive X-ray spectroscopy (EDX) was also used to study the chemical and elemental analysis of the sintered and aged copper joint.

Chapter 4 discusses about the sintering and densification behavior of nano-sized copper particles. TGA, DSC and in-situ electrical resistance measurements during sintering were used to study the thermal, physical and electrical changes that arose under the different processing parameters. It is observed that the heating up rate has a direct influence on the onset temperature of evaporation of organic materials $\left(\mathrm{T}_{\mathrm{E}}\right)$, which subsequently affects the fusing temperature $\left(\mathrm{T}_{\mathrm{F}}\right)$. Moreover, the rate of evaporation of organic materials under different environment such as inert and formic acid vapor, has an impact on the rate and uniformity of passivating layers' removal on the $\mathrm{Cu}$ NPs. These changes in process parameters and environment will eventually affect $\mathrm{T}_{\mathrm{E}}$ and $\mathrm{T}_{\mathrm{F}}$, electrical resistance and microstructure such as size and amount of porosities of the sintered $\mathrm{Cu}$ layer. The microstructure at different stages of sintering under different process parameters and environment were captured with the help of the in-situ electrical resistance measurements. Hence this chapter will provide an indepth study on the relationship between process parameters and final microstructure of sintered $\mathrm{Cu}$ NPs.

Chapter 5 discusses about the relationship between sintering parameters and the resultant microstructure of the $\mathrm{Cu}$ NPs that is used as a die attach material. As this study is targeted towards the bonding application, mechanical properties such as the shear strength of the bonded joints are tested and related with the amount of porosities and degree of necking between fused $\mathrm{Cu}$ NPs clusters. Since the removal of capping layer is critical for good fusion of $\mathrm{Cu}$ NPs, the capability to remove and the impact of fast and effective removal of these capping layers on the resultant microstructure and shear strength are presented and further discussed. Two different failure modes that led to a good or poor joint strength are outlined based on the type of microstructures that have resulted from the different sintering parameters. The effect of long term thermal stability of the sintered joints were also carried out to further understand the microstructure evolution, grain growth and degree of oxidation with its final mechanical shear strength. 
Chapter 6 discusses the feasibility of adopting such $\mathrm{Cu}$ NPs paste for high power LEDs applications. Commercially available high temperature solder, AuSn, was used as a comparison. From the initial bonding, the $\mathrm{Cu}$ NPs demonstrated a comparable or better performance than AuSn solder in terms of mechanical, electrical and optical properties. This is attributed to the good physical properties of $\mathrm{Cu}$, the lack of formation of IMCs or "big voids or cracks between $\mathrm{Cu}$ NPs and bonding interfaces". To understand the long term reliability of such material, long-term high temperature storage test at $200^{\circ} \mathrm{C}$ for 1000 hours and thermosmechanical test were carried to understand the reliability of this novel material on actual LED modules.

Chapter 7 gives an overall discussion with three sub sections that give a summary of the findings and implications for the three main findings of this study. It also addresses and discusses on the results achieved with the initial designed target that was eventually met. Some questions were raised during the course of study and future works are being proposed.

\subsection{Findings and Outcomes/Originality}

This research has led to several novel outcomes by:

1. Establishing a simple and quick technique to monitor the onset temperature of evaporation and fusion of NPs capped with organic materials. Such information is important for developing a good sintering profile for different NPs paste formulations for different applications. This technique enables the study of the initial dominating sintering mechanism of NPs by relating the changes in electrical resistance with time.

2. Understanding the relationship between the rates of change in electrical resistance, the onset temperature of evaporation and fusion with the resultant microstructures. The strength of the sintered joints, which is closely related to the microstructure, can thus be improved.

3. Providing an insight into the feasibility and reliability of such novel material as a die attach material for high power LEDs applications. 


\section{References}

1. Khazaka, R., L. Mendizabal, and D. Henry, Review on Joint Shear Strength of Nano-Silver Pasteand Its Long-Term High Temperature Reliability. Journal of Electronic Materials, 2014. 43(7): p. 2459-2466. 


\section{Chapter 2}

\section{Literature Review}

In this chapter, electronic packaging materials such as solder, copper pillar bumps and metallic nanoparticles will be reviewed. However, the focus will be on metallic nanoparticles, specifically the influence of process parameters on its sintering behavior. As nanoparticles faces a different set of challenges due to its high surface to volume ratio, the sintering mechanism of these nanoparticles and the challenges will be very different from bulk and thin film. Another topic that is considered is the removal of capping layers on these metallic nanoparticles. Such capping layers are a barrier to successful fusion of nanoparticles that will cause reliability issues if the removal is not complete. Moreover, the type of capping layers used and the type of by-products it produces can also affect the sintering temperature of the nanoparticles as the sintering temperature is heavily dependent on the decomposition or volatilization temperature and presence of such organic materials can hinder fusion of nanoparticles. To further study the feasibility of replacing current solder with these low processing temperatures metallic nanoparticles, the influence of different sintering parameters such as temperature, time and heating rate with its thermal stability are being discussed as well. Such thermal stability is particularly important for high or harsh environment applications. With these background knowledge, this thesis will focus on to develop and study on low temperature bonding process $\left(\sim 200^{\circ} \mathrm{C}\right)$ using copper nanoparticles for robust interconnection and die attach applications 


\subsection{Overview of interconnects}

In conventional technology for interconnecting electronics devices, it typically involves die-attaching one terminal of the semiconductor die to a heat-sinking substrate with solder alloys or conductive epoxies and wire-bonding fine aluminum or gold wires to the other terminal(s). This joint layer, which is typically referred to as the bond-line, acts as an electrical connection, a mechanical bond and a heat transfer medium. Therefore, the quality of this bondline in the chip attachment is very important to the overall performance and reliability of the electronic package.

As technology progresses, the drive to reduce the fabrication cost and energy conservation consumption has put an increasing pressure on the energy density within the power modules. This means that more chips must be placed into a single package. Hence, there has been a growing trend for flip chip interconnection using micro bumps with reducing pitch as the electronics industry moves towards high density and better performance devices. However, with fine-pitch solder bumps, it brings about several challenges and issues in terms of packaging assembly process and reliability performance [1]. Currently, there are three major types of chip attachment materials/techniques. They are solder reflow, $\mathrm{Cu}$ pillar and/or bumps, electrically conductive adhesive (ECAs) and some low temperature joining techniques that uses nanoparticles or nanowires. All these three materials would be reviewed subsequently.

\subsubsection{Solder}

The use of solder alloys as metal joint materials can be dated back to thousands of years. With the development of modern electronic packaging technology, solder alloy is used as an interconnecting material in electronic packaging as solder joints to provide both the electrical connection and mechanical support in electronic packaging modules [2]. The melting point of solder and its ability to self-align make it valuable in the microelectronics industry [3]. Since Pb-Sn solders have been acknowledged to be harmful to men's life and environment, new solders alloys are being looked into. When trying to identify alternatives to the $\mathrm{Pb}$-Sn solders, it is important to ensure that the properties of the replacement 
solder are either similar to or superior than $\mathrm{Pb}-\mathrm{Sn}$ solders. Table 2.1 summarizes the important properties that a solder alloy should possess [4].

Table 2.1 Important Properties of Solder Alloy

\begin{tabular}{|c|c|}
\hline Properties relevant to manufacturing & $\begin{array}{c}\text { Properties relevant to reliability and } \\
\text { performance }\end{array}$ \\
\hline Melting/liquidus temperature & Electrical conductivity \\
\hline Wettability & Thermal conductivity \\
\hline Cost & Coefficient of thermal expansion \\
\hline Environmental friendliness & Shear properties \\
\hline Availability and number of suppliers & Tensile properties \\
\hline $\begin{array}{c}\text { Manufacturability using current } \\
\text { processes }\end{array}$ & Creep properties \\
\hline Ability to be made into balls & Fatigue properties \\
\hline Copper pick-up rate & Corrosion and oxidation resistance \\
\hline Recyclability & Intermetallic compound formation \\
\hline Ability to be made into paste & \\
\hline
\end{tabular}

Though some lead-free solders can meet the regulation and properties requirements stated in Table 2.1, they are either high in price (Au80Sn20, Au97Si3, Au88Ge12) or hard to process (Zn95A15). Hence to date, most leadfree solders that are more economical are mostly Sn-based. The commonly used is the eutectic alloys of $\mathrm{Sn}$ and noble metals of $\mathrm{Au}, \mathrm{Ag}$ and $\mathrm{Cu}$ [5]. With regards to the microstructures of these Sn-noble metal eutectic solders, they consist of a mixture of Sn and intermetallic compounds (IMCs). Hence the mechanical properties of these eutectic solders will be anisotropic when the dispersion of the IMC is inhomogeneous [5]. In addition, with the formation of such IMCs, it could attribute to the formation of high stress region between solder bump and under-bump-metallization (UBM). Cracks are most likely to be initiated and will propagate along such interface leading to failure as shown is Figure 2.1. 


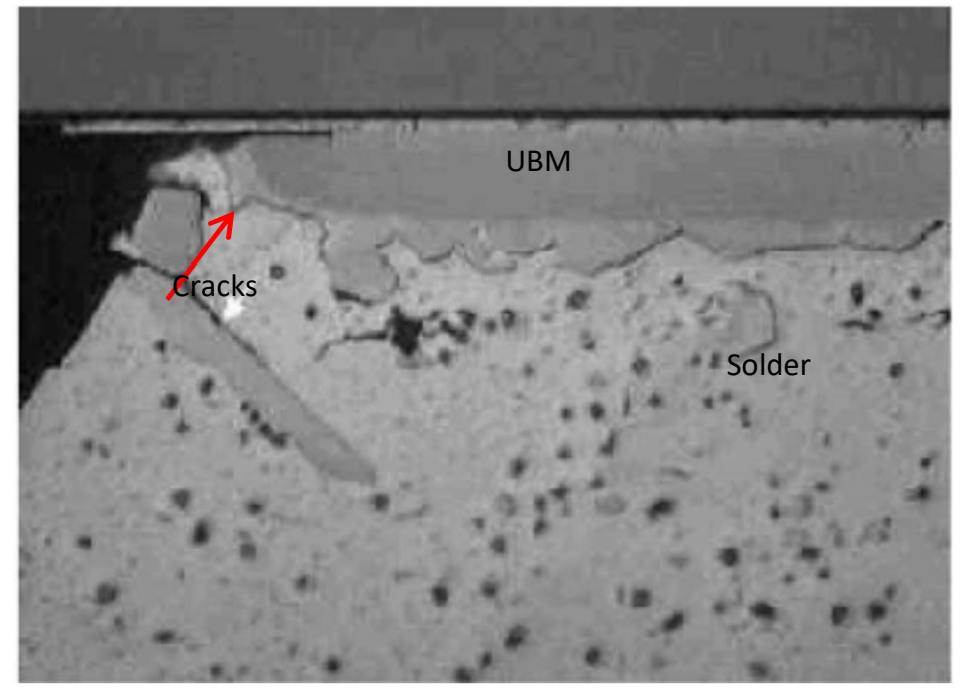

Figure 2.1 Fractured Flip Chip Joint [5]

The most commonly used lead-free solder, SAC (Tin-Silver-Copper), has a significantly higher melting point of $\sim 217^{\circ} \mathrm{C}$ than traditional $\mathrm{Sn} / \mathrm{Pb}$ solders $\left(183^{\circ} \mathrm{C}\right.$ for $63 / 37 \mathrm{Sn} / \mathrm{Pb}$ and $188^{\circ} \mathrm{C}$ for $\left.60 / 40 \mathrm{Sn} / \mathrm{Pb}\right)$, thus limiting the choice of substrates used for processing as well as requiring a higher thermal budget. Moreover, with the high Sn content in SAC solder, tin whisker formation can lead to electrical shorting $[6,7]$. In addition, traditional solders are becoming more restrictive as the interconnect size continues to shrink to meet the input/output (I/O) demands of high performance components [8]. The International Technology Roadmap for Semiconductors (ITRS) has forecasted that the minimum pitch for area array interconnects to shrink to $120 \mu \mathrm{m}, 100 \mu \mathrm{m}$, and $85 \mu \mathrm{m}$, in 2010, 2015, and 2020, respectively [9]. In the past, solder joints in flip-chip microelectronic packages have their diameters in the $100 \mu \mathrm{m}$ range. However, in today's development of the three-dimensional integrated circuits (3D ICs), the diameter of a typical micro-solder joint is merely about $10 \mu \mathrm{m}$. With such transition from flip-chip to 3D ICs, the volume of the solder joint has shrunk tremendously. Many new issues will arise due to the reduction of the solder volume and stand-off height $(\mathrm{SOH})$. This will eventually affect the reliability of the solder joints [10-12]. The low standoff height is of concern from mechanical fatigue life point of view because of the higher shear after assembly and void trapping during the underfill process [13]. 
Meanwhile, miniaturization of the solder volume could cause the entire solder layer to completely transform into intermetallic compounds (IMCs) during the device operation, or even after its fabrication. As IMCs tend to be hard and brittle, a solder joint composed entirely of IMCs would have poorer mechanical properties $[10,11,14,15]$.

For mechanical reliability issues, most solder joint failures fall under three major categories: 1) tensile fracture due to stress overloading, which is short-term; 2) creep failure due to the application of a long-term, permanent load; and 3) fatigue failure due to the application of cyclical stresses. More than one of these stresses can act on a solder joint in a given situation, so solder joint failure analysis can be challenging at times [4].

\subsubsection{Copper Pillar Bumps}

$\mathrm{Cu}$ pillar bumps are an interesting alternative to conventional solder bumps for first-level flip chip interconnections. Pillar bump is a novel interconnects structure, including a non-reflowable base and a reflowable cap like a pillar shape [16]. They offer benefits like finer pad pitch without sacrificing standoff, significantly higher current carrying capability and better thermal performance and resistance to electromigration [17-19]. Moreover, the solder cap does not wet the copper pillar sides thus allowing the benefit of more space for underfill flow which improves the reliability performance of copper pillars [18]. Another issue faced by conventional solder is bump bridging. However, such problem can be alleviated by using $\mathrm{Cu}$ pillar bumps which are designed to have thick $\mathrm{Cu}$ UBMs and thin solder layers for fine-pitch applications. In these cases, the $\mathrm{Cu}$ pillar bumps do not experience bump bridging because only small amounts of solder are used. Also, these bumps provide high mechanical strength, because thick $\mathrm{Cu}$ pillars allow them to maintain large standoff height between chip and substrate. These advantages will enable $\mathrm{Cu}$ pillar bumps to be adopted in finepitch applications, such as 3D system-in-package.

However, controlling the formation of brittle intermetallic compounds (IMCs) and weak interfaces during reflow or any heat-related process, and preventing copper migration during bonding and reliability testing remain challenges that 
the electronic packaging industry faces [19]. In addition, solder shorts might occur in an over-bonded $\mathrm{Cu}$ pillar die as shown in Figure 2.2 where the solder cap can be squeezed out to the sides of the joint [20]. Though the addition of solder cap had avoided the high temperature copper-to-copper bonding step, electrical and mechanical limitations of solder still exist [3].

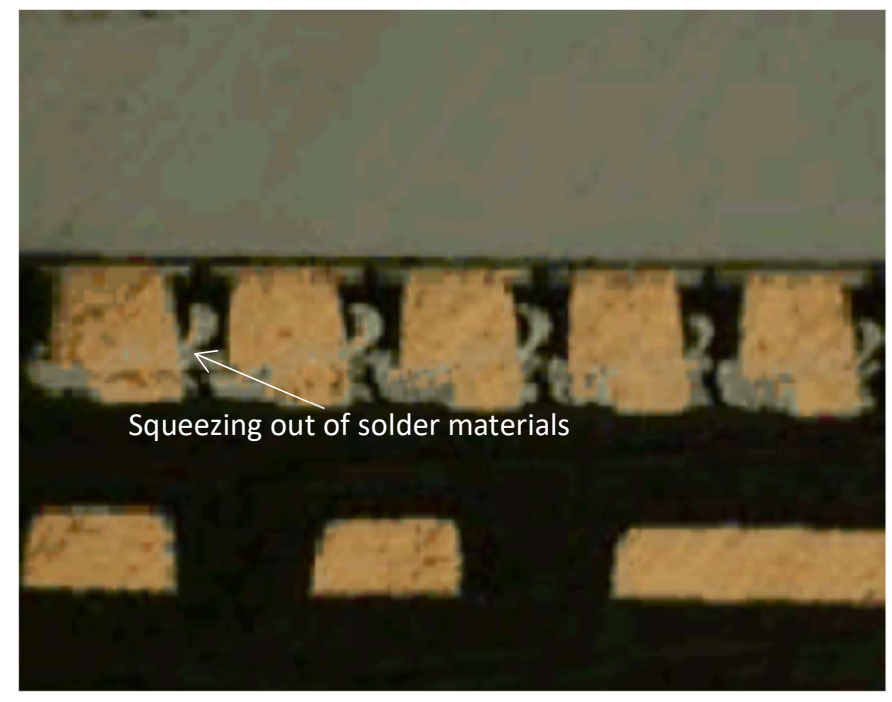

Figure 2.2 Example of squashed bump due to over bonding [20]

Therefore, the reliability of $\mathrm{Cu}$ pillar bumps has become increasingly important. However, at the interface between $\mathrm{Cu}$ and solder, $\mathrm{Cu}_{6} \mathrm{Sn}_{5}, \mathrm{Cu}_{3} \mathrm{Sn}$ and Kirkendall voids are usually formed. Formation of IMCs and Kirkendall voids are detrimental to the reliability of flip-chip bonding because IMCs are brittle and possess higher electrical and thermal resistivity than either $\mathrm{Cu}$ or solder alloy.

\subsubsection{Electrically Conductive Adhesives (ECAs)}

Another possible type of die-attached materials is known as the electrically conductive adhesives (ECAs). Such conductive adhesives have been around for a long time and basically they are made up of highly conductive metallic powder that dispersed in a polymer-based matrix. The polymeric resin can be epoxybased, silicone, or a polyimide and the metallic powder can be silver, gold, nickel or copper [21]. The conductivity of such material is dependent on percolated network formed by the conductive particles. The advantages of ECAs as 
compared to conventional solder materials is that it is more environmental friendly, it requires lower processing temperatures thus lower stress on the substrates and its ability to be used for fine pitch interconnects due to the small metallic powder present within the matrix. Therefore, solder are being replaced by ECAs in liquid crystal display (LCD), flip-chip assembly, chip scale package (CSP) and ball grid array (BGA) applications [21-23].

Though ECA offers many advantages such as lower stresses due to low Young's modulus, low processing temperature and relatively lower in cost compared to conventional solder technology, poorer electrical properties which are caused by poor fusion among metallic powder suffer and polymer degradation during high temperature humidity ageing is a major disadvantage [24]. Therefore, such material is not suitable for high-power applications. Therefore the following sections will look into other alternatives which are able to maintain good joint integrity under high temperature application yet economical and has low processing temperature.

\subsubsection{Die attach materials for high temperature applications}

In today's electronics devices, the demand for high power density and high temperature capability have increased tremendously. With the technologies advancing into SiC-based substrate and other high bandgap materials, it will improve many current limitations that are associated with Si-based technologies. This includes increasing the switching speed, power density and junction temperature $[25,26]$. These devices are largely needed in the aerospace, automotive and sensor technology that needs to have its performance maintained at extreme temperature conditions. Therefore, these new die-attach materials that are to be used in these devices must be able to withstand, cope and function suitably under extreme environment to maintain the reliability of the package's die to substrate interconnection.

\subsubsection{Requirements for High Temperature Die Attach Materials}

Usually the main heat dissipation path for high power semiconductor packaging is from the device through the die-attach material. Hence, the die attach layer's thermal characteristics are very important. These characteristics include thermal 
conductivity, thermal resistance at interfaces between the die attach, the device and the package, and the thickness of the die-attach layer. Another important property of the die-attach is its electrical conductivity. This is because the electrical resistance between package and die results in joule heating which is an energy-loss mechanism [27]. This is generally influenced by the electrical properties of the die-attach material itself that causes a reduction in energy efficiency of the entire device. In addition, the die-attach layer is also the mechanical interface between the die and the packaging material. If the coefficients of thermal expansion difference across the die, die-attach material and package are huge, certain parts of the die can go into tension and results in die cracking. Besides all the mentioned thermal and electrical properties, another important factor to consider is the cost. Cost consists of the raw materials cost and assembly cost, which is dependent on manufacturing throughput and yields. Other general requirements include the capability to resist corrosion, have good ductility, solidus points of $\geq 260^{\circ} \mathrm{C}$, liquidus point of $\geq 400^{\circ} \mathrm{C}$, thermal shock reliability, good thermo-mechanical fatigue resistance, high thermal conductivity, compliant CTE mismatch between die and substrate and electrical volume $[26,28]$.

Currently, there are a few commonly used high temperature Au-based solders. They are namely AuSn, AuGe and AuSi. Though they possess high thermal capability and high electrical conductivity, they are very expensive due to the larger portion of gold content. In addition, AuSn, AuGe and AuSi have low ductility, making CTE mismatch a problem, particularly when one considers the high die-attach temperature. Therefore, the common high temperature solder is still $\mathrm{Pb}_{90} \mathrm{Sn}_{10}$. Due to the ductile nature of $\mathrm{Pb}_{90} \mathrm{Sn}_{10}$, it minimizes CTE mismatch between die and substrate. This made the bonding of very large die possible without the risk of cracking. In addition, it has about $80 \%$ of the thermal conductivity of AuSn but costs 100 times cheaper. The only drawback of this material is the health risk it brings about. Therefore, a new lead-free alternative with good thermal, electrical conductivity, good ductility and reasonable cost is needed. 


\subsubsection{Metallic Nano-sized Materials}

Metallic nanoparticles and nanowires are becoming one of the possible alternatives that are gaining increasing research interest in recent years due to its ability to be processed at lower temperature and ultimately reducing the thermal stress [29]. The low processing temperature as reported by many is similar to that of the current high-lead solder processing temperature [30-32]. In addition, high thermal stability and conductivity, good mechanical and electrical properties as compared to the other lead-free solder substitutes available in the market are some of its advantages. Therefore, many research groups have been actively developing metallic nano-sized materials, $\mathrm{Ag}$ or $\mathrm{Cu}$, as the next possible lead-free die-attached materials used in electronics devices [30, 33-35]. Besides being a potential substitute for solder materials due to its ability to process at a lower processing temperature, it too has gained some attention in the flexible electronics sector as the organic substrates used in flexible electronics usually need to be processed at a lower temperature.

\subsection{Nanowires/ Nano-solder}

Nanowires is a $1 \mathrm{D}$ nanostructure that has been widely studied due to its potential to be used as a basic electronic circuit element or be assembled and integrated into functional structures [36]. There are various methods to fabricate such nanowires. One of the most common methods is electrodeposition of the desired material using a nano-porous template as this method is not time-consuming, inexpensive and the growth rate is high. [29, 37, 38]. These templates are usually made of alumina or polycarbarbonate. The template is subsequently removed and the nanowires are released. Good ohmic contacts between these nanowires can be made by using solder materials, usually tin-based, between two nanowires, direct nanowires-nanowires contact or metallic nanowires and metallic micropad as shown schematically in Figure $2.3[39,40]$. 


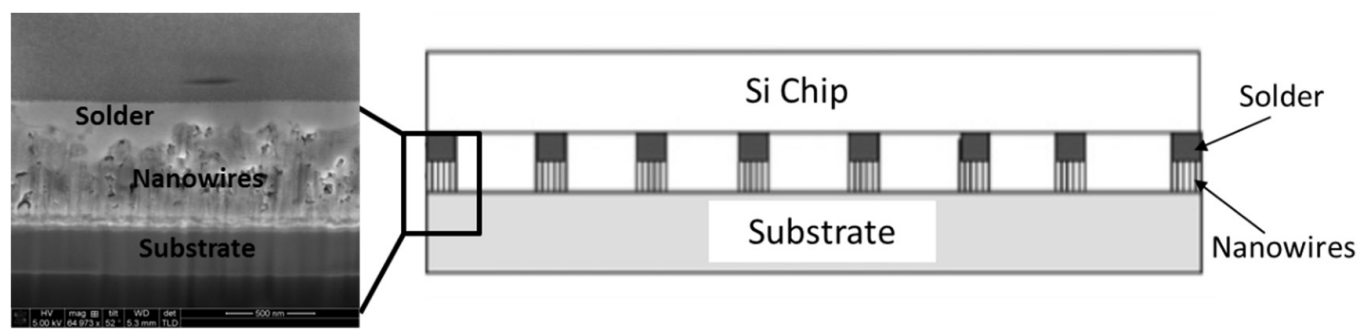

Figure 2.3 Schematic diagram and cross-sectioned FESEM of nanowires bonded with Sn-based solder

However, these 2 techniques do have its challenges. For those nanowires that contain nanosolders, though it can be reflowed under conventional method, addition steps have to be incorporated to include the solder materials on the nanowires. Moreover, the reflow of these tin-based nanosolders can be a complex issue when reactive surfaces such as $\mathrm{Cu}, \mathrm{Au}$ or $\mathrm{Ni}$ are used since they would react and form IMCs. As for direct nanowires-nanowires contact, the formation of oxide on these nanowires can hinder fusion between them and affect the electrical properties [41, 42]. In addition, due to the nanowires template fabrication technique, these nanowires could contain clustering that are more difficult to disperse uniformly as shown in Figure 2.4 [43].

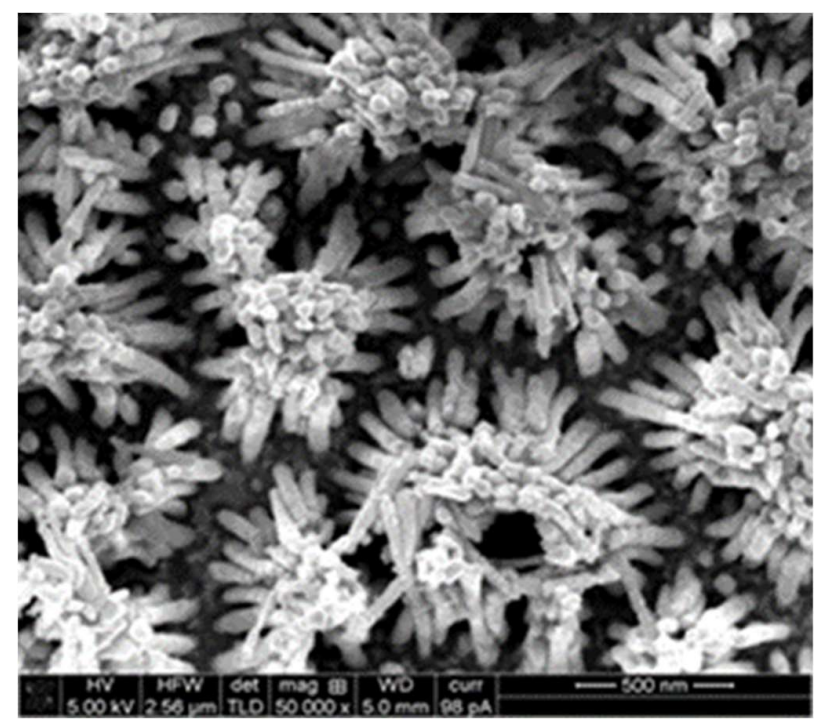

Figure 2.4 Top view of $\mathrm{Cu}$ nanowires clustering after removal of the AAO template 
Another method of adopting metallic nanowires for 3D interconnect is fabricating nanowires directly onto the template that are created on the substrate [44]. Though this method allows all nanowires to be well-dispersed and vertically standing on the substrate, it could possess some challenges when come to fabrication of nanoporous template for bigger substrates. Non-uniform pores can result and this is undesirable as it can affect the quality of the nanowires fabricated. In addition, oxidation of the standing NW array could result due to nanoscale Kirkendall effect that can affect the fusion temperature, electrical and mechanical properties [42]. Such rapid rate of oxidation could be due to the high aspect ratio of the nanowires. It is observed and explained by Gao et al. [41] that the oxidation on nanorod as compared to nanowires can be removed easily during reflow process. This is because when the reflow temperature goes beyond the melting point of the nanorod, the internal pressure of the liquidus nanorod core increases and the outer oxide shell will rupture due to higher tension experienced and this is observed in nanorod as its oxide shell suffers a higher tension as compared to those oxide shell of the high aspect ratio nanowires. Since these nanorods have demonstrated a better removal of oxides and have a depressed melting temperature due to its size and lower aspect ratio, those zerodimensional nanoparticles shall be considered.

\subsection{Metallic Nanoparticles (MNPs)}

Printable inks and solder materials which comprise of a certain amount of MNPs has been developed in recent years $[45,46]$. It is reported that due to the high surface energy of NPs, the melting point for most elements NPs, with a certain particle size range, reduces almost linearly with the inverse of its radius [47].

The theoretical size-dependent melting point of a material can be calculated through classical thermodynamic analysis using Gibbs-Thomson equation that relates melting temperature with particle size [48].

$$
T m(d)=T_{M B}\left(1-\frac{4}{\sigma_{s l} H_{f} \rho_{s} \mathrm{~d}}\right)
$$


Where: $T_{M B}=$ bulk melting temperature

$\sigma_{s l}=$ solid-liquid interface energy

$H_{f}=$ bulk heat of fusion

$\rho_{s}=$ density of solid

$d=$ particle diameter

Based on this equation, the relationship between melting temperature for a metal particle with its diameter can be graphically represented based on the normalized Gibbs-Thomson equation. This is represented in Figure 2.5 for gold [48].

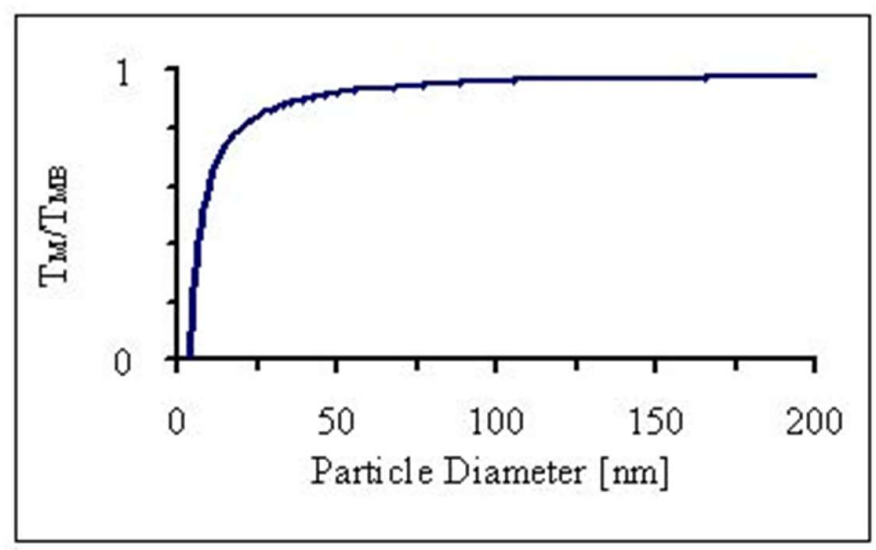

Figure 2.5 $\mathbf{T}_{\mathrm{m}} / \mathbf{T}_{\mathrm{MB}}$ ratio with particle diameter [48]

Furthermore, Herring's scaling law [49] predicts the sintering time required to get the same degree of sintering by the same sintering mechanism of powder which is geometrically similar and sintered under the same temperature. For the sintering of two kinds of powders with radii $a_{1}$ and $a_{2}$ and are related by an equation $a_{2}=\lambda a_{1}$, the relationship can be expressed as:

$$
\Delta t_{2}=\lambda^{\alpha} \Delta t_{1}
$$

where $\alpha$ is the exponent for the different sintering mechanisms stated in Table 2.1 while $\Delta t_{1}$ is the time required to produce a change in particle 1 and $\Delta t_{2}$ is the time required to produce a geometrically similar change with respect to particle 
1 in particle 2. The equation means that the time required to sinter a smaller particle will be shorter.

Table 2.2 Exponents for different sintering mechanisms [49]

\begin{tabular}{|l|c|}
\hline Sintering Mechanism & Exponent $\boldsymbol{\alpha}$ \\
\hline Viscous flow & 1 \\
\hline $\begin{array}{l}\text { Evaporation and } \\
\text { condensation }\end{array}$ & 2 \\
\hline Volume diffusion & 3 \\
\hline Surface Migration & 4 \\
\hline
\end{tabular}

However, there are a few limitations to Herring's scaling law. First, it assumes only one sintering mechanism is taking place. Secondly, the shape of the particles must be uniform throughout the process. Lastly, the particle size ratio, $\lambda$ is taken to be constant. For nanoparticles, they tend to agglomerate easily and that can potentially induce unpredicted grain coarsening that leads to a change of the particle ratio.

From Figure 2.5, it can be observed that melting temperature is significantly lower than its bulk when the particle diameter is less than $10 \mathrm{~nm}$. Hence to lower the sintering temperature significantly, the diameter of the nanoparticles should be sufficiently small. The cut-off particle size will differ across different materials as mathematically represented in equation (2.1). If particles are bigger than $50 \mathrm{~nm}$, in the case of gold, its melting temperature will be similar with the bulk. Thus, for such larger nanoparticles, the ability to sinter at a much lower temperature as compared to bulk is therefore not attributed to melting, but the high surface energy that caused sintering through diffusion.

An organic passivating material is required to cap these nanoparticles to prevent unwanted fusion and oxidation prior to sintering. Upon sintering, these organic materials will be detached and/or decomposed from the metallic NPs surfaces and these metallic nanoparticles will fuse to form a conductive network. Although low temperature sintering behavior of Ag NPs has been studied extensively [33, 35], few have reported on $\mathrm{Cu}$ NPs [30, 50]. Low temperature sintering of noble metal NPs for die attach is promising since they rely on the principle of atomic diffusion and consolidation rather than a change of state from 
solidus to liquidus [26]. In addition, NPs sintering does not need high pressure as compared to micrometer scale powder, as these NPs have much higher surface energy [26]. In Bai et al. [33] work, they made a comparison between Ag NPs and Au80Sn20 solder. They reported that the previous has a much lower calculated elastic modulus, i.e. $9 \mathrm{GPa}$, due to the presence of micro-pores in the sintered Ag NPs. This is an advantage over conventional high temperature solder as it can withstand the stress arising from thermal expansion mismatch during bonding. Though sintered Ag NPs has 2.4 times higher electrical resistivity than bulk Ag at room temperature, its electrical resistivity is still lower than current solder alloy due to presence of pores of these sintered Ag NPs [26]. Hence, factors influencing the final density of the sintered metallic NPs layer such as pressure, sintering temperature, particles size and removal of passivating layers should be considered.

When bonding, pressure is concerned, it is observed that as compared to micronsized Ag particles, these Ag NPs can be sintered at a much lower pressure i.e. 1 - $5 \mathrm{MPa}$ while keeping the same sintering temperature $[32,35]$. This pressure range is much lower than the $9-40 \mathrm{MPa}$ range as reported in micron-sized $\mathrm{Ag}$ particles sintering [51]. This decrease in sintering pressure is attributed to the higher surface energies due to the smaller size of the NPs.

However, Ag NPs often incurred higher cost and are susceptible to ion migration [52]. When Ag is used as a die-attach, with die pad as anode and a cathodic electrode nearby, the Ag metal can undergo dissolution, creating Ag+ ions in the presence of moisture and ionic contaminants. The $\mathrm{Ag}+$ ions can then migrate to the cathode since the moisture presence will act as an electrolyte. These Ag+ ions will then be reduced at the cathode and pure Ag will build up eventually. Such build-up will lead to dendrites formation that could potentially cause shorts between different interconnects and dies. This is especially so for printed interconnects. Hence the next alternative is to look into $\mathrm{Cu}$ NPs sintering as $\mathrm{Cu}$ also possesses high conductivity and has strong durability towards ion migration and it is lower in cost as compared to $\mathrm{Ag}$ and $\mathrm{Au}[30,52]$. 


\subsection{Copper Nanoparticles (Cu NPs)}

Copper $(\mathrm{Cu})$, with the absence of intermetallic compounds and precipitates formed on the $\mathrm{Cu}$ bonding pads, makes it a simpler material than common $\mathrm{Sn}$ based solder. Since $\mathrm{Cu}$ is already commonly used in microelectronics technology as trace, interconnect and pad material, it will minimize compatibility issues when adopted. Its ability to operate under high temperature, good electrical and thermal properties is indeed attractive for the next generation of solder alternative. However, to achieve a low processing temperature that is similar to Pb-based solder, a reduction in the particles size is needed. Hence the development of $\mathrm{Cu}$ NPs is recently being studied extensively [34, 53, 54]. It is known that $\mathrm{Cu}$ oxidizes easily in air which will reduce the electrical conductivity. Thus, these $\mathrm{Cu}$ NPs are usually passivated with organic materials to prevent oxidation, and fusion between particles before sintering. To enable low temperature sintering, these passivating layers should be easily removed upon heat treatment $\left(\leq 200^{\circ} \mathrm{C}\right)$. Since these passivated $\mathrm{Cu}$ NPs are not connected with one another, they thus behave like an insulator prior to sintering $[55,56]$. Apart from being passivated with layers of organic materials, organic additives are added into the $\mathrm{Cu}$ NPs paste. Such additives help to adjust the viscosity of the paste for the ease of dispensing through micron-sized aperture suitable for dieattach materials. These additives and passivating layers are usually made up of alcohol, thiol, amines or acid-based materials [57-60]. With these organic materials, they do affect the overall electrical resistance of the $\mathrm{Cu}$ NPs paste matrix [48]. Hence to achieve the desired electrical and mechanical properties of these $\mathrm{Cu}$ NPs, these organic materials must be removed from the $\mathrm{Cu}$ NPs matrix during thermal treatment to allow subsequent fusion among $\mathrm{Cu}$ NPs [48, $61,62]$. Since the removal of the passivating layers affects fusion of these metallic NPs, a fast technique should be developed for the removal of passivating layers and establish its co-relation with the final microstructures that determine the mechanical, electrical and thermal properties of the sintered layer. 


\subsection{Overview of Sintering Nanoparticles}

For many years, soldering technology has been commonly used in die bonding. However, some of the solders (SAC) cannot fulfil the reliability requirements of future power electronics devices whereas some solders are expensive (AuSn, $\mathrm{AuSi}$ ) or toxic $(\mathrm{PbSn})$ to be used. Hence, the sintering of metallic nanoparticles has been explored in recent years. This technique is promising as these nanoparticles can be sintered at low temperature with little or no pressure exerted due to their high surface energy and its ability to produce thermally and electrically conductive and highly reliable bonds after being sintered [35].

\subsubsection{Sintering Mechanism}

Sintering can be classified based on the mechanism that is responsible for the shrinkage or densification. Sintering that is proceeded by solid state diffusion falls under solid state sintering. The driving force for solid state sintering usually comes from the curved surface of the particles and presence of high surface energy. Polycrystalline materials are usually sintered by solid-state sintering while amorphous materials are sintered by viscous flow and are considered to undergo viscous sintering [63]. Another type of sintering that makes use of a transient second phase that exists as a liquid at the sintering temperature is known as liquid phase sintering. The liquid phase under the right conditions can provide a path for rapid transport and, therefore rapid sintering. Finally, processes that make use of an externally applied pressure to enhance densification are classified under pressure assisted sintering.

There are mainly three stages during the entire sintering process; the initial, intermediate and final stage. However, there is no clear distinction between these stages as the process tends to overlap one another but some simplifications can be made to differentiate the individual stages.

In the initial stage, the nanoparticles rearranged into more stable positions by rotating and sliding due to the sintering forces. This will lead to shrinkage and an increase in density. When these particles rearranged, the number of contact points between them increases. This leads to more neck formation among 
particles. Neck formation and growth can take place by diffusion, vapor transport, plastic flow, or viscous flow. The initial stage will finish when a neck radius $\sim 0.4-0.5$ of the particle radius is reached [64].

To analyze sintering, several mathematics models ranging from scaling laws [65], analytical and numerical models have been developed [66]. However, for analyzing the initial stage of sintering, a general equation for the initial neck growth, assuming 2 equal sized spheres can be expressed in a general form of [63, 67]:

$$
\left(\frac{X}{a}\right)^{m}=\left(\frac{H}{a^{n}}\right) t
$$

where $\mathrm{X}$ is the radius of the neck formed between the particles, $\mathrm{m}$, $\mathrm{n}$ are constant that depends on the sintering mechanism involved, $a$ is the initial radius of the particle, $\mathrm{H}$ is a coefficient characteristic of the sintering mechanism and $\mathrm{t}$ is the time. This general equation for neck growth was first reported by Frenkal [67]. Table 2.3 summarizes the values of $\mathrm{m}, \mathrm{n}$ and $\mathrm{H}$ for different sintering mechanism and Figure 2.6 show the schematic diagram of the different sintering mechanism for a two-particle model. 
Table 2.3 Values of $\mathrm{m}, \mathrm{n}$ and $\mathrm{H}$ for Equation 2.3 [68]

\begin{tabular}{|c|c|c|c|c|}
\hline $\mathbf{S} / \mathbf{N}$ & $\begin{array}{c}\text { Sintering } \\
\text { Mechanism }\end{array}$ & $\mathbf{m}$ & $\mathbf{n}$ & $\mathbf{H}$ \\
\hline 1 & Surface diffusion & 7 & 4 & $56 \mathrm{D}_{\mathrm{s}} \delta_{\mathrm{s}} \gamma_{\mathrm{s}} \mathrm{V} / \mathrm{kT}$ \\
\hline 2 & $\begin{array}{c}\text { Lattice diffusion } \\
\text { from surface }\end{array}$ & 4 & 3 & $20 \mathrm{D}_{\mathrm{l}} \gamma_{\mathrm{s}} \mathrm{V} / \mathrm{kT}$ \\
\hline 3 & Vapor transport & 3 & 2 & $3 \mathrm{p}_{\mathrm{o}} \gamma_{\mathrm{s}} \mathrm{V} /(2 \pi \mathrm{mkT}) 1 / 2 \mathrm{kT}$ \\
\hline 4 & $\begin{array}{c}\text { Grain boundary } \\
\text { diffusion }\end{array}$ & 6 & 4 & $96 \mathrm{D}_{\mathrm{gb}} \delta_{\mathrm{gb}} \gamma_{\mathrm{s}} \mathrm{V} / \mathrm{kT}$ \\
\hline 5 & $\begin{array}{c}\text { Lattice diffusion } \\
\text { from grain } \\
\text { boundary }\end{array}$ & 5 & 3 & $80 \pi \mathrm{D}_{\mathrm{l}} \gamma_{\mathrm{s}} \mathrm{V} / \mathrm{kT}$ \\
\hline 6 & $\begin{array}{c}\text { Plastic flow (by } \\
\text { dislocation } \\
\text { motion) }\end{array}$ & 2 & 1 & $3 \gamma_{\mathrm{s}} / 2 \eta$ \\
\hline
\end{tabular}

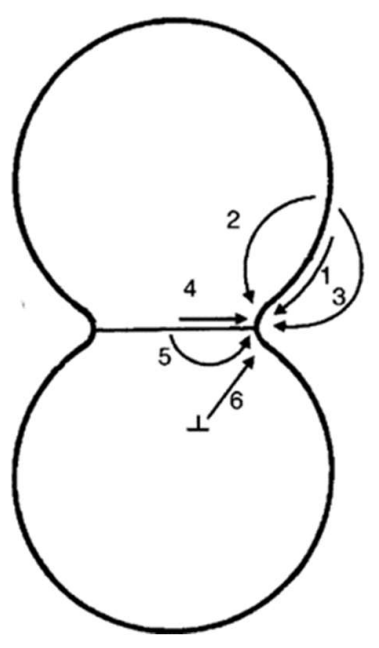

1. Surface diffusion (non-densifying)

2.Lattice diffusion from the surface (non-densifying)

3. Vapor Transport (no densifying)

4. Grain boundary diffusion (densifying)

5. Lattice diffusion from grain boundary (densifying)

6. Plastic flow by dislocation motion (densifying)

Figure 2.6 Schematic diagram of the different sintering mechanism for a twoparticle model

The intermediate stage will then proceed when the pores have attained their equilibrium shapes as determined by the surface and interfacial energies [69]. The reduction in the amount and size of pores is termed as densification. Among these three stages of sintering, the intermediate stage covers a huge portion of the entire sintering process. The final stage involves the removal of the isolated pores until the theoretical density is reached and is accompanied by grain growth where the larger grains tend to increase. The amount of grain growth is 
dependent on the sintering parameters and the material itself. Polycrystalline materials generally are sintered by diffusional processes while amorphous materials densify by viscous flow [70]. The driving force for all the sintering mechanisms is the affinity of the material to reduce its chemical potential or energy. This is done through transportation of material from regions of high energy to regions of lower energy. It is known that surfaces, interfaces and grain boundaries of particles have energies that are dependent on the surfaces or its boundary curvatures. Therefore, the overall energy of the material is reduced only when the curvature and number of surfaces are minimized or removed. Such surface diffusion does not produce densification and thus must be avoided. Those that lead to densification are known as volume diffusion of matter from the grain boundaries or from dislocations in the neck region [71].

\subsubsection{Challenges of Nanomaterial Sintering}

Materials with feature size from 1 to $100 \mathrm{~nm}$ are known as nanomaterials [72]. The difference between conventional microscale materials and nanoscale materials is that the latter has significantly larger surface energy. Therefore, reducing the particle size to nanoscale range will lead to a lower sintering temperature.

By definition, sintering is a process that is driven by surface energy minimization. Due to the high surface energy of nanomaterials, the first challenge is the prevention of agglomeration/aggregation of the nanomaterials prior to sintering. Agglomeration is a procedure whereby the nanoparticles are attracted together by weak forces such as Van der Waals or electrostatic forces. Aggregation on the other hand occurs when the nanoparticles are bonded together by solid necks of significant strength such as metallic force. In addition, agglomerations can be re-dispersed by external energy such as mechanical or ultrasonic forces while it cannot be applied to aggregation. Figure 2.7 shows the difference between an agglomeration and aggregation of nanoparticles. 


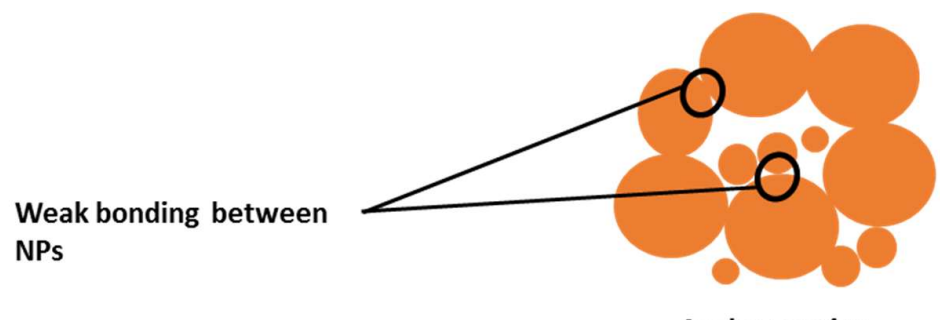

Agglomeration

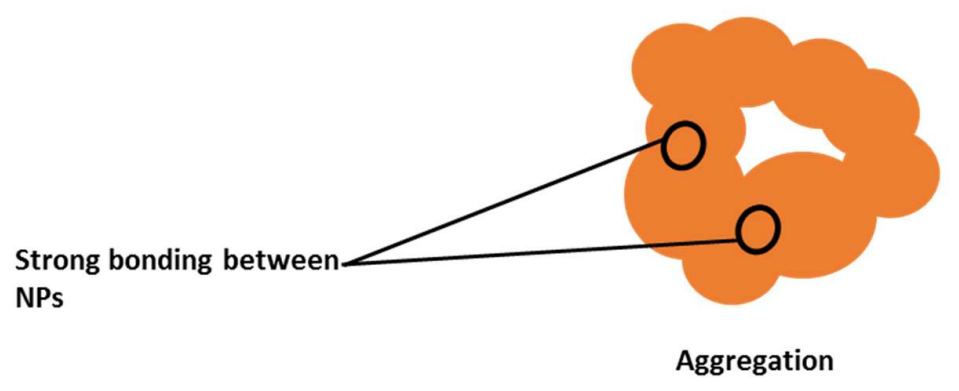

Figure 2.7 Difference between agglomeration and aggregation of nanoparticles during sintering

Another challenge for nanomaterial sintering is the non-densifying diffusion that occurs at the lower temperatures regime. Since these nanoparticles have high surface energy, they will fuse with one another even at room temperature [73, 74]. The temperature at which fusion occurs can affect the degree of densification. This is because if fusion occurs at a lower temperature, the sintering process of the nanoparticles will be controlled by surface diffusion and results in necking between particles. However, there is minimum densification. On the other hand, at higher temperatures, the grain boundary/lattice diffusion that governs the sintering process will lead to densification. Therefore, to attain a high degree of densification, the non-densifying diffusion such as surface diffusion should be avoided. A schematic diagram of densification as a function of temperature is shown in Figure 2.8.

If surface diffusion can occur, the nanoparticles will fuse at a low temperature and will consume the driving force that is needed for densifying diffusion to happen later at the higher temperature region. Such occurrence is very common in nanomaterials due to their high surface to volume ratio that causes surface diffusion to happen at very low temperatures. Hence high heating rate sintering 
processes to bypass the low temperature regime is proposed by some researchers $[75,76]$. However, the cracking of dies and non-uniform sintering of nanoparticles can occur at high heating rates. This is especially true for passivated metallic NPs since non-uniform removal can lead to non-uniform sintering. The removal of these passivating layers is dependent on a few factors. One factor is the interaction between the passivating ligands and NPs surfaces. If the interaction is strong, the removal may pose some challenges $[77,78]$. The second factor can be the NPs size. It was reported by Smith et. al [79] that ligands stability on larger NPs is not as good as smaller NPs. Therefore, the removal of passivating layer is easier for the previous. Since the removal of passivating layer is more critical that the size of the NPs, a simple technique to study the effect of the rate of removal of passivating layers and its final microstructures should be carried out.

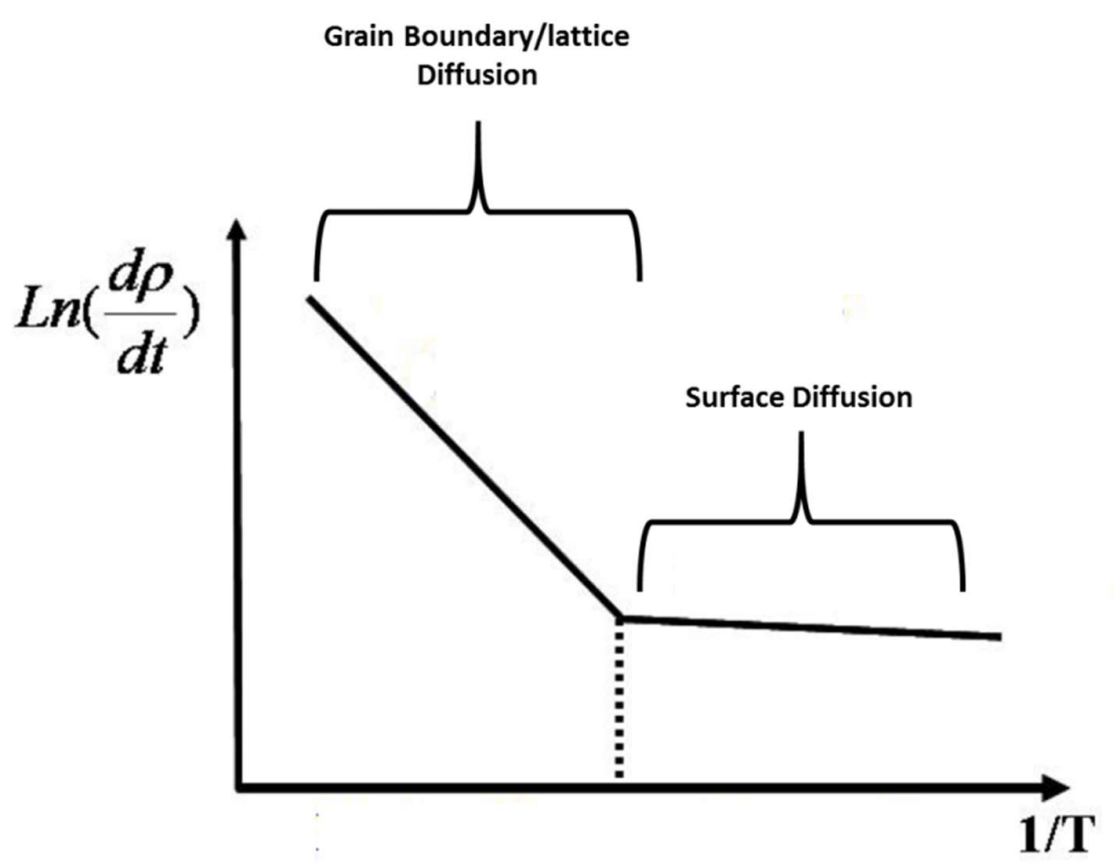

Figure 2.8 Schematic diagram of rate of densification as a function of temperature 


\subsection{Nano Cu Sintering and its Thermal Stability}

\subsubsection{Sintering Temperature}

Die attach materials used in power electronics devices are required to possess good mechanical, electrical and thermal properties. In addition, it must have good reliability against thermal cycling and fatigue. Metallic nanoparticles have been deemed as a possible alternative for high temperature Pb-based solder [57]. These metallic nanoparticles can be processed at a lower temperature due to their high surface energy yet they have similar properties to those of the bulk metals or alloy after sintering [47]. Due to the high surface energy of the nanoparticles, to prevent unwanted sintering at room temperature, these metallic nanoparticles are usually capped with an organic layer to prevent fusion. Therefore, though previous studies on the bondability of $\mathrm{Cu}$ NPs were carried out, they were either run at much higher temperatures, i.e. $230^{\circ} \mathrm{C}$ and above or under vacuum or forming gas environment $[30,46,80,81]$. Such high temperatures and special environment are needed because the capping layers used on the nanoparticles can only be removed completely at higher temperatures. Failure to remove these organic layers would hinder subsequent fusion of the nanoparticles [61]. Though room temperature sintering of Ag NPs with diameter around $8 \mathrm{~nm}$ has been demonstrated, it has a low shear strength of $\sim 8 \mathrm{MPa}$ [82]. In another Ag NPs study, the fusing of Ag NPs was observed at $150^{\circ} \mathrm{C}$ for a particle size of $20 \mathrm{~nm}$ but to achieve a good shear strength, a temperature of $>230^{\circ} \mathrm{C}$ is needed $[83,84]$. Such processing techniques will incur a higher operational cost and is not suitable for polymeric substrates. Processing of Cu NPs at $200^{\circ} \mathrm{C}$ or below and its ability to integrate into the current solder based process equipment and parameters have not been widely studied yet.

\subsubsection{Heating Rate}

Another factor that affects the sintering of NPs is the heating rate of the NPs paste up to the peak sintering temperature. As mention in Section 2.2.2, NPs are prone to fuse when the capping layers are removed. Hence if fusion can occur at lower temperature, surface diffusion is likely to occur. However, this does not contribute to the densification of the sintered joint. Thus, a faster heating up rate 
will promote a denser structure since surface diffusion is the dominant mechanism at low temperature while grain boundary or lattice diffusion dominates at the higher temperatures regime. This means that at higher heating up rate, it minimizes aggregation of nanoparticles during the heating up phase as it bypasses the low temperature regime faster to reach the peak sintering temperature. Therefore, these nanoparticles will not aggregate or agglomerate into a larger effective radius during heating up and will be able to keep its nanosized properties till the peak sintering temperature to achieve a denser structure subsequently. On the other hand, the heating rate must not be too fast as it must provide sufficient time for the outgassing of solvent. A rate of $\sim 10-20^{\circ} \mathrm{C} / \mathrm{min}$ appears to be the optimum heating rate for Wang et al. [9] although others have used higher heating rates of $60^{\circ} \mathrm{C} / \mathrm{min}$ with an added pressure on the die so that the dies are not lifted during sintering [85]. In addition, a higher heating up rate might not result in uniform removal or decomposition of capping layers as the thickness of the sintered joint is usually not considered. When heating rates are high, those NPs that are located near to the surfaces will fuse first due to faster removal of capping layers as compared to NPs located at the bottom of the layer. When the top layer of the NPs has fused, it might minimize the number of paths available for subsequent removal of organic materials. This can potentially lead to a non-homogenous sintered layer/joint. Therefore, besides a high heating rate, an effective method of removal of the capping layers faster and uniformly must be investigated.

\subsubsection{Sintering Time}

As mentioned previously, sintering is a diffusion-controlled process. Hence the duration of sintering will influence the sintered NPs joint. However, the optimum time for every type of NPs and joint design varies. For Wang et al. [9], shear strength of $17-18 \mathrm{MPa}$ was reported after 1 hour of sintering of the Ag NPs. However, for Knoerr et al. [35], shear strength of $40 \mathrm{MPa}$ was achieved when sintering time increased from 5 to $60 \mathrm{secs}$ and the density of sintered joint increased from $68 \%$ to $75 \%$. The occurrence of such fast sintering is due to the fusion of Ag NPs once the capping layers were decomposed or volatilized under heat and/or pressure. Therefore, the rate of capping layer removal has a huge influence on the sintering mechanism of NPs. This rate of capping layer removal 
is affected by the type of capping layer used and its affinity with the metallic NPs surfaces. It is quite difficult to compare the mechanical properties of these sintered joints and the NPs as they are synthesized and capped differently. Such differences could contribute to difference in sintering parameters such as temperature and/or time to obtain a strong sintered joint. Therefore, a quick and easy method should be used to characterize all the different types of capped metallic nanoparticles to enable one to tune the processing parameters appropriately.

\subsubsection{Stability of Cu Joint}

In addition, most studies focus only on the feasibility of using these $\mathrm{Cu}$ NPs for low temperature processing application, high power electronics and/or replacing $\mathrm{Sn}-\mathrm{Pb}$ solder $[30,57]$. To adopt the usage of $\mathrm{Cu}$ NPs paste to replace high temperature solder materials, the long-term stability of sintered $\mathrm{Cu}$ joints must be studied in detail. This can be done by measuring the die shear strength after annealing at elevated temperature for a specific duration. Though it is reported that increase in sintering time enhances $\mathrm{Cu}$ densification, pro-long annealing could lead to degradation taking place that can affect the overall shear strength. In some of the thermal reliability studies on sintered $\mathrm{Cu}$ NPs joints between $\mathrm{Cu}$ or Au surfaces, it has been shown that these sintered $\mathrm{Cu}$ NPs joints are able to withstand a higher temperature than conventional solder or have a better shear strength after prolong annealing due to no formation of inter-metallic compounds (IMCs) within the joints itself $[86,87]$. However, the relationship between grain growth of these particles, changes in the grain orientation, and porosities evolution with shear strength are still not studied.

\subsection{Sintering Behavior of Cu NPs and Removal of Organic Materials}

As mentioned in Section 2.3, various researcher groups synthesized their Cu NPs uniquely with different passivating layers and dispersed in different additives, hence the optimum sintering profile used will vary. In general, the sintering of these capped metallic nanoparticles goes through two major steps. The first step involves the decomposition or volatilization of solvents and capping molecules on the surfaces of the NPs. After which, fusion of NPs which is observed as the 
formation of necks between NPs will occur [57, 61, 75]. Most groups have used TGA and DSC/DTA to understand the sintering behavior of their NPs used [46, $59,88]$. Such equipment can quantify the loss of organic materials and onset of fusing during constant heating up and/or isothermal annealing under inert or air condition. However, such technique does have its shortcomings. Firstly, the heating mechanisms in this thermal analysis equipment and the actual oven or hotplate used during sintering are different. In addition, for bonding application, a sandwiched structure is used. Hence, the removal path of the volatiles will be different from an open structure. The removal of solvent and capping layers under a sandwiched structure is even more challenging when the die size increases [75]. All these differences might lead to some discrepancy in the temperature of volatilization and/or decomposition of solvent, capping organic materials and subsequent fusion of the NPs. Secondly, using TGA or DSC/DTA will require an additional step and time prior to sintering. Moreover, the heating rate that is set when using such thermal analysis equipment is usually about $10^{\circ} \mathrm{C} / \mathrm{min}$. However, based on literature, many researchers had tried higher heating rates sintering of NPs to benefit from its high surface energy i.e. $>20^{\circ} \mathrm{C} / \mathrm{min}$ [85]. Such high heating rates are usually not compatible with the TGA or DSC/DTA used. Therefore, for such situation, it is hard to use the conventional instrument to design a suitable sintering profile to study the sintering behavior of NPs. Therefore, other simple and direct quantifying techniques should be considered to understand the sintering behavior of these NPs paste when they are subjected to different heating profiles, environment and sintering structures.

\subsubsection{Removal of solvent and capping layers}

Prior to fusion, effective removal of solvent and other organic materials within or on the NPs should be completed. These solvents are added into the NPs paste formulation to achieve a suitable viscosity for dispensing the material for dieattach applications. The weight percentage of metallic NPs is usually more than $50 \%$ with percentage as high as $80 \%$ [57, 87]. Usually, mixtures of solvents and/or surfactants are used within the NP paste formulation to provide viscosity adjustment, steric resistance between NPs to prevent agglomeration prior to 
sintering. Hence, these organic contents might not be removed easily and nonhomogenous sintered layer can be observed [61]. This means that the densification rate across sintered joints is different. Though a longer annealing time, higher temperature or even application of pressure can help to improve the situation, it might not be feasible in actual applications. Some researchers have proposed a 2-step sintering method to ensure uniform microstructures. The first step of the sintering is done at a lower temperature to remove the solvent present. Next, a high heating up rate is used to ramp to the peak sintering temperature for the next step of sintering [57]. Other method of improving the removal of capping layers is to introduce a 2-step sintering under different environment. As reported by Yi et al. [89], since the removal of capping molecules is minimum under vacuum condition, the heating up of NPs is done under vacuum. Once the peak sintering temperature is reached, air would be introduced. This will ensure that both removal of capping layer and the fusing of NPs happen at the peak sintering temperature. Another method reported by Jang et al. [61] on their amine-capped $\mathrm{Au}$ NPs is the introduction of $\mathrm{N}_{2}$ gas that is bubbled through formic acid. They did a comparison on the effect of different types of sintering environment (air, $\mathrm{N}_{2}$ and $\mathrm{N}_{2}$ with formic acid) on the microstructure of the sintered Au NPs. It is observed that those that are sintered with formic acid have more coalescence and grain growth than those that were sintered under air or $\mathrm{N}_{2}$ at the lower sintering temperature of $200^{\circ} \mathrm{C}$. For Au NPs that were sintered under air or $\mathrm{N}_{2}$, grain growth was only observed when sintering was done at $290^{\circ} \mathrm{C}$. The ability of sintering at lower temperature when formic acid is introduced is due to the etching of amine molecules by the formic acid. This helps to remove the capping layer faster and thus able to sinter at lower temperature. However, low level of densification is observed due to large number of pores being distributed within the sintered Au film. Though this technique helps to remove the capping layer faster, large pores were observed and this leads to a higher resistivity as reported.

Therefore, based on all these literature, a more detailed study on the removal of organic materials with temperature, time and heating rate should be carried out. The resultant microstructures at different stages of sintering should also be given some attention as it would relate to the final mechanical strength of the sintered 
joint. Since the removal of organic materials has a huge influence on the final microstructure of the sintered joint, detail study should be carried out to study this initial step of the sintering process. This is very crucial when the sintering of NPs is done at a higher heating up rate to achieve a more homogenous sintered layer.

\subsection{PhD in Context of literature}

Based on the questions raised in the previous section, this work aims to develop and study on low temperature bonding process $\left(\sim 200^{\circ} \mathrm{C}\right)$ using $\mathrm{Cu}$ NPs for robust interconnection and die attach applications. A deeper understanding on the effects of bonding parameters such as ramping rate, bonding pressure and soak duration at peak temperature of $200^{\circ} \mathrm{C}$ on the joint strength will be studied. The bondability of joints obtained from $\mathrm{Cu}$ NPs sintering will be studied mainly by characterizing their respective shear strength, electrical resistance during annealing and co-relating it with its resultant microstructures and porosities. The onset temperature of volatilization and fusion of these $\mathrm{Cu}$ NPs that result in different microstructures will be an area of interest. These changes in the final microstructure and its effect on mechanical and electrical properties can shed some light to future metallic NPs paste development that will be used in interconnections and die-attached applications. Joint stability test such as isothermal ageing test $150^{\circ} \mathrm{C}$ up till 1000 hours in air is used to study and understand the mechanical properties and microstructure evolution of the sintered $\mathrm{Cu}$ joint for its potential to be used to replace current solder material. A deeper understanding in terms of grain growth and orientation evolution and degree of oxidation over time will also be looked into as they can affect the longterm reliability of the sintered $\mathrm{Cu}$ NPs. The final aim of this work is to apply this novel $\mathrm{Cu}$ NPs paste as a die-attach material for actual high power LEDs modules. Its initial performance will be directly compared with commercially available AuSn solder. Reliability tests such as long-term high temperature storage and thermo-mechanical test would be carried out to investigate the reliability of the $\mathrm{Cu}$ NPs joints. Some of its challenges faced will also be discussed. 


\section{References}

1. Sa, Y.-K., et al. Joint properties of solder capped copper pillars for $3 D$ packaging. in Electronic Components and Technology Conference (ECTC), 2010 Proceedings 60th. 2010.

2. Ma, H. and J. Suhling, A review of mechanical properties of lead-free solders for electronic packaging. Journal of Materials Science, 2009. 44(5): p. 1141-1158.

3. He, A., et al., Low-temperature bonding of copper pillars for all-copper chip-to-substrate interconnections. Electrochemical and Solid State Letters, 2006. 9(12): p. C192-C195.

4. Abtew, M. and G. Selvaduray, Lead-free Solders in Microelectronics. Materials Science and Engineering: R: Reports, 2000. 27(5-6): p. 95-141.

5. Zeng, K. and K.N. Tu, Six cases of reliability study of Pb-free solder joints in electronic packaging technology. Materials Science and Engineering: R: Reports, 2002. 38(2): p. 55-105.

6. Nakadaira, Y., et al., Growth of tin whiskers for lead-free plated leadframe packages in high humid environments and during thermal cycling. Microelectronics Reliability, 2007. 47(12): p. 1928-1949.

7. Kim, K.S., et al., Investigation of relation between intermetallic and tin whisker growths under ambient condition. Microelectronics Reliability, 2008. 48(1): p. 111-118.

8. Osborn, T., et al. All-copper chip-to-substrate interconnects: Bonding, testing, and design for electrical performance and thermo-mechanical reliability. in Electronic Components and Technology Conference, 2008. ECTC 2008. 58th. 2008.

9. Wang, T., et al., Low-Temperature Sintering with Nano-Silver Paste in Die-Attached Interconnection. Journal of Electronic Materials, 2007. 36(10): p. 1333-1340.

10. Chuang, H.Y., et al. Critical new issues relating to interfacial reactions arising from low solder volume in $3 D$ IC packaging. in Electronic Components and Technology Conference (ECTC), 2011 IEEE 61st. 2011. 
11. Tang, W.-m., et al., Solid state interfacial reactions in electrodeposited $\mathrm{Ni} / \mathrm{Sn}$ couples. International Journal of Minerals, Metallurgy, and Materials, 2010. 17(4): p. 459-463.

12. Bin, D., et al. Effect of stand-off height on microstructure and tensile strength of $\mathrm{Cu} / \mathrm{Sn}-8 \mathrm{Zn}-3 \mathrm{Bi} / \mathrm{Cu}$ and $\mathrm{Cu} / \mathrm{Sn}-9 \mathrm{Zn} / \mathrm{Cu}$ solder joints. in Electronic Components and Technology Conference, 2009. ECTC 2009. 59th. 2009.

13. Nah, J.-W., et al., Electromigration in flip chip solder joints having a thick Cu column bump and a shallow solder interconnect. Journal of Applied Physics, 2006. 100(12): p. 123513-5.

14. Jeong-Won Yoon, H.-S.C.a.S.-B.J., Reliability analysis of Au-Sn flipchip solder bump fabricated by co-electroplating. Journal of Materials Research, 2007. 22 p. 1219-1229

15. Kang, H.-B., et al., Characterization of Interfacial Reaction Layers Formed Between Sn-3.5Ag Solder and Electroless Ni-Immersion AuPlated Cu Substrates. Journal of Electronic Materials, 2008. 37(1): p. 8489.

16. Tie, W., et al. Studies on a novel flip-chip interconnect structure - pillar bump. in Electronic Components and Technology Conference, 2001. Proceedings., 51st. 2001.

17. Ebersberger, B. and C. Lee. Cu pillar bumps as a lead-free drop-in replacement for solder-bumped, flip-chip interconnects. in Electronic Components and Technology Conference, 2008. ECTC 2008. 58th. 2008.

18. Jinhua, Y., et al. Reliability Study on Copper Pillar Bumping with Lead Free Solder. in Electronics Packaging Technology Conference, 2007. EPTC 2007. 9th. 2007.

19. Huang, M., et al., Intermetallic Formation of Copper Pillar With Sn\&\#x2013;Ag\&\#x2013;Cu for Flip-Chip-On-Module Packaging. Components and Packaging Technologies, IEEE Transactions on, 2008. 31(4): p. 767-775.

20. Gerber, M., et al. Next generation fine pitch $\mathrm{Cu}$ Pillar technology \&\#x2014; Enabling next generation silicon nodes. in Electronic Components and Technology Conference (ECTC), 2011 IEEE 61st. 2011. 
21. Li, Y. and C.P. Wong, Recent advances of conductive adhesives as a lead-free alternative in electronic packaging: Materials, processing, reliability and applications. Materials Science and Engineering: R: Reports, 2006. 51(1-3): p. 1-35.

22. Kristiansen, $\mathrm{H}$. and $\mathrm{J}$. Liu, Overview of conductive adhesive interconnection technologies for LCDs. IEEE Transactions on Components, Packaging, and Manufacturing Technology: Part A, 1998. 21(2): p. 208-214.

23. Murray, C., et al., Conductive adhesives for electronic assemblies. MRS bulletin, 2003. 28(06): p. 449-454.

24. Li, Y., K.-s. Moon, and C. Wong, Electronics without lead. Science, 2005. 308(5727): p. 1419-1420.

25. Hornberger, J., et al. Silicon-carbide (SiC) semiconductor power electronics for extreme high-temperature environments. in Aerospace Conference, 2004. Proceedings. 2004 IEEE. 2004. IEEE.

26. Manikam, V.R. and C. Kuan Yew, Die Attach Materials for High Temperature Applications: A Review. Components, Packaging and Manufacturing Technology, IEEE Transactions on, 2011. 1(4): p. 457478.

27. JONATHAN HARRIS, M.M. Selecting Die Attach Technology for High-Power Applications. 2009 [cited 201611 Apr]; Available from: http://powerelectronics.com/dc-dc-converters/selecting-die-attachtechnology-high-power-applications.

28. Hartnett, A. and S. Buerki, Process and reliability advantages of AuSn eutectic die attach. Proc. 42nd IMAPS, 2009: p. 281-287.

29. Gao, F., et al., Synthesis, characterization, and thermal properties of nanoscale lead-free solders on multisegmented metal nanowires. The Journal of Physical Chemistry C, 2009. 113(22): p. 9546-9552.

30. Krishnan, S., A.S.M.A. Haseeb, and M.R. Johan, Preparation and LowTemperature Sintering of Cu Nanoparticles for High-Power Devices. Components, Packaging and Manufacturing Technology, IEEE Transactions on, 2012. 2(4): p. 587-592. 
31. Mei, Y., et al., Simplification of Low-Temperature Sintering Nanosilver for Power Electronics Packaging. Journal of Electronic Materials, 2013. 42(6): p. 1209-1218.

32. Albert, A.D., et al., Low temperature, pressure-assisted sintering of nanoparticulate silver films. Acta Materialia, 2008. 56(8): p. 1820-1829.

33. Bai, J.G., J.N. Calata, and L. Guo-Quan, Processing and Characterization of Nanosilver Pastes for Die-Attaching SiC Devices. Electronics Packaging Manufacturing, IEEE Transactions on, 2007. 30(4): p. 241-245.

34. Kobayashi, Y., et al., Preparation of metallic copper nanoparticles in aqueous solution and their bonding properties. Solid State Sciences, 2011. 13(3): p. 553-558.

35. Knoerr, M. and A. Schletz. Power semiconductor joining through sintering of silver nanoparticles: Evaluation of influence of parameters time, temperature and pressure on density, strength and reliability. in Integrated Power Electronics Systems (CIPS), 2010 6th International Conference on. 2010.

36. GU, Z. and D.H. GRACIAS, NANOWIRE ASSEMBLY AND INTEGRATION, in Nanofabrication. 2012, WORLD SCIENTIFIC. p. 187-211.

37. Oh, J. and C.V. Thompson, Abnormal Anodic Aluminum Oxide Formation in Confined Structures for Lateral Pore Arrays. Journal of The Electrochemical Society, 2011. 158(3): p. C71-C75.

38. Hurst, S.J., et al., Multisegmented One-Dimensional Nanorods Prepared by Hard-Template Synthetic Methods. Angewandte Chemie International Edition, 2006. 45(17): p. 2672-2692.

39. Peng, Y., T. Cullis, and B. Inkson, Bottom-up Nanoconstruction by the Welding of Individual Metallic Nanoobjects Using Nanoscale Solder. Nano Letters, 2009. 9(1): p. 91-96.

40. Lu, Y., et al., Cold welding of ultrathin gold nanowires. Nature nanotechnology, 2010. 5(3): p. 218-224.

41. Gao, F., et al., Effect of surface oxide on the melting behavior of leadfree solder nanowires and nanorods. Applied Surface Science, 2012. 258(19): p. 7507-7514. 
42. Chun, S.R., et al., Joining Copper Oxide Nanotube Arrays Driven by the Nanoscale Kirkendall Effect. Small, 2013. 9(15): p. 2546-2552.

43. Mukherjee, S., et al., An Efficient Silver Etchant for the Fabrication of Active Nanowires Using Anodized Aluminum Oxide Templates. Electrochemical and Solid-State Letters, 2010. 13(7): p. D50-D52.

44. Chun, S.R., et al., Low Temperature Bonding via Copper Nanowires for 3D Integrated Circuits. MRS Online Proceedings Library Archive, 2010. 1249: p. 1249-F04-21 (6 pages).

45. Kim, D. and J. Moon, Highly Conductive Ink Jet Printed Films of Nanosilver Particles for Printable Electronics. Electrochemical and Solid-State Letters, 2005. 8(11): p. J30-J33.

46. Jang, S., et al., Sintering of inkjet printed copper nanoparticles for flexible electronics. Scripta Materialia, 2010. 62(5): p. 258-261.

47. Allen, G.L., et al., Small particle melting of pure metals. Thin Solid Films, 1986. 144(2): p. 297-308.

48. Yonezawa, T., et al., Preparation of naked silver nanoparticles in a TEM column and direct in situ observation of their structural changes at high temperature. Chemical Physics Letters, 2012. 537: p. 65-68.

49. Herring, C., Effect of Change of Scale on Sintering Phenomena. Journal of Applied Physics, 1950. 21(4): p. 301-303.

50. Ishizaki, T., et al., Thermal characterizations of $\mathrm{Cu}$ nanoparticle joints for power semiconductor devices. Microelectronics Reliability, 2013. 53(9-11): p. 1543-1547.

51. Siow, K., Are Sintered Silver Joints Ready for Use as Interconnect Material in Microelectronic Packaging? Journal of Electronic Materials, 2014. 43(4): p. 947-961.

52. Watanabe, R. and T. Ishizaki, High-Strength Pressure-Free Bonding Using $\mathrm{Cu}$ and Ni-Sn Nanoparticles. Particle \& Particle Systems Characterization, 2014: p. n/a-n/a.

53. Zinn, A.A., Stabilized metal nanoparticles and methods for production thereof. 2012, Google Patents.

54. Kim, I., et al., Synthesis of oxidation-resistant core-shell copper nanoparticles. RSC Advances, 2013. 3(35): p. 15169-15177. 
55. Lee, D.G., et al., Estimation of the Properties of Silver Nanoparticle Ink During Laser Sintering via $<i>$ In-Situ $</ i>$ Electrical Resistance Measurement. Journal of Nanoscience and Nanotechnology, 2013. 13(9): p. 5982-5987.

56. Yabuki, A. and N. Arriffin, Electrical conductivity of copper nanoparticle thin films annealed at low temperature. Thin Solid Films, 2010. 518(23): p. 7033-7037.

57. Yamakawa, T., et al., Influence of Joining Conditions on Bonding Strength of Joints: Efficacy of Low-Temperature Bonding Using Cu Nanoparticle Paste. Journal of Electronic Materials, 2013. 42(6): p. 1260-1267.

58. Haque, M.M., D. Cho, and C.S. Lee, Investigation of sintering behavior of octanethiol-coated copper nano ink under various atmospheres. Thin Solid Films, 2013. 536: p. 32-38.

59. Deng, D., et al., Antioxidative effect of lactic acid-stabilized copper nanoparticles prepared in aqueous solution. Journal of Materials Chemistry, 2012. 22(45): p. 23989-23995.

60. Pulkkinen, P., et al., Poly(ethylene imine) and Tetraethylenepentamine as Protecting Agents for Metallic Copper Nanoparticles. ACS Applied Materials \& Interfaces, 2009. 1(2): p. 519-525.

61. Jang, S., J. Joung, and Y. Oh, Microstructure changes in nanoparticulate gold films under different thermal atmospheres and the effects on bondability. Acta Materialia, 2009. 57(18): p. 5613-5620.

62. Coutts, M.J., et al., Rapid and Controllable Sintering of Gold Nanoparticle Inks at Room Temperature Using a Chemical Agent. The Journal of Physical Chemistry C, 2009. 113(4): p. 1325-1328.

63. Kingery, W.D. and M. Berg, Study of the Initial Stages of Sintering Solids by Viscous Flow, Evaporation-Condensation, and Self-Diffusion. Journal of Applied Physics, 1955. 26(10): p. 1205-1212.

64. Demirskyi, D., D. Agrawal, and A. Ragulya, Neck growth kinetics during microwave sintering of copper. Scripta Materialia, 2010. 62(8): p. 552555.

65. Herring, C., Effect of Change of Scale on Sintering Phenomena. Journal of Applied Physics, 1950. 21(4): p. 301-303. 
66. RAHAMAN, M.N., CERAMIC PROCESSING AND SINTERING. 2005: MARCEL DEKKER, INC.

67. Frenkel, J., Viscous flow of crystalline bodies. Zhurnal Eksperimentalnoi i Teoreticheskoi Fiziki, 1946. 16(1): p. 29-38.

68. Fang, Z.Z., Sintering of Advanced Materials Fundamentals and Processes. 2010: Woodhead Publishing.

69. Zhang, D., et al., The kinetics of initial stage in sintering process of BaTiO 3-based PTCR ceramics and its computer simulation. Materials Science and Engineering: B, 2003. 99(1): p. 88-92.

70. Boccaccini, N.P.B.A.R., CERAMICS AND COMPOSITES PROCESSING METHODS. 2012, A JOHN WILEY \& SONS, INC., PUBLICATION.

71. Calata, J.N., DENSIFICATION BEHAVIOR OF CERAMIC AND CRYSTALLIZABLE GLASS MATERIALS CONSTRAINED ON A RIGID SUBSTRATE in Materials Science and Engineering 2005, Blacksburg, Virginia

72. Nanomaterials. 12 Apr 2016]; Available from: https://en.wikipedia.org/wiki/Nanomaterials.

73. Wakuda, D., M. Hatamura, and K. Suganuma, Novel method for room temperature sintering of Ag nanoparticle paste in air. Chemical Physics Letters, 2007. 441(4-6): p. 305-308.

74. Magdassi, S., et al., Triggering the Sintering of Silver Nanoparticles at Room Temperature. ACS Nano, 2010. 4(4): p. 1943-1948.

75. Siow, K.S., Mechanical properties of nano-silver joints as die attach materials. Journal of Alloys and Compounds, 2012. 514(0): p. 6-19.

76. Fu, S., et al., Parametric Study on Pressureless Sintering of Nanosilver Paste to Bond Large-Area ( $\geq 100 \mathrm{~mm} 2)$ Power Chips at Low Temperatures for Electronic Packaging. Journal of Electronic Materials, 2015. 44(10): p. 3973-3984.

77. Chen, Y., R.E. Palmer, and J.P. Wilcoxon, Sintering of Passivated Gold Nanoparticles under the Electron Beam. Langmuir, 2006. 22(6): p. 28512855.

78. Anto, B.T., et al., Hydrophilic Sparse Ionic Monolayer-Protected Metal Nanoparticles: Highly Concentrated Nano-Au and Nano-Ag "Inks" that 
can be Sintered to Near-Bulk Conductivity at $150^{\circ} \mathrm{C}$. Advanced Functional Materials, 2010. 20(2): p. 296-303.

79. Smith, B.L. and J.E. Hutchison, Transformations during Sintering of Small (Dcore < $2 \mathrm{~nm}$ ) Ligand-Stabilized Gold Nanoparticles: Influence of Ligand Functionality and Core Size. The Journal of Physical Chemistry C, 2013. 117(47): p. 25127-25137.

80. Lee, B., et al., A low-cure-temperature copper nano ink for highly conductive printed electrodes. Current Applied Physics, 2009. 9(2, Supplement): p. e157-e160.

81. Park, B.K., et al., Direct writing of copper conductive patterns by ink-jet printing. Thin Solid Films, 2007. 515(19): p. 7706-7711.

82. Wakuda, D., K.-S. Kim, and K. Suganuma, Ag nanoparticle paste synthesis for room temperature bonding. Components and Packaging Technologies, IEEE Transactions on, 2010. 33(2): p. 437-442.

83. Moon, K.-S., et al., Thermal behavior of silver nanoparticles for lowtemperature interconnect applications. Journal of Electronic Materials, 2005. 34(2): p. 168-175.

84. Akada, Y., et al., Interfacial bonding mechanism using silver metalloorganic nanoparticles to bulk metals and observation of sintering behavior. Materials transactions, 2008. 49(7): p. 1537-1545.

85. Ide, E., et al., Metal-metal bonding process using Ag metallo-organic nanoparticles. Acta Materialia, 2005. 53(8): p. 2385-2393.

86. Ishizaki, T., et al., Reliability of $\mathrm{Cu}$ nanoparticle joint for high temperature power electronics. Microelectronics Reliability, 2014. 54(9-10): p. 1867-1871.

87. Byung Hoon, L., et al. Evaluation of copper nanoparticles for low temperature bonded interconnections. in Physical and Failure Analysis of Integrated Circuits (IPFA), 2015 IEEE 22nd International Symposium on the. 2015.

88. Jianfeng, Y., et al., Preparation of PVP coated $\mathrm{Cu} N P$ s and the application for low-temperature bonding. Journal of Materials Chemistry, 2011. 21(40): p. 15981-15986. 
89. Yi, S.-M., et al., Improvement of electrical and mechanical properties of Ag nanoparticulate films by controlling the oxygen pressure. Journal of The Electrochemical Society, 2010. 157(12): p. K254-K259. 
Experimental Methodology

Chapter 3

\section{Chapter 3}

\section{Experimental Methodology}

This chapter describes the experimental and characterization techniques used in this project. The rational, limitations and assumptions made with each technique would also be discussed. This includes the technique of post-processing the as-synthesized copper nanoparticles, the reasons for different types of surfactant added and sample preparations for subsequent experiments and characterizations. Thermal characterizations of these Cu NPs were carried out using thermal gravimetric analysis (TGA) and differential scanning calorimetry (DSC). These techniques are used to understand the basic thermal behavior of the Cu NPs when subjected to different heating profiles. A DIY furnace for sintering of $\mathrm{Cu} N$ Ps paste that is coupled with in-situ electrical resistance measurement is used to study the change in electrical resistance under various suitable sintering conditions that were previously derived from the thermal characterizations results. The microstructures of the sintered $\mathrm{Cu} N P$ s from different sintering conditions were analyzed using a field emission scanning electron microscope (FESEM) coupled with focus ion beam milling (FIB) capability. This allows the top surface morphology and crosssectioned of the sintered $\mathrm{Cu} N$ S layer to be studied concurrently. Lastly, the working principle of an X-ray diffraction (XRD) method was outlined and justified for its usage to understand grain growth and crystallite orientation of sintered $\mathrm{Cu} N \mathrm{~N}$. 


\subsection{Rationale for Selection of Methods}

The main objective of this work is to develop an understanding of the basic properties and behaviour of the organic passivated metallic NPs and demonstrate its feasibility to be used for low temperature process applications. Therefore, initial post-processing of these as-synthesized $\mathrm{Cu}$ NPs and understanding the thermal behaviour of the $\mathrm{Cu}$ NPs is necessary. Since these $\mathrm{Cu}$ NPs is targeted towards the die-attach and/or 3D interconnect applications, suitable viscosities of these $\mathrm{Cu}$ NPs paste for different applications have to be adjusted by adding suitable type of solvents and surfactants. In addition, to form a conductive metallic network at low processing temperature $\left(\leq 200^{\circ} \mathrm{C}\right)$, these organic materials present within and on the Cu NPs have to be completely removed at or below $200^{\circ} \mathrm{C}$. Hence, the first step is to establish a detailed understanding of the thermal behavior of the $\mathrm{Cu}$ NPs paste after adding suitable solvents and surfactants when it is subjected to different sintering conditions. To do this, TGA and DSC are often used to study the basic thermal characteristics of the organic materials as it is a fast and simple technique to study the thermal decomposition and critical thermal activities such as melting, enthalpy of reaction and thermal degradation respectively with respect to time or temperature. In addition, the environment of test can be controlled to be inert or at atmospheric environment.

A suitable thermal profile is selected after the basic thermal characteristics of $\mathrm{Cu}$ NPs are known. Since the main purpose of this study is to develop a lead-free die-attach material for high power applications and/or 3D interconnects, the mechanical, electrical properties and the microstructures of the material after processing are important. The transition from high electrical resistance to a conductive metallic network depends on the removal of organic materials and the fusion of these $\mathrm{Cu}$ NPs. Hence an in-situ resistance measurement is set-up within the sintering oven to enable the study of resistance change with temperature, time and environment. Such study provides a fast and effective way to study the electrical property directly during the sintering process. Microstructure evolution of the $\mathrm{Cu}$ NPs can also be directly studied by freezing the respective microstructure when a critical temperature during sintering is reached. FESEM coupled with a FIB that comes with milling capability is used to study the top and cross-sectioned microstructures. 
Experimental Methodology

Chapter 3

To enable the use of such sintered $\mathrm{Cu}$ NPs for die-attach and interconnect applications, the long-term thermal stability of the joint needs to be understood. Grain size and texture of the aged $\mathrm{Cu}$ NPs joints which have a direct influence on mechanical and electrical properties, needs to be understood and characterized. Therefore, $\mu \mathrm{XRD}$ is carried out to understand the grain growth and crystal orientation with time. This technique is chosen due to its capability to analyze small grain size and small localized area of interest.

\subsection{Post-Processing and Sample Preparation of Cu NPs}

\subsubsection{Washing of as-synthesized Cu NPs}

The $\mathrm{Cu}$ NPs paste, Cuantumfuse ${ }^{\mathrm{TM}}$, was synthesized by Dr Alfred A. Zinn et al. at Lockheed Martin ATC Corporation [1]. They were kept in a $50 \mathrm{ml}$ syringe for ease of transportation, storage and dispensing. Prior to sintering, washing of the raw $\mathrm{Cu}$ NPs is necessary to remove unwanted and unreacted substances left behind after the synthesis process. After the washing procedure was completed, additives which include low boiling points solvent and some surfactants were added to adjust the viscosity of the $\mathrm{Cu}$ NPs paste. It was then transferred into a $10 \mathrm{ml}$ syringe and mixed between 2 syringes before using it for subsequent studies. A schematic diagram on the washing procedure is shown in Figure 3.1.

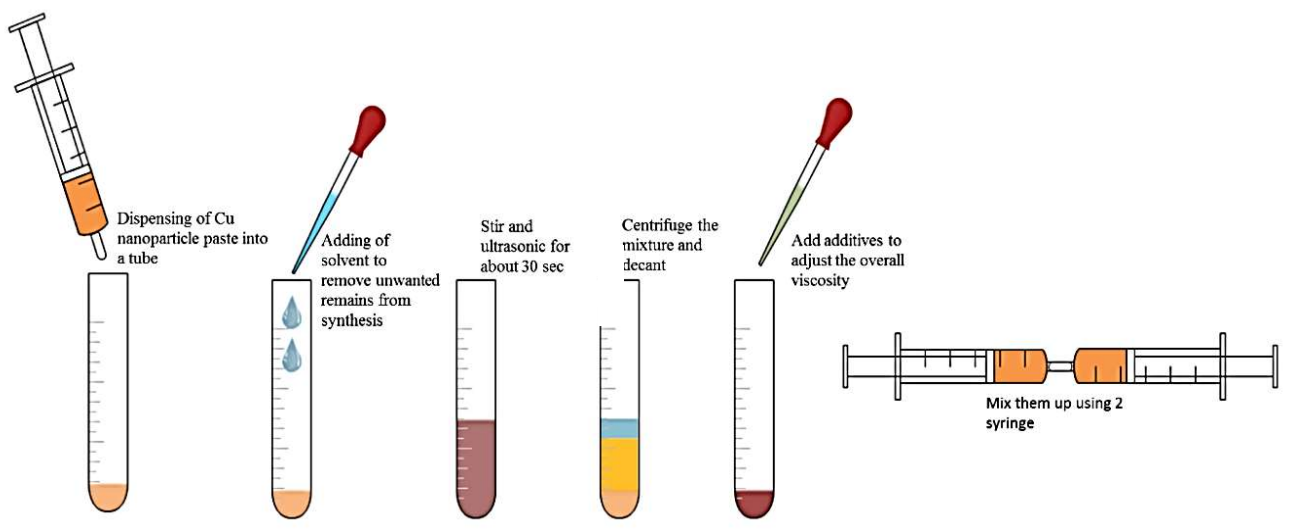

Figure 3.1 Schematic diagram of the post-processing of $\mathrm{Cu}$ nanoparticles before sintering

**All surfactants used are proprietary information and will not be disclosed in this thesis. 


\subsubsection{Sample Preparation for Electrical Resistance Studies}

A simple electrical test structure is constructed using a glass slide, copper and Kapton tape. It was connected to a Kiethley 2400 sourcemeter. A 4-point probe connection was set-up for the electrical resistance measurements as shown in Figure 3.2. A sourcing current of $1 \mathrm{~mA}$ was applied and the resistance was measured during the sintering process. The main objective for carrying out this electrical resistance measurements is to provide a fast and effective way to understand the sintering behaviour and observe any abnormal behaviour of the $\mathrm{Cu}$ NPs when subjected to different sintering conditions through monitoring the resistance in-situ. A picture of the test structure for bonding and non-bonding testing is shown in Figure 3.2.
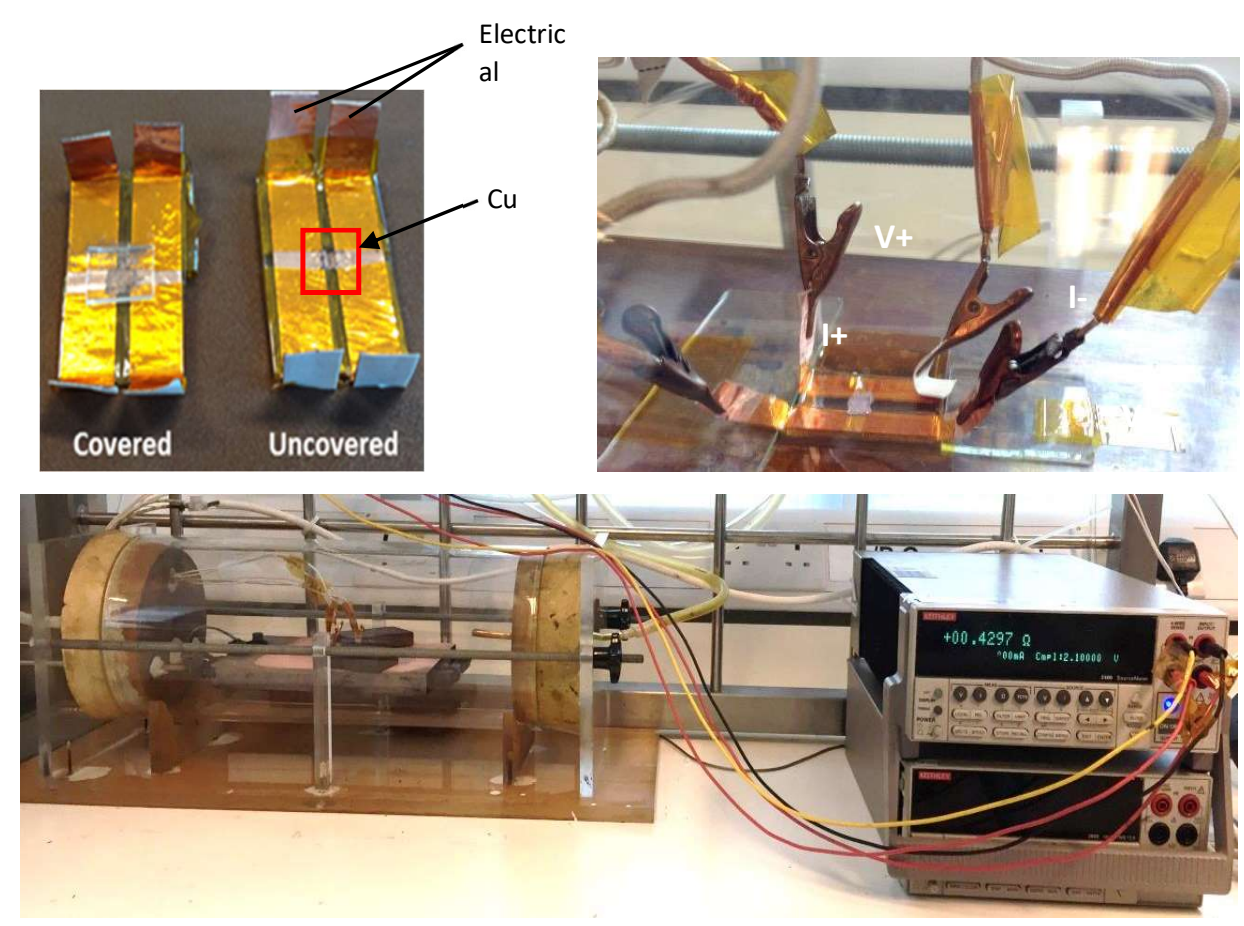

Figure 3.2 Pictures of the simple electrical test structures and set-up

However, there are some advantages and limitations to the use of such test structures. The advantages as mentioned earlier are the ease of creating such test structure and the variable area of the dispensed NPs can be adjusted with the copper and Kapton tape for various die size characterisations. However, the thickness of the $\mathrm{Cu}$ NPs is rather thick $(\sim>80 \mu \mathrm{m})$ as it is dependent on the 
Experimental Methodology

Chapter 3

thickness of the tapes used. The thickness of bonded layer that is applicable is usually $<10 \mu \mathrm{m}$. Since the layer spread onto the test structure is thick, it will be prone to cracking during the intermediate stage of sintering where shrinkage and densification take place. When cracking occurs, there is a discontinuity within the sintered $\mathrm{Cu}$. This prevents the resistance of the $\mathrm{Cu}$ NPs to be measured properly. Hence this method is good for studying the initial sintering process of the $\mathrm{Cu}$ NPs whereby minimum shrinkage and densification is observed.

In addition, the thickness and thermal conductivity of glass and Si chip have to be considered as well in setting the temperature. When testing with different substrates, the heating profile and set temperatures have to be adjusted accordingly. Prior to measuring the electrical resistance, a thermocouple was placed onto the test structure to ensure that the actual temperature on the substrate and the set temperature of the temperature controller is similar to achieve a comparable and unbiased result.

\subsubsection{Sample Preparation for Bonding Applications}

The feasibility of using these $\mathrm{Cu}$ NPs as a die-attach material is first proven on a similar metallic material surface, $\mathrm{Cu}$. Hence, $\mathrm{SiO}_{2}$ wafers were sputtered with a $10 \mathrm{~nm}$-thick $\mathrm{TiO}_{2}$ for adhesion purpose between $\mathrm{Cu}$ and $\mathrm{SiO}_{2}$. A $500 \mathrm{~nm}$ thick $\mathrm{Cu}$ was sputtered onto the $\mathrm{TiO}_{2}$ layer. After which the wafer was diced into 1 $\mathrm{mm} X 1 \mathrm{~mm}$ and $5 \mathrm{~mm}$ X $5 \mathrm{~mm}$ chip and substrate, respectively for subsequent bonding purposes. A $1 \mathrm{~mm} \mathrm{X} 1 \mathrm{~mm}$ area chip was selected due to several reasons. One of the reasons is the ease of controlling the wetting of $\mathrm{Cu}$ NPs paste across the entire bonding area. Secondly is to avoid or minimise non-uniform volatilisation across bigger die area as it is harder for solvent located at the inner area of the die to volatilise during the sintering process [2]. Hence to minimise the effects due to die size dimension, a $1 \mathrm{~mm}$ X $1 \mathrm{~mm}$ die was chosen.

Prior to bonding, the chips and substrate were washed with acetic acid to remove copper oxide from the surface [3]. Otherwise, the bonding between substrate and $\mathrm{Cu}$ NPs would not be good as the oxide could hinder fusion between bonding surfaces and $\mathrm{Cu}$ NPs. No further test was carried out that to verify the 

and consistent for all bonding samples.

After preparing the bonding dies and substrates, small amount of $\mathrm{Cu}$ NPs paste $(\sim 10 \mathrm{mg})$ was dispensed manually onto the $5 \mathrm{~mm}$ X $5 \mathrm{~mm}$ substrate and a Mayer rod was used to spread the $\mathrm{Cu}$ NPs paste evenly across the entire substrate. The $1 \mathrm{~mm} \mathrm{X} 1 \mathrm{~mm}$ die was then placed on top of the substrate with some light pressure exerted to ensure good contact and spread across and between the bonding surfaces. Therefore, it is observed that the viscosity of the $\mathrm{Cu}$ NPs paste plays an important role for the initial spreading across the entire bonding area. A good contact between bonding surfaces is essential for forming strong bonds especially at the bonding interfaces. The thickness of the paste was kept between $5-10 \mu \mathrm{m}$ as thicker joints would induce more cracks due to shrinkage during sintering.

\subsection{Characterization of Cu NPs}

\subsubsection{Thermal gravimetric analysis (TGA)}

Thermal gravimetric analyses (TGA) of the $\mathrm{Cu}$ NPs were carried out on TA Instrument Q500 to characterize the thermal characteristics of the Cu NPs at different temperatures and time. TGA is commonly used for various thermal analyses such as (1) characterization of decomposition patterns, (2) studies on degradation mechanisms and reaction kinetics, (3) loss of organic content in samples as a function of time or temperature, and (4) mass loss or gain due to oxidation, evaporation or decomposition. TGA can be carried out under inert ambient such as nitrogen or argon or in air condition. The weight of the samples is recorded as a function of changing temperature or time. A schematic diagram of a TGA is shown in Figure 3.3. In this project, it is mainly used to determine the loss of organic content due to volatilization as a function of temperature or at different heating rates by observing the change in weight. All tests were run under nitrogen $\left(\mathrm{N}_{2}\right)$ condition to prevent oxidation of copper during the process. The flow rate of $\mathrm{N}_{2}$ used was 60 SCCM. The system was cooled naturally after the experiment. The temperature range tested was between $25^{\circ} \mathrm{C}-300^{\circ} \mathrm{C} .10$ $\mathrm{mg}$ of the copper nanoparticles paste were placed on a tared aluminum pan. The results were used to determine the minimum temperature used for sintering of 
Experimental Methodology

Chapter 3

the $\mathrm{Cu}$ NPs paste in subsequent experiments. The onset temperature of volatilization and sintering for each heating rate was an average of three runs.

However, there are a few limitations and assumptions made when using this technique. One of the limitations is the inability to effectively heat up at a higher heating rate i.e. $>10^{\circ} \mathrm{C} / \mathrm{min}$. Though the program allows a heating rate up till $40^{\circ} \mathrm{C} / \mathrm{min}$, the actual temperature and the set temperature do not match once a higher heating rate is adopted. This is due to the limitation of heating element capability in the TGA equipment. The second limitation is that the un-passivated $\mathrm{Cu}$ NPs are susceptible to oxidation. Though the test was carried out at inert condition, oxidation could occur at the higher temperature, $>200^{\circ} \mathrm{C}$, due to poor control of the furnace ambient. An increase in weight was usually observed. Therefore, thermal characteristics of these $\mathrm{Cu}$ NPs at higher temperature range or even prolong isothermal annealing test are hard to achieve.

Based on the layout of the TGA equipment, the heating mechanism is largely dependent on convection process since the sample is not placed directly on the heating element. In our study, both conduction and convection play a role in the sintering process. Hence the difference in heating mechanism should be kept in mind when comparing results.

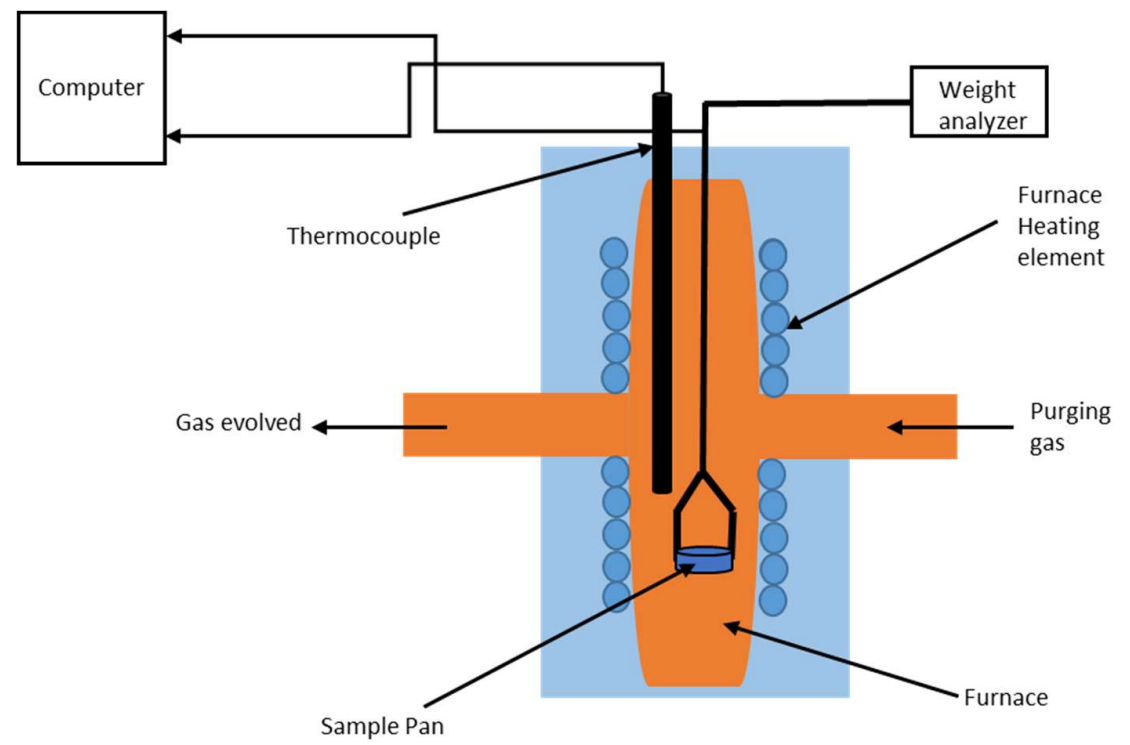

Figure 3.3 Schematic diagram of a TGA 


\subsubsection{Differential Scanning Calorimetry (DSC)}

From the TGA results, weight loss as a function of temperature and time is known. However, some thermal transition activities such as melting and fusion do not lead to a weight change, but is accompanied by heat flow. This will enable the user to identify precisely the phrase transitions of the samples and other chemical reactions that do not lead to weight change. To identify the onset fusing temperature of the $\mathrm{Cu}$ NPs, DSC measurements were carried out on a DSC TA Q10 under $\mathrm{N}_{2}$ atmosphere. Samples were run from $25^{\circ} \mathrm{C}$ to $300^{\circ} \mathrm{C} .10 \mathrm{mg}$ of the $\mathrm{Cu}$ NPs paste were placed in a pre-weighed aluminum hermetic sealing pan. DSC uses a feedback loop to maintain the sample at a set temperature while at the same time measures the power needed to do this against the reference sample. Hence the result of heat flow against time or temperature can be plotted. In addition, DSC data can be used for determination of the enthalpy and specific heat capacity ( $c p$ ) of the tested material. In this study, the DSC measurements were used to correlate with the TGA data. With the combination of both, it provides an overview of the thermodynamics transitions that happen during the heating up process of the $\mathrm{Cu}$ NPs within the set temperature range. Figure 3.4 shows the schematics of a DSC setup.

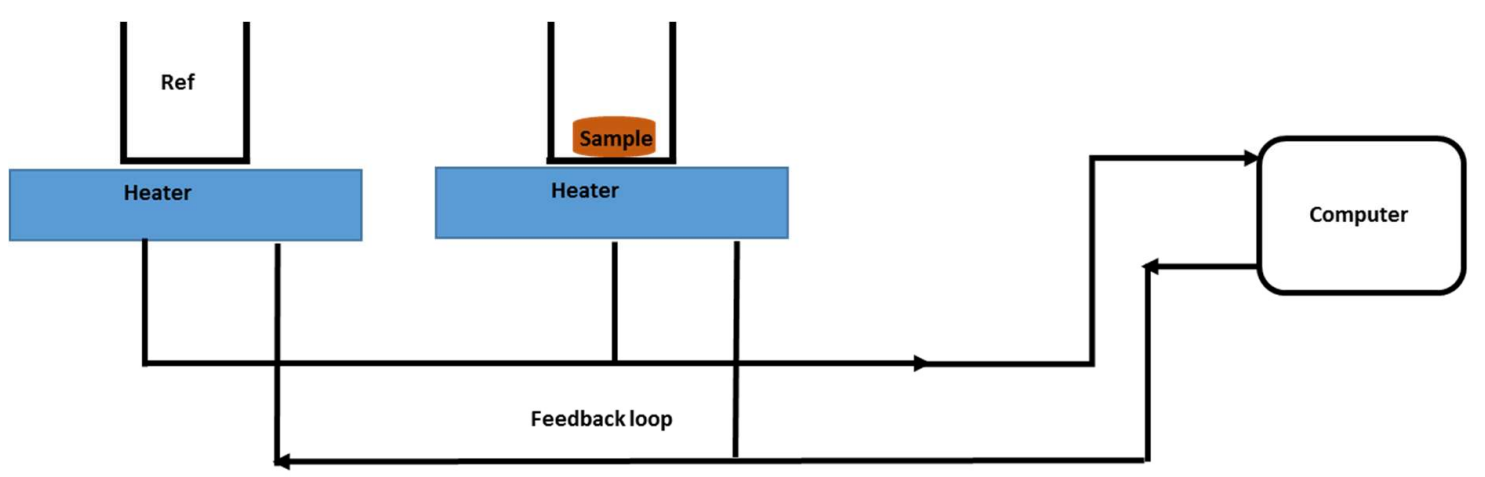

Figure 3.4 Schematic diagram of a DSC

However, since TGA and DSC were run separately, there might be some discrepancy arising from different amount of samples since it would have some effect on volatilizations and fusion of $\mathrm{Cu}$ NPs. Hence to minimize the errors, 

types of characterizations.

\subsubsection{In-situ electrical resistance measurements}

Though the general thermal characteristics of the $\mathrm{Cu}$ NPs are known, it is limited to heating rate below $10^{\circ} \mathrm{C} / \mathrm{min}$ due to equipment constraint. The thermal characteristics of these $\mathrm{Cu}$ NPs at higher heating rates were not achievable based on previous techniques. In addition, the characterizations were done separately from the actual sintering equipment. Hence some differences in terms of heating mechanism might cause inaccurate observations. Thus, the ability to carry out an in-situ thermal characterization during the sintering process will be the most accurate to indicate the actual mechanism.

As explained earlier, the sintering of the $\mathrm{Cu}$ NPs is based on the transition from an insulator that is made up of many organic passivated metallic NPs to a conductive metallic network after thermal treatment. Such transition would cause the electrical properties of the $\mathrm{Cu}$ NPs to change. Hence in-situ electrical resistance measurements were carried out in a heating furnace equip with fast heating up rate to as a proxy to monitor the transitions of the $\mathrm{Cu}$ NPs. With such measurements, the electrical resistance of the $\mathrm{Cu}$ NPs will be measured during heating up and isothermal annealing. Such information can be used to correlate with the $\mathrm{Cu}$ NPs fusion process at different process conditions. Details on the sample preparation and the type of electrical test structure used was mentioned Section 3.2.2.

Before thermal treatment, high electrical resistance is expected due to the presence of organic materials as observed from the TGA data ( 20 wt. \%). During heating, the removal of organic materials present within and on the $\mathrm{Cu}$ NPs would cause the Cu NPs to fuse due to their high surface energy. Therefore, different onset temperatures of volatilization and fusion at various sintering conditions can be gathered accordingly due to a sudden change in electrical resistance of the $\mathrm{Cu}$ NPs during sintering.

With this characterization technique, it is assumed that the thickness of the $\mathrm{Cu}$ NPs layer remains largely constant and similar for all samples. Since resistance 
Experimental Methodology

Chapter 3

instead of resistivity is measured, the thickness of the $\mathrm{Cu}$ NPs is assumed to be constant for all samples and does not have a huge influence on the onset temperatures of volatilization and fusion. Based on the data derived from this technique, a model is developed to predict the dominant sintering mechanism when subjected to different heating up rates. In this model, minimum or no shrinkage of equal sized spherical $\mathrm{Cu}$ NPs is assumed.

\subsubsection{Shear Test}

After bonding the Si-based chips with Cu NPs, shear testing was done to measure the shear strength of the bonded joint. Figure 3.5 shows the setup of shear tester. The mechanical shear strength of the bonded joint is characterized by the die shear test. All shear testings were carried out using a shear tester (DAGE 400) with a maximum load of $5 \mathrm{~kg}$.

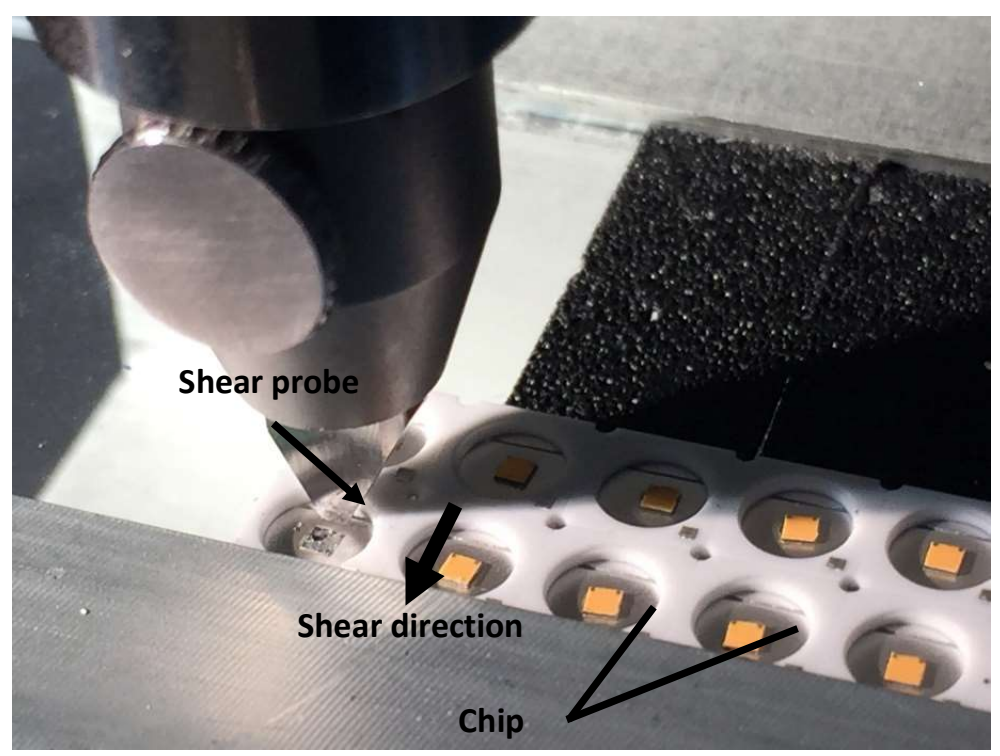

Figure 3.5: Shear test setup

Die shear testing is the process of determining the strength of adhesion of a die to a substrate, with a stress being applied to a die in parallel to the plane of the die attach substrate. This can result in a shearing stress at 3 possible locations:

1. between the die-die attach material interface,

2. within the die-attach material itself, and

3. between the die attach material-substrate interface 
The failure location of each sample must be noted and analysed separately as it could indicate how the changes in bonding parameters affect the failure location. During shear testing, the force applied to the die must be sufficient to shear the die from the substrate or twice the lower specification limit for the die shear strength. The direction of the applied force must be perpendicular to the die edge and parallel to the die attach or substrate plane. After the initial contact has been made and the application of force starts, the relative position of the tool should not change throughout the shearing process. The tip of the probe should not contact both the die attach material and the substrate. All these are represented schematically in Figure 3.6. To achieve statistically reliable results, 6 measurements were taken for each data point.

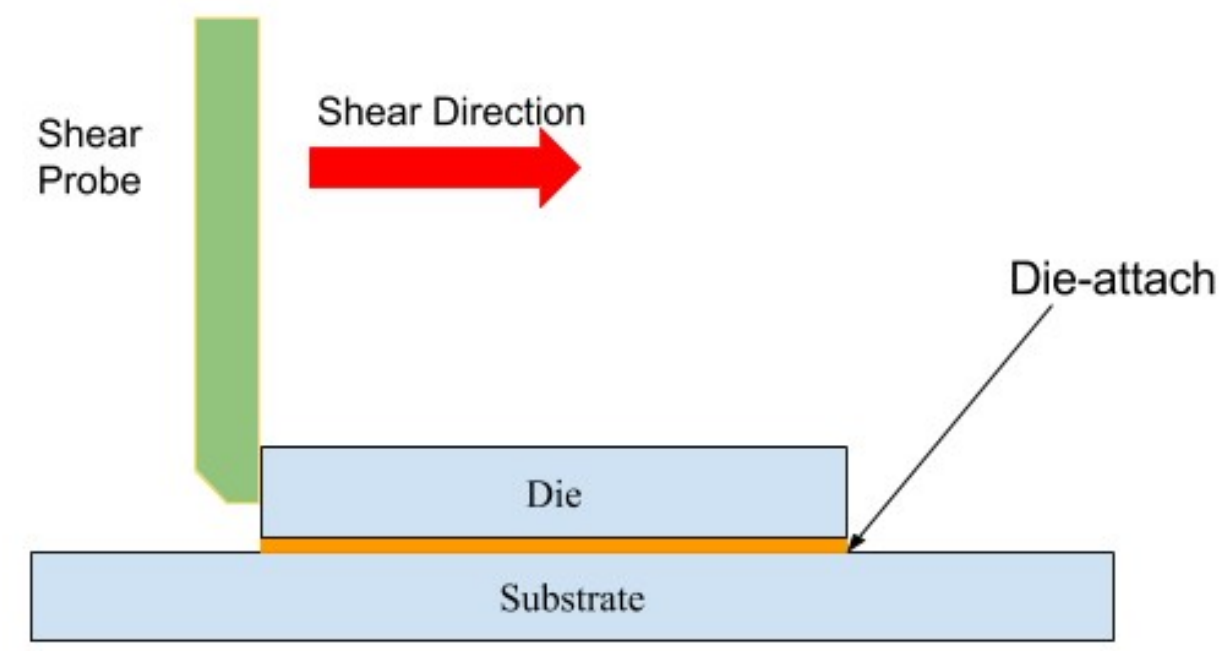

Figure 3.6 Schematics diagram of the shear test setup

\subsubsection{Field Emission Scanning Microscopy with Focused Ion Beam Milling Capability}

After understanding the thermal characteristics of the $\mathrm{Cu}$ NPs at different sintering conditions, microstructure analysis is needed to explain the difference in thermal and electrical properties of the $\mathrm{Cu}$ NPs before and after sintering. Microstructures analysis is usually done using a Scanning Electron Microscope (SEM) or Field Emission Scanning Electron Microscope (FESEM). Both are electron microscopes that are capable of imaging the sample surfaces by raster scanning over the surfaces with high energy beam of electrons. These electrons 

information such as compositions and topography. The difference between a SEM and FESEM is the type of emitter. SEM uses a thermionic emitter while FESEM uses a field emitter. The difference between them is that electrical current is used to heat up the filament in the thermionic emitters. The electrons will escape from the filament material when the heat is sufficient to overcome the work function of the filament material [4]. In addition, such thermionic sources usually have a relative low brightness and suffer from thermal drift during operation. However, all these limitations can be solved by using a field emission emitter to generate electrons. A Field Emission Gun (FEG) does not heat the filament. The principle of electron emission in a FESEM is based on having a huge electrical potential gradient in the filament material [5]. The FEG is usually a wire of Tungsten (W) made into a sharp point that has a small tip radius $(\sim 100 \mathrm{~nm})$, so that the electric field can be concentrated to an extreme level. As a result, the work function of the material is overcome and allows the electrons to leave the cathode. Therefore, by using such emitter in a FESEM, it is able to produce a cleaner image, less electrostatic distortions and spatial resolution of $<2 \mathrm{~nm}$, which is much better than a SEM [5]. With such a high spatial resolution, it is commonly used for characterization of nanomaterials structures.

The FESEM coupled with a FIB system used in this project is FEI Nanolab Dualbeam $^{\mathrm{TM}} 600 \mathrm{i}$. This equipment is able to perform high resolution field emission scanning electron microscopy, focused ion beam cutting and energy dispersive $\mathrm{x}$-ray spectroscopy (EDS). The full specification can be found here [6]. In this project, this system was mainly used to carry out top and crosssectioned analysis of the sintered $\mathrm{Cu}$ layers. A protective layer of $\mathrm{Pt}$ was deposited on the sample at the place of interest prior to milling. A $10 \mu \mathrm{m}$ length and $1 \mu \mathrm{m}$ width and height were typically being deposited. After which a "multipass" cutting was performed to make a coarse milling at the area of interest. The Ga ion current and voltage used for this cutting was set at $9.3 \mathrm{nA}$ and a $30 \mathrm{kV}$, respectively. After the cut, cleaning of the exposed area will be carried out for better imaging. The mode used for cleaning was "clean cross section" with a current of $93 \mathrm{pA}$ and voltage of $30 \mathrm{kV}$. Figure 3.7 shows a typical cross sectioned 
Experimental Methodology

Chapter 3

image of a sintered copper layer on a Si substrate after cleaning. However, due

to the reactive nature of these sintered $\mathrm{Cu} \mathrm{NPs}$, care should be taken when doing ion beam milling as unintentional fusing of these $\mathrm{Cu}$ NPs by the Ga ion-beam irradiation can take place. This eventually could affect the final microstructure when comparing against different samples.

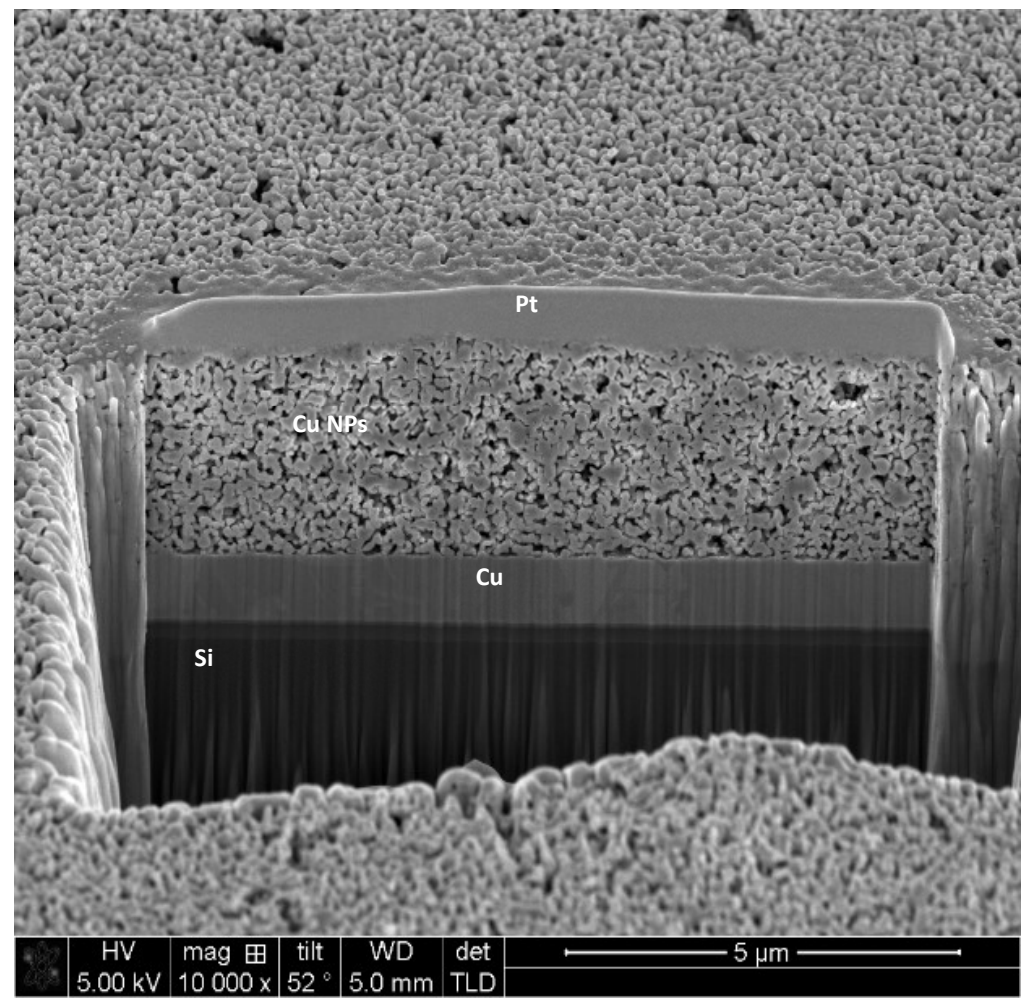

Figure 3.7 Cross-sectioned SEM image of a sintered Cu NPs layer

\subsubsection{X-ray diffraction (XRD)}

Apart from microstructure, the crystalline structure and the grain growth evolution of the sintered or aged $\mathrm{Cu}$ NPs is an important piece of information for further study in the mechanical, electrical and thermal properties. X-ray diffraction (XRD) is a non-destructive technique for characterizing crystalline materials in terms of its phase identifications and preferred crystal orientations (texture). In addition, it can also provide structural information such as the crystallinity, strain, crystal defects and average grain size of the materials [7]. 
The basic principle of a XRD is based on Bragg's law. When an incident beam of X-ray comes into contact with the crystalline sample, they are diffracted by the atomic planes. The X-ray diffraction peaks that are produced are due to the constructive interference of a monochromatic beam of X-rays scattered at specific angles from each of the lattice plane. The constructive inference can be deduced by Bragg's equation as given by

$$
n \lambda=2 d \sin \theta
$$

where $d$ is the spacing between parallel lattice planes, $\theta$ is the angle between the incident $\mathrm{X}$-ray and lattice planes, $\lambda$ is the wavelength of the incoming $\mathrm{X}$-ray and $n$ is an integer. Figure 3.8 shows the pictorial representation of Bragg's law.

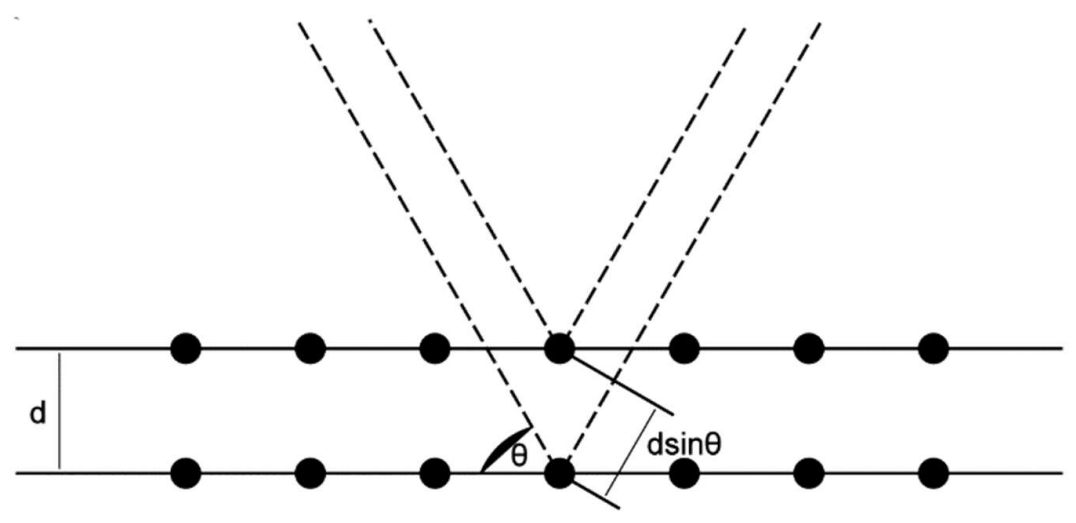

Figure 3.8 Schematic diagram of Bragg's law [8]

The peak intensities are then determined by the distribution of atoms within the lattice. Therefore, these x-ray diffraction patterns are unique periodic atomic arrangements within a particular material and can be cross-referenced with the database provided by any XRD software to determine the structural information of the desired sample. In addition, the width of the peak produced in XRD has also been used to estimate grain size. This equation is commonly known as the Scherrer equation [9]. It can be written as 


$$
\tau=\frac{\kappa \lambda}{\beta \cos \theta}
$$

where $\tau$ is the mean size of the ordered (crystalline) domains, which may be smaller or equal to the grain size; $K$ is a dimensionless shape factor, which has a value close to unity but varies with the actual shape of the crystallite; $\lambda$ is the $\mathrm{X}$ ray wavelength; $\beta$ is the line broadening at half the maximum intensity (FWHM) in radian, after subtracting the instrumental line broadening; $\theta$ is the Bragg angle.

With this equation, a good estimation of the crystallite size can only be done when there is no lattice imperfection in the crystal since it can cause peak broadening as well [10]. In addition, there are some limitations of XRD characterisation. Firstly, depth profiling is not possible. Hence, structure comparison across sintered layer depth is not possible. Therefore, in this study, it is assumed that the crystal structure is similar across the sintered layer. Since depth profiling is not possible, specific area of scan is important for observing structure difference across similar samples. However, due to its large spot size area scan, it is challenging for characterising the bonded structures in this study.

To overcome this problem, micro-XRD ( $\mu$ XRD) coupled with Synchrotron radiation was used as it is able to scan a smaller area. The grain growth and texture of the fused $\mathrm{Cu}$ NPs after ageing for 1000 hours at $150^{\circ} \mathrm{C}$ were studied using synchrotron radiation micro-beam X-ray diffraction at Advanced Light Source, Berkeley. The beamline used is 12.3 .2 with a wavelength of $1.033 \mathrm{~nm}$. These samples were scanned under a $1 \mu \mathrm{m}$ size polychromatic beam with an energy band pass of $5-24 \mathrm{keV}$. The wavelength of the radiation used is 1.0332 $\AA$ and the diffraction patterns were processed using XMAS software [11]. All the XRD line profiles were Lorentzian in shape which is typically used for nanocrystalline material [12].

\subsection{Overview of Methodologies}

All experimental methodology used in this thesis have been described and explained in this chapter. The rationale and limitations of each processing and characterisation method must be considered for better data collection, analysis 
Experimental Methodology

Chapter 3

and model building in the subsequent studies. The availability of resources must be taken into considerations at times. Due to limited time and resources, the insitu electrical resistance of the $\mathrm{Cu}$ NPs on the DIY test structure is the approach taken to understand the sintering mechanism. With each characterisation tool comes with its own set of limitations, it is sometimes beneficial to adopt a few characterization tools for drawing a more accurate conclusion as they complement the shortcomings of the other techniques. This is why with the combination of TGA, DSC, in-situ electrical resistance measurements and microstructure analysis, it might be able to provide a better explanation of the sintering behaviour of these $\mathrm{Cu}$ NPs. This is very important when dealing with a novel material where little is known. In the following chapters, the results and discussion of each experiment would be explained in detail.

\section{References}

1. Zinn, A.A., Stabilized metal nanoparticles and methods for production thereof. 2012, Google Patents.

2. Siow, K.S., Mechanical properties of nano-silver joints as die attach materials. Journal of Alloys and Compounds, 2012. 514(0): p. 6-19.

3. Chavez, K.L. and D.W. Hess, A Novel Method of Etching Copper Oxide Using Acetic Acid. Journal of The Electrochemical Society, 2001. 148(11): p. G640-G643.

4. Thermionic emission. Available from: https://en.wikipedia.org/wiki/Thermionic_emission.

5. Field emission SEM. Available from: http://areeweb.polito.it/ricerca/carbongroup/fac_fesem.html.

6. Dr Chee Lip GAN. Available from: http://www.ntu.edu.sg/home/clgan/. 7. X-ray Diffraction (XRD) Analysis. Available from: http://www.eag.com/mc/x-ray-diffraction.html.

8. X-ray crystallography. [cited 20151 Nov]; Available from: https://en.wikipedia.org/wiki/X-ray_crystallography.

9. Patterson, A.L., The Scherrer Formula for X-Ray Particle Size Determination. Physical Review, 1939. 56(10): p. 978-982. 
Experimental Methodology

Chapter 3

10. Ungár, T., Microstructural parameters from X-ray diffraction peak broadening. Scripta Materialia, 2004. 51(8): p. 777-781.

11. Tamura, N., XMAS: A Versatile Tool for Analyzing Synchrotron X-ray Microdiffraction Data, in Strain and Dislocation Gradients from Diffraction. 2014, IMPERIAL COLLEGE PRESS. p. 125-155.

12. Pantleon, K. and M.A.J. Somers, X-ray diffraction investigation of selfannealing in nanocrystalline copper electrodeposits. Scripta Materialia, 2006. 55(4): p. 283-286. 
Sintering and Densification Behavior of Nano-sized Copper Particles Chapter 4

\section{Chapter 4}

\section{Sintering and Densification Behavior of Nano-sized Copper Particles}

This chapter discusses about the sintering and densification behavior of nano-sized copper particles. TGA, DSC and in-situ electrical resistance measurements during sintering are used to study the thermal, physical and electrical changes that arise from different processing parameters. It is observed that the heating rate has a direct influence on the onset temperature of volatilization of organic materials $\left(T_{E}\right)$, which then affects the subsequent fusing temperature $\left(T_{F}\right)$ of the $\mathrm{Cu} N \mathrm{NP}$ and the resultant microstructure. Moreover, the rate of volatilization of organic materials under different environment such as inert, vacuum and formic acid vapor has a direct impact on the rate of removal of the passivating layers on the $\mathrm{Cu} N \mathrm{~N}$, as well as on the uniformity of removal. The different process parameters and environment thus affect $T_{E}$ and $T_{F}$, the electrical resistance of the sintered $\mathrm{Cu}$, and its microstructure such as size and amount of porosities of the sintered Cu layer. Hence, this chapter will provide in-depth studies on the relationship between the process parameters and the final microstructures of sintered Cu NPs. 
$\underline{\text { Sintering and Densification Behavior of Nano-sized Copper Particles Chapter } 4}$

\subsection{Introduction}

Metallic nanoparticles (NPs) have been a field of interest owing to their unique characteristics that are different from their bulk state, such as high surface energy. Although noble metallic nanoparticles such as $\mathrm{Au}$ and Ag are commercially available, $\mathrm{Cu}$ NPs may be a cheaper alternative with superior properties. However, $\mathrm{Cu}$ is known to be very sensitive to oxidation. Hence, different types of passivating materials for $\mathrm{Cu}$ NPs and ways to eliminate $\mathrm{Cu}$ oxidation have been widely studied [1-6]. Some research groups have been actively developing metallic nanoparticles paste, $\mathrm{Ag}$ or $\mathrm{Cu}$, as a bonding material for electronics devices [7-9]. Besides being a potential substitute for solder materials due to its low processing temperature, it too has gained some attention in the flexible electronics sector. Hence, printable inks which comprise of these metallic nanoparticles have also been developed in recent years $[10,11]$.

It is reported that the melting point of NPs for most elements reduces almost linearly with the inverse of its radius [12]. However, in Chapter 2, it is mentioned that if the diameter of the particles is not sufficiently small, its melting temperature will be similar to its bulk melting temperature. Hence in this study, the size of the nanoparticles that were used consists of $\mathrm{Cu}$ NPs with different sizes as shown in Figure 4.1(a). Therefore, one can expect sintering to occur in solid state and surface energy minimizing is the main driving force of these metallic nanoparticles to fuse and form a conductive path at a lower processing temperature since majority of the NPs are $>50 \mathrm{~nm}$. Meanwhile, organic passivating materials are required to prevent unwanted fusion among the particles or oxidation prior to sintering. Although low temperature sintering behavior of silver (Ag) NPs has been studied extensively [13-16], few have reported on $\mathrm{Cu}$ NPs $[5,17]$. It is known that $\mathrm{Cu}$ oxidizes easily in air which lowers its electrical conductivity. Therefore, these $\mathrm{Cu}$ NPs, which are passivated with organic materials to prevent oxidation and fusion, is an insulator prior to sintering. To achieve the desired electrical and mechanical properties of the sintered NPs, these passivating layers must be completely removed during the thermal treatment to allow fusion among these NPs $[18,19]$. 
Sintering and Densification Behavior of Nano-sized Copper Particles Chapter 4

Presently, most literatures have indicated that a processing temperature of more than $230^{\circ} \mathrm{C}$ is required for good $\mathrm{Cu}$ NPs sintering under inert conditions [3, 10, 11, 20-22]. High temperature is usually needed for the decomposition, desorption or volatilization of the organic additives present within the Cu NPs. Some groups have proposed to reduce the size or change the shape of the nanoparticles to take advantage of thermodynamic effects to lower the processing temperature $[23,24]$. However, depending on the final applications, the reduction in particle size might not be feasible for thin film application. In thin film application, it is better to use larger nanoparticles as a denser film can be achieved [25]. However, bigger nanoparticles will need higher sintering temperature and/or longer time to be fused, while in manufacturing conditions, the sintering requirements are shorter processing time and lower temperature. As a result, smaller particles size can help to optimize the process condition but may not lead to a dense film after sintering. Therefore in this study, a mixture of $\mathrm{Cu}$ NPs sizes as shown in Figure 4.1 were used so that it could be fused at a lower temperature and shorter time, yet at the same time achieve a dense structure.

The solvent used in the formulation of the $\mathrm{Cu}$ nanoparticles paste is an alcohol that can evaporate at low temperature. The surfactants were chosen based on its volatilization temperature as the aim is for them to be removed during sintering at $200^{\circ} \mathrm{C}$. Another consideration factor is that these surfactants must be able to cover the surface of the nanoparticles during synthesis to prevent agglomeration (weak electrostatic force). A simple schematic diagram of the ligands on the $\mathrm{Cu}$ NPs is added as Figure 4.1(c) in the thesis as below. Details of the formulation are proprietary information and thus could not be disclosed in the thesis. 


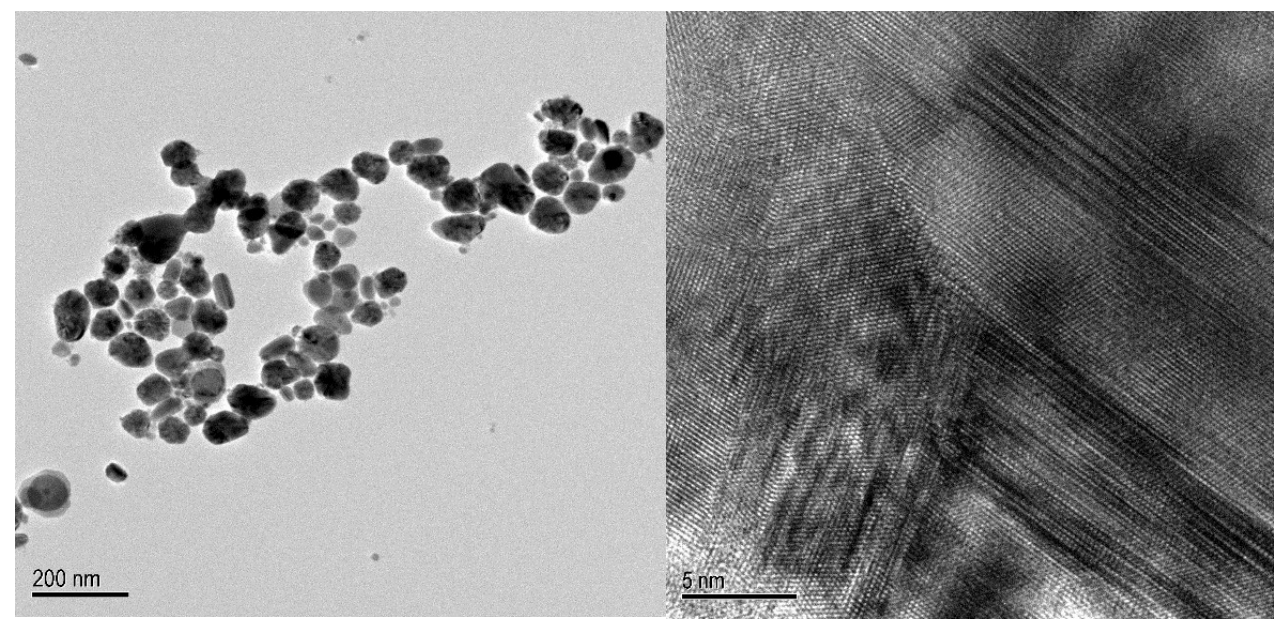

(a)

(b)

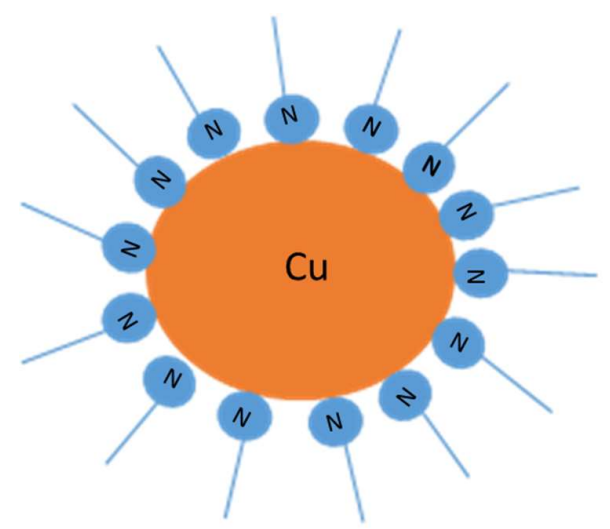

Amine-based surfactants

(c)

Figure 4.1 (a) TEM image of Cu NPs used (b) Zoomed-in image of a Cu NP (c) Schematic diagram of how the ligands are attached on Cu NPs

Though there are challenges in integrating these $\mathrm{Cu}$ NPs into current reflow processes, its ability to be sintered at a relatively low temperature with substantially good electrical, thermal and mechanical properties is a major advantage [26]. Hence, detailed studies on the effects of sintering parameters such as sintering temperature, time and type of ambient have been carried out [27-29]. The relationship between heating rate and densification of nanoparticles has been reported $[28,30,31]$ and it is stated that higher heating rate is preferred to achieve a denser microstructure as it bypasses the low temperature regime [16]. However, these studies were mostly done on non-metallic NPs that are not passivated with organic materials. For metallic NPs that are passivated with 
$\underline{\text { Sintering and Densification Behavior of Nano-sized Copper Particles Chapter } 4}$ organic materials, the sintering of particles requires an additional step of removing the passivating layers prior to fusing. Therefore, whether a higher heating rate is preferable for these passivated metallic particles as well will be an interesting area to explore.

Hence in this chapter, the microstructure evolution of these $\mathrm{Cu}$ NPs sintered to a maximum temperature of $200^{\circ} \mathrm{C}$ at different heating rates, and isothermal annealed at $200^{\circ} \mathrm{C}$ for $5-30$ minutes for subsequent fusion and densification under $\mathrm{N}_{2}$ condition will be studied. In addition, sintering of these $\mathrm{Cu}$ NPs under acid-based environment were carried out to study the thermal stability of the passivating layers under various type of ambient.

\subsection{Principle Outcomes}

\subsubsection{Characterizations of $\mathrm{Cu}$ NPs}

Figure 4.2 shows the TGA results overlaid with the in-situ electrical resistance measurements at a heating rate of $10^{\circ} \mathrm{C} / \mathrm{min}$ under $\mathrm{N}_{2}$ ambient. A large percentage drop in weight $(\sim 16 \mathrm{wt} \%)$ was observed from $25^{\circ} \mathrm{C}-100^{\circ} \mathrm{C}$ while a smaller percentage drop $(<5 \mathrm{wt} \%)$ continued from $100-230^{\circ} \mathrm{C}$. A total weight loss of $18 \%$ was recorded. 


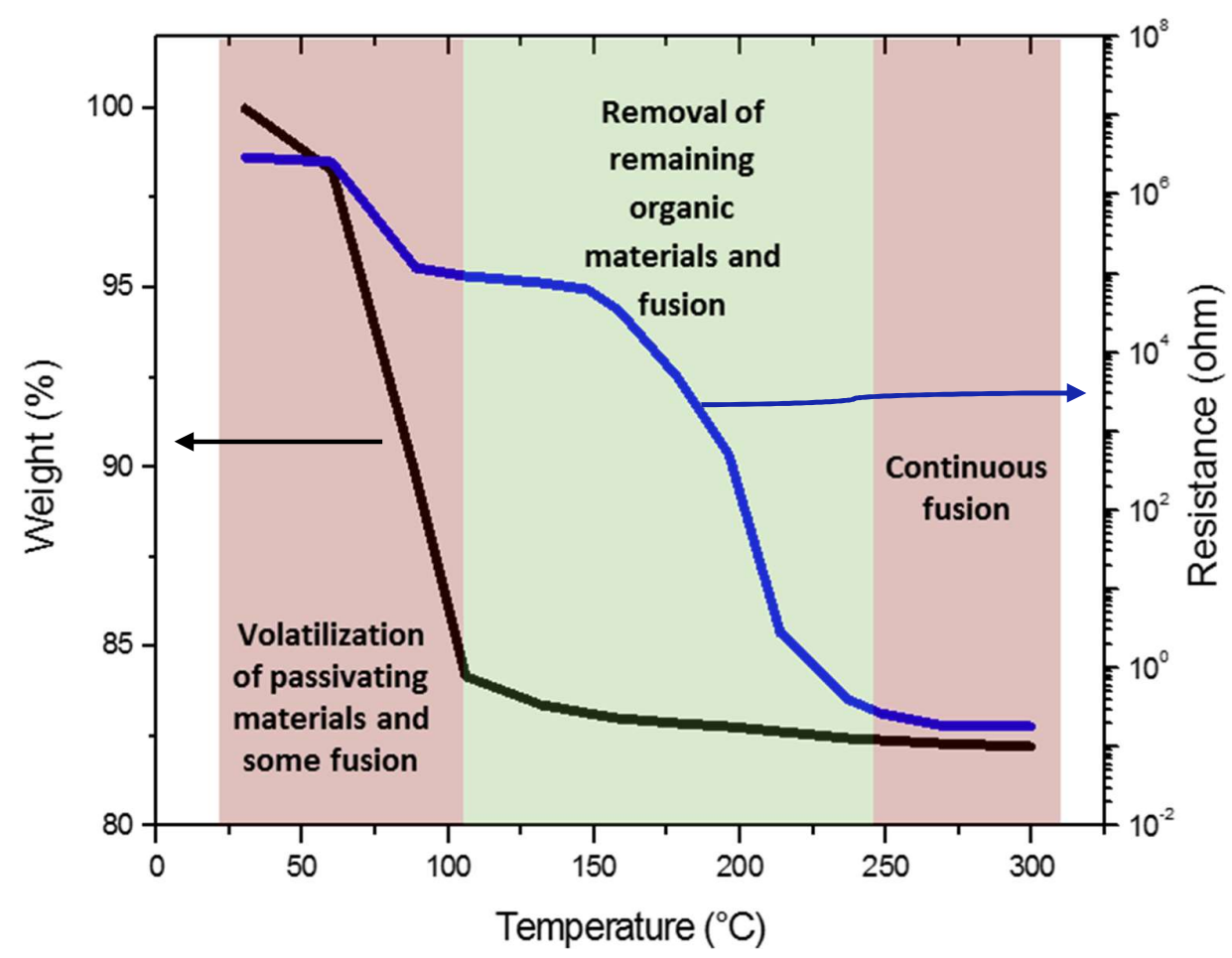

Figure 4.2 TGA and electrical resistance curves of $\mathrm{Cu}$ NPs heated from $25^{\circ} \mathrm{C}$ to $300^{\circ} \mathrm{C}$

This overall weight loss of $18 \%$ is possibly due to the removal of organic materials within the $\mathrm{Cu}$ NPs paste. Between $75^{\circ} \mathrm{C}-100^{\circ} \mathrm{C}$, the mass loss is suggested to be due to solvent volatilization from the $\mathrm{Cu}$ NPs paste that leads to a $16 \%$ weight decrease and a large decrease in resistance was also measured. This phenomenon was observed in Coutts et al. study as well [32]. In addition, a second and smaller decrease in weight occurring between $100^{\circ} \mathrm{C}-200^{\circ} \mathrm{C}$ could be due to desorption of the remaining passivating layers that saw a $<5 \mathrm{wt} \%$ lost in the TGA data. A slight drop in weight of approximately $0.4 \mathrm{wt} \%$ was observed after $200^{\circ} \mathrm{C}$ with further decrease in electrical resistance.

Though the thermal behavior of the $\mathrm{Cu}$ NPs can be studied via TGA, the study of microstructure evolution of $\mathrm{Cu}$ NPs during sintering might be difficult as fast cooling of TGA furnace is rather challenging due to equipment constraints. Since these $\mathrm{Cu}$ NPs are not electrically connected initially due to the presence of passivating layers, the sintering behavior of such passivating metallic NPs could be better studied through the change in electrical resistance during sintering. 
Sintering and Densification Behavior of Nano-sized Copper Particles Chapter 4

Hence a method to relate the degree of contact (fusion) between $\mathrm{Cu}$ NPs in terms of a decrease in electrical resistance will be discussed in the following section.

\subsubsection{In-situ Electrical Resistance Measurement}

At the start of sintering, a high electrical resistance of the Cu NPs typically in the mega-ohm range is measured. This is due to the presence of the passivating organic materials that prevent the $\mathrm{Cu}$ NPs from forming percolated metallic networks. A schematic of a 2-particle illustration and FESEM image of un-fused $\mathrm{Cu}$ NPs is shown in Figure 4.3.

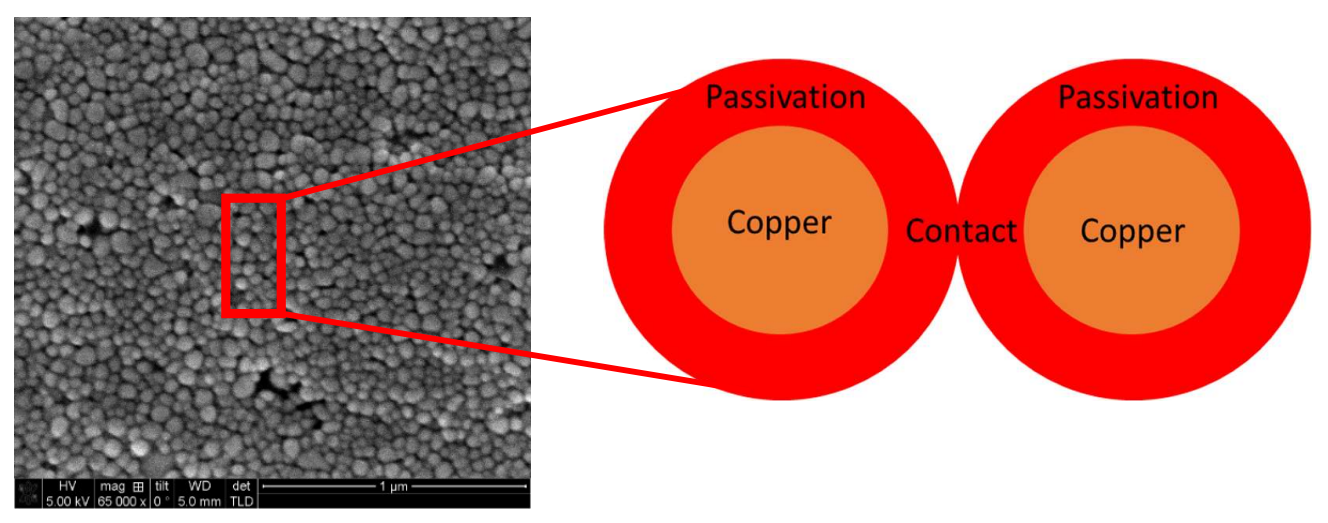

Figure 4.3 FESEM image and schematic illustration of $\mathrm{Cu}$ NPs before sintering

Assuming 2 spherical un-fused $\mathrm{Cu}$ NPs are in contact with each other, the total electrical resistance across the $2 \mathrm{Cu}$ NPs, $R_{\text {Total }}$, can be divided into 3 parts, i.e. $R_{\text {passivation }}, R_{\text {contact }}$ and $R_{\text {Cu}} . R_{\text {passivation }}$ is dependent on the thickness of passivating layer while $R_{\text {contact }}$ is dependent on the contact area between the $2 \mathrm{Cu}$ NPs and $R_{c u}$ is due to the Cu NPs itself.

When a drastic drop in weight occurred between $50^{\circ} \mathrm{C}-100^{\circ} \mathrm{C}$, a decrease in electrical resistance by 3 orders was observed (Figure 4.2). This change in electrical resistance is possibly caused by the volatilization of organic materials within the $\mathrm{Cu}$ NPs paste as measured by the TGA. Hence the total electrical resistance between $2 \mathrm{Cu}$ NPs after volatilization can be represented as

$$
\mathrm{R}_{\text {Total }}=\mathrm{R}_{\text {Contact }}+2 \mathrm{R}_{\mathrm{Cu}}
$$


Sintering and Densification Behavior of Nano-sized Copper Particles Chapter 4 assuming all passivating layers are removed.

Here, the $\mathrm{Cu}$ NPs are assumed to be arranged in a regular manner (Figure 4.4) and are equal in size. The total electrical resistance for 1 layer of $\mathrm{Cu}$ NPs can be expressed as

$$
\mathrm{R}_{1}=(\mathrm{n}+1) \mathrm{R}_{\text {Contact }}+\mathrm{nR}_{\mathrm{Cu}}
$$

where $n$ is the number of Cu NPs in 1 layer.

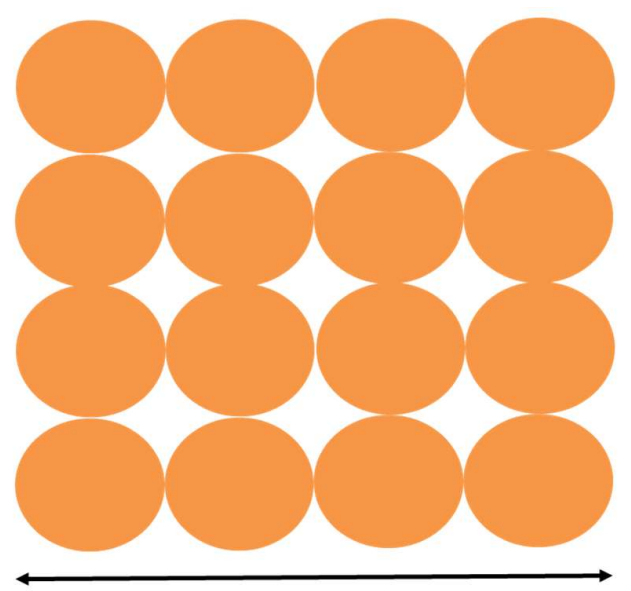

$\mathrm{n}$

Figure 4.4 Schematic illustration of the regularly arranged Cu NPs

The total resistance of the entire fused $\mathrm{Cu}$ NPs stack is assumed to be equivalent to the parallel resistance of individual $\mathrm{Cu}$ NPs layers. Therefore,

$$
\mathrm{R}_{\text {Total }}=\frac{(\mathrm{n}+1) \mathrm{R}_{\text {Contact }}+\mathrm{nR}_{\mathrm{Cu}}}{\mathrm{d}}
$$

where $d$ is the total number of layers within the fused Cu NPs stack.

However, during the onset and initial stage of neck growth, the contact resistance between $2 \mathrm{Cu}$ NPs is assumed as one contact spot. When these $\mathrm{Cu}$ NPs touch one another over a small area, there is a constriction resistance between them as the electrical current flow within that small area is not a continuous flow, but 
$\underline{\text { Sintering and Densification Behavior of Nano-sized Copper Particles Chapter } 4}$ electrons will scatter off impurities and atomic defects in the conductor [33]. Therefore, the electronic collision mean free path, $y$, needs to be taken into consideration when developing the contact resistance model. When the radius of the constriction is equal to or less than the mean free path $y$, electrons will pass through the contact ballistically. To define the electronic conduction regime, Knudsen ratio $\mathrm{K}=\frac{\mathrm{y}}{\mathrm{x}}$ is included in the calculation, where $X$ is the radius of the constriction. Therefore, between classical and ballistic electronic conduction, the contact resistance, $R_{\text {contact }}$, across the small contact point between $\mathrm{Cu}$ NPs during the initial stage of neck formation after capping layers are removed can be expressed as $[34,35]$

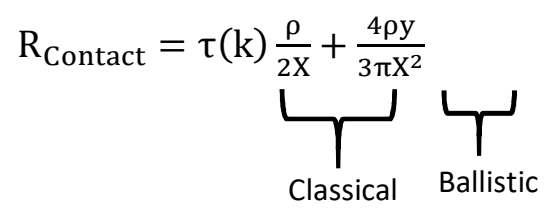

where $\rho$ is the resistivity of the bonded material, $\boldsymbol{X}$ is the contact radius, $\boldsymbol{y}$ is the electron mean free path, which $\mathrm{Cu}$ has a value of $38.7 \mathrm{~nm}$ at room temperature, $\boldsymbol{K}$ is the Knudsen ratio and $\tau(\mathrm{k})$ is a function decreasing from 1 to 0.694 as $y / X$ increases from 0 to $\infty$.

From Eqn. (4.4), consider that if the neck radius $X$ is much smaller than the mean free path $y,(X<<y)$, the conduction will be dominated by ballistic transport. 


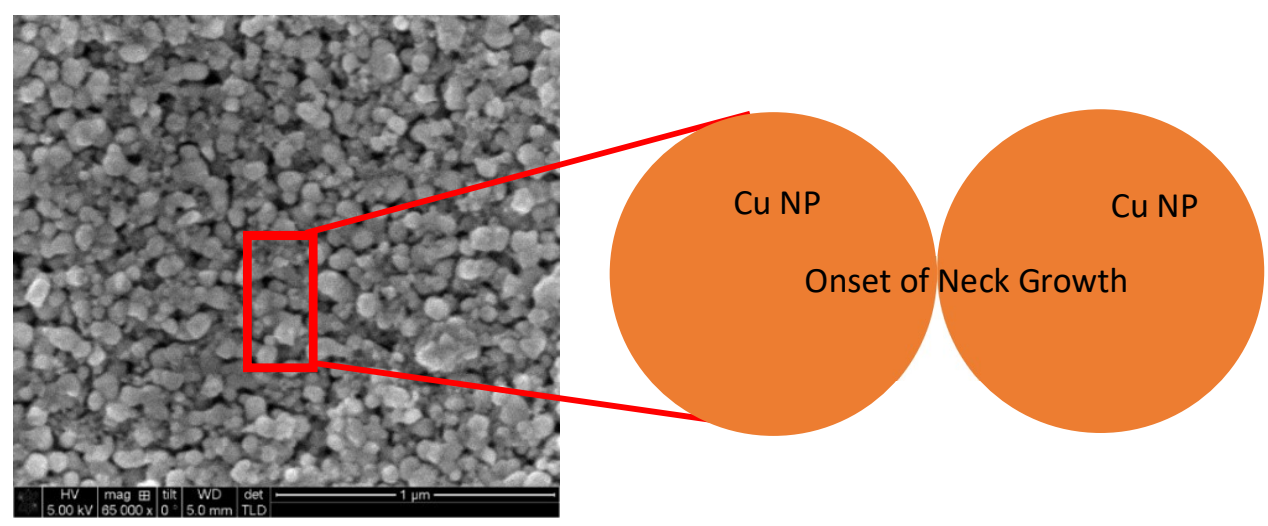

Figure 4.5 FESEM image and schematic illustration of $\mathrm{Cu}$ NPs after volatilization and onset of neck growth at $150^{\circ} \mathrm{C}$

As fusion of $\mathrm{Cu}$ NPs continues at higher temperature, the contact radius $X$ increases due to surface and/or lattice diffusion from the NPs surfaces as shown schematically in Figure 4.6. Another drop in $R_{\text {Total }}$ was measured from $150^{\circ} \mathrm{C}$ to $300^{\circ} \mathrm{C}$ (Figure 4.2) with further necking and growth of the NPs. The microstructure evolution of the $\mathrm{Cu}$ NPs during sintering will be shown and explained in Section 4.2.1.2.

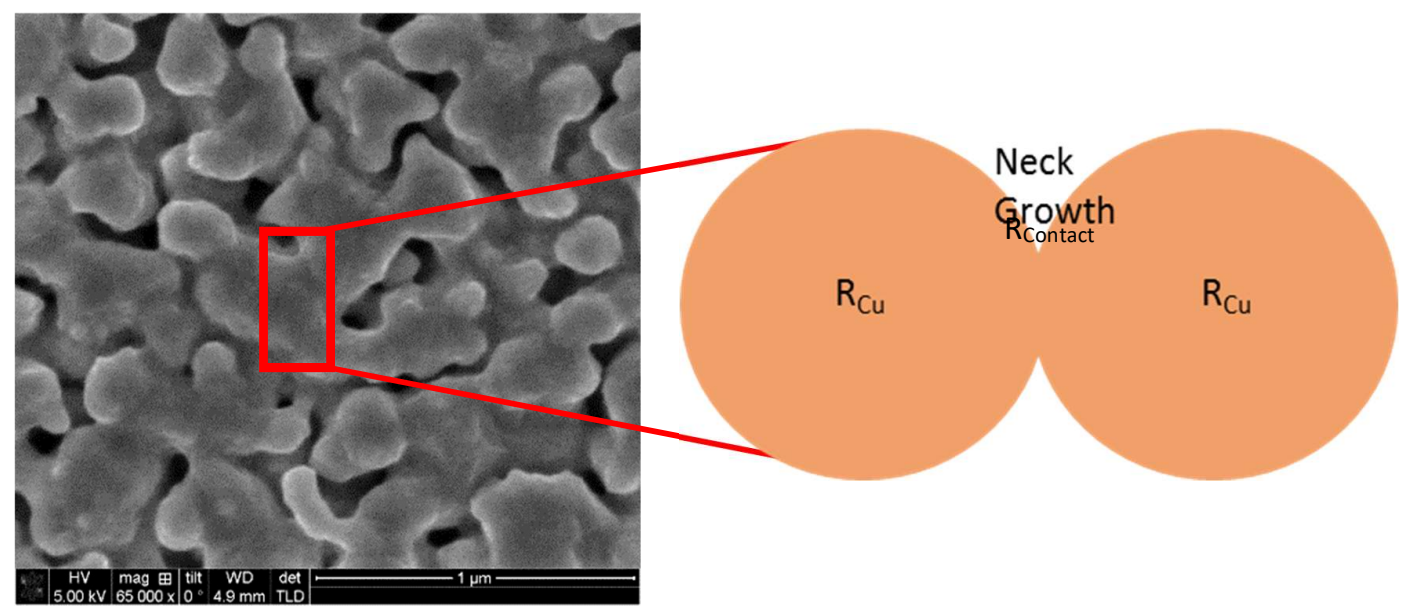

Figure 4.6 FESEM image and schematic illustration of subsequent neck growth of $\mathrm{Cu} N P s$ and its agglomerated regions at $300^{\circ} \mathrm{C}$ when heated at $10^{\circ} \mathrm{C} / \mathrm{min}$ 


\subsubsection{Particle growth and electrical resistance measurements}

Since the change in electrical resistance is postulated to correlate with the different sintering stages of the $\mathrm{Cu}$ NPs, the microstructures of the $\mathrm{Cu}$ NPs at various stages can be captured and used for understanding the sintering behavior.

Using the FESEM images of Cu NPs taken at different stages of sintering, the size of the agglomerated region at various stages can be measured using image analysis method $[19,36]$. When a significant change in resistance was observed in-situ during the sintering process, the sample would be cooled down rapidly to freeze the respective microstructure. The respective samples would then be analyzed using a FESEM and the micrographs would be used to measure the particle sizes at each stage. From the particle size curve shown in Figure 4.7, it can be seen that the $\mathrm{Cu}$ NPs grew exponentially with temperature and increased rapidly when the sintering temperature went beyond $230^{\circ} \mathrm{C}$. Since heat flow increased and no change in weight was observed by DSC or TGA after about $230^{\circ} \mathrm{C}$, it can be assumed that all the organic materials had been removed and fusing of $\mathrm{Cu}$ NPs occurred. Hence, the fused $\mathrm{Cu}$ NPs started to grow and further drop in resistance was observed. 


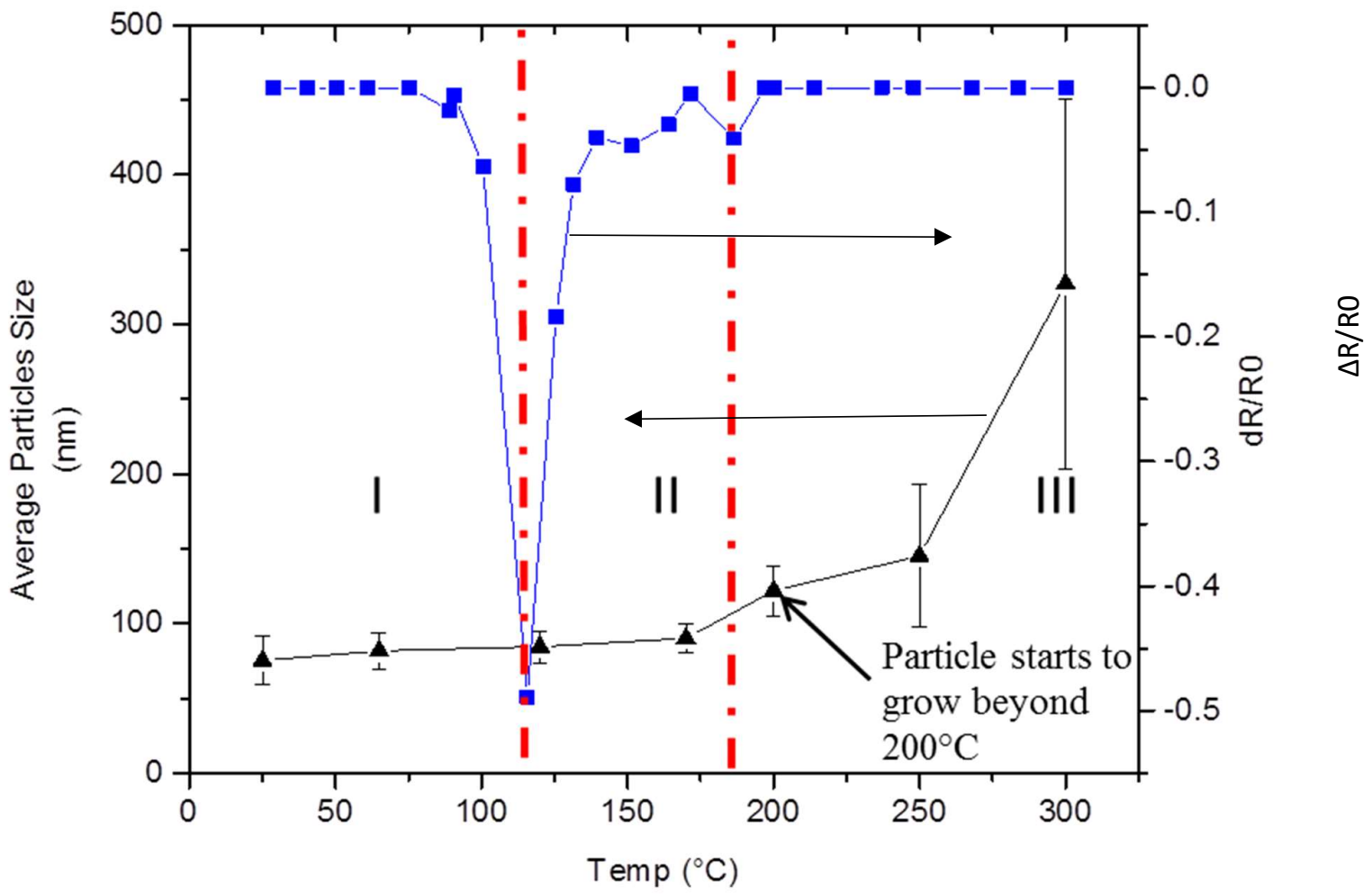

Figure 4.7 Fused Cu NPs sizes as a function of temperature and the corresponding change in electrical resistance

Crossed-sectioned FESEM images of the microstructure evolution up to $300^{\circ} \mathrm{C}$ are shown in Figure 4.8(a). At the start of sintering, individual NPs of various sizes were observed. After the first drastic drop in both weight and electrical resistance is observed at about $120^{\circ} \mathrm{C}$, most particles had yet to be fused. This is indicated by the $\mathrm{Cu}$ NPs remaining isolated, with little or no neck formation. The growth of these $\mathrm{Cu}$ NPs as charted in Figure 4.7 shows little or no increase in size from $25^{\circ} \mathrm{C}-110^{\circ} \mathrm{C}$. This agrees well with our previous explanation in Section 4.2.1.1 that the $15 \mathrm{wt} \%$ loss and 2 orders magnitude drop in electrical resistance were due to solvent volatilization. Subsequent heating $\left(>150^{\circ} \mathrm{C}\right)$ would see significant neck formations and increase in particle sizes (Figure 4.7) as the passivating layers were desorbed and volatilized between $110^{\circ} \mathrm{C}-230^{\circ} \mathrm{C}$. This observation thus provides an explanation for the 5 orders magnitude drop in electrical resistance and a $3 \mathrm{wt} \%$ drop as indicated in Figure 4.2. As heating 
Sintering and Densification Behavior of Nano-sized Copper Particles Chapter 4 proceeded beyond $230^{\circ} \mathrm{C}$, rapid growth in particle size could be observed in Figure 4.7 and Figure 4.8(a). However, no drastic change in electrical resistance or weight is detected (Figure 4.2). This indicates that all or most of the organic materials had been volatilized by $230^{\circ} \mathrm{C}$. Further small changes in resistance are due to further fusion and densification of these nanoparticles. However, after most of the $\mathrm{Cu}$ NPs have formed necking and majority of the organic materials were removed, the change in resistance is slower beyond $230^{\circ} \mathrm{C}$. Based on all the data, a schematic diagram showing the overall sintering behavior of the $\mathrm{Cu}$ NPs is illustrated in Figure 4.8(b).

$25^{\circ} \mathrm{C}$

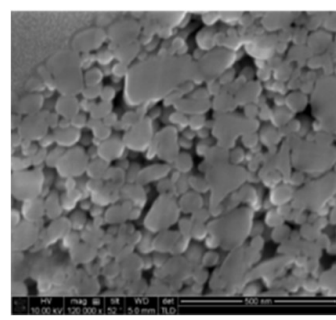

$125^{\circ} \mathrm{C}$

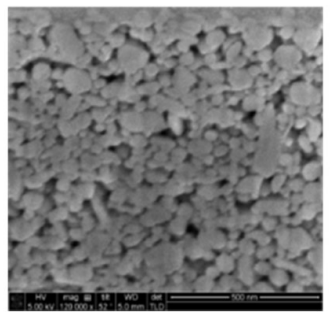

$250^{\circ} \mathrm{C}$

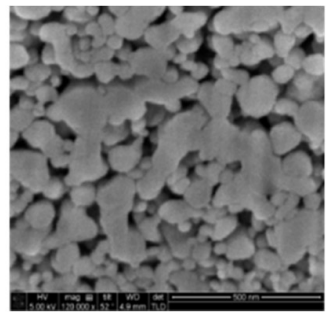

$300^{\circ} \mathrm{C}$

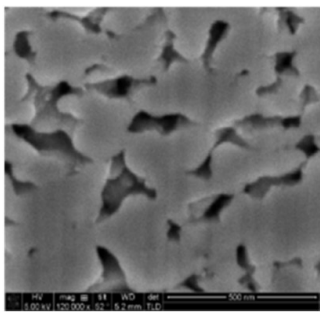

(b)

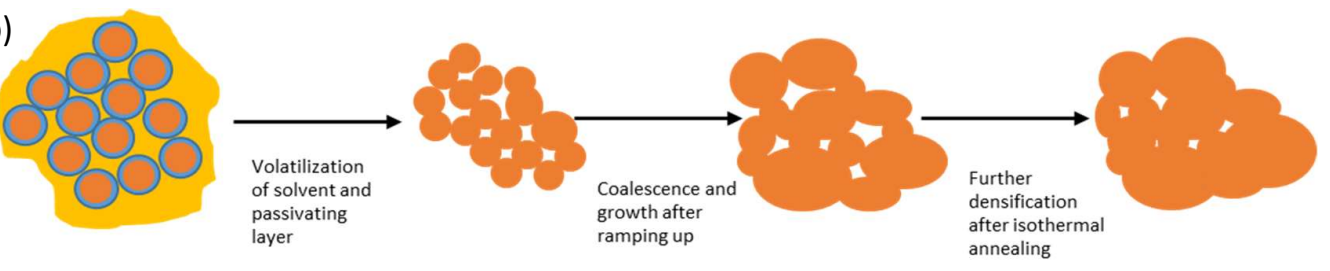

Figure 4.8 (a) FESEM images of microstructure evolution (Scale $500 \mathrm{~nm}$ ), and (b) Schematic diagram of the $\mathrm{Cu}$ nanoparticles at different stages of sintering 
Sintering and Densification Behavior of Nano-sized Copper Particles Chapter 4

\subsubsection{Sintering Process of Cu NPs}

From the above results, the fusion of these passivated $\mathrm{Cu}$ NPs requires the complete removal of the passivating organic layers prior to fusing. Upon fusion, the transition from an insulator to metal will lead to a significant decrease in electrical resistance. It is observed previously that the onset of fusion only occurs when the organic materials are volatilized. Hence any factor that can influence the temperature of volatilization of organic material, $T_{E}$, will eventually affect fusion temperature, $T_{F}$, and the final state of fusion i.e. degree of necking. It has been reported that the rate of desorption of passivating layers from the NPs surfaces is dependent on how good the interaction between the passivating ligands and surfaces that they are attached to [25]. In addition, when these ligands are desorbed, they need to be quickly removed away from the NPs to prevent re-deposition that could hinder subsequent fusion. Such fusion process, commonly termed as sintering, is a thermally activated process. Hence variables such as diffusivity and viscosity, which are temperature sensitive, can affect the rate of sintering.

Generally, polycrystalline materials are sintered by solid-state diffusional processes [37]. The entire sintering process of the $\mathrm{Cu}$ NPs can be generalized into three stages. The first stage, Stage 1, includes the removal of most organic materials and rearrangement of particles that follows the onset of neck growth between $\mathrm{Cu}$ NPs in Stage 2. During the neck growth stage, the sintering mechanism of the $\mathrm{Cu}$ NPs is considered to be due to surface diffusion as opposed to Oswald ripening for sintering of metallic NPs on a support, in which larger particles grow as the expense of smaller particles [38]. The signs of necking formed between adjacent $\mathrm{Cu}$ NPs that were heated up till $300^{\circ} \mathrm{C}$ as shown in Figure 4.8(a) could provide an indication that the sintering mechanism of these $\mathrm{Cu}$ NPs is dominated by surface diffusion since large amount of porosities were observed. Such surface diffusion is due to the high surface energy of these $\mathrm{Cu}$ NPs [26, 39]. Further studies and discussion on the dominant sintering mechanism will be presented in Section 4.2.2.5. While surface diffusion could have dominated in Stage 2, during Stage 3 when all or most of the organic materials are removed, these fused $\mathrm{Cu}$ NPs clusters grew rapidly as shown in 
Sintering and Densification Behavior of Nano-sized Copper Particles Chapter 4

Figure 4.7. However, continuous fusion of these fused $\mathrm{Cu}$ NPs might be hindered by the increasing pore sizes between fused $\mathrm{Cu}$ NPs due to limited particle mobility [40]. Therefore, about $20 \%$ porosities were still observed after the sintering process. Detailed information on porosities will be discussed further in Chapter 5.

\subsubsection{Relationship between $T_{E}$ and $T_{F}$}

Since there is a correlation between the changes in resistance and the sintering behavior of $\mathrm{Cu}$ NPs, a relationship between the onset temperature of volatilization, $\mathrm{T}_{\mathrm{E}}$ and fusion temperature, $\mathrm{T}_{\mathrm{F}}$, can be established based on thermal and electrical analysis. From the DSC curve that is overlaid with the change in resistance measurement shown in Figure 4.9, two distinct endothermic peaks at 2 different volatilization temperatures are identified as $T_{E 1}$ and $T_{E 2}$. These two temperatures are defined to be the midpoint transition temperature of the first and second endothermic peak corresponding to the volatilization of organic materials. On the other hand, fusion temperature $T_{F 1}$ and $T_{F 2}$, located on the change in electrical resistance curve, are defined to be the first and second midpoint transition temperature of fusion, respectively. At $T_{F 1}$, volatilization of the solvents has occurred and the NPs become electrically conductive as they become connected. Although the capping layer is still present, current can flow through as it is very thin and not completely insulating. At $T_{F 2}$, volatilization of the capping materials occurs and the $\mathrm{Cu}$ NPs fuse to form more electrically conductive paths.

From Figure 4.9, it is shown that removal of organic materials was followed by a change in electrical resistance. After most of the passivating layers have been removed, the electrical resistance continues to drop due to fusion between $\mathrm{Cu}$ NPs. With this thermal and electrical data, it has demonstrated the feasibility of using such electrical resistance measurement technique to study the sintering behavior of passivated metallic nanoparticles during sintering. 


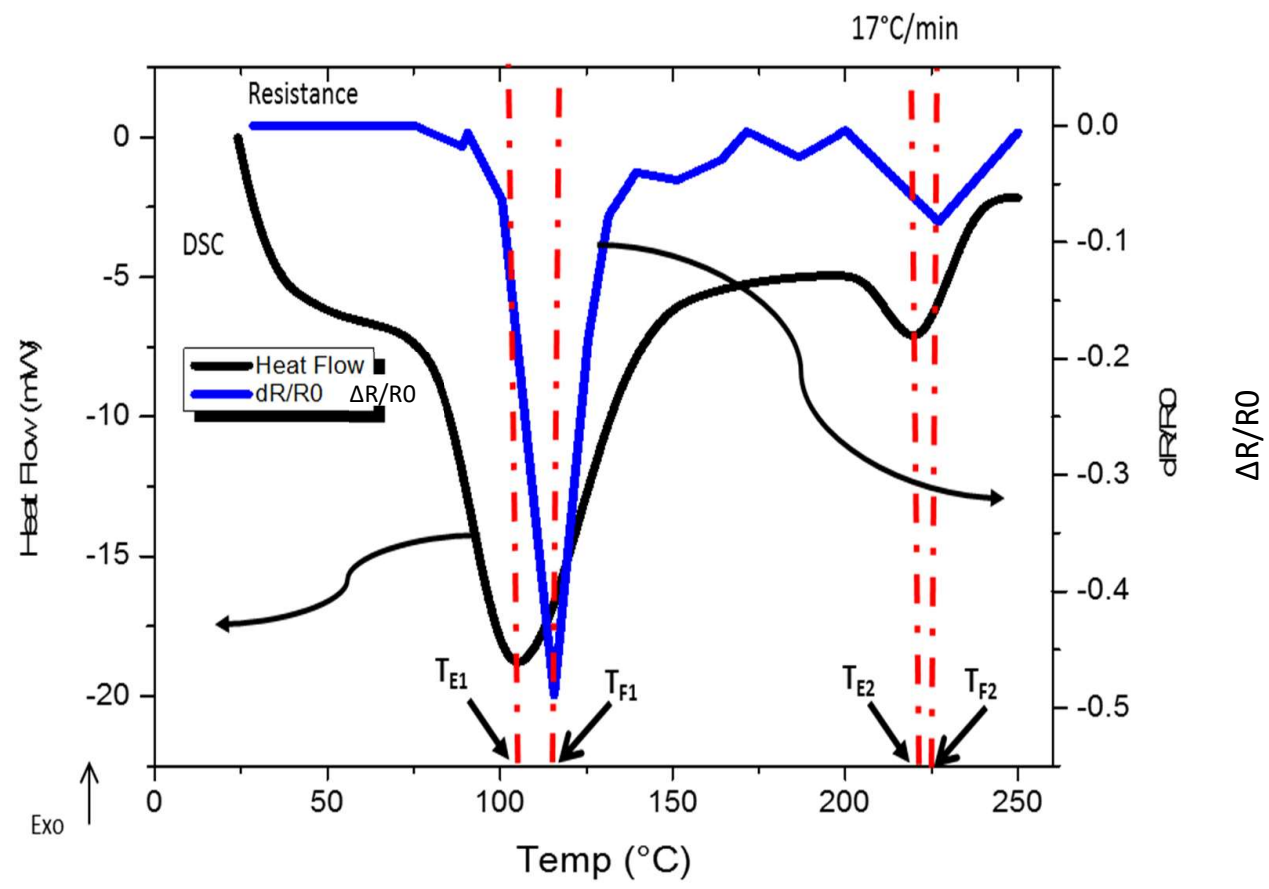

Figure 4.9 Heat flow and change in electrical resistance of $\mathrm{Cu}$ NPs as a function of temperature

\subsubsection{Relationship between Heating Rates and Volatilization}

Since the sintering process of such passivated $\mathrm{Cu}$ NPs is heavily dependent on the degree and rate of removal of organic materials, presence of any remaining organic materials will hinder the subsequent fusing of $\mathrm{Cu}$ NPs to form a conducting metallic layer. Therefore, factors affecting the rate of volatilization need to be studied to achieve an optimal fused layer of conductive $\mathrm{Cu}$ NPs.

When the $\mathrm{Cu}$ NPs are subjected to a low heating rate, it will spend a longer time at the lower temperature regime. Hence the solvents will evaporate at a lower temperature regime, i.e. lower $T_{E}$. As heating rate increases, the NPs bypass the lower temperature regime faster and thus volatilization occurs at higher temperatures and this will cause an increase in $T_{E}$ with increasing heating rate. Since volatilization is a kinetics reaction, it is dependent on both time and temperature [41].

From the TGA test results, in-situ electrical resistance measurements and FESEM images discussed in the previous section, it can be concluded that all 

organic materials present need to be substantially removed to enable good fusion among these $\mathrm{Cu}$ NPs. Though these $\mathrm{Cu}$ NPs were sintered successfully at $200^{\circ} \mathrm{C}$, nano-sized pores were still observed. It was reported that coarsening of $\mathrm{Ag}$ or $\mathrm{Cu}$ NPs without any passivating layers is controlled by surface diffusion from room temperature to about $150^{\circ} \mathrm{C}$ [13]. Since surface diffusion occurs at the lower temperature regime, the $\mathrm{Cu}$ NPs would have started fusing. Hence upon further heating, it will most likely not lead to much further densification of these fused $\mathrm{Cu}$ NPs as higher thermal energy is needed to further densify them since the effective radius of these fused $\mathrm{Cu}$ NPs has increased when compared to their initial radius $[26,42]$. Hence, by increasing the heating rate, it will shorten the time spent at the lower temperature regime and increase $T_{E}$, which intuitively increases the onset temperature of fusion, $T_{F}$, subsequently. This helps to maintain the small effective radius of the NPs till its peak sintering temperature. Since the surface energy of these NPs is high, higher degree of densification can therefore take place at the peak sintering temperature $\left(200^{\circ} \mathrm{C}\right)$ [26]. However, care needs to be taken as the removal of organic materials will be affected when the heating rate becomes too fast. Wang et al. [16] had reported partial sintering among NPs when these passivated Ag NPs were sintered directly at the peak processing temperature. As these Ag NPs were subjected to a high thermal energy at the start of sintering, it caused the organic materials to decompose or volatilized rapidly. When this happened, desorption of passivating layers and fusion of NPs would occur rapidly and non-uniformly. For organic materials near to open surfaces, they would be removed faster and caused rapid fusion of NPs that are located nearer to the surfaces. When the top layer fused faster than the bottom layer, it would close up the pores to the surface and thus prevent the escape of the remaining volatiles at the bottom of the $\mathrm{Cu}$ NPs layer. When this happens, it could potentially cause non-homogeneous sintering across the NPs, especially for thick layers. Hence a balance between removal of organic content and fusion of NPs needs to be established.

Since the fusion process of these organic passivated $\mathrm{Cu}$ NPs can be studied electrically, electrical resistance measurements were taken at different heating rates. Figure 4.10 shows the resistance curves of $\mathrm{Cu}$ NPs sintered at different heating rates from room temperature till $200^{\circ} \mathrm{C}$ under $\mathrm{N}_{2}$. 
From Figure 4.10, it is observed that there is an increase in the magnitude of final resistance of the sintered $\mathrm{Cu}$ NPs as heating rates increases. For heating rate of $7^{\circ} \mathrm{C} / \mathrm{min}$, a 5 order drop in electrical resistance was observed at the end of sintering compared to less than 1 order drop in electrical resistance for samples heated at $40^{\circ} \mathrm{C} / \mathrm{min}$ to $200^{\circ} \mathrm{C}$. The reason for the high electrical resistance is likely caused by the incomplete removal of the organic materials that prevented the dense fusion between the $\mathrm{Cu}$ NPs. Hence, FESEM images were taken at the end of each stage of sintering for different heating rates to analyze the microstructures and correlate with the change in electrical resistance. This will be discussed in the following Section 4.2.2.3.

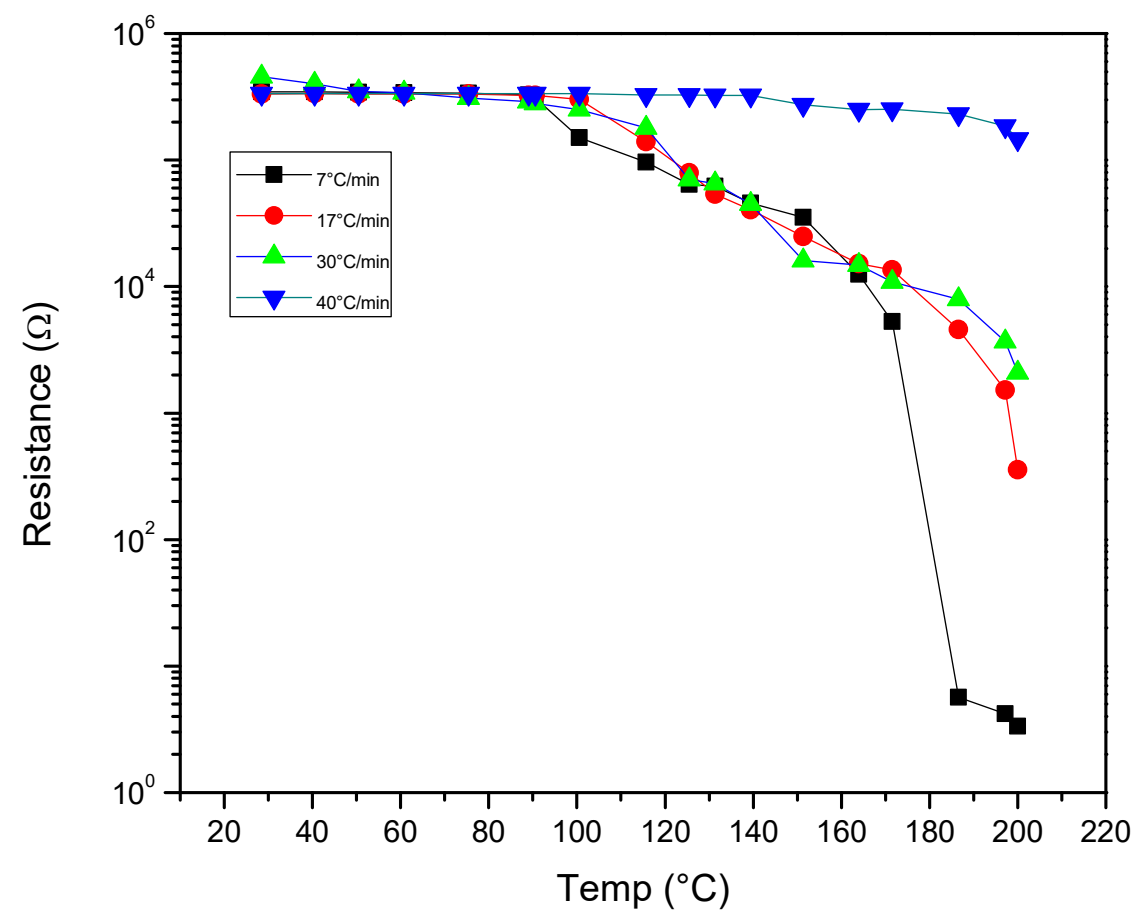

Figure 4.10 In situ electrical resistance for $\mathrm{Cu}$ nanoparticles heated at different rates to $200^{\circ} \mathrm{C}$

\subsubsection{Microstructure evolution of Cu NPs at Different Heating Rates}

At low heating rate of $7^{\circ} \mathrm{C} / \mathrm{min}$, it is observed that the electrical resistance started to drop at $90^{\circ} \mathrm{C}\left(T_{F 1}\right)$ and $150^{\circ} \mathrm{C}\left(T_{F 2}\right)$ (Figure 4.10). This shows that the removal of organic materials from the $\mathrm{Cu}$ NPs started at $90^{\circ} \mathrm{C}$ (Figure 4.11(a)). After the majority of organic materials were removed between $90^{\circ} \mathrm{C}$ to $150^{\circ} \mathrm{C}$, the onset 

of neck formation and growth between $\mathrm{Cu}$ NPs could lead to further decrease in the resistance. This phenomenon was also observed by Leite et al. [31]. It was reported that sintering, when done at a lower heating rate, would proceed in 2 stages. The first stage is the densification of agglomerates that will occur after solvent volatilization and in the second stage, the non-agglomerated particles will densify. After heating up to $200^{\circ} \mathrm{C}$, though fusion among $\mathrm{Cu}$ NPs were observed, large pores were still present (Figure 4.11(a)).

As heating rate was raised to $17^{\circ} \mathrm{C} / \mathrm{min}, T_{F 1}$ and $T_{F 2}$ increased to $118^{\circ} \mathrm{C}$ and $180^{\circ} \mathrm{C}$, respectively. From the microstructures images (Figure 4.11(b)), it is observed that after the first drop in resistance at $118^{\circ} \mathrm{C}$, there was little or no fusion among $\mathrm{Cu}$ NPs unlike samples that were heated up at $7^{\circ} \mathrm{C} / \mathrm{min}$. This is because for the sample that was heated up at $17^{\circ} \mathrm{C} / \mathrm{min}$, it did not stay at the low temperature regime for extended period. Hence, significant fusion of $\mathrm{Cu}$ NPs after volatilization is not observed. At $180^{\circ} \mathrm{C}$, an increase in particle size and sign of fusion were observed. In addition, it was observed that the $\mathrm{Cu}$ NPs that were sintered at $17^{\circ} \mathrm{C} / \mathrm{min}$ has a denser microstructure with lower porosity after desorption of the passivating layers.

As heating rates was further increased to $30^{\circ} \mathrm{C} / \mathrm{min}$, it was observed that $T_{F 1}$ occurred at about $140^{\circ} \mathrm{C}$. Further heating to $200^{\circ} \mathrm{C}$ led to further reduction in electrical resistance as desorption of remaining passivating layers and fusion of these $\mathrm{Cu}$ NPs proceeded. This demonstrates the possibility of achieving a denser microstructure by subjecting $\mathrm{Cu}$ NPs to higher heating rates that maintain a larger driving force for densification with smaller effective radius of the Cu NPs up to the peak sintering temperature of $200^{\circ} \mathrm{C}$. However, it is observed from the FESEM images that there were still significant amount of porosities and unfused $\mathrm{Cu}$ NPs after heating up to $200^{\circ} \mathrm{C}$. These observations were even more noticeable in high heating rate samples, i.e. $40^{\circ} \mathrm{C} / \mathrm{min}$ (Figure $4.11(\mathrm{~d})$ ). This also provides an explanation on the high electrical resistance (observed throughout the sintering process (Figure 4.10) as there was little fusion among the $\mathrm{Cu}$ NPs. This phenomenon could be due to the short temperature ramp up time of about 5 minutes from room temperature to $200^{\circ} \mathrm{C}$. Hence, it might not provide sufficient time for complete removal of the organic materials within the Cu NPs layer. Since large existence of un-fused $\mathrm{Cu}$ NPs might be the reason for the high 
$(>100 \Omega)$ electrical resistance for higher heating rates samples, a longer annealing time at $200^{\circ} \mathrm{C}$ might lead to a further decrease in the resistance. Therefore, isothermal annealing at $200^{\circ} \mathrm{C}$ after the heating up cycle was carried out to promote further growth and densification of these $\mathrm{Cu}$ NPs that were heated up at different heating rates.

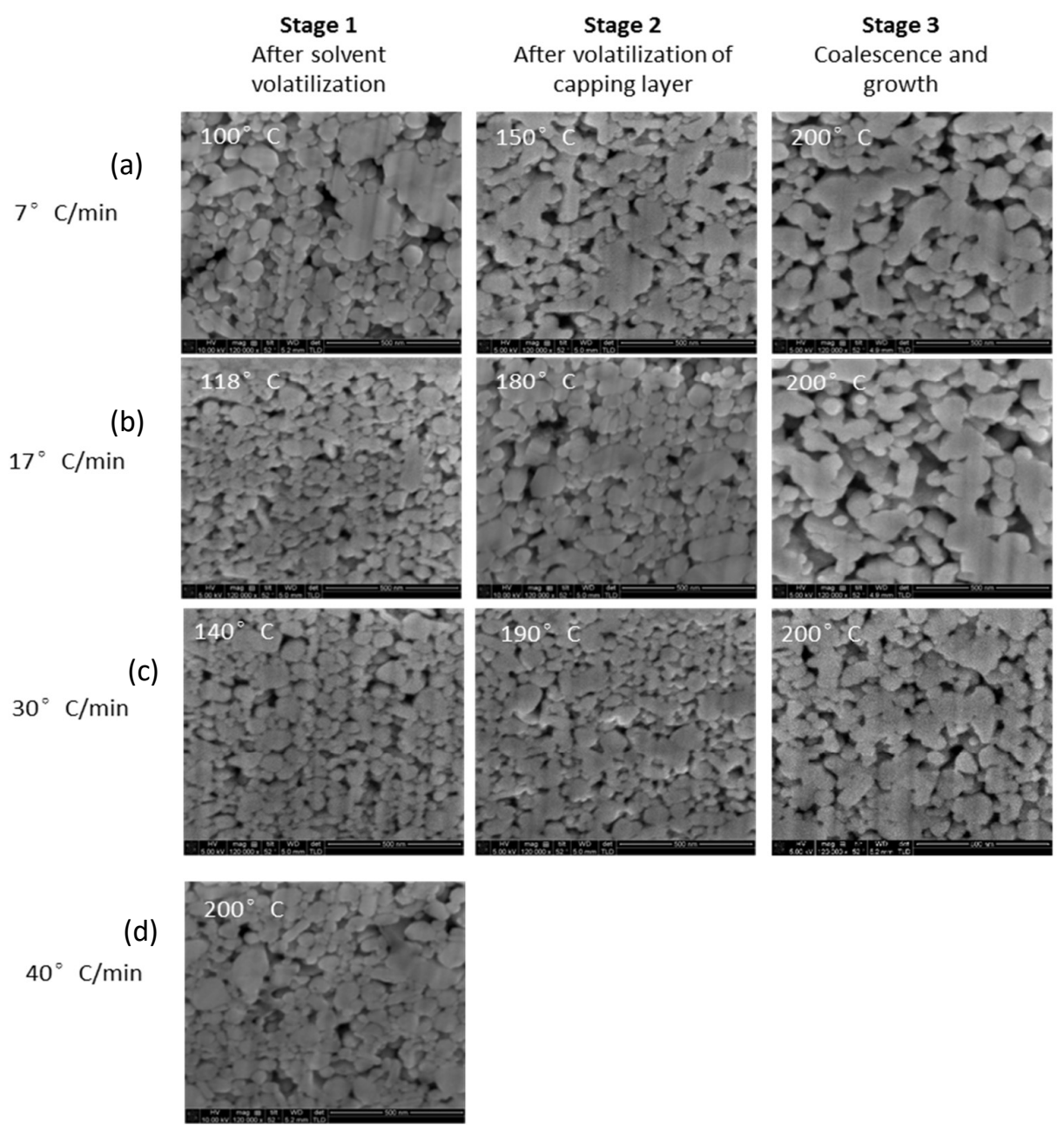

Figure 4.11 Microstructure changes of $\mathrm{Cu}$ sintered at (a) $7^{\circ} \mathrm{C} / \mathrm{min}$ (b) $17^{\circ} \mathrm{C} / \mathrm{min}$ (c) $30^{\circ} \mathrm{C} / \mathrm{min}$ (d) $40^{\circ} \mathrm{C} / \mathrm{min}$ (Scale: $500 \mathrm{~nm}$ )

\subsubsection{Further Growth and Densification during Isothermal Annealing}

After subjecting the $\mathrm{Cu}$ NPs at different heating rates to $200^{\circ} \mathrm{C}$, we next investigate the change in electrical resistance and microstructure evolution with time as the atomic transport from the surfaces of $\mathrm{Cu}$ NPs to the neck is due to diffusion [26]. In-situ electrical resistance measurements were carried out to 
Sintering and Densification Behavior of Nano-sized Copper Particles Chapter 4 relate subsequent fusion of $\mathrm{Cu}$ NPs with changes in electrical resistance during isothermal annealing. During the heating up process, after the organic materials were removed from the $\mathrm{Cu}$ NPs surfaces, the $\mathrm{Cu}$ NPs started to fuse. Based on the initial stage of sintering model as mentioned in Chapter 2, the general equation for neck growth, Eq. (2.1), can be used to describe the sintering mechanism. By rearranging Eq. (2.1) to express $\mathrm{X}$ in terms of $m, n, H$ and $t$, it will be:

$$
X=\left(\frac{H}{a^{m-n}}\right) t^{1 / m}
$$

where $X$ is the radius of the neck formed between the particles, $m, n$ are constants that depend on the sintering mechanism involved, $a$ is the initial radius of the $\mathrm{Cu}$ NPs, $H$ is a coefficient characteristic of the sintering mechanism and $t$ is the time.

Eq. (4.5) can be used subsequently to relate the contact resistance to the neck radius during isothermal annealing.

As explained in Section 4.2.1.1, if the neck radius is smaller than the mean free path, $y, R_{c}$ will be dominated by the ballistic electronic conduction. This means that the contact resistance, $R_{\text {contact }}$, that is dependently mostly on ballistic conduction during initial stage of sintering, can expressed in terms of the neck radius $X$ as:

$$
\mathrm{R}_{\text {Contact }}=\frac{4 \rho \mathrm{y}}{3 \pi \mathrm{X}^{2}}
$$

By combining Eq. (4.5) with Eq. (4.6) $R_{\text {contact }}$ can be expressed as,

$$
\mathrm{R}_{\text {Contact }}=\frac{4 \rho y\left(\mathrm{a}^{2 \mathrm{~m}-2 \mathrm{n}}\right)}{3 \pi \mathrm{H}^{2} \mathrm{t}^{2 / \mathrm{m}}}
$$


Assuming no oxidation of $\mathrm{Cu}$, the total resistance will be dominated by the contact resistances such that

$$
R_{\text {Total }} \approx R_{\text {contact }}
$$

From Eq. (4.3),

$$
\mathrm{R}_{\text {Total }}=\frac{(\mathrm{n}+1) \mathrm{R}_{\text {Contact }}}{\mathrm{d}}
$$

Substituting Eq. (4.7) into Eq. (4.8)

$$
\mathrm{R}_{\text {Total }}=\frac{(\mathrm{n}+1) \frac{4 \rho y\left(\mathrm{a}^{2 \mathrm{~m}-2 \mathrm{n}}\right)}{3 \pi \mathrm{H}^{2} \mathrm{t}^{2 / \mathrm{m}}}}{\mathrm{d}}
$$

Simplifying Eqn. (4.9), the time dependence of the total resistance of the fused $\mathrm{Cu}$ NPs network can then be represented as

$$
\mathrm{R}_{\text {Total }} \propto \mathrm{t}^{-2 / \mathrm{m}}
$$

From Eq. (4.10), it is shown that the total resistance is related to the neck formation and growth of the NPs at constant temperature and the resistance follows the power law with time. We can therefore measure the electrical resistance of $\mathrm{Cu}$ NPs during isothermal annealing and determine the value $m$ to suggest a possible sintering mechanism.

From Figure 4.12, the change in electrical resistance is very substantial during the first $5-10$ minutes of isothermal annealing at $200^{\circ} \mathrm{C}$. Based on the above explanation, this could indicate the fast transport of materials between $\mathrm{Cu}$ NPs 
Sintering and Densification Behavior of Nano-sized Copper Particles Chapter 4 that led to neck formation and growth. However, it is observed that after 10 minutes of isothermal annealing, the rate of resistance change, represented by the slope of the curve, decreases. This is due to the decrease in driving force of the $\mathrm{Cu}$ NPs to further densify since they have grown bigger. Longer annealing time and/or higher temperature would be needed to further increase the fusion of the sintered $\mathrm{Cu}$ layer.

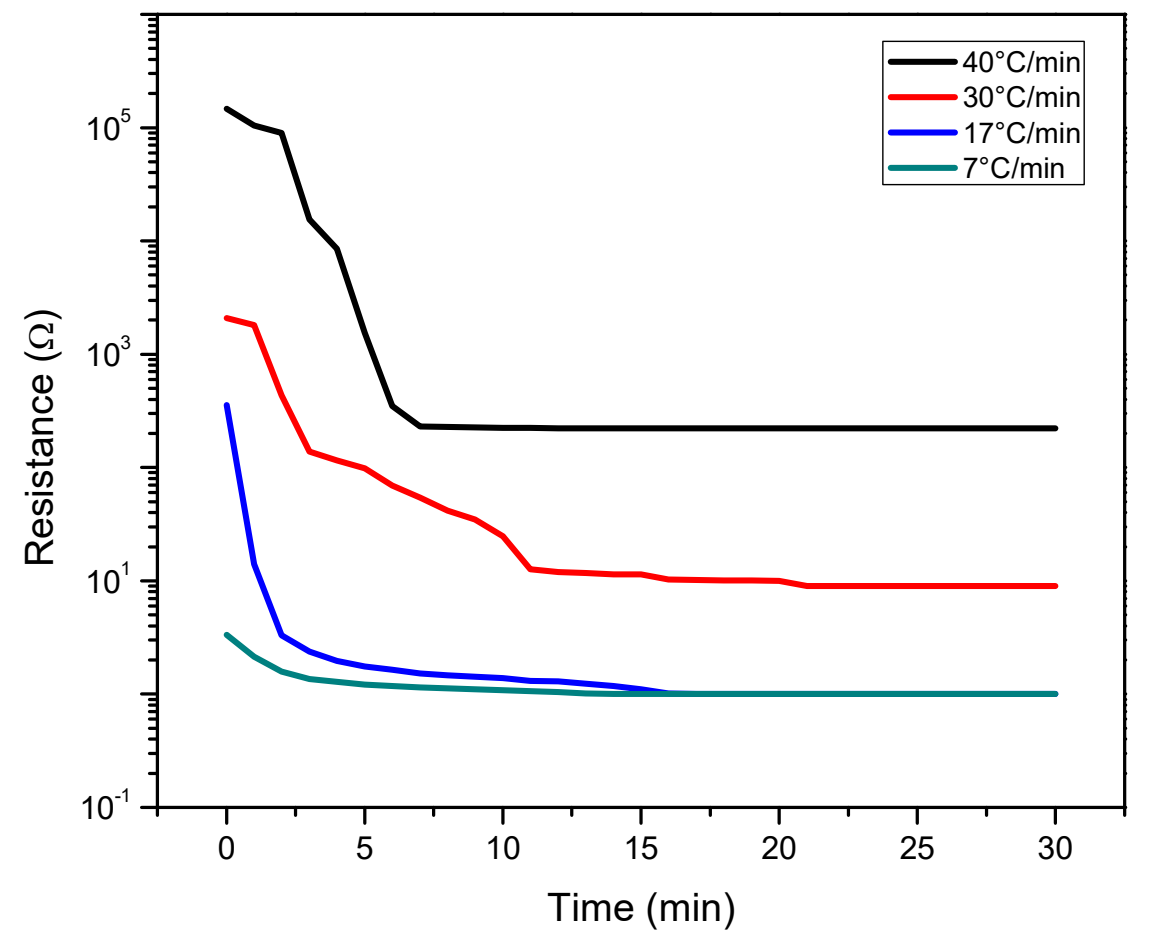

Figure 4.12 Resistance as a function of isothermal annealing duration for different heating rate samples

The microstructure evolution images of initial and subsequent fusion of these $\mathrm{Cu}$ NPs were analyzed and shown in Figure 4.13. At higher heating rates $\left(>7^{\circ} \mathrm{C} / \mathrm{min}\right)$, the samples did not spend significant amount of time at the lower temperature regime during heating up, hence they were able to fuse and grow during isothermal annealing at $200^{\circ} \mathrm{C}$. This translates to more neck formations and growth that led to the significant decrease in resistance observed. This is because the effective radius of the $\mathrm{Cu}$ NPs remained almost unchanged during heating up due to the short heating up time. On the other hand, for samples that were heated with a low heating rate of $7^{\circ} \mathrm{C} / \mathrm{min}$, it was observed that the drop in electrical resistance (Figure 4.12) and the microstructure evolution during 
Sintering and Densification Behavior of Nano-sized Copper Particles Chapter 4 isothermal annealing (Figure 4.13(a)) are not significant. This can be explained that these $\mathrm{Cu}$ NPs had fused into bigger particles during heating up as they had longer exposure to the lower temperature regime. This increased their effective radius and caused them to lose their high surface energy to further densify at $200^{\circ} \mathrm{C}$. When this happens, they will need a higher processing temperature, i.e. $>$ $200^{\circ} \mathrm{C}$, or external factors such as pressure for further growth and densification of these agglomerates. Since there is no further obvious increase in particle size and/or neck size, it is hypothesized that the paths available for electrons to flow remain relatively unchanged. Hence, minimum drop in electrical resistance was observed.

With the above observations, it can be concluded that a faster heating rate will be able to attain a denser layer since the samples will have a higher $T_{E}$ and $T_{\mathrm{F}}$. By observing the FESEM images of $17^{\circ} \mathrm{C} / \mathrm{min}-40^{\circ} \mathrm{C} / \mathrm{min}$ samples shown in Figure 4.13(b) - (d), it is observed that as isothermal annealing time increases, the fused $\mathrm{Cu}$ NPs grew significantly for the first 5-20 minutes. This fusion and growth phenomenon was accompanied by 2 orders drop in magnitude of electrical resistance shown in Figure 4.12. Hence, it can be proven that the neck formation (fusing) is responsible for providing a pathway for electrons to flow that led to a drop in resistance. Beyond 20 minutes of isothermal annealing, no noticeable change in microstructures and electrical resistance was observed. It was reported by Kim et al. [14] that once necking was observed, a conductive film can be formed even though it is still porous but further densification will not have significant change in conductivity. This phenomenon is supported in Figure 4.12 that upon isothermal annealing for extended period of time $(>20$ min), no significant change in electrical resistance is observed even though bigger fused $\mathrm{Cu}$ and large amount of pores were still present between 20 and 30 $\min$. The final electrical resistances of samples were about $1 \Omega$ for $7^{\circ} \mathrm{C} / \mathrm{min}$ and $17^{\circ} \mathrm{C} / \mathrm{min}, 9 \Omega$ for $30^{\circ} \mathrm{C} / \mathrm{min}$ and $200 \Omega$ for $40^{\circ} \mathrm{C} / \mathrm{min}$. The high electrical resistance observed in higher heating rate samples, i.e. $40^{\circ} \mathrm{C} / \mathrm{min}$, might be due to the entrapment of organic materials since the presence of small and un-fused $\mathrm{Cu}$ NPs were still observable after 30 minutes of isothermal annealing shown in the FESEM images of $40^{\circ} \mathrm{C} / \mathrm{min}$ sample (Figure $4.13(\mathrm{~d})$ ). 

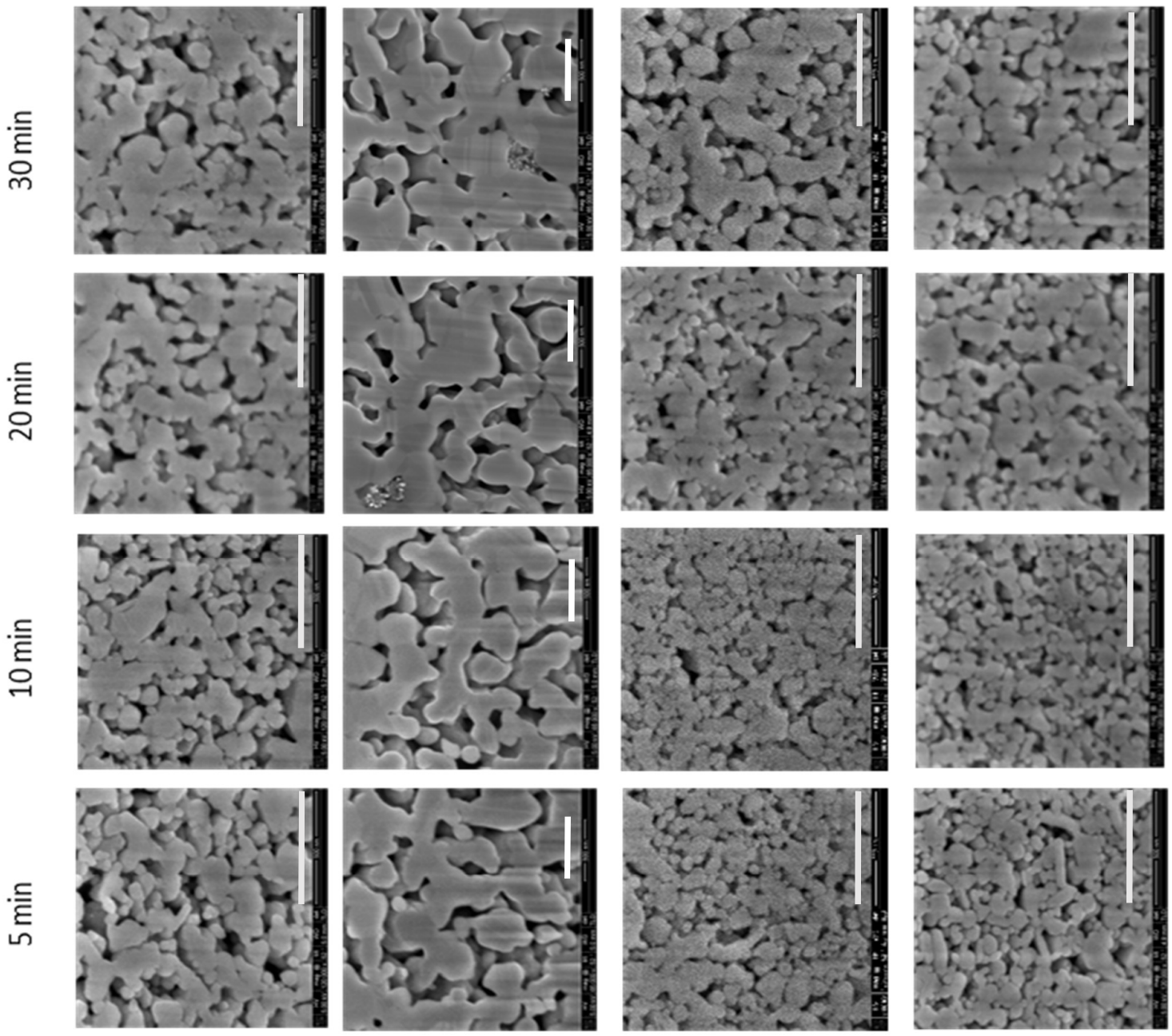

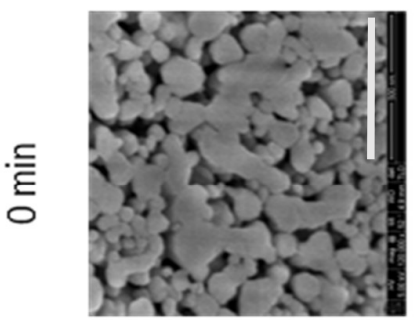

(a)

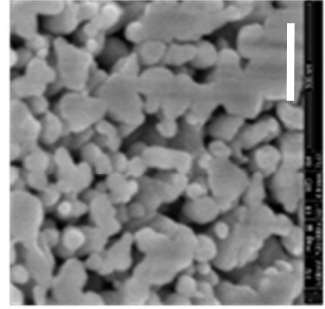

(b)

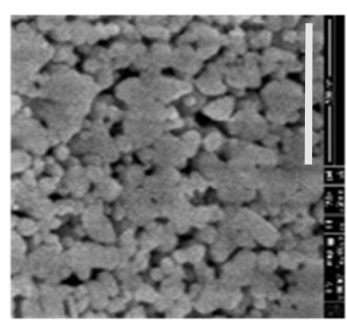

(c)

$30^{\circ} \mathrm{C} / \mathrm{min}$

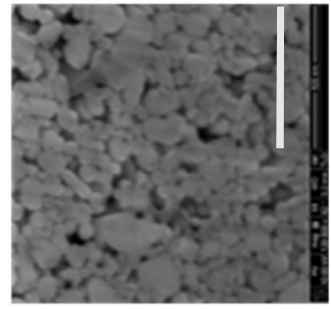

(d)

$40^{\circ} \mathrm{C} / \mathrm{min}$

Figure 4.13 Microstructure evolution during isothermal annealing of $\mathrm{Cu}$ particles that were previously heated up at different heating rates (Scale bar in white: $\mathbf{5 0 0}$ 


\subsubsection{Determining the Dominant Sintering Mechanism}

Based on the electrical resistance measurements (Figure 4.12) and FESEM images (Figure 4.13), heating rates of $7^{\circ} \mathrm{C} / \mathrm{min}$ and $17^{\circ} \mathrm{C} / \mathrm{min}$ seem to have removed the passivating layers successfully during heating up for fusion to occur during isothermal annealing at $200^{\circ} \mathrm{C}$. Hence to determine the dominant sintering mechanism, the change in resistance with time of the sintered $\mathrm{Cu}$ NPs that were heated to $200^{\circ} \mathrm{C}$ with a heating rate of $7^{\circ} \mathrm{C} / \mathrm{min}$ and $17^{\circ} \mathrm{C} / \mathrm{min}$ were used to determine the value of $m$.

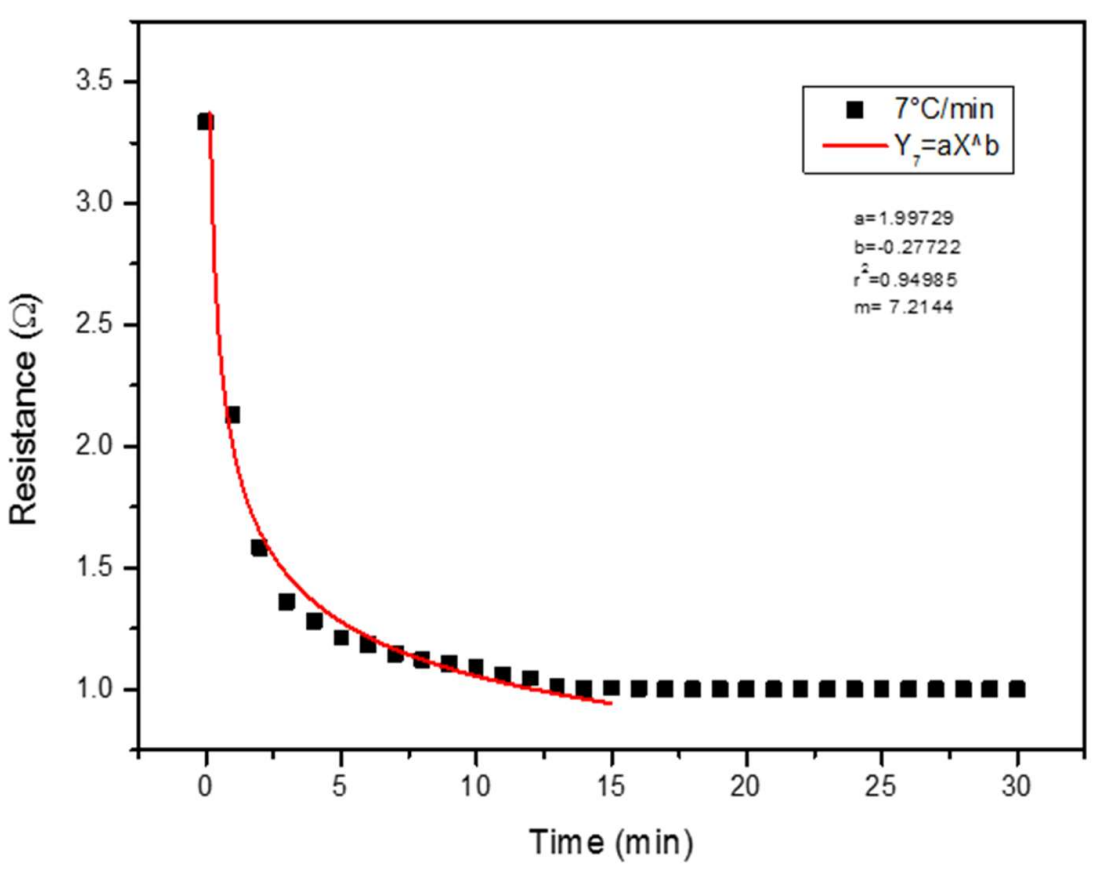

(a) 


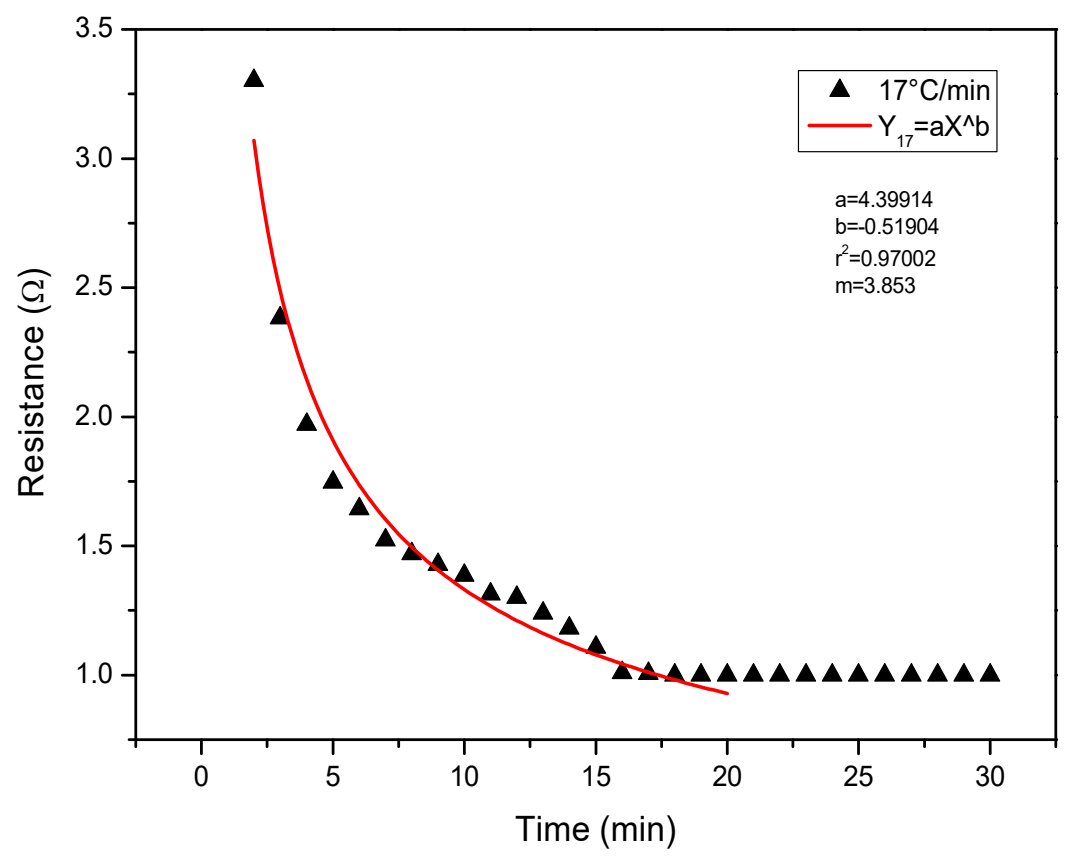

(b)

Figure 4.14 Experimental results and proposed model prediction of resistance as a function of time (a) $7^{\circ} \mathrm{C} / \mathrm{min}$ (b) $17^{\circ} \mathrm{C} / \mathrm{min}$

In Figure 4.14(a) for the sample heated at a rate of $7^{\circ} \mathrm{C} / \mathrm{min}$ to $200^{\circ} \mathrm{C}$, the decrease in electrical resistance is best fitted with $m=7.2$ (red line) during the first 15 minutes of isothermal annealing, which is close to the value of 7 stated in Table 2.3 of Chapter 2 for surface diffusion. Beyond 15 minutes, the proposed model does not fit to the experimental results. This is because the proposed model assumes ballistic conduction as the dominating electronic conduction. Hence, a change in the dominant electronic conduction regime, i.e. from ballistic to classical, would affect the accuracy of the model. In addition, after prolonged sintering, the $\mathrm{Cu}$ NPs will fuse and causes shrinkage that causes discontinuity that could affect the resistance measurements since the $\mathrm{Cu}$ NPs paste is spread onto a self-made electrical test structure as shown in Figure 3.2. Another possible reason that the model does not match the actual resistance is that this model assumes minimum or no shrinkage of the sintered $\mathrm{Cu}$ NPs. Hence the ratio of $\left(\frac{\mathrm{X}}{\mathrm{a}}\right)$ is kept constant, assuming any change in neck size $X$ is proportional to the particle size, $a$. However, as isothermal annealing proceeds further, sintering could transit to Stage 2 whereby densification occurs. Hence the particle size, $a$, 
$\underline{\text { Sintering and Densification Behavior of Nano-sized Copper Particles Chapter } 4}$ changes and needs to be taken into consideration for the model as the ratio of $\left(\frac{\mathrm{X}}{\mathrm{a}}\right)$ will change to predict subsequent densification behavior.

From the FESEM images shown in Figure 4.13(a), the neck size grew with increasing isothermal duration, i.e. beyond 10 minutes, and less spherical $\mathrm{Cu}$ NPs was observed. Hence, it is reasonable to postulate that the deviation of the model after 15 minutes comes from the change in the proportion of ballistic conduction to classical conduction and the particle size.

On the other hand, for samples that were heated up at $17^{\circ} \mathrm{C} / \mathrm{min}$, the best fitted $\mathrm{m}$ value is 3.853. Therefore, according to Table 2.3 and Figure 2.6 (2), the dominating sintering mechanism could probably be lattice diffusion from the surface which is still considered as another form of surface diffusion since no densification was observed in Figure 4.13 (b). This is because unlike conventional lattice diffusion whose source of material during sintering comes from the grain boundary that eventually leads to densification, the source of material for such "lattice diffusion" comes from the surface. Hence it does not lead to densification. For this sample that was previously heated up at $17^{\circ} \mathrm{C} / \mathrm{min}$, the model is only able to predict up to the first 20 minutes of isothermal annealing as the model starts to deviate from the measured data eventually. 

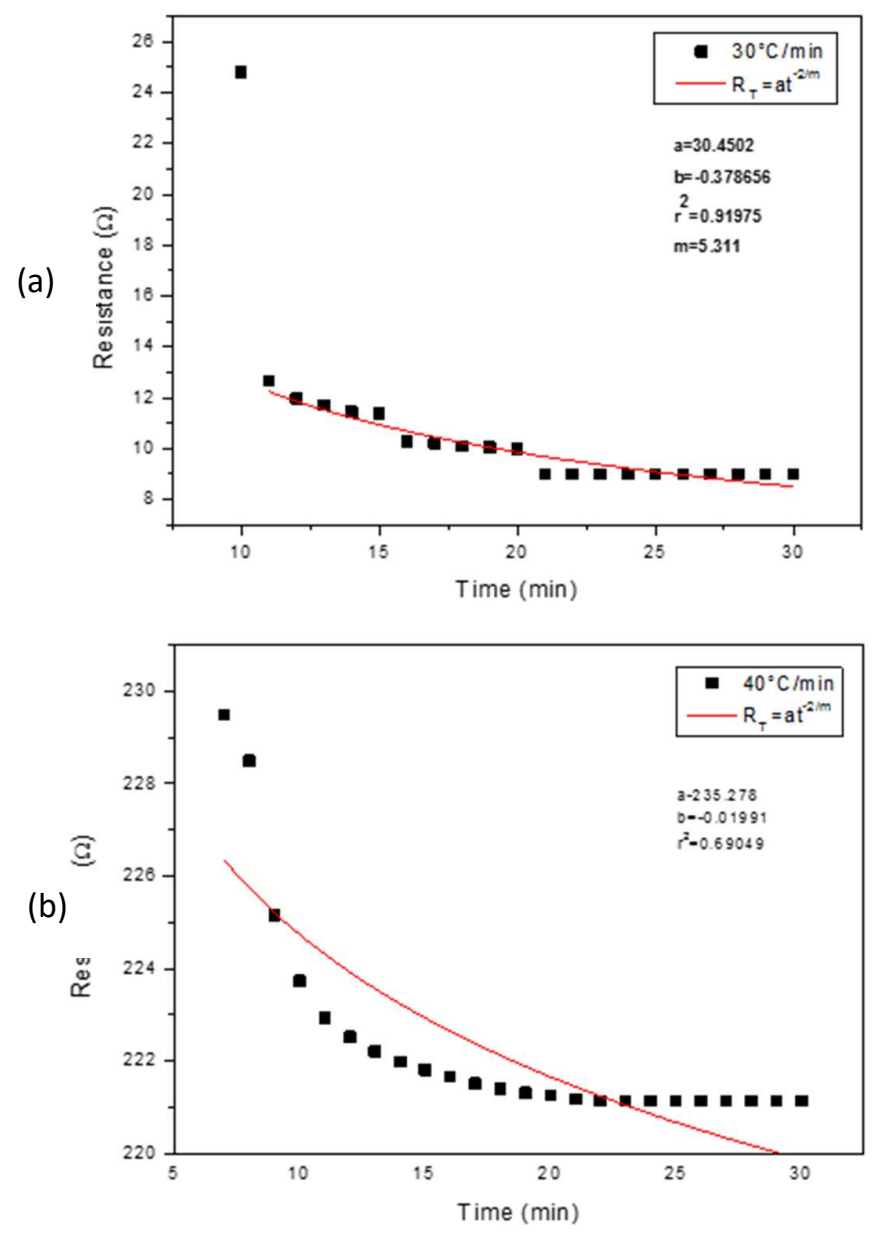

Figure 4.15 Experimental results and proposed model prediction of resistance as a function of time (a) $30^{\circ} \mathrm{C} / \mathrm{min}$ (b) $40^{\circ} \mathrm{C} / \mathrm{min}$

Based on the model that was developed and the values of $m$ and $n$ calculated, when the heating rate was increased further to $30^{\circ} \mathrm{C} / \mathrm{min}$, the dominating sintering mechanism is lattice diffusion from grain boundary for samples that were heated up at $30^{\circ} \mathrm{C} / \mathrm{min}$ (Figure $4.15(\mathrm{a})$ ) when referred to the summarized values of the different sintering mechanism listed in Table 2.3 [43]. However, this is not true as lattice diffusion from grain boundary will lead to shrinkage, i.e. change in thickness and/or densification, and both are not observed in this study. In addition, from Figure 4.13(c), many un-fused $\mathrm{Cu}$ NPs were still present. For even higher heating rate of $40^{\circ} \mathrm{C} / \mathrm{min}$ (Figure $4.15(\mathrm{~b})$ ), the fitting was poor with $r^{2}$ value of 0.69 . Hence, the proposed model has failed to predict those higher heating rates samples as the sintering behavior could be more complicated. 
The difference in sintering mechanism predicted by the model for samples heated at $7^{\circ} \mathrm{C} / \mathrm{min}$ and $17^{\circ} \mathrm{C} / \mathrm{min}$ could be attributed to the different $T_{E}$ and $T_{F}$ at different heating up rates. Since a higher heating rate will give a higher $T_{E}$ that leads to a higher $T_{F}$, the effective radius of the Cu NPs is assumed to be small when it reaches the peak process temperature. Hence, when the $\mathrm{Cu}$ NPs are subjected to the maximum temperature without spending more time at the lower temperature regime, lattice diffusion from the surface can happen. On the other hand, if a low heating rate is used $\left(7^{\circ} \mathrm{C} / \mathrm{min}\right)$, the $\mathrm{Cu}$ NPs would have spent a longer duration at the lower temperature regime. Hence, surface diffusion which usually prevails at lower temperature due to its lower activation energy, would be the dominating mechanism.

With all these results from TGA, DSC, FESEM and in-situ electrical resistance measurements, a schematic model for this sintering process of $\mathrm{Cu}$ NPs is proposed. Based on the proposed schematic model shown in Figure 4.16, at optimized heating rate as depicted in Figure 4.16(a), the volatilization of solvent will occur first, follow by desorption of the passivating layers which subsequently lead to the fusion of $\mathrm{Cu}$ NPs. During isothermal annealing, the particles will continue to grow. A slightly porous yet low electrical resistance layer is thus formed.

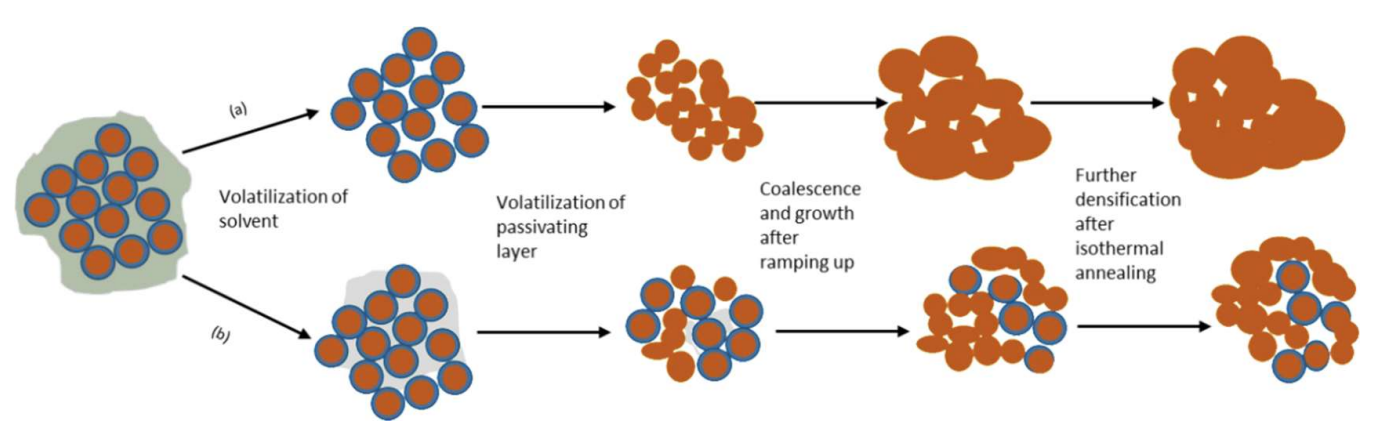

Figure 4.16 Schematics diagram of $\mathrm{Cu}$ NPs microstructure evolution after (a) complete removal, (b) incomplete removal of organic materials.

On the other hand, if the heating rate is too fast $\left(>17^{\circ} \mathrm{C} / \mathrm{min}\right)$ as shown in Figure 4.16(b), volatilization of solvent and desorption of passivating layers might be 
Sintering and Densification Behavior of Nano-sized Copper Particles Chapter 4 incomplete. The organic materials that are trapped within the layer will lead to non-fusing or partial fusing of $\mathrm{Cu}$ NPs even after prolong isothermal annealing. This will eventually lead to a porous sintered $\mathrm{Cu}$ layer with high electrical resistance. Therefore, from the proposed schematic model, it highlights the importance of removing the organic materials completely. A slower heating rate might be one of the possible solutions. However, a higher sintering temperature is needed for further growth and densification due to the presence of agglomerates with larger effective radius that were formed during the slow heating up process. Therefore, the ability to completely remove the passivating layers from these $\mathrm{Cu}$ NPs surfaces fast to prevent partial and non-homogenous fusion will be explored in the next section.

\subsubsection{Stability of Passivating Ligands under Acidic Environment}

There are several factors that can increase the rate of desorption and volatilization of these passivating layers. These factors include providing a higher thermal energy to enhance desorption, increasing the flow rate of air to remove the volatiles quickly from the $\mathrm{Cu}$ NPs surfaces or introducing other gases to react with the passivating layers. As reported by Anto et al. [25], $T_{E}$ is dependent on the thermal stability and packing density of the ligands on the particles' surfaces rather than the size of the nanoparticles. Since the amine ligands that were on the $\mathrm{Cu}$ NPs surfaces are able to volatilize below $200^{\circ} \mathrm{C}$, they thus do not share strong bonds with the Cu NPs surfaces. Hence, by introducing a gas that can react with the passivating ligands and the by-products formed are able to volatilize readily to prevent redisposition, could enable better and faster removal of these passivating layers. This will effectively promote better fusion among $\mathrm{Cu}$ NPs.

Feeding $\mathrm{N}_{2}$ gas into formic acid is a technique used to create a reduction atmosphere and it is also used in the industries for soldering applications (eutectic bonding) to prevent oxidation [44-46]. However, the main purpose of introducing formic acid vapor in our experiments is not to reduce copper oxide to copper. Its purpose here is to react with the amine ligands that are attached onto the $\mathrm{Cu}$ NPs surfaces. From the previous section, it is observed that the $\mathrm{Cu}$ 
Sintering and Densification Behavior of Nano-sized Copper Particles Chapter 4 NPs that were used could be sintered at $300^{\circ} \mathrm{C}$ under $\mathrm{N}_{2}$ with minimum presence of copper oxide. Figure 4.17 shows the XRD data of the as sintered $\mathrm{Cu}$ NPs film at $300^{\circ} \mathrm{C}$. This proves that the reason for the high resistance measured and presence of un-fused $\mathrm{Cu}$ NPs especially at higher heating rates, is most likely caused by non-uniform removal of organic materials that led to poor fusion among $\mathrm{Cu}$ NPs.

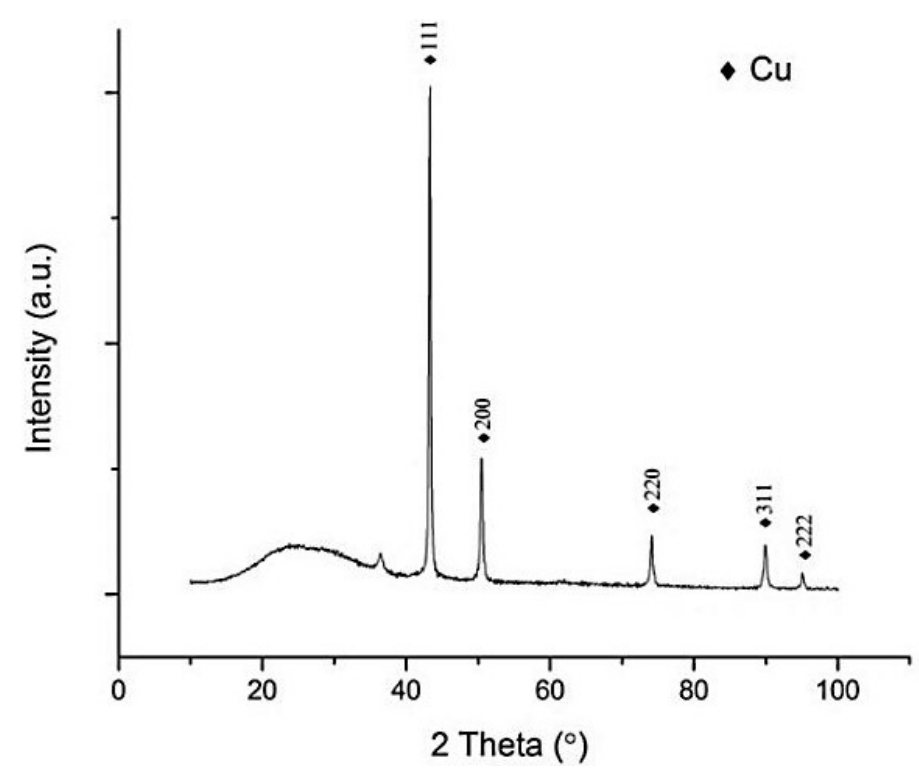

Figure 4.17 XRD of sintered Cu NPs film at $300^{\circ} \mathrm{C}$

Therefore, to improve the removal of the amine-based ligands from the Cu NPs surfaces, formic acid was used to understand the effectiveness of removing the passivating layers. In Figure 4.18, the in-situ electrical resistance as a function of time for $\mathrm{Cu}$ NPs sintered under $\mathrm{N}_{2}$ and formic acid at a heating rate of $40^{\circ} \mathrm{C} / \mathrm{min}$ shows a significant drop in resistance even during the short heating up period under formic acid environment. 


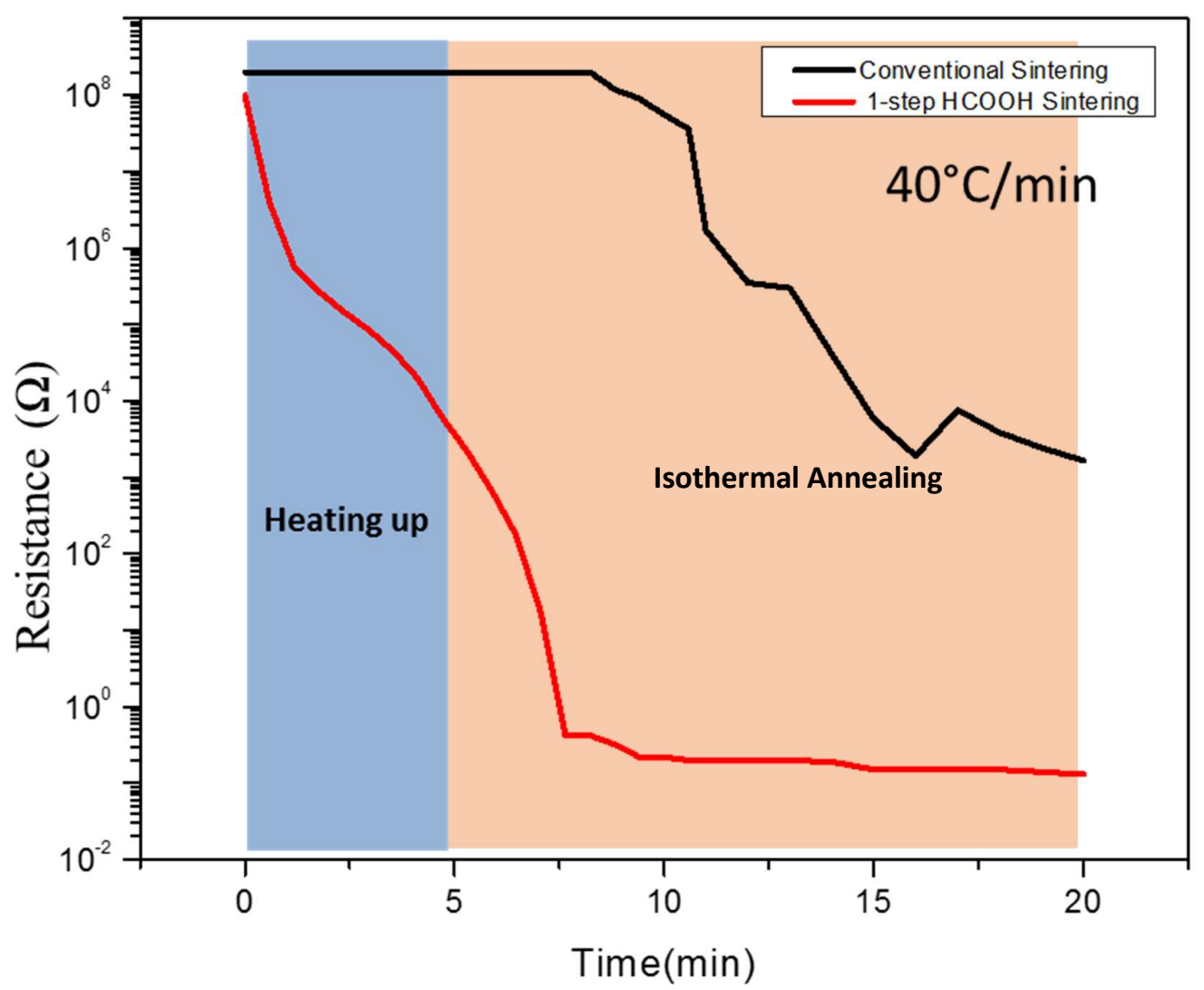

Figure 4.18 in situ electrical resistance measurements during heat up at $40^{\circ} \mathrm{C} / \mathrm{min}$ under $\mathbf{N}_{2}$ and formic acid

From Figure 4.18, the rate of sintering under formic acid as represented by the rate of resistance change increases rapidly within the first 7 minutes of the sintering process, though heating up to peak temperature takes about 5 minutes. This shows that the reaction between formic acid and the amine-based passivating layer is possible even at low temperatures. The possible reaction between formic acid and the amine-based passivating layer is [27]:

$$
\mathrm{R}-\mathrm{NH}_{2}+\mathrm{HCOOH} \rightarrow \mathrm{R}-\mathrm{CONH}_{2}+\mathrm{H}_{2} \mathrm{O}
$$

With the reaction between formic acid and amines, it can form some by-products that volatilize readily, i.e. removed from the $\mathrm{Cu}$ NPs surfaces below $200^{\circ} \mathrm{C}$. Hence it will allow fusion of the $\mathrm{Cu}$ NPs to occur rapidly due to the nano-size effect. Detailed chemical reactions between formic acid and the amine-based 
Sintering and Densification Behavior of Nano-sized Copper Particles Chapter 4

ligands are beyond the scope of this study. Since these $\mathrm{Cu}$ NPs are not passivated anymore, they are not thermodynamically stable due to their high surface energy. In addition, the reduction of melting point for nanoparticles will enhance surface diffusion, thus reducing the onset temperature of fusion, $T_{F}$ (Figure 4.19). The microstructure evolution of $\mathrm{Cu}$ NPs under conventional heating and formic acid vapor is shown in Figure 4.20.

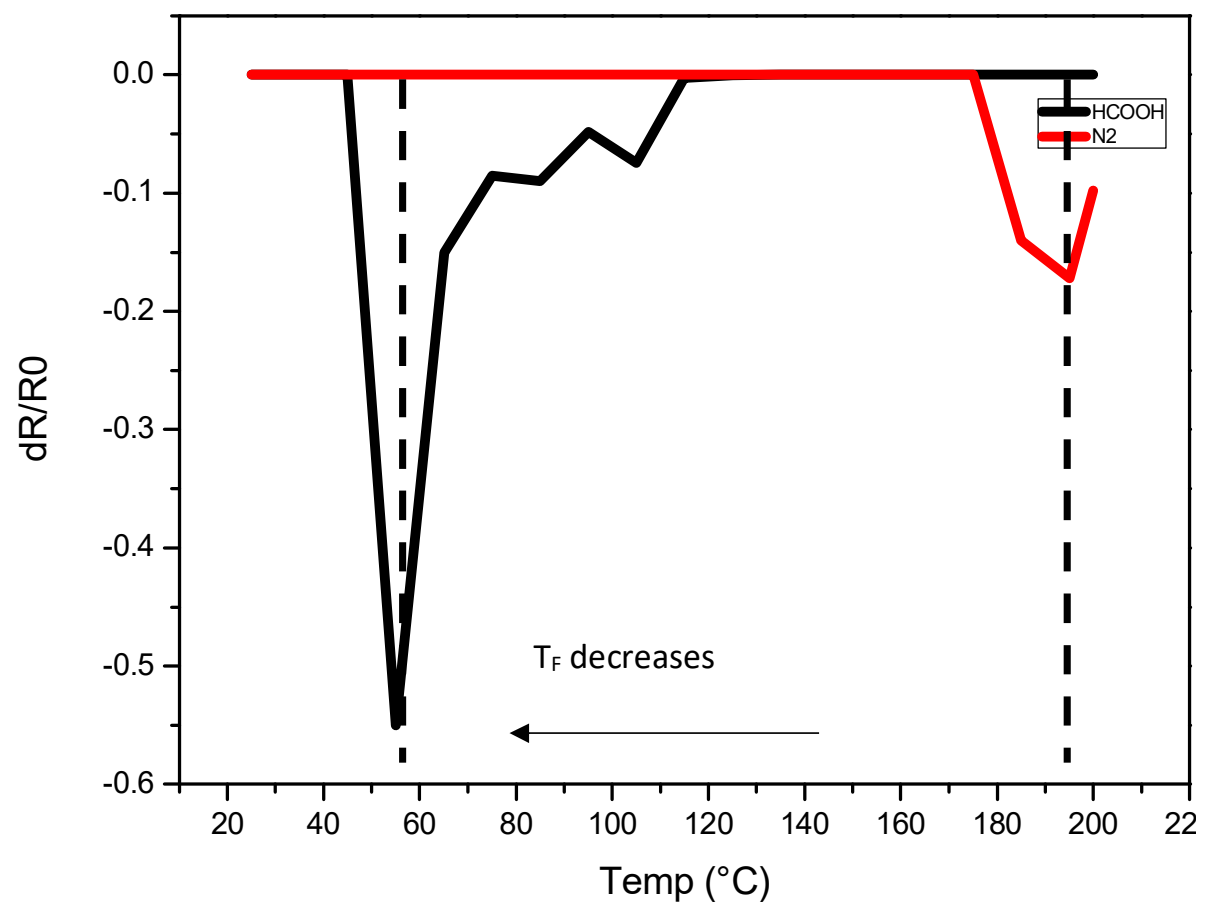

Figure 4.19 Changes in $T_{F}$ when $\mathrm{HCOOH}$ vapor is introduced with a heating rate of $40^{\circ} \mathrm{C} / \mathrm{min}$ 
(a)

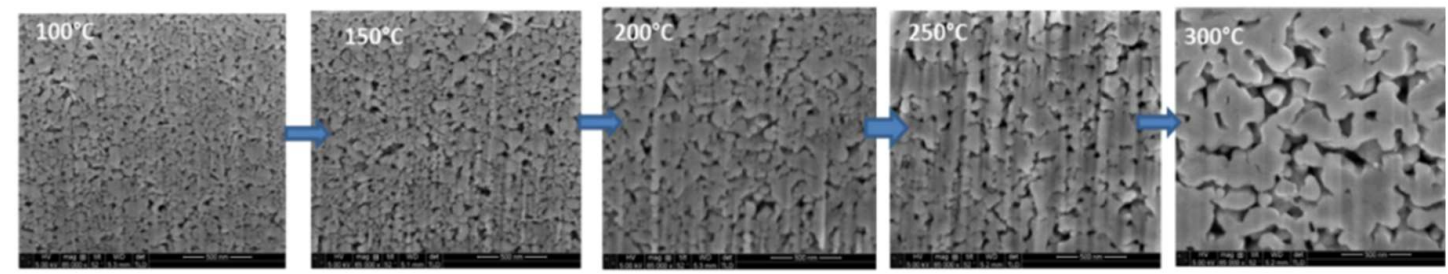

$70 \% \mathrm{HCOOH}$ (throughout the whole sintering cycle)

(b)
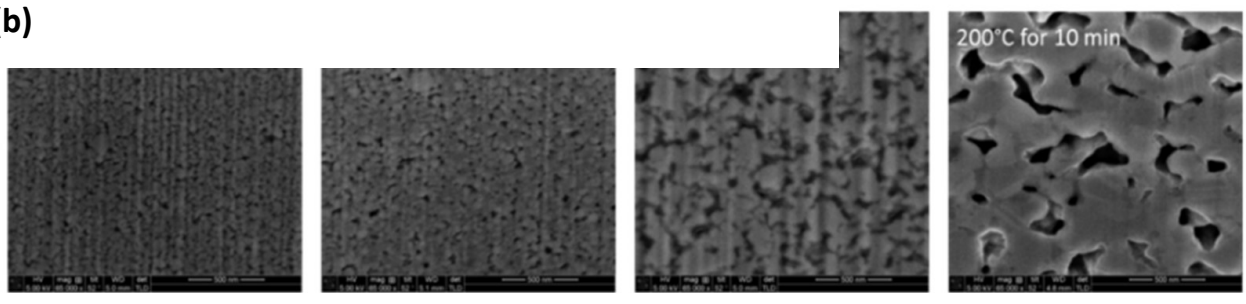

Figure 4.20 Microstructure evolutions of $\mathrm{Cu}$ NPs (a) under conventional $\mathrm{N}_{2}$ sintering profile (b) under high heating up rate with 18.125M НСООН vapor

(Scale bar: 500 nm)

From the resulting microstructures, fast removal of passivating layers leads to fast fusion among the NPs that resulted in the formation of highly interconnected string-like structures as shown in Figure 4.21(b). Larger particle sizes, with larger pores due to enhanced neck growth, which indicate better fusion, was observed for sample sintered under formic acid vapor. On the other hand, when passivating layers are removed slowly, the fused $\mathrm{Cu}$ looks "round" (Figure 4.21(a)). This observation is similar to what have been reported by Ristau et al. [47] where fast sintering of $\mathrm{Au}$ NPs using electron beam leads to string-like structure. However, for both conditions, the SEMs images do suggest that the same non-densifying mechanism had taken place since the porosity after sintering does looks similar. This shows that non-densifying mechanism is responsible for both sintering conditions since large amount of porosities were observed and sintering was done at a relative low temperature. However, for both conditions, the SEMs images do suggest that the same non-densifying mechanism had taken place since the porosity after sintering does looks similar. Nevertheless, the difference between fast sintering rate in formic acid is that the $\mathrm{Cu}$ NPs are well-connected while those that were sintered in $\mathrm{N}_{2}$ still has some 
$\underline{\text { Sintering and Densification Behavior of Nano-sized Copper Particles Chapter } 4}$ small unfused $\mathrm{Cu}$ NPs. This is due to the non-uniform and slow removal of capping layers under $\mathrm{N}_{2}$. On the other hand, under formic acid, the passivation removal is fast since sintering (i.e. resistance drops) started to occur at $60^{\circ} \mathrm{C}$. However, because the sintering temperature is low, only surface diffusion could occur which is a non-densifying mechanism as discussed in Chapter 2, that leads to high porosity of the $\mathrm{Cu}$ NPs after sintering.

$\mathbf{N}_{2}$

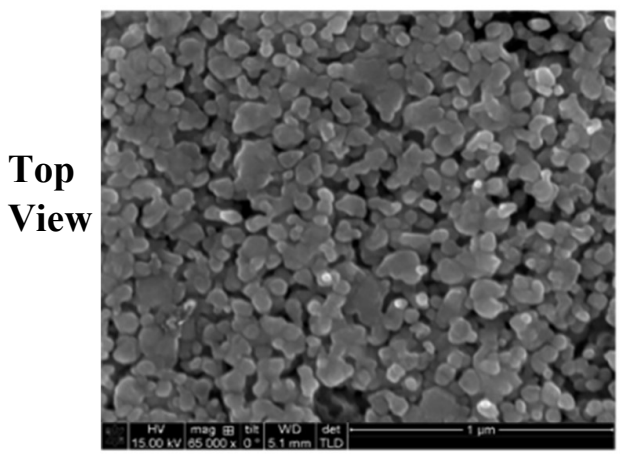

Crosssectioned View

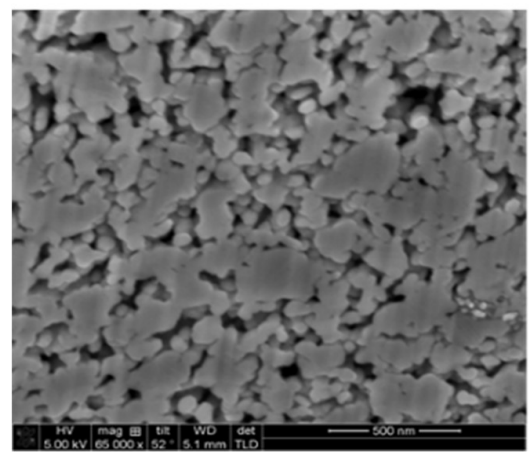

(a)
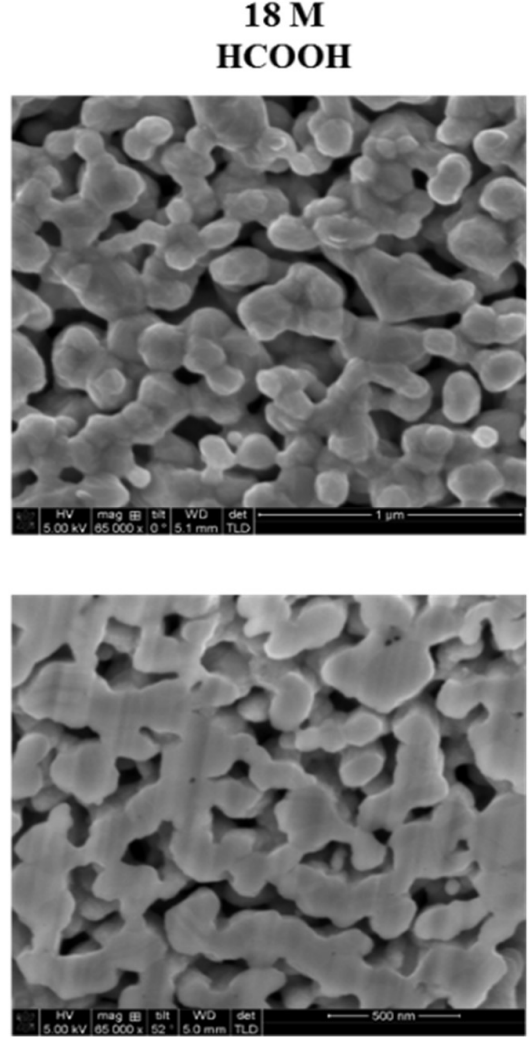

(b)

Figure 4.21 Microstructure of $\mathrm{Cu}$ NPs sintered under (a) $\mathrm{N}_{2}\left(17^{\circ} \mathrm{C} / \mathrm{min}\right)$ (b)

\subsection{Formic Acid Vapor $\left(40^{\circ} \mathrm{C} / \mathrm{min}\right)$}

As the final microstructures are very much different, $\mu$ XRD was carried out to understand the grain orientation of the fused $\mathrm{Cu}$ NPs under different sintering environment. For $\mathrm{Cu}$ NPs that were sintered under $\mathrm{N}_{2}$ (Figure 4.22(a)), no preferred grain orientations were observed as the relative intensities of all orientations were similar when sintered under $\mathrm{N}_{2}$ with initial heating rate of $17^{\circ} \mathrm{C} / \mathrm{min}$ and annealed at $200^{\circ} \mathrm{C}$ for 10 minutes. On the other hand, when $\mathrm{Cu}$ 
Sintering and Densification Behavior of Nano-sized Copper Particles Chapter 4 NPs were sintered under formic acid vapor (Figure 4.22(b)), a preferred grain orientation of (111) was observed though a much faster heating rate $\left(40^{\circ} \mathrm{C} / \mathrm{min}\right)$ was used. This phenomenon is believed to be due to the initial capping surfactants being more weakly bonded to the (111) orientation of $\mathrm{Cu}$. Hence when formic acid vapor is used, these capping organic materials on the (111) surfaces will be the first to react with the formic acid vapor. This would cause fusion to start from this direction and eventually lead to a textured $\mathrm{Cu}$ formation. Such control growth direction by using surfactants to attach on a particular crystal orientation has been reported for controlled nanowires growth direction and shape $[48,49]$. It has been suggested that capping surfactants in a particular direction could change a NP to grow into a nano-rod. This could also be the reason why the fused $\mathrm{Cu}$ NPs shown in Figure 4.21(b) appears to be elongated. With better grain orientation, it would translate to less grain boundaries that could explain the lower electrical resistance observed after sintering as well. This fast fusion between $\mathrm{Cu}$ NPs is made possible due to the reaction between formic acid and the amine-based passivating ligands that formed some by-products that can be decomposed or volatilized readily at low temperature. Thus a "clean" $\mathrm{Cu}$ NPs surfaces would be exposed to enable better and faster fusion to happen.

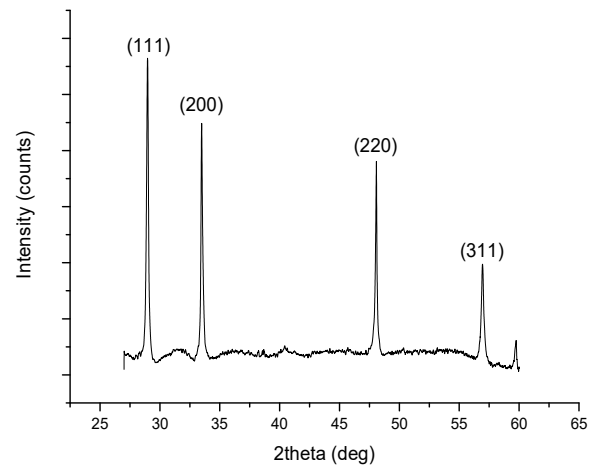

(a)

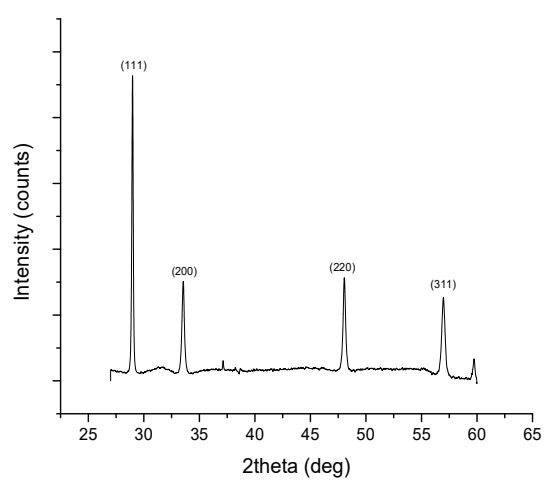

(b)

Figure 4.22 $\mu$ XRD for samples heated under (a) $\mathrm{N}_{2}$ (b) Formic acid

Though some reports $[44,45]$ have stated the use of formic acid to reduce $\mathrm{CuO}$ from the $\mathrm{Cu}$ NPs surfaces to enhance fusion, the main role of formic acid in this study is to remove the amine-based passivating layers on the $\mathrm{Cu}$ NPs surfaces to promote better fusion among $\mathrm{Cu}$ NPs. Though there could be some reduction of 
Sintering and Densification Behavior of Nano-sized Copper Particles Chapter 4 copper oxide $(\mathrm{CuO})$ to $\mathrm{Cu}$ or even preventing the $\mathrm{Cu}$ from being oxidize when sintering, the main reason for poor fusion among $\mathrm{Cu}$ NPs is largely due to presence of passivating layers since no obvious $\mathrm{CuO}$ peaks were detected for samples sintered under $\mathrm{N}_{2}$ environment (Figure 4.21). Hence, the postulation made based on these findings is that the formic acid vapor reacts with the passivating ligands which were speculated to happen on the $\mathrm{Cu}$ NPs (111) direction and forms some volatile by-products that can be remove below $200^{\circ} \mathrm{C}$. These by-products are able to evaporate away from the $\mathrm{Cu}$ without any redisposition. This exposes a "clean" $\mathrm{Cu}$ surface and allows fusion among these $\mathrm{Cu}$ NPs along this (111) direction. The removal of the by-product is critical because if it is not removed, the electrical resistance of the sintered $\mathrm{Cu}$ NPs will be affected. After ligands removal, the subsequent fusion of $\mathrm{Cu}$ will be driven thermodynamically by its size effect. From the combination of in-situ electrical resistance measurement, FESEM images and $\mu \mathrm{XRD}$ data, it is possible to come up with an enhanced schematic diagram of the sintering process of $\mathrm{Cu}$ NPs under different environment as shown in Figure 4.23 assuming all passivating layers are removed completely.

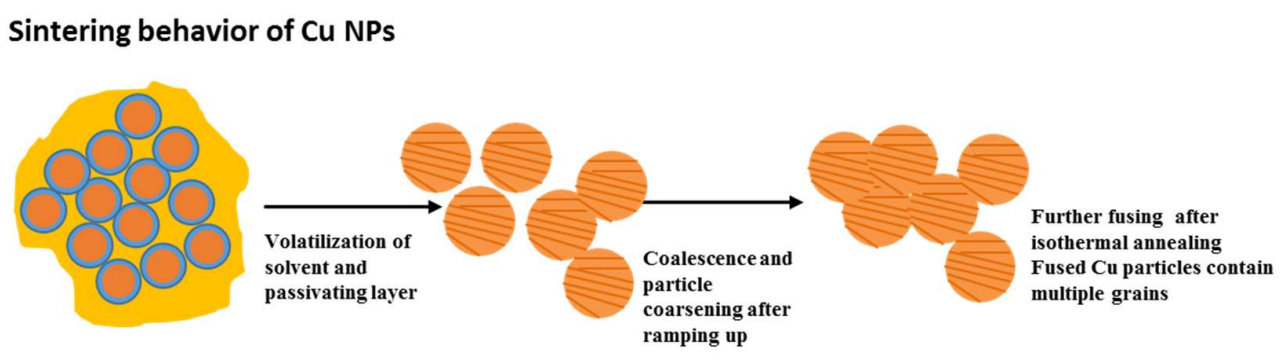

(a) 


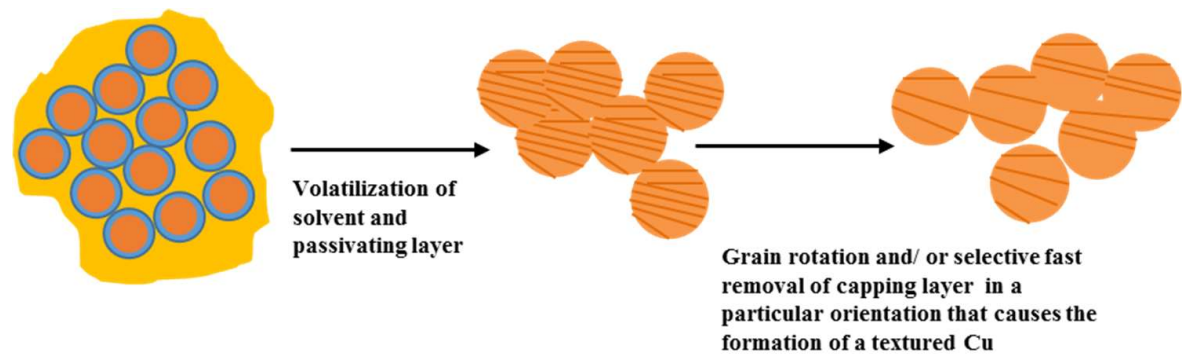

(b)

Figure 4.23 Schematic diagrams showing the sintering behavior under (a) $\mathrm{N}_{2}$ and

(b) Formic acid

However, bigger pores were observed when sintering was performed under formic acid due to low the $T_{E}$ and $T_{F}$. Therefore, to achieve a denser microstructure, $T_{E}$ and $T_{F}$ have to be higher. Since from the previous data, the removal of passivating layers is slow under $\mathrm{N}_{2}$, a 2-step sintering process under different environment can be considered. This means that only $\mathrm{N}_{2}$ is introduced during fast heating up to prevent oxidation and minimize volatilization, followed by introducing formic acid vapor at the peak temperature to ensure that $T_{E}$ and $T_{F}$ are close together at the peak sintering temperature. This will allow the effective radius of the $\mathrm{Cu}$ NPs to remain small up till the peak sintering temperature. Further studies on this can be carried out in the future.

\subsection{Conclusion}

It is frequently reported that the processing temperature of NPs can be low due to its low melting point. However, in this study, this is not the main contributing factor for passivated metallic NPs but is due to the sintering mechanism. The onset temperature of sintering is more dependent on the removal of ligands that are attached onto the $\mathrm{Cu}$ NPs surfaces. In the first part of the study, a conventional sintering profile was designed based on the thermal properties derived from the TGA and DSC analysis. From these data, the Cu NPs displayed the possibility of fusion at $200^{\circ} \mathrm{C}$. However, as heating rate increases beyond $17^{\circ} \mathrm{C} / \mathrm{min}$, minimum or no fusion among these $\mathrm{Cu}$ NPs occurs and high electrical resistance will be observed. The increase in heating rates increases $T_{E}$ and $T_{F}$, 

which causes rapid volatilization and non-uniform fusion, especially for thicker $\mathrm{Cu}$ NPs layer. When this happens, there will be inhomogeneous removal of passivating layers as the volatility of the passivating layers is not as high. This subsequently affects the degree of fusion of these $\mathrm{Cu}$ NPs across the layer. A resistance-time model that is based on ballistic electronic conduction is proposed to estimate the dominant sintering mechanism of these $\mathrm{Cu}$ NPs held at constant temperature after the removal of the passivating layers. The stability of the passivating ligands on these $\mathrm{Cu}$ NPs surfaces can be lowered with the introduction of formic acid vapor. With the passivating layer removed effectively even at high heating up rates, these $\mathrm{Cu}$ NPs are able to fuse with a (111) preferred grain orientation at $200^{\circ} \mathrm{C}$ within a short period of time. A low resistance of about $0.1 \Omega$ was achieved due to higher degree of fusion and better grain orientation. With all these results, a few conclusions can be made in this chapter.

- Complete removal of passivating layers is crucial for these $\mathrm{Cu}$ NPs to fuse and form a percolated network.

- A suitable heating rate must be designed to allow a balance between $T_{E}$ and $T_{F}$. A higher $T_{E}$ will lead to a delayed volatilization of the passivating layers, thus preventing fusion of NPs to occur at lower temperature. Therefore, if the passivating ligands are not very volatile, a fast heating rate will lead to non-homogenous fusion across layer due to non-uniform removal from the $\mathrm{Cu}$ NPs surfaces.

- A model based on ballistic electronic conduction at constant temperature was proposed to understand the initial sintering behavior and predicting the dominating sintering mechanism.

\section{References}

1. Kim, I., et al., Synthesis of oxidation-resistant core-shell copper nanoparticles. RSC Advances, 2013. 3(35): p. 15169-15177.

2. Knoerr, M. and A. Schletz. Power semiconductor joining through sintering of silver nanoparticles: Evaluation of influence of parameters time, temperature and pressure on density, strength and reliability. in Integrated Power Electronics Systems (CIPS), 2010 6th International Conference on. 2010. 
Sintering and Densification Behavior of Nano-sized Copper Particles Chapter 4

3. Kobayashi, Y., et al., Preparation of metallic copper nanoparticles in aqueous solution and their bonding properties. Solid State Sciences, 2011. 13(3): p. 553558.

4. Deng, D., et al., Antioxidative effect of lactic acid-stabilized copper nanoparticles prepared in aqueous solution. Journal of Materials Chemistry, 2012. 22(45): p. 23989-23995.

5. Krishnan, S., A.S.M.A. Haseeb, and M.R. Johan, Preparation and LowTemperature Sintering of $\mathrm{Cu}$ Nanoparticles for High-Power Devices. Components, Packaging and Manufacturing Technology, IEEE Transactions on, 2012. 2(4): p. 587-592.

6. Kanninen, P., et al., Influence of ligand structure on the stability and oxidation of copper nanoparticles. Journal of Colloid and Interface Science, 2008. 318(1): p. 88-95.

7. Wang, S., et al., Rapid pressureless low-temperature sintering of $\mathrm{Ag}$ nanoparticles for high-power density electronic packaging. Scripta Materialia, 2013. 69(11-12): p. 789-792.

8. Mei, Y., et al., Simplification of Low-Temperature Sintering Nanosilver for Power Electronics Packaging. Journal of Electronic Materials, 2013. 42(6): p. 1209-1218.

9. Yamakawa, T., et al., Influence of Joining Conditions on Bonding Strength of Joints: Efficacy of Low-Temperature Bonding Using Cu Nanoparticle Paste. Journal of Electronic Materials, 2013. 42(6): p. 1260-1267.

10. Cheon, J., J. Lee, and J. Kim, Inkjet printing using copper nanoparticles synthesized by electrolysis. Thin Solid Films, 2012. 520(7): p. 2639-2643.

11. Lee, B., et al., A low-cure-temperature copper nano ink for highly conductive printed electrodes. Current Applied Physics, 2009. 9(2, Supplement): p. e157e160.

12. Allen, G.L., et al., Small particle melting of pure metals. Thin Solid Films, 1986. 144(2): p. 297-308.

13. Wang, T., et al., Shrinkage and Sintering Behavior of a Low-Temperature Sinterable Nanosilver Die-Attach Paste. Journal of Electronic Materials, 2012. 41(9): p. $2543-2552$. 
Sintering and Densification Behavior of Nano-sized Copper Particles Chapter 4

14. Moon, K.-S., et al., Thermal behavior of silver nanoparticles for lowtemperature interconnect applications. Journal of Electronic Materials, 2005. 34(2): p. 168-175.

15. Lei, T.G., et al., Low-Temperature Sintering of Nanoscale Silver Paste for Attaching Large-Area Chips. Components and Packaging Technologies, IEEE Transactions on, 2010. 33(1): p. 98-104.

16. Wang, T., et al., Low-Temperature Sintering with Nano-Silver Paste in DieAttached Interconnection. Journal of Electronic Materials, 2007. 36(10): p. 1333-1340.

17. Ishizaki, T., et al., Thermal characterizations of Cu nanoparticle joints for power semiconductor devices. Microelectronics Reliability, 2013. 53(9-11): p. 15431547.

18. Ide, E., et al., Metal-metal bonding process using Ag metallo-organic nanoparticles. Acta Materialia, 2005. 53(8): p. 2385-2393.

19. Yi, S.-M., et al., Improvement of electrical and mechanical properties of $\mathrm{Ag}$ nanoparticulate films by controlling the oxygen pressure. Journal of The Electrochemical Society, 2010. 157(12): p. K254-K259.

20. Jang, S., et al., Sintering of inkjet printed copper nanoparticles for flexible electronics. Scripta Materialia, 2010. 62(5): p. 258-261.

21. Park, B.K., et al., Direct writing of copper conductive patterns by ink-jet printing. Thin Solid Films, 2007. 515(19): p. 7706-7711.

22. Jianfeng, Y., et al., Preparation of PVP coated Cu NPs and the application for low-temperature bonding. Journal of Materials Chemistry, 2011. 21(40): $p$. 15981-15986.

23. Couchman, P.R. and W.A. Jesser, Thermodynamic theory of size dependence of melting temperature in metals. Nature, 1977. 269(5628): p. 481-483.

24. Lee, C.-L., K.-C. Chang, and C.-M. Syu, Silver nanoplates as inkjet ink particles for metallization at a low baking temperature of $100^{\circ} \mathrm{C}$. Colloids and Surfaces A: Physicochemical and Engineering Aspects, 2011. 381(1-3): p. 85-91.

25. Anto, B.T., et al., Hydrophilic Sparse Ionic Monolayer-Protected Metal Nanoparticles: Highly Concentrated Nano-Au and Nano-Ag "Inks" that can be Sintered to Near-Bulk Conductivity at $150^{\circ} \mathrm{C}$. Advanced Functional Materials, 2010. 20(2): p. 296-303. 
Sintering and Densification Behavior of Nano-sized Copper Particles Chapter 4

26. Greer, J.R. and R.A. Street, Thermal cure effects on electrical performance of nanoparticle silver inks. Acta Materialia, 2007. 55(18): p. 6345-6349.

27. Jang, S., J. Joung, and Y. Oh, Microstructure changes in nanoparticulate gold films under different thermal atmospheres and the effects on bondability. Acta Materialia, 2009. 57(18): p. 5613-5620.

28. Palmero, P., et al., Effect of Heating Rate on Phase and Microstructural Evolution During Pressureless Sintering of a Nanostructured Transition Alumina. International Journal of Applied Ceramic Technology, 2009. 6(3): p. 420-430.

29. Shan, J., et al., Molecular dynamics study of neck growth in laser sintering of hollow silver nanoparticles with different heating rates. Journal of Physics D: Applied Physics, 2013. 46(33): p. 335302.

30. Kim, D.-G., et al., Effect of heating rate on microstructural homogeneity of sintered $W-15 w t \% C u$ nanocomposite fabricated from $W-C u O$ powder mixture. Scripta Materialia, 2004. 51(7): p. 677-681.

31. Leite, E.R., et al., The effect of heating rate on the sintering of agglomerated NaNbO3 powders. Journal of Materials Science, 1998. 33(19): p. 4791-4795.

32. Coutts, M.J., et al., Rapid and Controllable Sintering of Gold Nanoparticle Inks at Room Temperature Using a Chemical Agent. The Journal of Physical Chemistry C, 2009. 113(4): p. 1325-1328.

33. Timsit, R.S., Electrical conduction through small contact spots. Components and Packaging Technologies, IEEE Transactions on, 2006. 29(4): p. 727-734.

34. Leong, H.L., et al., Experimental characterization and modeling of the contact resistance of $\mathrm{Cu}-\mathrm{Cu}$ bonded interconnects. Journal of Applied Physics, 2009. 105(3): p. 033514.

35. GREENWOOD, J., Constriction resistance and the real area of contact. Brit, J. Appl. Phys., 1966. 17: p. 1621-1632.

36. Jung, J.K., et al., Characteristics of microstructure and electrical resistivity of inkjet-printed nanoparticle silver films annealed under ambient air. Philosophical Magazine, 2008. 88(3): p. 339-359.

37. RAHAMAN, M.N., CERAMIC PROCESSING AND SINTERING. 2005: MARCEL DEKKER, INC. 
Sintering and Densification Behavior of Nano-sized Copper Particles Chapter 4

38. Wunscher, S., et al., Simulation and prediction of the thermal sintering behavior for a silver nanoparticle ink based on experimental input. Journal of Materials Chemistry C, 2014. 2(31): p. 6342-6352.

39. Lewis, L.J., P. Jensen, and J.-L. Barrat, Melting, freezing, and coalescence of gold nanoclusters. Physical Review B, 1997. 56(4): p. 2248-2257.

40. Chen, Y., R.E. Palmer, and J.P. Wilcoxon, Sintering of Passivated Gold Nanoparticles under the Electron Beam. Langmuir, 2006. 22(6): p. 2851-2855.

41. Albert, A.D., et al., Low temperature, pressure-assisted sintering of nanoparticulate silver films. Acta Materialia, 2008. 56(8): p. 1820-1829.

42. Kingery, W.D. and M. Berg, Study of the Initial Stages of Sintering Solids by Viscous Flow, Evaporation - Condensation, and Self - Diffusion. Journal of Applied Physics, 1955. 26(10): p. 1205-1212.

43. Bai, G., Low-temperature sintering of nanoscale silver paste for semiconductor device interconnection. 2005, Virginia Polytechnic Institute and State University.

44. Woo, K., et al., Effect of Carboxylic Acid on Sintering of Inkjet-Printed Copper Nanoparticulate Films. ACS Applied Materials \& Interfaces, 2011. 3(7): p. 23772382.

45. Kim, I. and J. Kim, The effect of reduction atmospheres on the sintering behaviors of inkjet-printed Cu interconnectors. Journal of Applied Physics, 2010. 108(10): p. 102807.

46. Formic Acid Module. [cited 20157 nov]; Available from: http://eu.finetech.de/products/micro-assembly/fineplacerrlambda/modules-for-lambda/formic-acid-module.html.

47. Ristau, R., et al., Electron microscopy studies of the thermal stability of gold nanoparticle arrays. Gold Bulletin, 2009. 42(2): p. 133-143.

48. Chen, C.-J., et al., Control of growth orientation and shape for epitaxially grown In2O3 nanowires on a-plane sapphire. Materials Research Bulletin, 2010. 45(2): p. 230-234.

49. Sun, Y. and Y. Xia, Shape-Controlled Synthesis of Gold and Silver Nanoparticles. Science, 2002. 298(5601): p. 2176-2179.

50. Zhang, Q., S.-J. Liu, and S.-H. Yu, Recent advances in oriented attachment growth and synthesis of functional materials: concept, evidence, mechanism, and future. Journal of Materials Chemistry, 2009. 19(2): p. 191-207. 
$\underline{\text { Sintering and Densification Behavior of Nano-sized Copper Particles Chapter } 4}$ 

$\underline{\text { Influence of Sintering Parameters of } \mathrm{Cu} \text { NPs \& its Structure Stability Chapter } 5}$

\section{Chapter 5}

\section{Influence of Sintering Parameters on Bond Strength of Cu NPs}

As discussed in Chapter 4, it was concluded that the removal of the passivating layer is essential for fusing the $\mathrm{Cu} N P$ s at a low temperature of $200^{\circ} \mathrm{C}$. This is because the degree of passivating layer removal prior to the Cu NPs fusion will eventually affect the final microstructure of the sintered $\mathrm{Cu}$ layer. It was concluded that the heating rate and sintering environment have a significant influence on the removal of the passivating layer on the Cu NPs. From the previous chapter, it was shown that the Cu NPs are well fused and have a low electrical resistance when they are sintered at $200^{\circ} \mathrm{C}$. Therefore, in this chapter, these Cu NPs, which are in a paste-like form, are sandwiched between two Si chips that were sputtered with a thin layer of $\mathrm{Cu}$. This structure will allow shear testing to be carried out and its bond strength to be quantified. The porosity, degree of necking between particles and sheared interface morphology from different sintering parameters will be studied based on the FESEM images of the fractured surface after shear test. A correlation between the final microstructure and bonding strength is then established. Isothermal annealing at $150^{\circ} \mathrm{C}$ in air was also carried out for 1000 hours to investigate the thermal stability of these $\mathrm{Cu} N \mathrm{NS}$ bonded joint. Some degree of grain growth and a (111) texture were found after 1000 hours of ageing. 
Influence of Sintering Parameters of Cu NPs \& its Structure Stability Chapter 5

\subsection{Introduction}

In recent years, many researchers are investigating on metallic NPs for low temperature interconnections [1-4]. These metallic NPs have shown its ability to be sintered at a lower temperature, and yet upon fully sintered, possess properties that are similar to its bulk metals $[5,6]$. Therefore, metallic NPs have been greatly studied as a viable alternative to replace high temperature $\mathrm{Pb}$-based solder as a joining material $[1,4,7]$. The ability to process at a lower temperature provides an advantage of adopting the metallic NPs as a mainstream interconnection material as this means that during processing, the semiconducting devices could avoid initial die level stress and other possible circuit damages [8]. To date, many have reported using Ag or Au NPs as a bonding material [9-13]. Low temperature fusion of noble metal NPs for die attach is promising since they rely on the principle of atomic diffusion and consolidation rather than a change of state from solidus to liquidus [14]. In Bai et al. [15] work, they made a comparison between Ag NPs and Au80Sn20 solder. It was reported that the previous has a much lower calculated elastic modulus, i.e. $9 \mathrm{GPa}$, due to the presence of micro-pores in the sintered Ag NPs. This is an advantage over conventional high temperature solder as it is able to withstand the stress arising from thermal expansion mismatch during bonding. Though sintered Ag NPs has 2.4 times higher electrical resistivity than bulk Ag at room temperature, its electrical resistivity is still lower than current solder alloy [14].

In comparison with micron-sized Ag particles, these Ag NPs can be fused at a much lower pressure, i.e. $1-5 \mathrm{MPa}$, while keeping the same processing temperature as micron sized Ag particles. This pressure range is definitely much lower than the 9-40 $\mathrm{MPa}$ used during bonding of micron-sized Ag particles [16]. This decrease in bonding pressure is attributed to the higher surface energies due to the size of the NPs [14].

However, Ag NPs often incurred higher cost and are subjected to ion migration [17]. Hence the next alternative is to look into $\mathrm{Cu}$ NPs as $\mathrm{Cu}$ also possesses high electrical conductivity and has strong durability towards ion migration and it is lower in cost $[8,17]$. Though previous studies on the bondability of $\mathrm{Cu}$ NPs have been carried out, they were either done at a much higher temperature, i.e. $230^{\circ} \mathrm{C}$ 
Influence of Sintering Parameters of Cu NPs \& its Structure Stability Chapter 5 and above or under vacuum and forming gas environment [8, 18-20]. Such processing techniques will incur higher operational costs and is not suitable for polymeric substrates. In addition, there is a lack in understanding about the relationship between microstructures and mechanical properties that arises from different sintering parameters. Fu et al. [3] had stated that the sintering temperature, annealing time and heating rate has a direct influence on the pore size and pore distribution, which eventually affect the overall shear strength.

Therefore, this chapter aims to study the microstructure of the sintered $\mathrm{Cu}$ in detail and specifically its relationship with the mechanical properties. The first half of this chapter will discuss the effects of various sintering parameters on the shear strength of sintered $\mathrm{Cu}$ NPs bonded between 2 sputtered $\mathrm{Cu}$ layers. The fusion mechanism, degree of neck growth and porosity will also be looked into. After which, the stability of the sintered $\mathrm{Cu}$ NPs joints will be studied in terms of degree of grain growth and preferred texture after thermal annealing under air condition for 1000 hours.

\subsection{Experimental Method}

\subsubsection{Bonding and characterizations of fused $\mathrm{Cu}$ NPs}

Various heating rate $\left(7-40^{\circ} \mathrm{C} / \mathrm{min}\right)$, different isothermal annealing duration $(5$ -30 minutes) at $200-300^{\circ} \mathrm{C}$, bonding pressure ranging from $0-5 \mathrm{MPa}$ and nitrogen or formic acid environment were studied on their impact on $\mathrm{Cu}$ NPs bonding. Correlation between all these bonding parameters with the joint strength will be studied. The mechanical shear strength of the bonded joint was characterized with a die shear test. To achieve statistically reliable results, 6 measurements were taken for each data point. After shear test, the crosssectioned of the sheared surfaces were characterized using FESEM and the percentage of porosity of the fused $\mathrm{Cu}$ after bonding with applied pressure was calculated using ImageJ software from the obtained images. The grain sizes evolution and texture of the aged $\mathrm{Cu}$ NPs after isothermal ageing test were studied using synchrotron radiation $\mu$ XRD diffraction patterns. 
$\underline{\text { Influence of Sintering Parameters of Cu NPs \& its Structure Stability Chapter } 5}$

\subsection{Effects of Bonding Parameters}

\subsubsection{Effect of Heating Rate}

In Chapter 4 , a heating rate between $7^{\circ} \mathrm{C} / \mathrm{min}-17^{\circ} \mathrm{C} / \mathrm{min}$ was deemed to be an appropriate heating rate for fusing these $\mathrm{Cu}$ NPs. However as compared to the previous chapter, the focus of this chapter is targeted towards bonding applications. This means that the $\mathrm{Cu}$ NPs paste is sandwiched between two $\mathrm{Si}$ chips that have been sputtered with a $500 \mathrm{~nm}$ thick $\mathrm{Cu}$ film. As fusion of the $\mathrm{Cu}$ NPs is heavily dependent on the removal of the organic materials, a covered structure will pose some additional challenges to the removal of organic materials due to confined space [12]. The path available for volatilization will be less as compared to an uncovered structure. Hence the rate of volatilization is postulated to be slower than an open structure, and this in turn might affect the degree of fusion among $\mathrm{Cu}$ NPs if they are sintered under the same conditions as stated in Chapter 4. The different pathways for volatilizations under covered and uncovered structure are schematically presented in Figure 5.1.

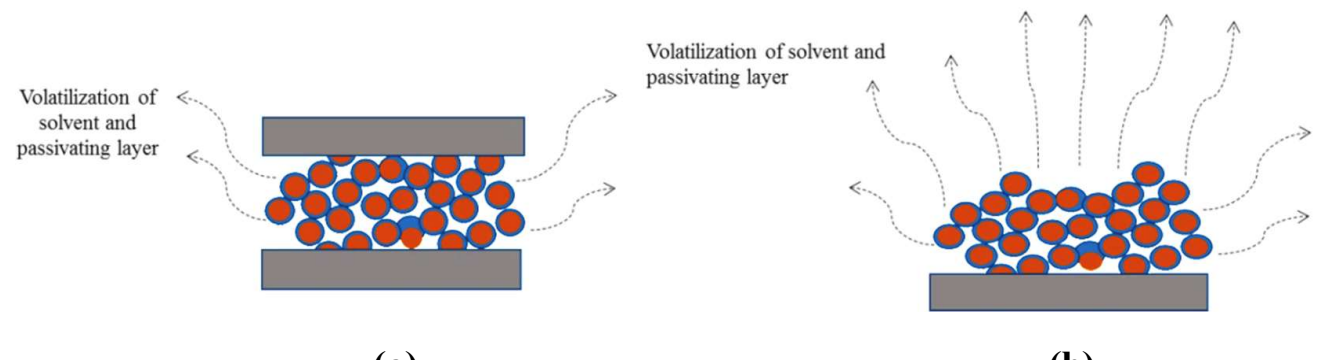

(a)

(b)

Figure 5.1 Schematic diagram of how the passivating layers on the Cu NPs escape under (a) covered and (b) uncovered structure

Since the volatilization may be more challenging under a covered structure, the optimum heating rate needs to be re-investigated. Prior to bonding, the microstructure of an un-sintered $\mathrm{Cu}$ NPs layer was characterized using FESEM coupled with FIB milling capability. This is to analyze the microstructure evolution of these covered $\mathrm{Cu}$ NPs before and after bonding at different heating rates. Small, individual and un-fused $\mathrm{Cu}$ NPs were observed as shown in Figure 5.2(a). The black regions that are shown in Figure 5.2(b) indicate the presence of organic materials before bonding. A zoom-in image of the joint layer, Figure 5.2(c), shows that there were different sizes of $\mathrm{Cu}$ NPs and no sign of necking 
$\underline{\text { Influence of Sintering Parameters of Cu NPs \& its Structure Stability Chapter } 5}$ among them. This indicates the effectiveness of the passivating layers in preventing spontaneous fusion of $\mathrm{Cu}$ NPs under ambient condition.

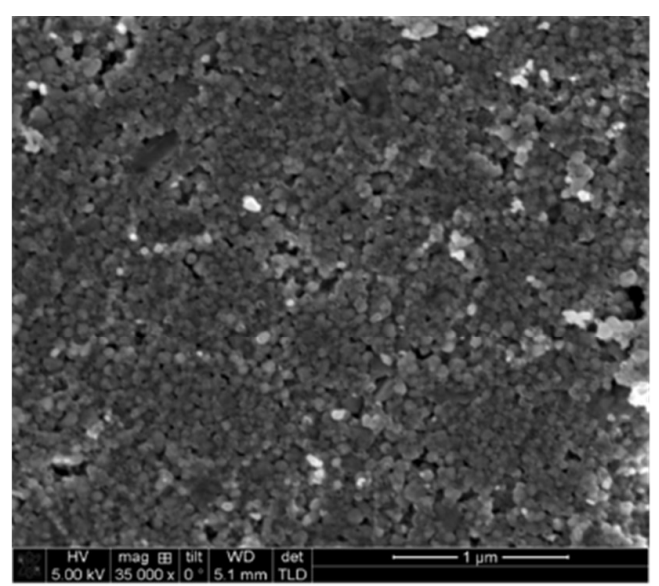

(a)

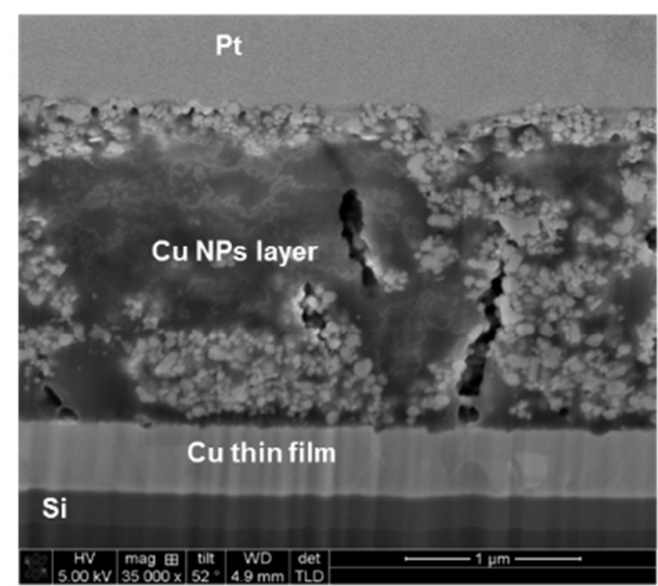

(b)

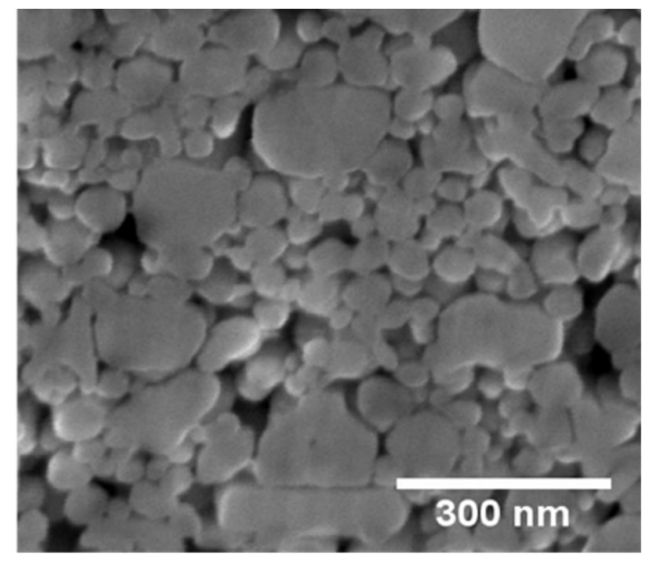

(c)

Figure 5.2 FESEM images of un-sintered Cu NPs. (a) Top view, (b) Cross sectioned and (c) Zoom in of the bonded layer

After bonding and shear testing, the shear strength of the sintered $\mathrm{Cu}$ joint and its corresponding microstructure from each heating rate are presented in Figure 5.3 and Figure 5.4, respectively. 
Influence of Sintering Parameters of Cu NPs \& its Structure Stability Chapter 5

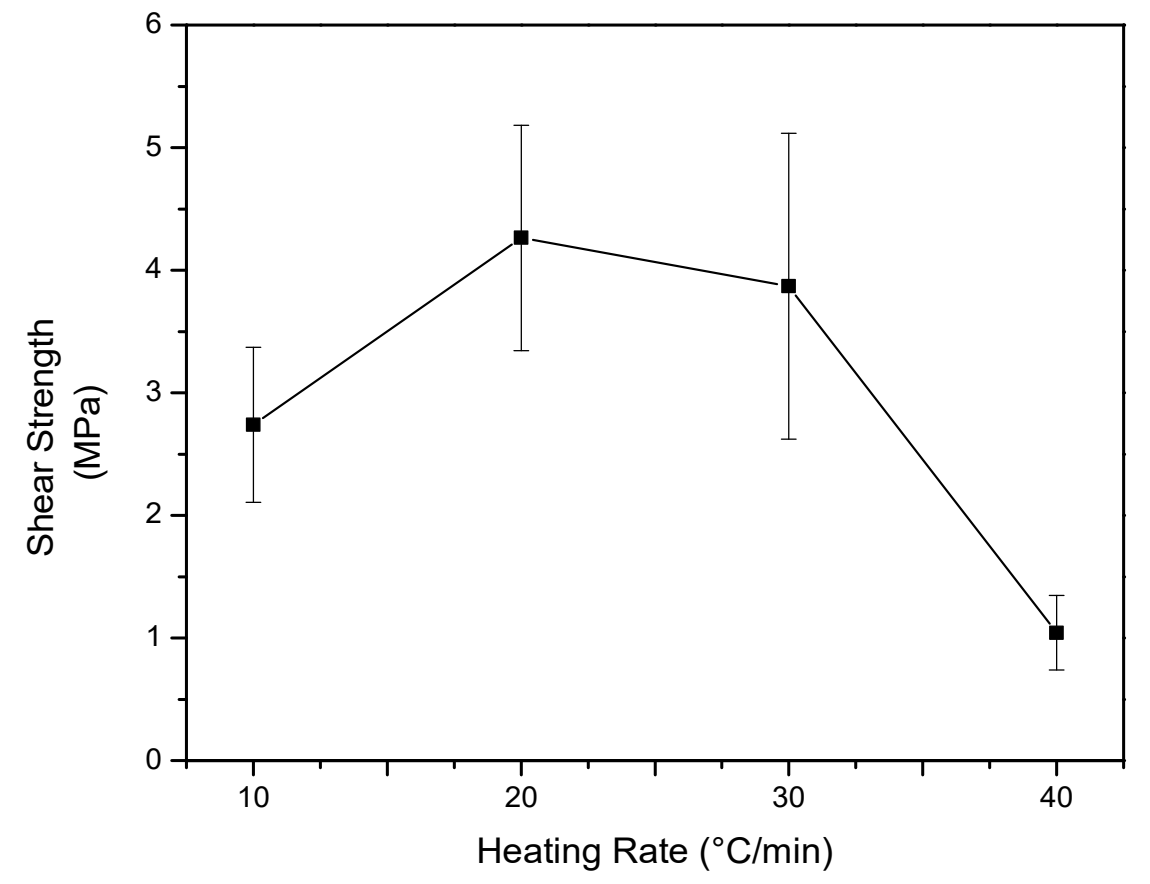

Figure 5.3 Shear strength of sintered $\mathrm{Cu}$ NPs joints at different heating rate 
$\underline{\text { Influence of Sintering Parameters of Cu NPs \& its Structure Stability Chapter } 5}$
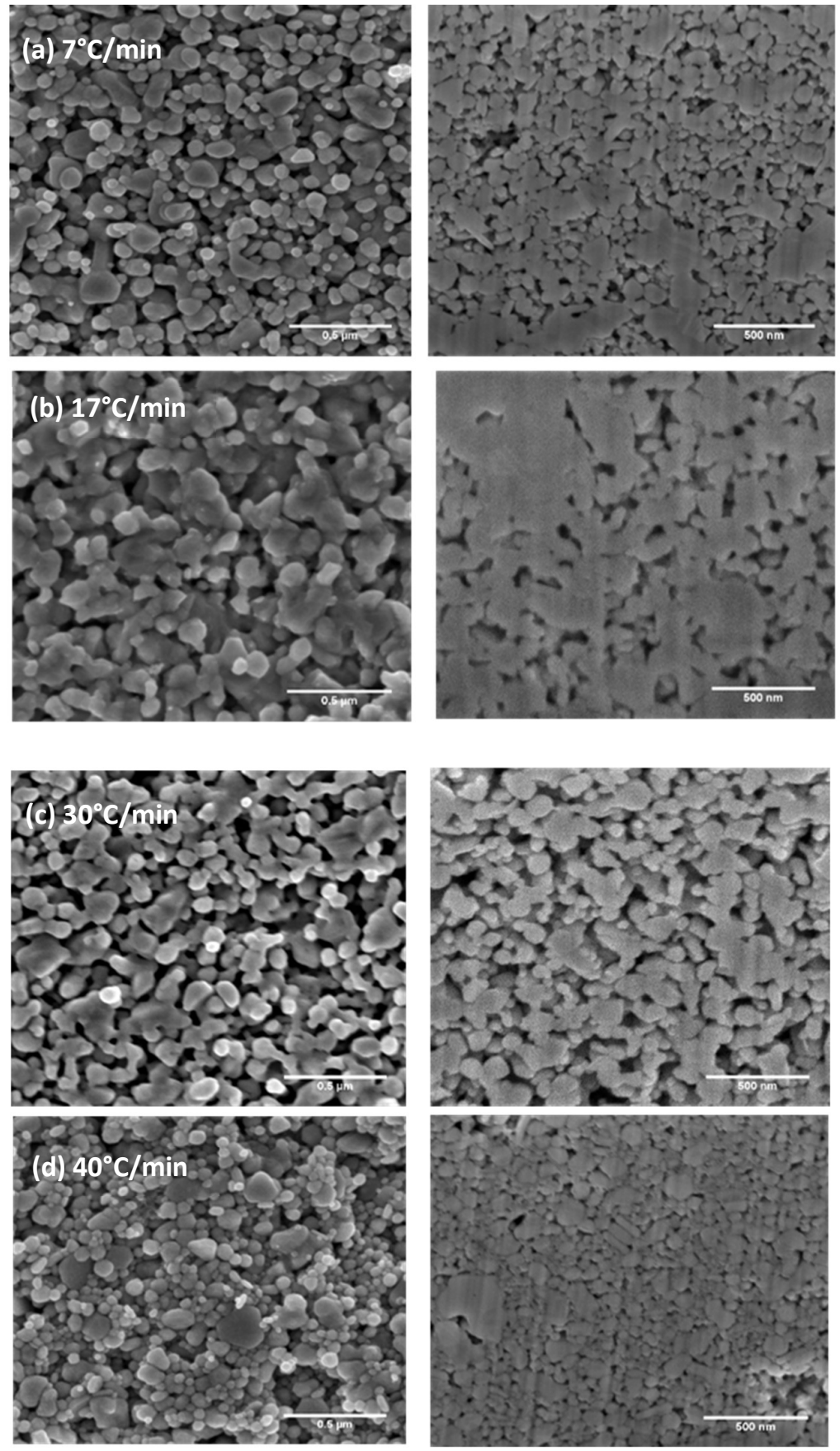

Figure 5.4 Microstructure of $\mathrm{Cu}$ NPs joint at ramping rate of (a) $7^{\circ} \mathrm{C} / \mathrm{min}$ (b)

$17^{\circ} \mathrm{C} / \mathrm{min}$ (c) $30^{\circ} \mathrm{C} / \mathrm{min}$ (d) $40^{\circ} \mathrm{C} / \mathrm{min}$ (Scale Bar: $500 \mathrm{~nm}$ )

A comparison between heating rate and shear strength shows that shear strength increases with increasing heating rate up till $17^{\circ} \mathrm{C} / \mathrm{min}$. However, as the heating rate increases beyond $17^{\circ} \mathrm{C} / \mathrm{min}$, the shear strength of the sintered $\mathrm{Cu}$ joint starts to drop. Further examination on the microstructure (Figure 5.4(c) and (d)), indicates that as the heating rate increases to $30^{\circ} \mathrm{C} / \mathrm{min}$ and beyond, there is little 
Influence of Sintering Parameters of Cu NPs \& its Structure Stability Chapter 5 or no fusion among some $\mathrm{Cu}$ NPs. This could perhaps be caused by incomplete removal and/or trapping of the organic materials within the $\mathrm{Cu}$ NPs layer due to shorter total cycle time and confined space. Though fast heating rate promotes denser structure due to minimization of aggregation during the heating up stage, it was reported that unstable volatilization at higher heating rates during bonding can cause cracks within the layer and weaken the joint strength $[8,12]$. Hence the rate of heating used should allow sufficient time for the removal of organic materials that leads to subsequent fusion yet minimize the formation of cracks within the layer that could affect the shear strength [21]. Since the presence of organic materials will impede NPs from fusing and thus affect densification, it will be particularly more critical for the covered structure to have a suitable heating rate that allows complete volatilization of organic materials and fusion of $\mathrm{Cu}$ NPs within a reasonable cycle time. In our study, we have observed that more necking, growth and densification of $\mathrm{Cu}$ NPs for samples bonded at $7^{\circ} \mathrm{C} / \mathrm{min}$ and $17^{\circ} \mathrm{C} / \mathrm{min}$ (Figure 5.4(a) and (b)) as compared to the higher heating rate samples (Figure 5.4(c) and (d)). However, if the heating rate was $7^{\circ} \mathrm{C} / \mathrm{min}$, after the passivating layers on the $\mathrm{Cu}$ NPs have volatilized at the lower temperature regime $\left(<150^{\circ} \mathrm{C}\right)$, these $\mathrm{Cu}$ NPs would start to fuse due to their high surface energy. It was reported that the coarsening of un-passivated $\mathrm{Ag}$ or $\mathrm{Cu}$ NPs is dominated by surface diffusion mechanism from room temperature to around $150^{\circ} \mathrm{C}[9,22]$. Since the removal of these passivating layers leads to fusion of the NPs, the onset temperature of volatilization of solvent and desorption of passivating layers is crucial. A lower onset temperature of volatilization and desorption of passivating layers will lead to the earlier removal of organic material and fusion to happen at the lower temperature regime, which leads to surface diffusion which was observed in Chapter 4. This is deemed undesirable as surface diffusion does not contribute to densification [23]. Hence, to enable further growth and densification, a higher thermal energy will be needed, i.e. $>200^{\circ} \mathrm{C}$. This is proven from the microstructural images of samples heated at $7^{\circ} \mathrm{C} / \mathrm{min}$ and $17^{\circ} \mathrm{C} / \mathrm{min}$ shown in Figure 5.4(a) and Figure 5.4(b). The average size of the fused $\mathrm{Cu}$ for $7^{\circ} \mathrm{C} / \mathrm{min}$ sample, Figure 5.4(a), is smaller than that of $17^{\circ} \mathrm{C} / \mathrm{min}$ sample (Figure 5.4(b)) though the total cycle time for sample heated at $7^{\circ} \mathrm{C} / \mathrm{min}$ is 15 minutes longer. The presence of unfused $\mathrm{Cu}$ NPs observed in $7^{\circ} \mathrm{C} / \mathrm{min}$ samples may provide a possible explanation on the lower 
$\underline{\text { Influence of Sintering Parameters of } \mathrm{Cu} \text { NPs \& its Structure Stability Chapter } 5}$ shear strength attained. With these results, it is noted that a heating rate of $17^{\circ} \mathrm{C} / \mathrm{min}$ is more suitable for the $\mathrm{Cu}$ NPs to be fused under covered structure. Such a heating rate is able to provide sufficient time for the removal of organic materials and yet at the same time able to keep the effective radius of the Cu NPs small up till the peak bonding temperature of $200^{\circ} \mathrm{C}$ for good fusion and densification.

\subsubsection{Effect of Bonding Temperature}

The fusion between these $\mathrm{Cu}$ NPs is dependent on the removal of the passivating layers. Subsequently when these passivating layers are removed, the onset of fusion will occur. From Chapter 4, it was suggested that the sintering mechanism is dominated by surface diffusion. Since both removal of passivating layers and fusion of $\mathrm{Cu}$ NPs are temperature dependent, a temperature higher than $200^{\circ} \mathrm{C}$ would increase the bond integrity. Hence, the mechanistic change in bond formation at different temperatures, its bond integrity and final microstructure will be investigated in this section.

Figure 5.5 shows the different microstructures of $\mathrm{Cu}$ NPs bonded at different temperatures. It is observed that the $\mathrm{Cu}$ NPs size and necking among particles increase with increasing temperature and time. Intuitively, a higher temperature will accelerate diffusion since it has an Arrhenius relationship, leading to more necking and bigger fused particles. With better fusion and bigger particle size, it would give a denser sintered layer that result in a higher bonding strength. 

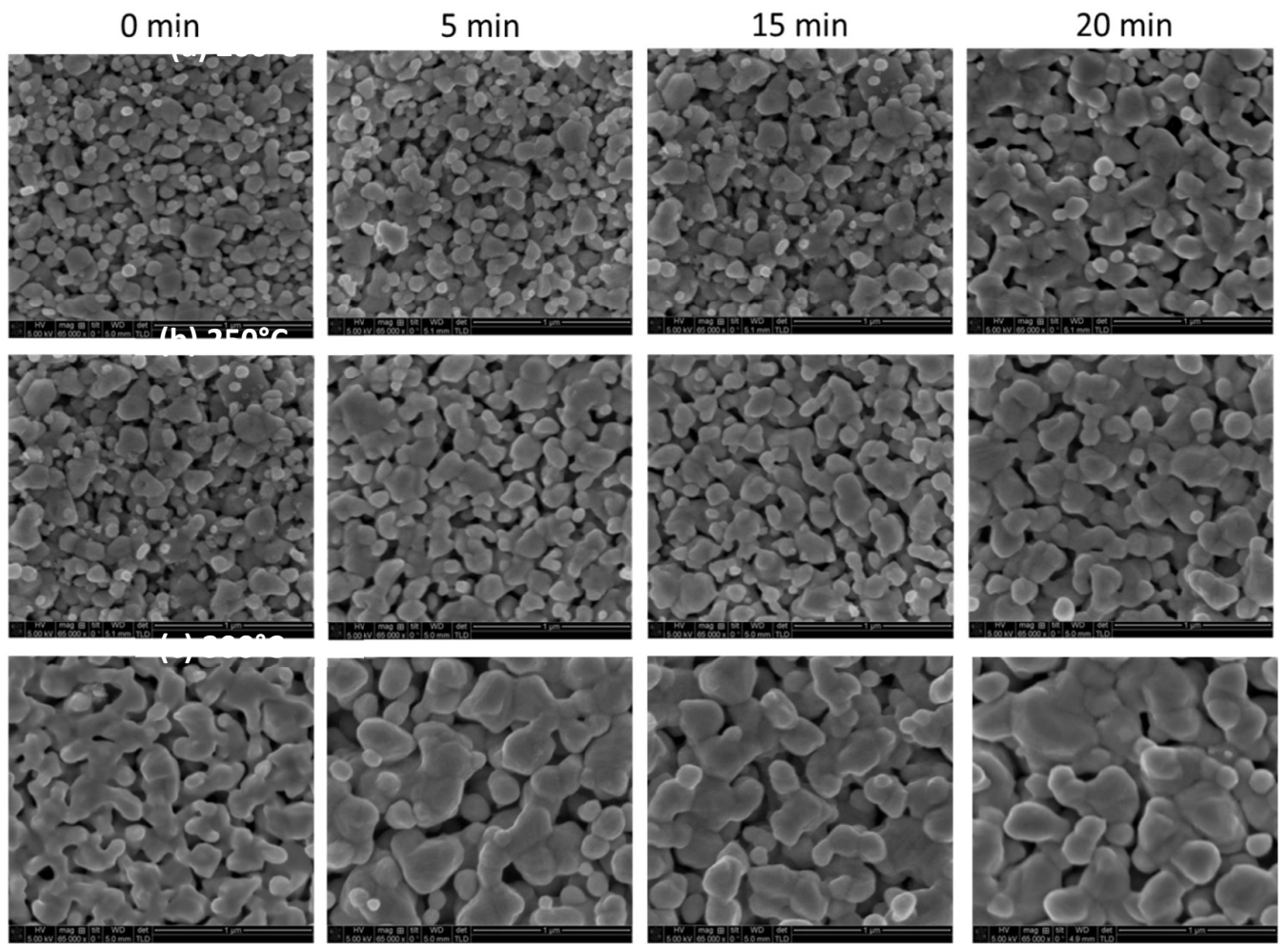

Figure 5.5 Microstructures evolution of $\mathrm{Cu}$ NPs bonded at (a) $200^{\circ} \mathrm{C}$ (b) $250^{\circ} \mathrm{C}$

(c) $300^{\circ} \mathrm{C}$ for $0-20 \mathrm{~min}$ (scale bar: $1 \mu \mathrm{m}$ )

The shear strength of the bonded samples from different bonding temperature was measured as shown in Figure 5.6. In addition, the average porosities were calculated based on the FESEM images shown in Figure 5.5. The cross-section image of each sample was taken and binarized using imaging software, ImageJ, which would make the $\mathrm{Cu}$ NPs appear black and pores as white. The porosities were then calculated using the particle analysis function found within ImageJ. To calculate the porosity of each condition, an average of 3 cross-sectioned SEM images were taken from each sample and plotted in Figure 5.7. 
$\underline{\text { Influence of Sintering Parameters of } \mathrm{Cu} \text { NPs \& its Structure Stability Chapter } 5}$

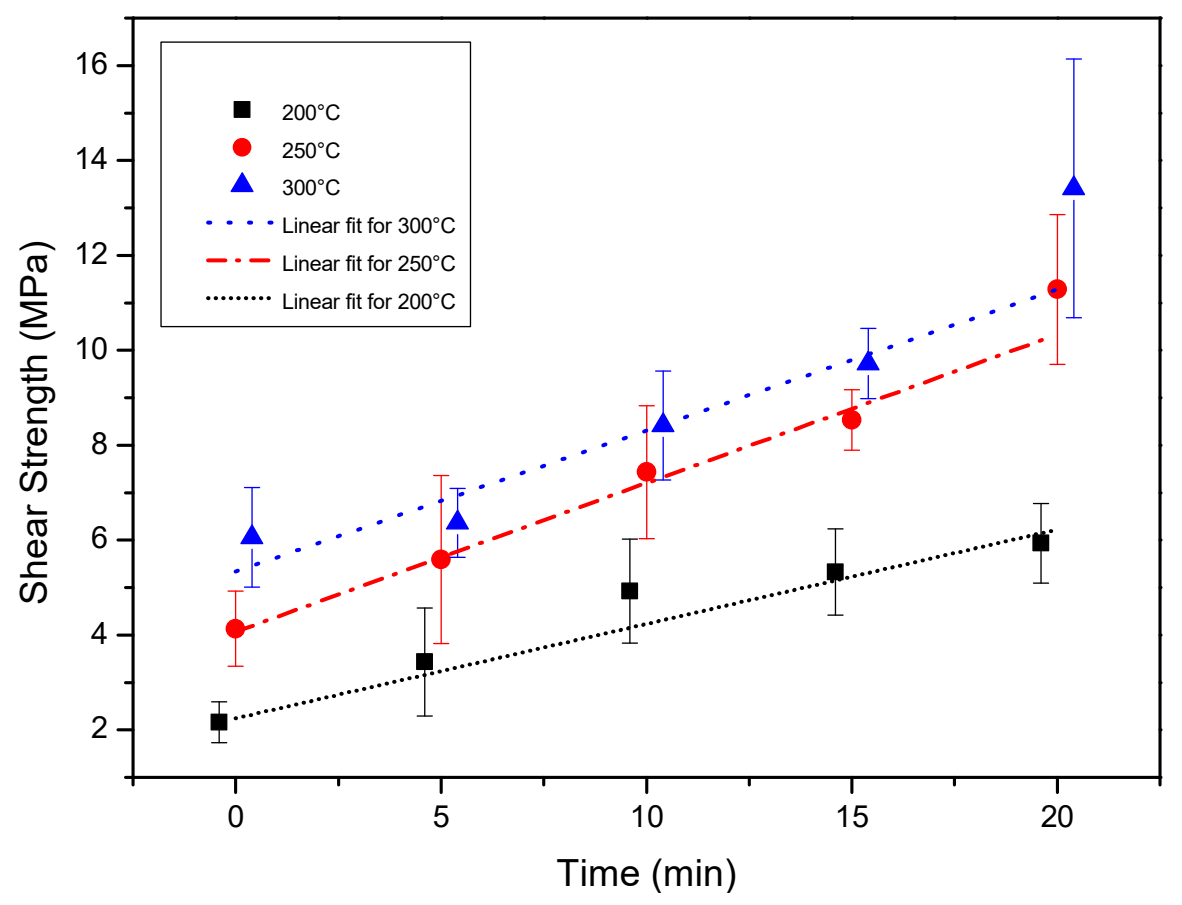

Figure 5.6 Shear Strength as a function of isothermal duration at $200^{\circ} \mathrm{C}, 250^{\circ} \mathrm{C}$ and $300^{\circ} \mathrm{C}$

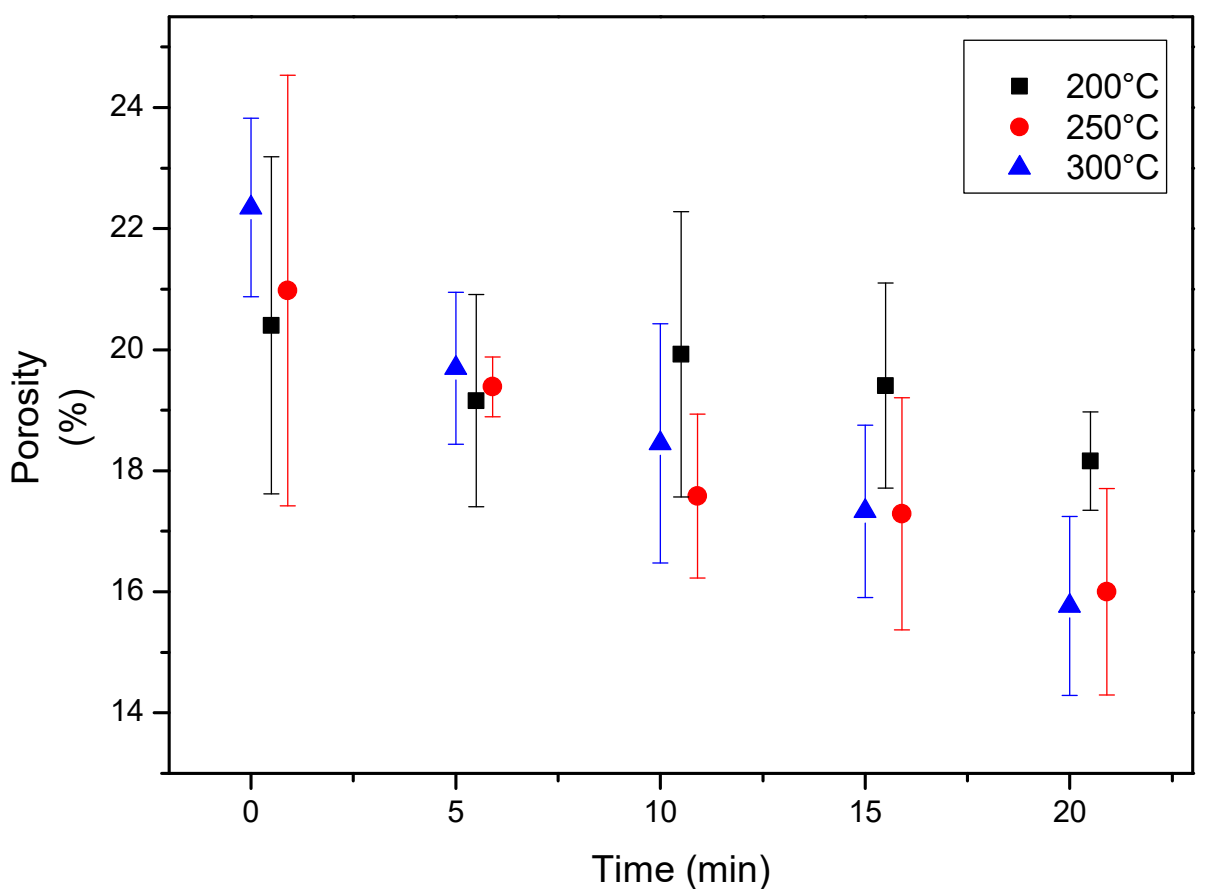

Figure 5.7 Porosity of Cu NPs layer with respect to time for samples bonded at $200^{\circ} \mathrm{C}, 250^{\circ} \mathrm{C}$ and $300^{\circ} \mathrm{C}$ 
Influence of Sintering Parameters of Cu NPs \& its Structure Stability Chapter 5 From the bond strength and porosity results, there are 2 major observations. When bonding is done at higher temperature, the bond strength increases faster with increasing bonding time. This rate of improvement is represented by the slope of the curve shown in Figure 5.6. This trend was also observed in Nichting et. al. [24] study whereby for low processing temperature $\left(<200^{\circ} \mathrm{C}\right)$, prolong annealing does not have significant improvement to bond integrity.

To correlate porosity with shear strength, it is observed that the change in percentage of porosity with time across these three temperatures is very different as well. For samples bonded at $250^{\circ} \mathrm{C}$ and $300^{\circ} \mathrm{C}$, the amount of porosity decreases with time due to densification which could explain the increase in shear strength. However, the changes in porosity with time for the $200^{\circ} \mathrm{C}$ samples were small. This could be due to the lower bonding temperature that is insufficient for densification mechanism to take place. This again proves that prolong isothermal annealing for low temperature bonding is not as effective as high temperature $\left(>200^{\circ} \mathrm{C}\right)$ bonding.

However, care has to be taken when correlating porosity with shear strength. This is because when the $\mathrm{Cu}$ NPs were sintered at $300^{\circ} \mathrm{C}$, it has the highest amount of porosity at the start of isothermal annealing. However, it also accounts for the highest bond strength ( $\sim 6 \mathrm{MPa})$ as compared to the $\mathrm{Cu}$ NPs sintered below $300^{\circ} \mathrm{C}$. Such observation can be explained from the microstructures as shown in Figure 5.5. Though $300^{\circ} \mathrm{C}$ has the highest percentage of porosity, the neck size and amount of necking in the sintered $\mathrm{Cu}$ NPs was also bigger and higher. Though the porosity of samples sintered at $200^{\circ} \mathrm{C}$ was close to the samples sintered at $250^{\circ} \mathrm{C}$, small spherical $\mathrm{Cu}$ NPs with minimum necking were observed up till 15 minutes of isothermal annealing. Hence this resulted in a lower bond strength for samples sintered at $200^{\circ} \mathrm{C}$. These results show that using the amount of porosity to correlate with shear strength can be very misleading if the degree and number of necking across sintered layer is not taken into consideration when comparison is made.

\subsubsection{Effect of Applied Pressure}

Though with the increase in bonding temperature can lead to better bond integrity, low temperature bonding is still very much preferable as some 
$\underline{\text { Influence of Sintering Parameters of Cu NPs \& its Structure Stability Chapter } 5}$ substrates are temperature sensitive and a lower processing temperature is more economical. Many studies have reported that the addition of pressure could help to break down the organic layers on the NPs locally. This increases the number of contact points among adjacent particles and bonding interface for better fusion that eventually leads to a denser structure with a better joint strength since the total contact area has increased $[11,21,25]$. This is schematically represented in Figure 5.8. With the introduction of pressure, it helps to increase the sintering rate as materials are brought closer which increases the number of pathways and reducing the distance for atomic diffusion and thus increases the overall driving force for sintering $[11,26,27]$. Thus, sintering of these NPs can be done with a lower thermal budget. In order to make this applied pressure the critical factor affecting NPs fusion, it has to be larger than the intrinsic pressure within the material itself. This intrinsic pressure is dependent on the particle size. It has been reported that there is an increasing contribution from the surface curvature as the particle gets smaller. This could provide an explanation for the lower bonding pressure needed for NPs sintering as compared to micro-sized powder sintering [28].

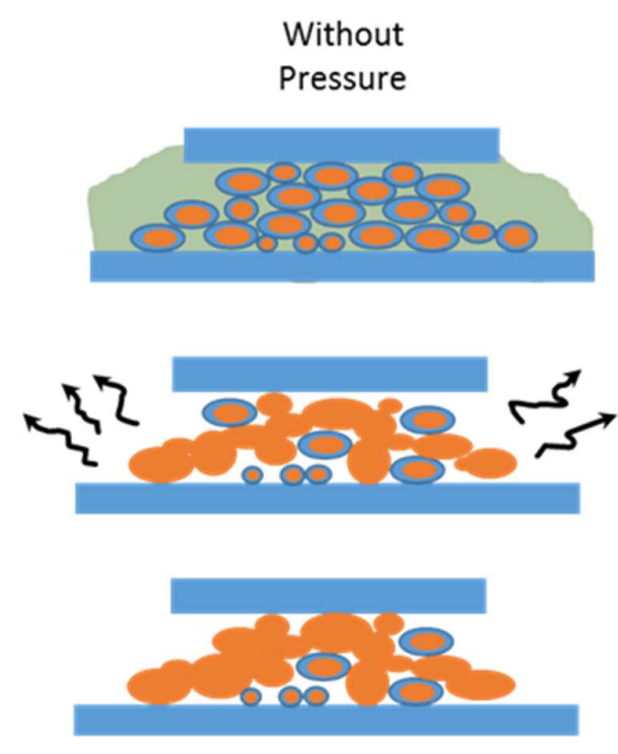

With Pressure
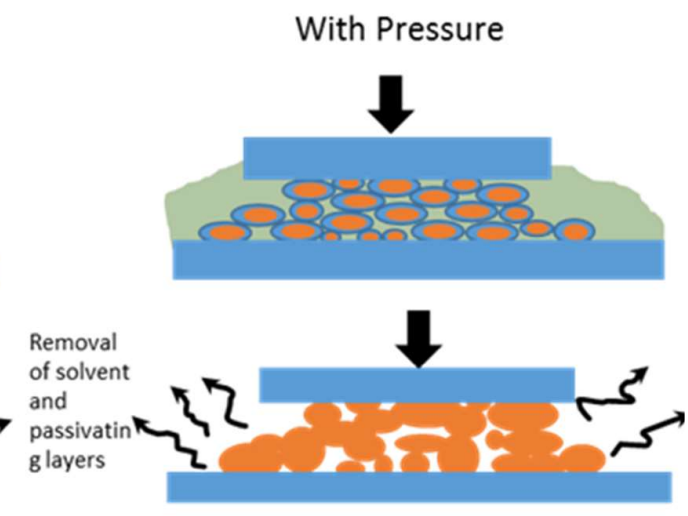

Figure 5.8 Schematic diagram of bonding without and with bonding pressure exerted 
Based on Mo et al. [29] study, a linear relationship between contact area and joint strength exists which determines the bond integrity. Such a relation can be represented as

$$
F=k A_{c}
$$

where $F$ is the joint strength, $k$ is the proportional constant and $A_{c}$ is the contact area.

Assuming that all organic materials are removed and the surfaces of $\mathrm{Cu}$ NPs are free of oxide and other impurities, the increase in neck formation and growth when a bonding load is applied will bring these $\mathrm{Cu}$ NPs closer to one another for better diffusion. This will lead to some material deformation that can increase the contact area and thus result in joint strength improvement $[11,30]$.

Under a constant load during bonding, the duration of bonding and the amount of pressure exerted could allow these $\mathrm{Cu}$ NPs to come into contact with one another or with the bonding substrate. The overall increase in contact area can be due to diffusional mechanism or creep deformation if the pressure exerted exceeds the intrinsic pressure of the $\mathrm{Cu}$ NPs. 


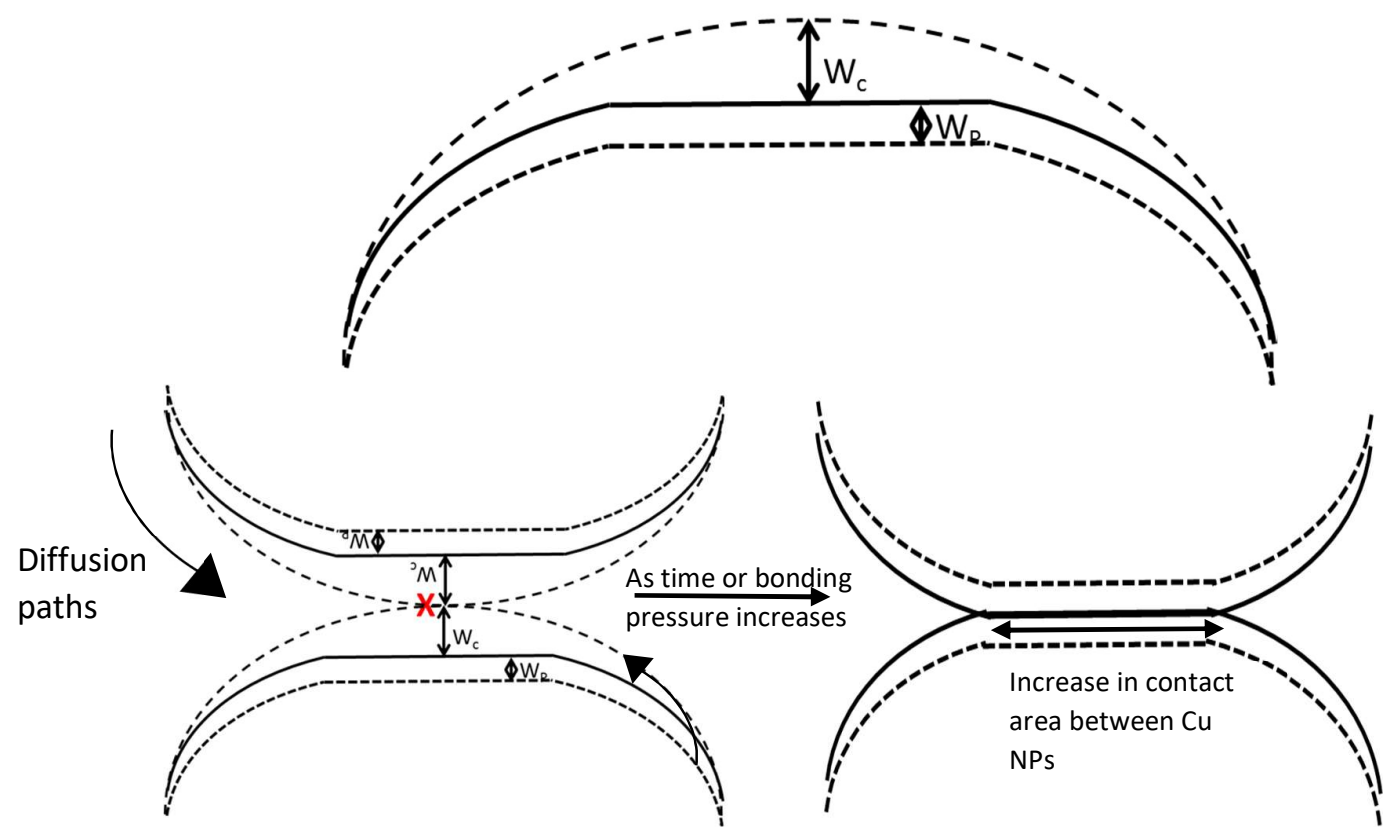

Figure 5.9 Schematic diagram of deformation between $\mathrm{Cu}$ NPs

As shown schematically in Figure 5.9, when the applied pressure did not exceed the intrinsic pressure, the contact area between bonding surface would not be maximized as it would be purely driven by Van der Waals force as marked by $\mathrm{x}$ in Figure 5.9. Hence, any increase in contact area is purely due to diffusional mechanism and the amount of atoms taking part in the diffusion process could be low. However, when bonding pressure is introduced or increased, the amount of deformation, $w$, will increase and when $w$ has reached or has gone beyond the critical deformation, termed as $w_{c}$, some form of deformation is observed and an increase in contact area has resulted. This will increase the number of atoms taking part in the diffusion process and at the same time increases the rate of diffusion.

From the above explanation, such deformation of the $\mathrm{Cu}$ NPs at the bonding interfaces and between $\mathrm{Cu}$ NPs can also increase the van der Waals force between bonding surfaces as the distance between $\mathrm{Cu}$ NPs and bonding substrate is now closer. As reported by Joo et. al [31], one of the factors that cause particle adhesion through van der Waals forces is the distance between bonding surfaces. Hence by introducing some bonding pressure, these $\mathrm{Cu}$ NPs are brought closer towards the surface of the bonding substrate and other $\mathrm{Cu}$ NPs which therefore 
Influence of Sintering Parameters of Cu NPs \& its Structure Stability Chapter 5 helps to enhance adhesion through the increase in van der Waals forces. In addition, the shorter distance between bonding surfaces can also increase the possibility of diffusion interfacial reaction as explained in Chapter 4. As bonding pressure and time increase further, the amount of deformation as illustrated in Figure 5.9, w, will increase. When this deformation goes beyond the critical deformation, termed as $w_{c}$, some form of deformation can be observed. Hence there could be a change from initial diffusional mechanism to creep deformation when external pressure is exerted [32]. It is reported that for metals, power-law creep is usually the dominant densification mechanism when external pressure is used during sintering [33]. This eventually can help to improve the overall joint integrity since the overall contact area of bonding surfaces have increased.

Hence, experimental studies were carried out in this section to study the effect of bonding pressure on the joint strength and to find out the dominant sintering mechanism (diffusional or creep) under different bonding pressure. These samples were bonded with a bonding pressure between $0-5 \mathrm{MPa}$ and held isotherm at $200^{\circ} \mathrm{C}$ for $0-20$ minutes. It is observed that these $\mathrm{Cu}$ NPs will selffuse even without application of any bonding pressure due to the high surface energy that comes from the surface curvature and van der Waals forces between $\mathrm{Cu}$ NPs and substrate that increases surface diffusion (Figure 5.10). However, the failure location of these pressureless bonded samples during shear test occurs mainly at the bonding interfaces. In addition, the contact between fused Cu NPs and the bonding interfaces were weak leading to adhesive failure. Figure 5.10 shows that by adding a relatively low bonding pressure of $1 \mathrm{MPa}$, it will cause the average shear strength to increase by more than $100 \%$ as compared to pressureless bonding. This improvement in strength could possibly be due to two reasons. One is that when pressure is added, it can help to break down the passivation layers and aid the physical desorption of these passivating layer from the $\mathrm{Cu}$ NPs surfaces during fusion [26]. When this happened, these organic materials are detached from the Cu NPs surfaces to enable fusion among Cu NPs to occur. The second possible reason could be the exertion of pressure during bonding increases the number of contact areas among adjacent $\mathrm{Cu}$ NPs and $\mathrm{Cu}$ NPs/bonding surfaces as it brings the $\mathrm{Cu}$ NPs and bonding surfaces closer to one another to enhance diffusion. The thickness of the joint was also reduced and the 
Influence of Sintering Parameters of Cu NPs \& its Structure Stability Chapter 5 spread of $\mathrm{Cu}$ NPs was more even due to the introduction of pressure during bonding. This could eventually help to form stronger bonds as the removal of organic layer is easier for thinner joint and the wettability between chip and substrate has improved. In addition, it was reported that the shear strain induced by bonding pressure tends to aid in the rearrangement of the NPs to form a denser structure, better grain alignment and minimizes the size of the pores formed [26]. However, no sign of ductile failure was observed on the fracture surfaces for samples that were bonded with a pressure between 1-3 MPa though an increase in shear strength was observed (Figure 5.11(a) - (c)). This means that the increase in shear strength could just be attributed to diffusional dominated mechanism with no plastic deformation. On the contrary, as pressure increases to $5 \mathrm{MPa}$, sign of plastic deformation as shown in the corresponding microstructures in Figure 5.11(d) was observed on the failure surface. In addition, from the microstructural images shown in Figure 5.11, it is noted that as pressure increases, the layer did become more densified i.e. less porous. However, plastic deformation on the $\mathrm{Cu}$ NPs failure surfaces was only observed when $5 \mathrm{MPa}$ of pressure was added (Figure 5.11(d)). This could mean that the deformation, $w$ has gone beyond the critical deformation, $w_{c}$ and a combination of diffusional fusion and plastic deformation could have taken place and increases the contact area between $\mathrm{Cu}$ NPs to improve the bonding at the interfaces and between $\mathrm{Cu}$ NPs. A handful of researchers had reported that with the formation of such dimple-like morphology, it would result in higher bonding strength as it indicates ductile failure which was torn off by shear stress $[1,4,34]$. Therefore, a minimum bonding pressure of $5 \mathrm{MPa}$ is needed to overcome the intrinsic pressure of the $\mathrm{Cu}$ NPs for stronger joints.

From the FESEM images of both the failure surface and cross-sectional area, all the $\mathrm{Cu}$ NPs had fused well (Figure 5.11). Hence porosity comparison can be done across these samples. To quantify the amount of porosity, the percentage of porosity was again calculated using imaging technique. Cross-sectioned FESEM images of the sheared samples from different bonding pressure were used. The black regions shown in the FESEM images were taken to be the porosities of the sintered layer. Therefore, from the porosity percentage curve shown in Figure 5.10, an inverse relationship between shear strength and 
$\underline{\text { Influence of Sintering Parameters of Cu NPs \& its Structure Stability Chapter } 5}$ porosity was observed. A lower percentage of porosity will see a higher shear strength as the degree of densification of the sintered layer is deemed to be higher. Hence with the introduction of an external pressure, it might be able to bring these $\mathrm{Cu}$ NPs and bonding surfaces closer to one another for better fusion during bonding.

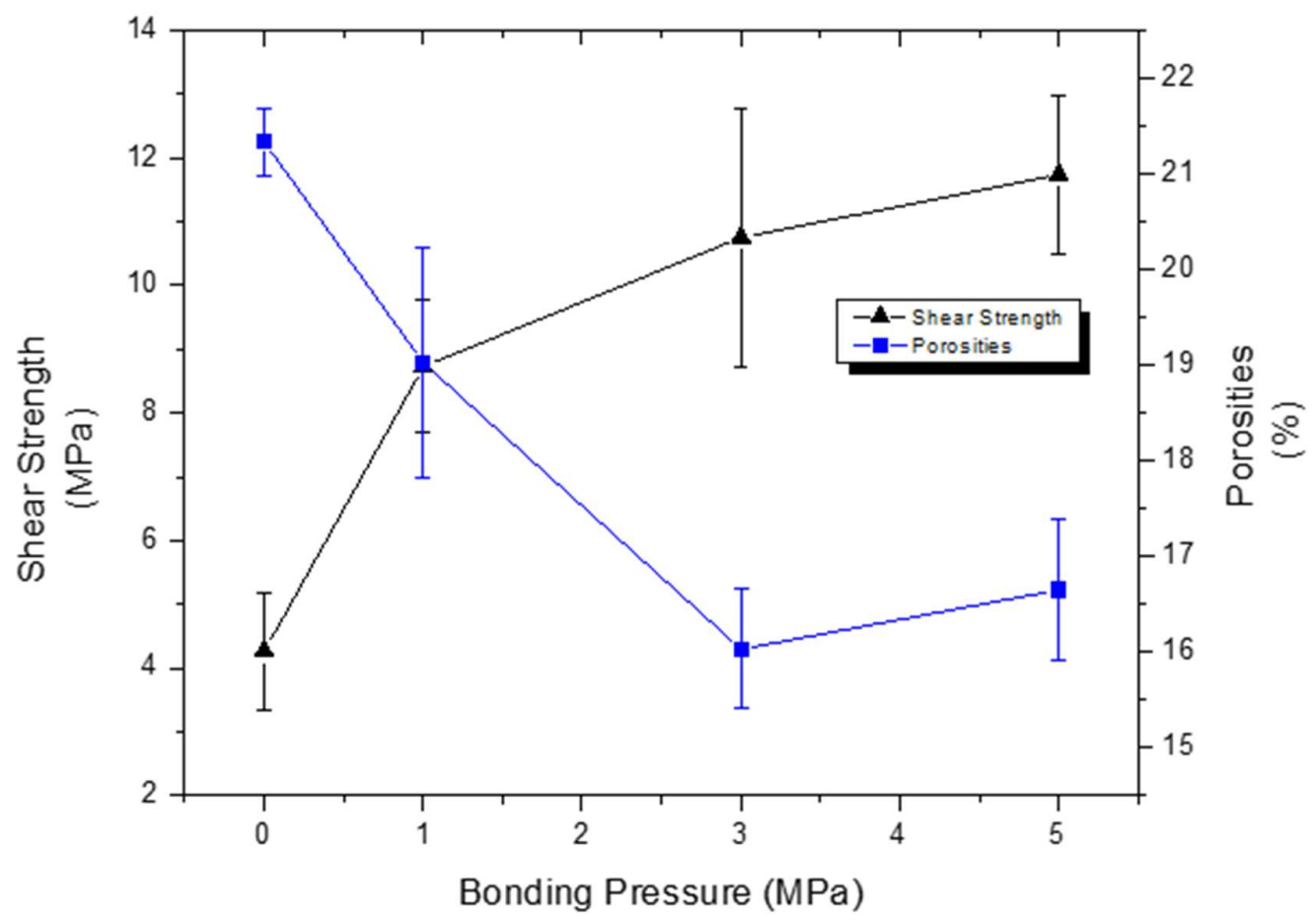

Figure 5.10 Relationship between shear strength and porosity as a function of bonding pressure 
Influence of Sintering Parameters of $\mathrm{Cu}$ NPs \& its Structure Stability Chapter 5

(a) $0 \mathrm{MPa}$
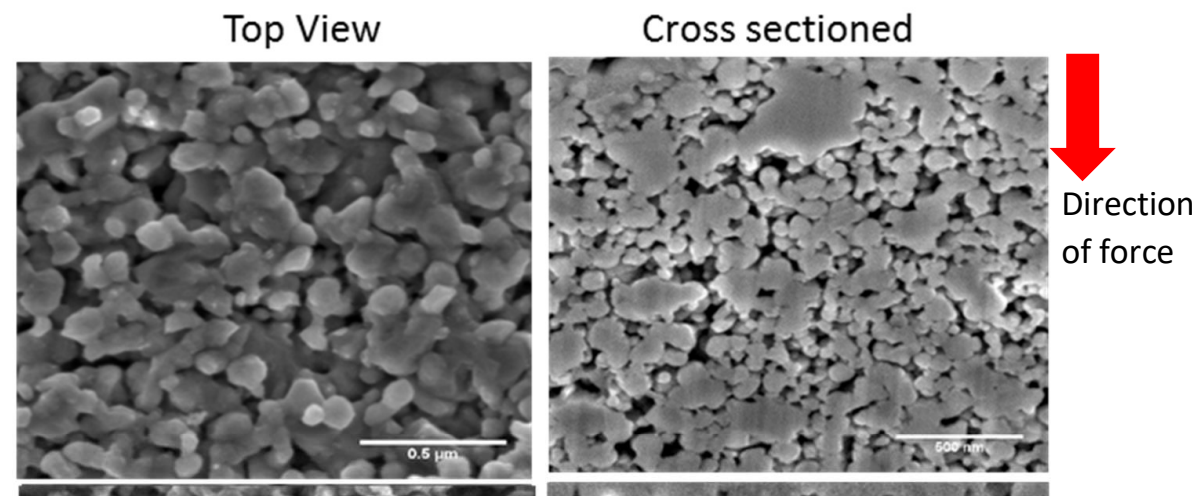

(b) $1 \mathrm{MPa}$
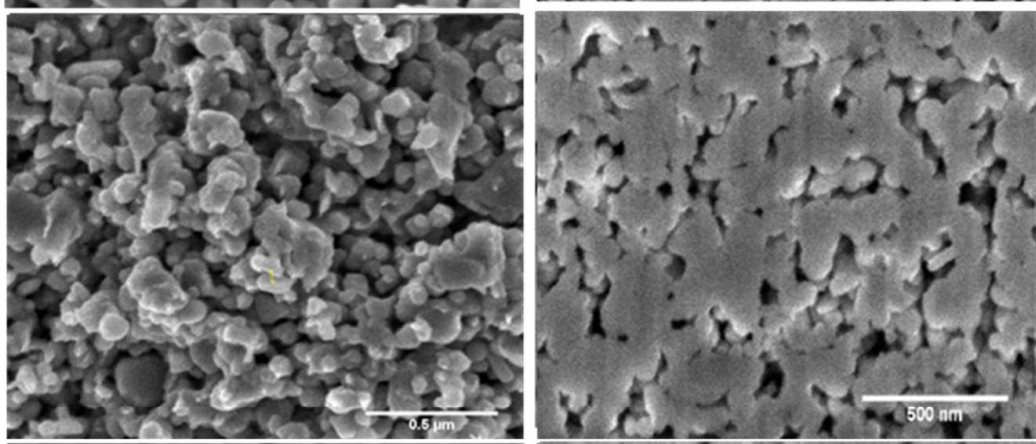

(c) $3 \mathrm{MPa}$
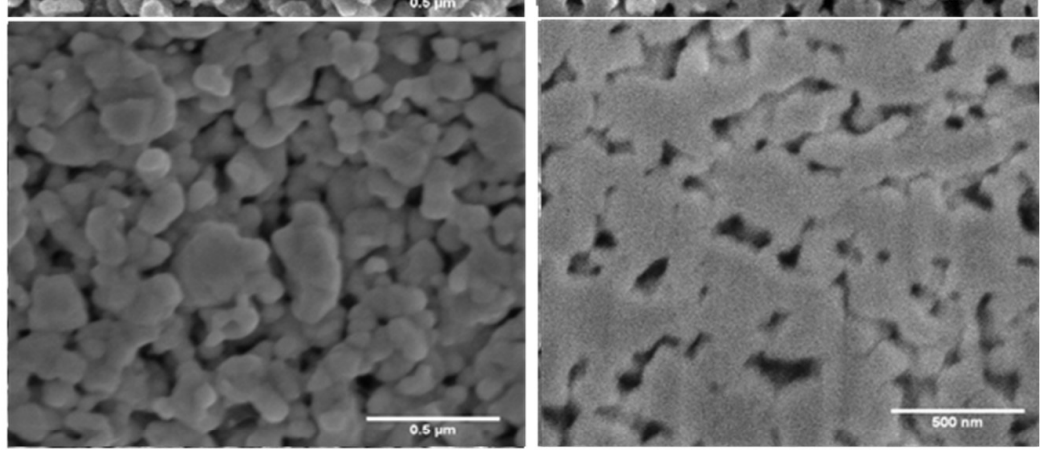

(d) $5 \mathrm{MPa}$
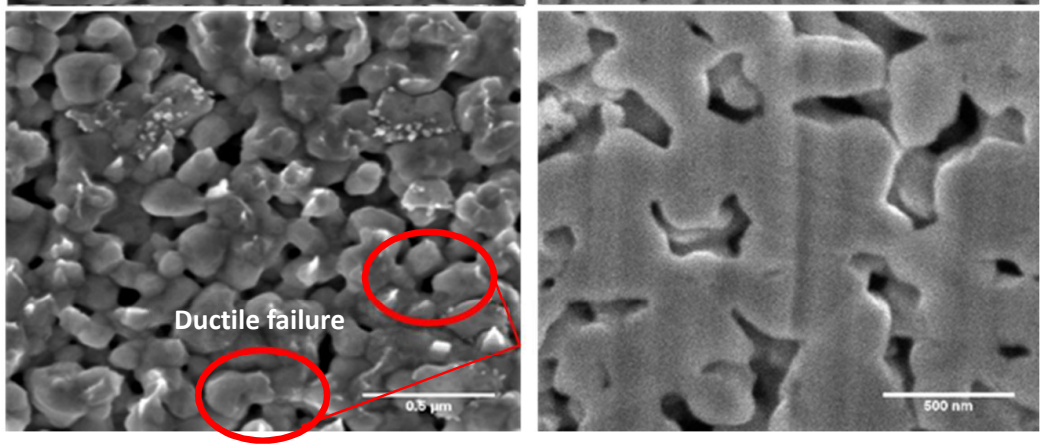

Figure 5.11 FESEM images of fracture surfaces and cross sectioned of sintered Cu joints at (a) 0 MPa (b) 1 MPa (c) 3 MPa (d) 5 MPa (Scale bar of $500 \mathrm{~nm}$ )

With the introduction of a small amount of pressure $(\sim 1-5 \mathrm{MPa})$, it is also observed that the improvement in shear strength can be due to better bonding between $\mathrm{Cu}$ NPs and the bonding surfaces. When pressure is applied, it is sufficient to bring the $\mathrm{Cu}$ NPs closer, thus increases the number of contact points 
$\underline{\text { Influence of Sintering Parameters of Cu NPs \& its Structure Stability Chapter } 5}$ or area between $\mathrm{Cu}$ NPs for better diffusion. If the pressure exerted exceeds the threshold stress, further material deformation will increase the contact area. Cross-sectioned FESEM images of the sintered $\mathrm{Cu}$ layer with the bonding interface (with and without pressure) are shown in Figure 5.12. It is observed that the number of voids between sintered $\mathrm{Cu}$ NPs and bonding interface decreases with the introduction of pressure, which changes the failure mode to cohesive failure.
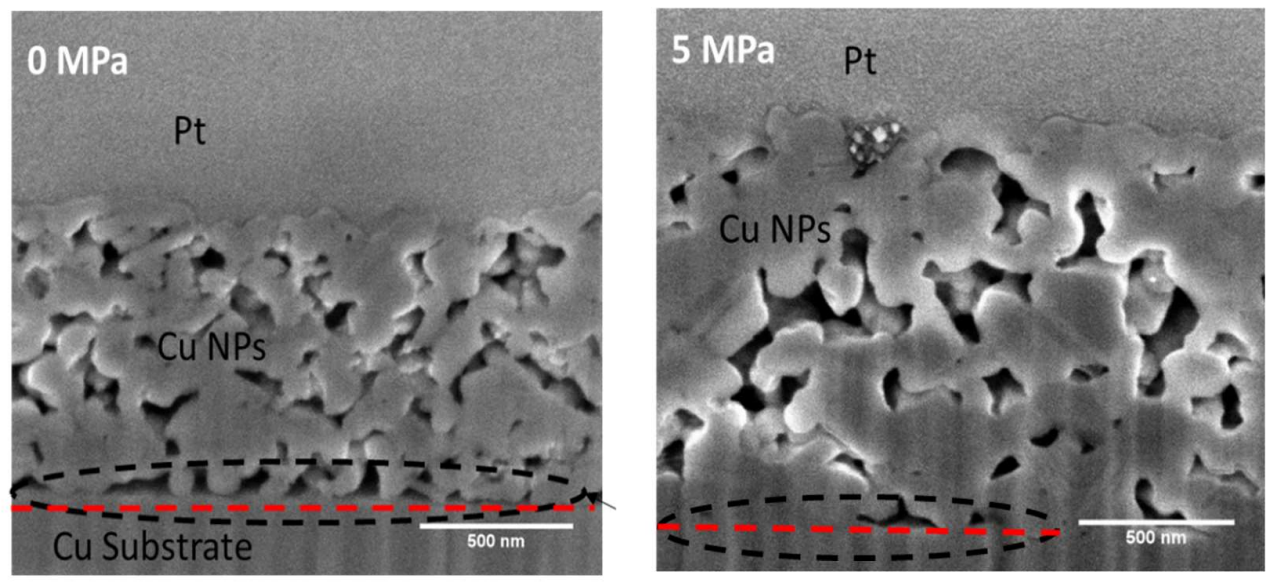

Figure 5.12 Cross-sectioned FESEM images of sintered $\mathrm{Cu}$ with and without pressure

Though $5 \mathrm{MPa}$ seems to be the threshold pressure that could effectively cause plastic deformation of $\mathrm{Cu}$ NPs and enhance joint integrity, it is also dependent on the bonding temperature, density of Cu NPs, type of passivation layers used and size of the $\mathrm{Cu}$ NPs.

\subsubsection{Effect of Bonding Environment}

Though the application of pressure can produce a stronger bonded joint at $200^{\circ} \mathrm{C}$, pressureless bonding may still be preferred in certain applications. Hence, based on the data gathered in previous sections, the rate and effectiveness in removing the passivating layers remains the key determining factor for joint integrity.

Based on the results gathered in Chapter 4, it was established that the removal of passivating layers is fast and effective under formic acid vapor as compared to under $\mathrm{N}_{2}$ environment. In addition, a higher heating rate is good as it 
Influence of Sintering Parameters of $\mathrm{Cu}$ NPs \& its Structure Stability Chapter 5 minimizes aggregation of the $\mathrm{Cu}$ NPs during the temperature ramp up stage, hence densification would only occur at the peak bonding temperature. Based on this knowledge, a heating rate of $40^{\circ} \mathrm{C} / \mathrm{min}$ was chosen and introduction of formic acid vapor only at the peak bonding temperature of $200^{\circ} \mathrm{C}$ was designed.

In Figure 5.13, it is observed that the shear strength of the bonded joint increases by threefold when bonding was done under formic acid vapor environment. A closer look at the corresponding microstructures in Figure 5.14 shows that the $\mathrm{Cu}$ NPs are well-fused though a higher heating rate of $40^{\circ} \mathrm{C} / \mathrm{min}$ was used, and the total process time was only 14 minutes.

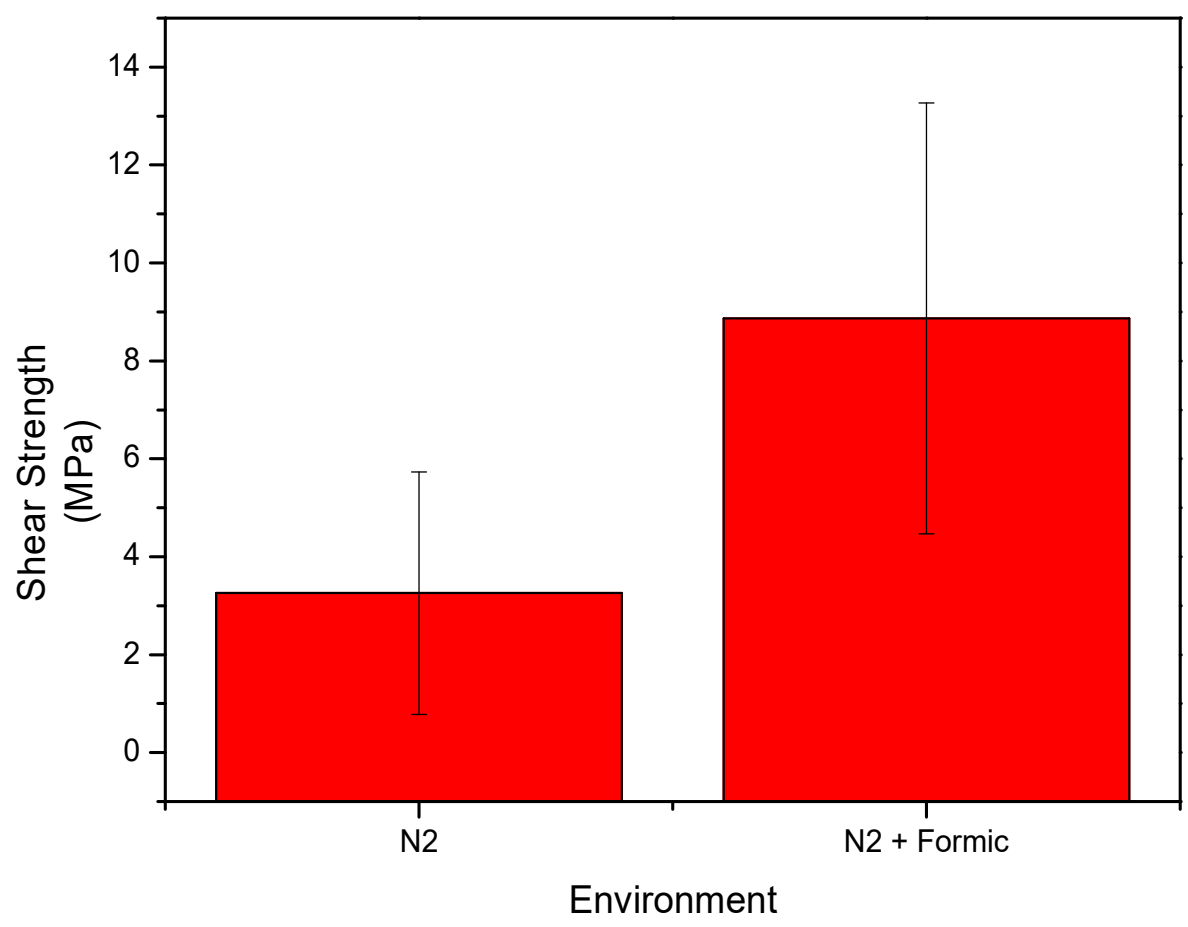

Figure 5.13 Shear Strength of Cu NPs joint under $\mathrm{N}_{2}$ and Formic Acid 
(a)

$$
\mathrm{N}_{2} \quad \text { Top view }
$$
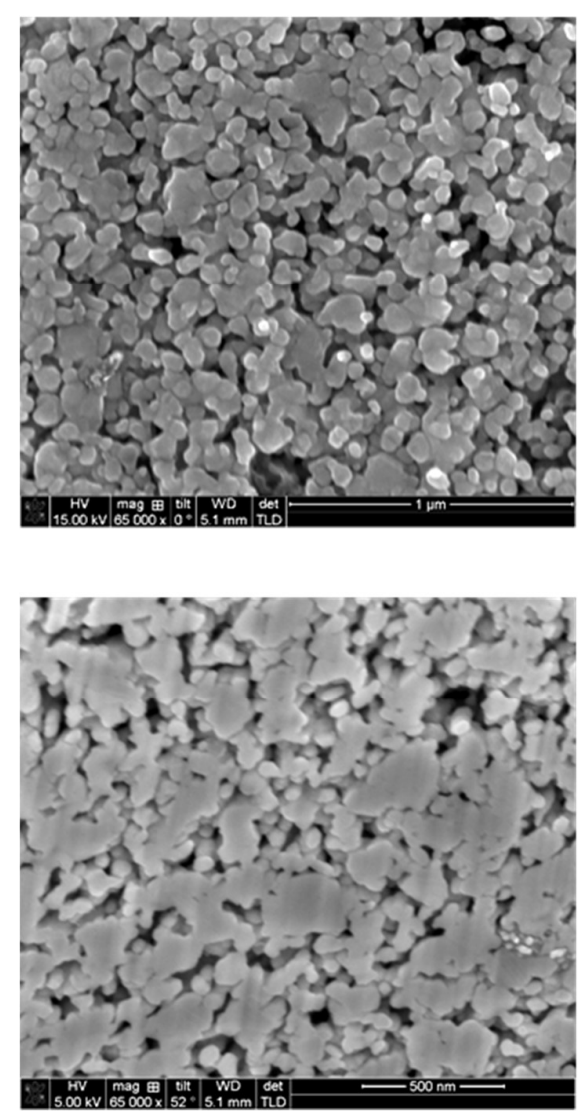

(b)

$$
\begin{aligned}
& \mathrm{N}_{2}+1 \text { (erbss- sectioned } \\
& \mathrm{HCOOH}
\end{aligned}
$$
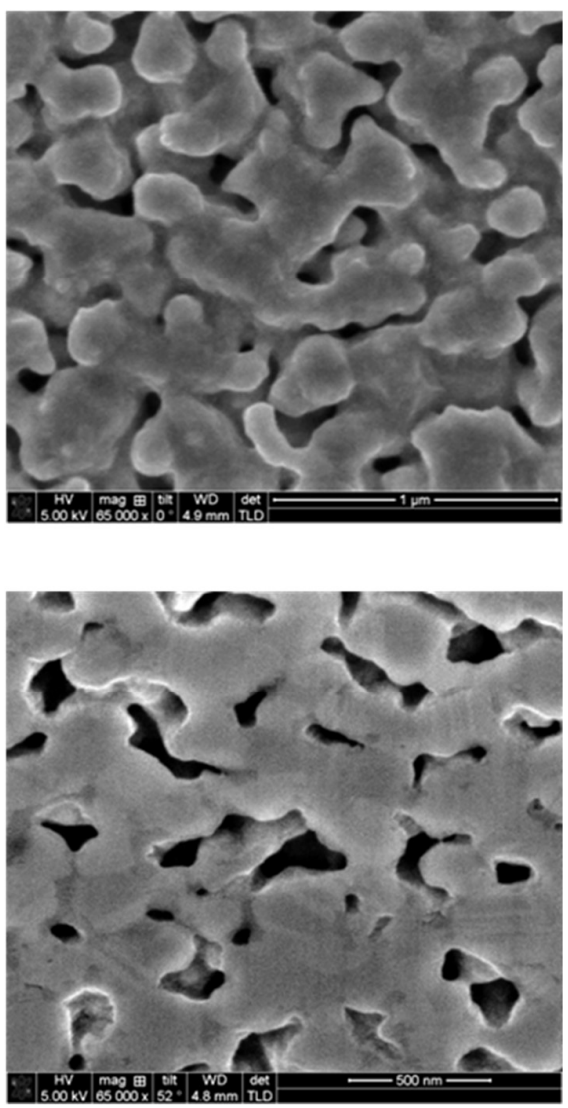

Figure 5.14 Microstructures of the sintered Cu NPs under (a) $\mathrm{N}_{2}$ and (b) formic acid vapor

To explain the significant improvement in joint strength, in-situ electrical resistance measurement was deployed to understand the fusion mechanism as adopted in section 4.2.1.2 (Figure 5.15). 
$\underline{\text { Influence of Sintering Parameters of } \mathrm{Cu} \text { NPs \& its Structure Stability Chapter } 5}$

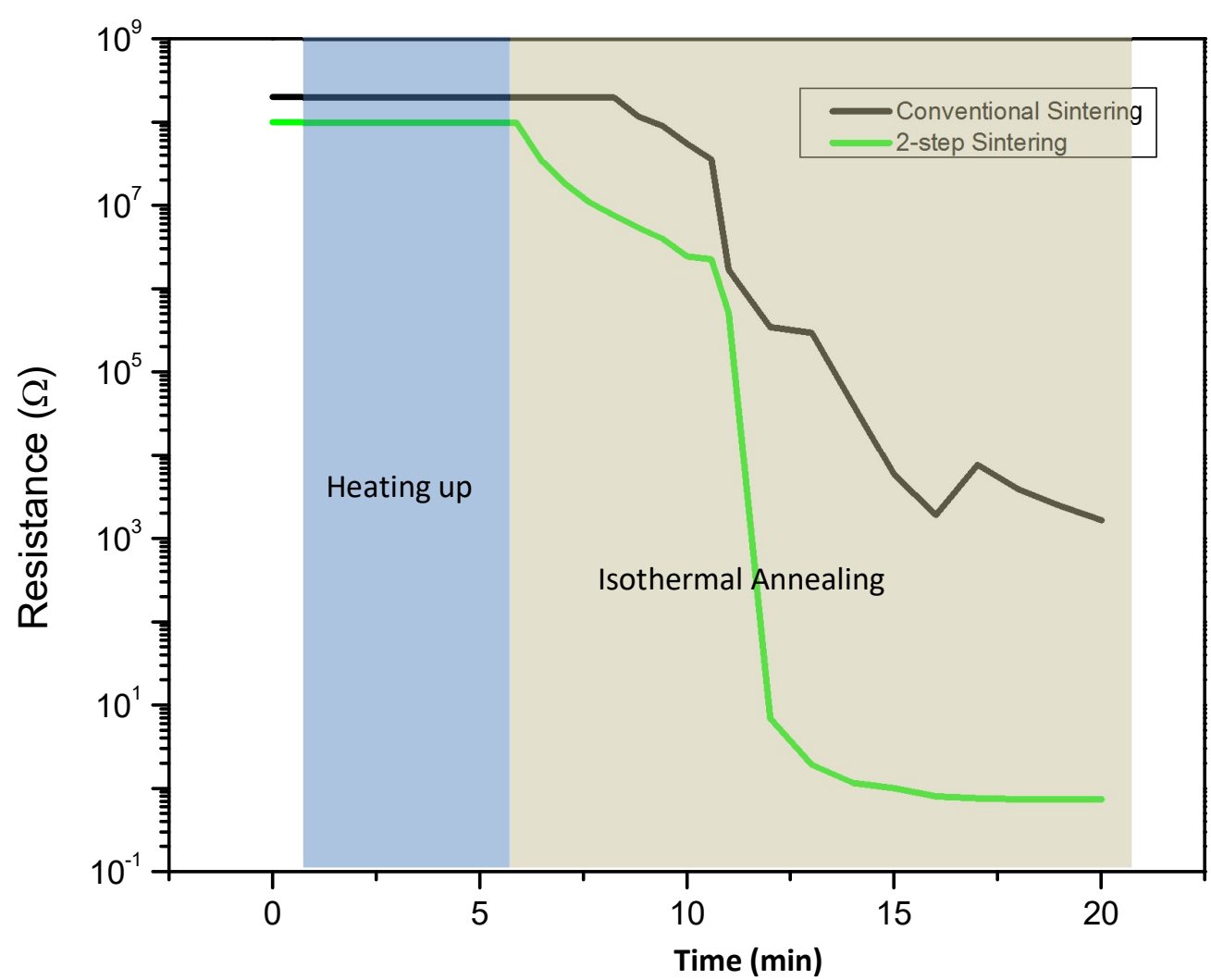

Figure 5.15 in-situ Electrical resistance measurements under $\mathrm{N}_{2}$ and formic acid vapor environment whereby isothermal annealing is done at $200^{\circ} \mathrm{C}$

It is observed that the change in resistance under formic acid is very rapid after 6 minutes of isothermal annealing and its final resistance is in the ohmrange. As discussed in section 4.2.1.2, the removal of the passivating layer under formic acid is faster since it is a chemical reaction between formic acid vapor and the amine-based passivating layer. However, for samples that were bonded under $\mathrm{N}_{2}$ environment, the rate of change is slower as the removal of passivating layer is solely dependent on the volatilization process. Hence complete removal of passivating layers might not be possible and hence results in a higher final resistance. From the previous study, it is concluded that the high resistance is due to poor fusion between $\mathrm{Cu}$ NPs and is caused by the remaining passivating layers. This again shows that the rate and degree of passivating layer removal is critical for good fusion of $\mathrm{Cu}$ NPs to achieve a high bond integrity with low electrical resistance. 
Influence of Sintering Parameters of Cu NPs \& its Structure Stability Chapter 5 In the data presented above, the purpose of using the formic acid vapour is for more effective removal of the capping layer, and not for reduction of any preexisting copper oxide or prevention of copper oxidation. If the capping layer is removed effectively, it can allow the $\mathrm{Cu}$ NPs to be sintered at a much lower temperature and even lead to a textured growth of the $\mathrm{Cu}$ grains. Nevertheless, based on the author's knowledge, the use of formic acid might not be conventional in the current manufacturing process.

Therefore, we can envisage that by tuning the chemistry of the $\mathrm{Cu}$ NPs paste formulation through having a component with similar characteristics as the formic acid that could be activated upon heating to react with the capping layers to volatize them, fusion of the $\mathrm{Cu}$ NPs can take place without the use of formic acid vapor.

\subsubsection{Relationship between Microstructure, Porosity and Bond Strength}

From the above findings, the porosity of the bonded $\mathrm{Cu}$ NPs layer is dependent on bonding parameters such as heating rate, bonding temperature, applied pressure and bonding environment. A good bond, which is known to have a higher true contact area $[35,36]$, is defined in this thesis as having high contact area at the bonding interfaces with the chip/substrate and strong bonding among the $\mathrm{Cu}$ NPs within the bonded layer. The amount of porosity might not be closely related with the mechanical strength if the bonding among $\mathrm{Cu}$ NPs, and between $\mathrm{Cu}$ NPs and bonding interface is not strong, i.e. significant amount of neck growth between $\mathrm{Cu}$ NPs and at the interface.

It is observed that when bonding was done at a lower temperature, i.e. $200^{\circ} \mathrm{C}$, introducing pressure does help to increase the true contact area due to diffusional mechanism and creep deformation between $\mathrm{Cu}$ NPs. This increases the amount and degree of necking that leads to an increase in bond strength. As shown schematically in Figure 5.16(a), when bonding is done at $200^{\circ} \mathrm{C}$ without any pressure and for a short duration (i.e. $\sim 10$ minutes), the non-uniform volatilization of passivating layers would lead to poor fusion. Hence, most of the $\mathrm{Cu}$ NPs remain small and are attracted toward one another by weak forces such as Van der Waals forces (Figure 5.16(b)). However as bonding temperature increases beyond $200^{\circ} \mathrm{C}$ or when pressure is exerted, the degree of necking 
$\underline{\text { Influence of Sintering Parameters of Cu NPs \& its Structure Stability Chapter } 5}$ increases which increases the contact area, and thus the joint strength of the $\mathrm{Cu}$ NPs layer is enhanced.

Therefore, the type of bonding of the $\mathrm{Cu}$ NPs affects how the joint fails. When cracks occur among the $\mathrm{Cu}$ NPs agglomerates, they are able to propagate along the $\mathrm{Cu}$ NPs easily when they are bonded by weak forces. On the other hand, if the $\mathrm{Cu}$ NPs are bonded together by solid necks, though higher porosity is observed, the resultant bond strength will be higher. This higher bond strength is attributed to the strong metallic bonds made between these $\mathrm{Cu}$ NPs through the fusion and necking process. Hence from this result, it shows that though shear strength is a function of the contact area, the true contact area between the NPs from the solid-state bonding is the critical parameter. The degree of neck growth across different samples has to be taken into consideration rather than taking porosity as a simple estimation of bond integrity. This is to ensure that the type of bonding between sintered $\mathrm{Cu}$ NPs is similar (van de Waals forces vs. solid neck formation) before further comparison and studies are done.

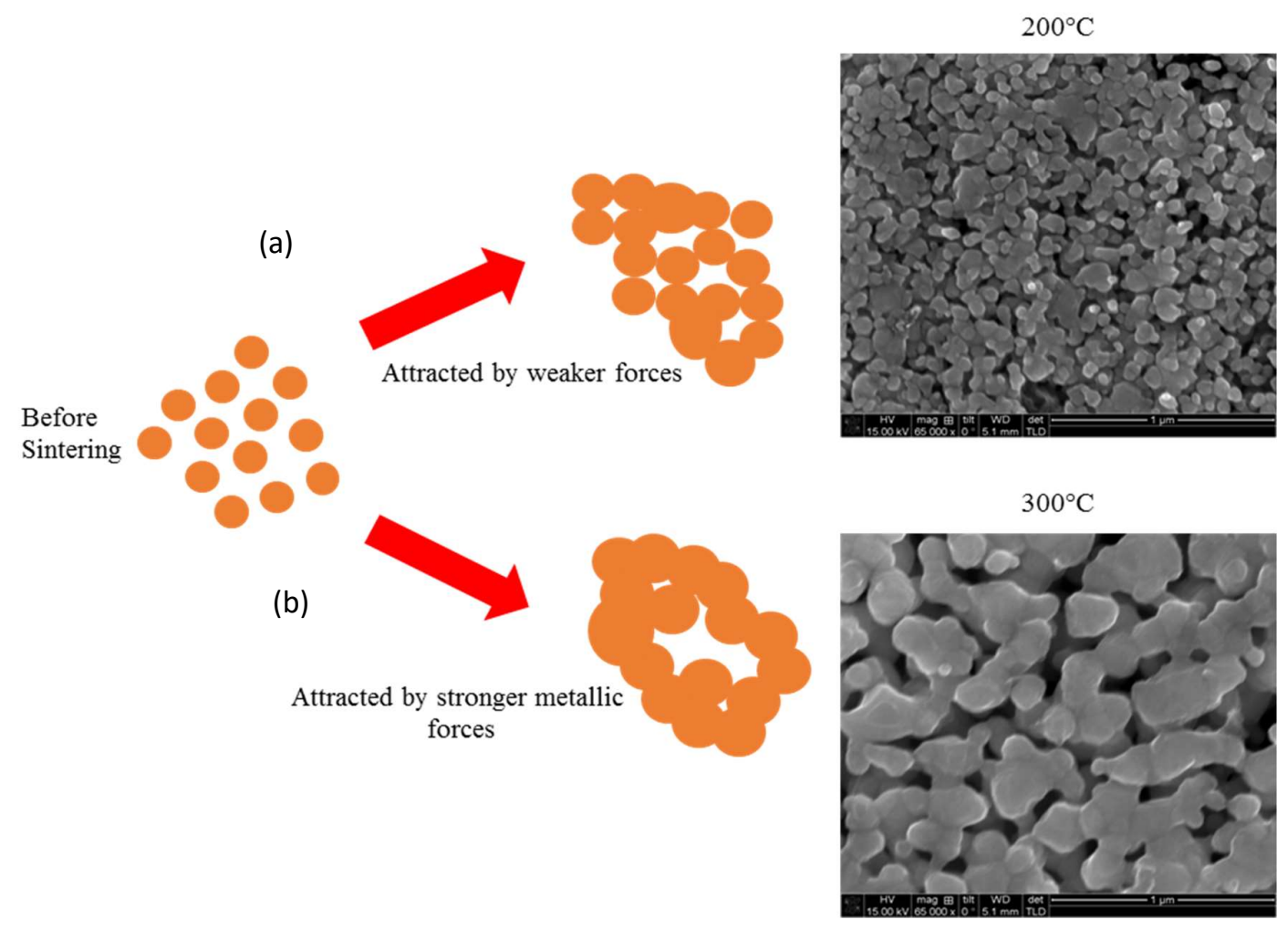

Figure 5.16 Schematics illustration of densification at (a) $200^{\circ} \mathrm{C}$ and (b) $300^{\circ} \mathrm{C}$

(Scale bar: $1 \mu \mathrm{m}$ ) 
$\underline{\text { Influence of Sintering Parameters of Cu NPs \& its Structure Stability Chapter } 5}$ With different types of bonding occurring between $\mathrm{Cu}$ NPs after fusion, two different types of failure were proposed. Type 1 failure is defined in this thesis as failure along the weakly bonded $\mathrm{Cu}$ NPs whereas Type 2 failure refers to failure occurring between the $\mathrm{Cu}$ NPs that are strongly bonded by solid necks (Figure 5.17). Hence when relating the relationship between shear strength and porosity, it must be compared against similar failure type. If the comparisons were not done according to the type of failure, the true contact area theory will not hold. This has been shown in Figure 5.6 and Figure 5.7. Though a lower or similar amount of porosity was observed in $200^{\circ} \mathrm{C}$ bonded samples as compared to $300^{\circ} \mathrm{C}$ ones, higher bond strength was observed in the latter. From the FESEM images (Figure 5.16), the type of failure in $200^{\circ} \mathrm{C}$ samples is most likely to be Type 1 . Whereas for $300^{\circ} \mathrm{C}$ samples, Type 2 will be more dominant. Therefore, the amount of porosity does not always correlate with the bond strength unless comparison is done across samples with the same type of failure.

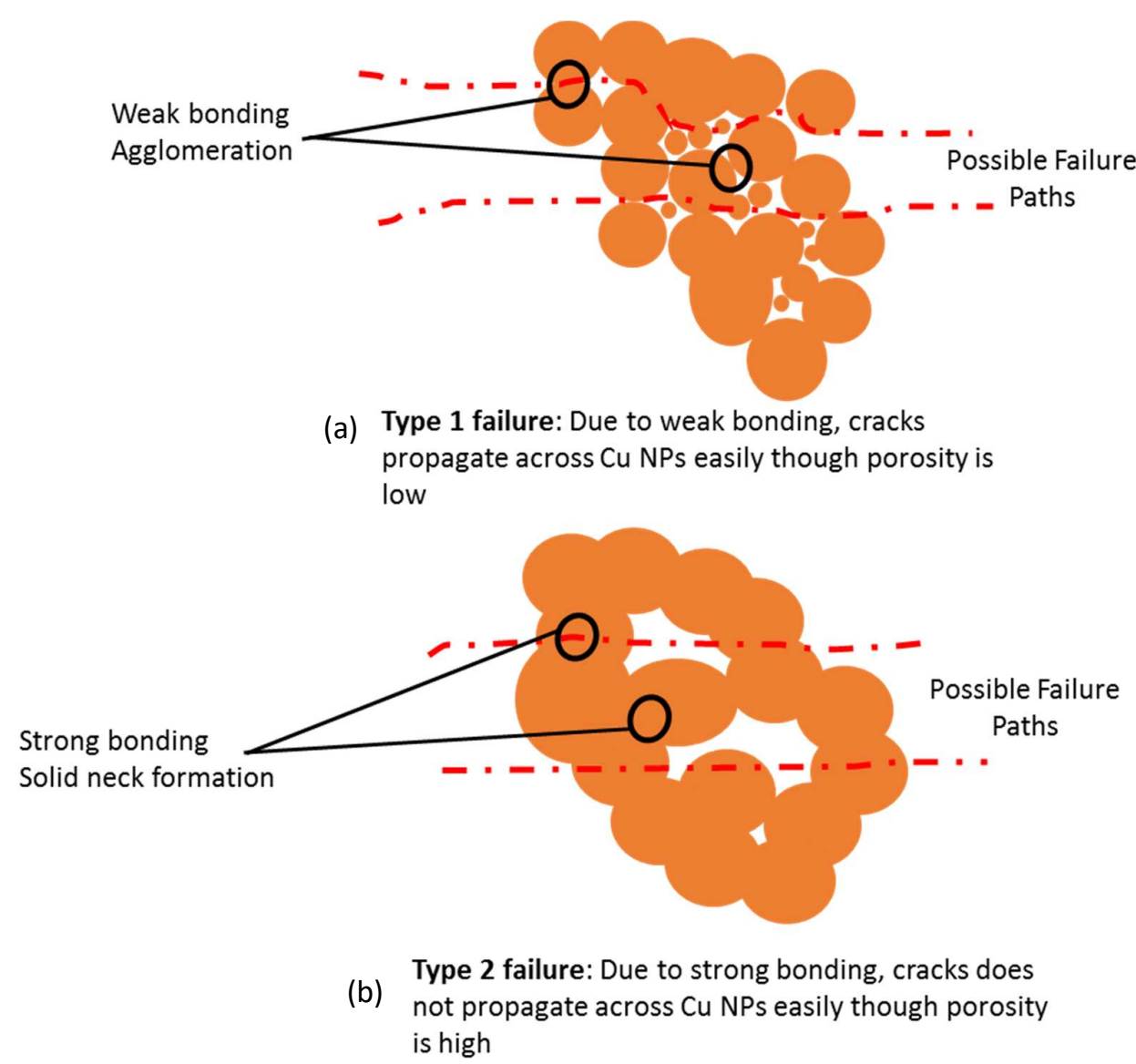


$\underline{\text { Influence of Sintering Parameters of Cu NPs \& its Structure Stability Chapter } 5}$

Figure 5.17 Failure types and locations (a) Type 1: Propagate along weakly bonded Cu NPs (b) Type 2: Does not propagate easily along Cu NPs due to strong bonding

\subsection{Bonded Cu NPs stability over time}

To study the thermal stability of these sintered $\mathrm{Cu}$ joints, isothermal ageing test at $150^{\circ} \mathrm{C}$ under air condition was done on these samples for up to 1000 hours. At every 200 hours, 6 samples were removed from the furnace for shear testing, cross-sectional FESEM imaging and synchrotron XRD characterization to characterize the bond strength, microstructure and grain growth of the aged samples.

\subsubsection{Bond strength}

5 samples were taken for shearing at every 200 hours interval and the shear strengths are shown in Figure 5.18.

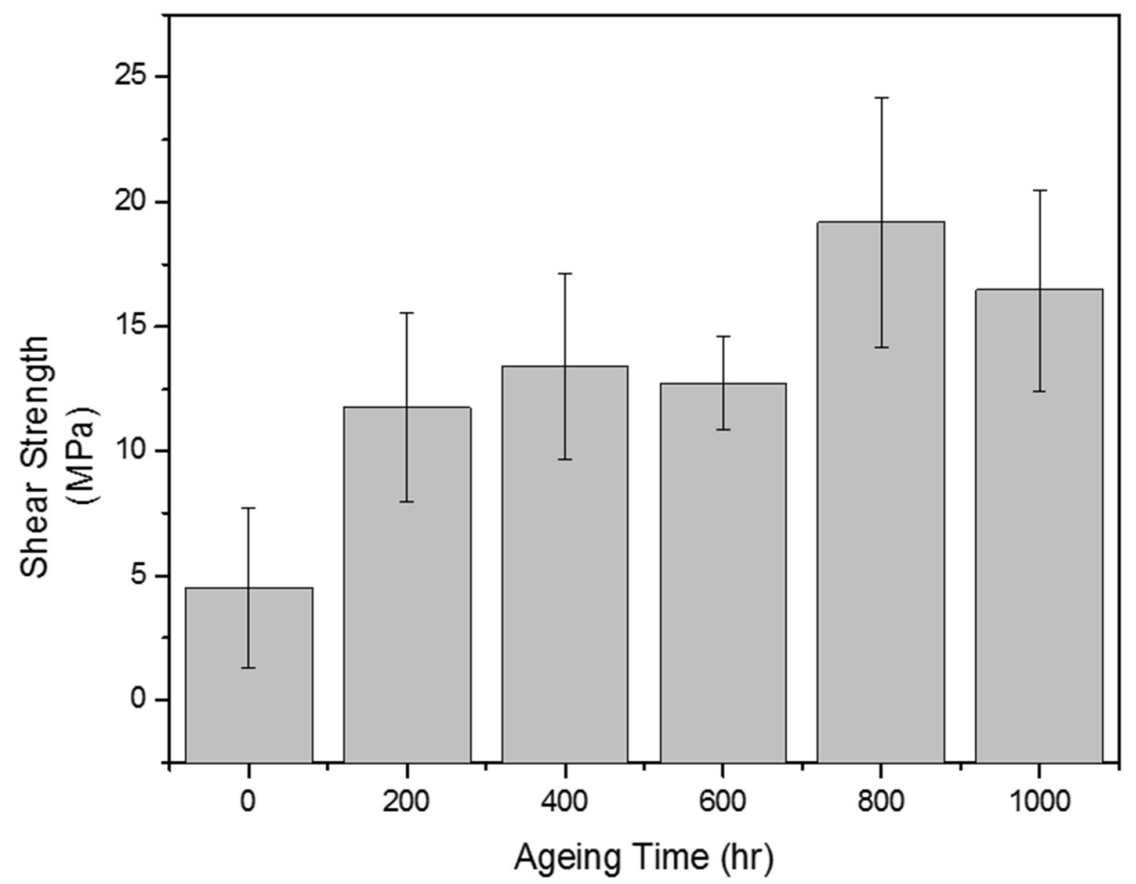

Figure 5.18 Shear strength of sintered $\mathrm{Cu}$ NPs under isothermal ageing at $150^{\circ} \mathrm{C}$ for 1000 hours 
$\underline{\text { Influence of Sintering Parameters of Cu NPs \& its Structure Stability Chapter } 5}$

From the results, the shear strength of the bonded samples increased significantly ( $\sim 3$ times) for the first 200 hours. This drastic improvement can be correlated with the microstructure of the sintered $\mathrm{Cu}$ NPs. From the microstructure evolution from $0-1000$ hours (Figure 5.19), it is observed that the porosity of the bonded layer has decreased tremendously for the first 200 hours. This would cause the increment in shear strength as the Cu NPs are better fused, and a denser bonded layer has been formed. An overall increase in shear strength was observed throughout the ageing process. However, no significant change was observed from the microstructures after 200 hours though there is an increase in shear strength. This could mean that grain growth of these $\mathrm{Cu}$ NPs could have affected the shear strength. To verify if any grain growth or crystallographic texture changes of the $\mathrm{Cu}$ NPs had occurred during the isothermal ageing process, synchrotron micro X-ray diffraction analysis ( $\mu \mathrm{XRD}$ ) was used.
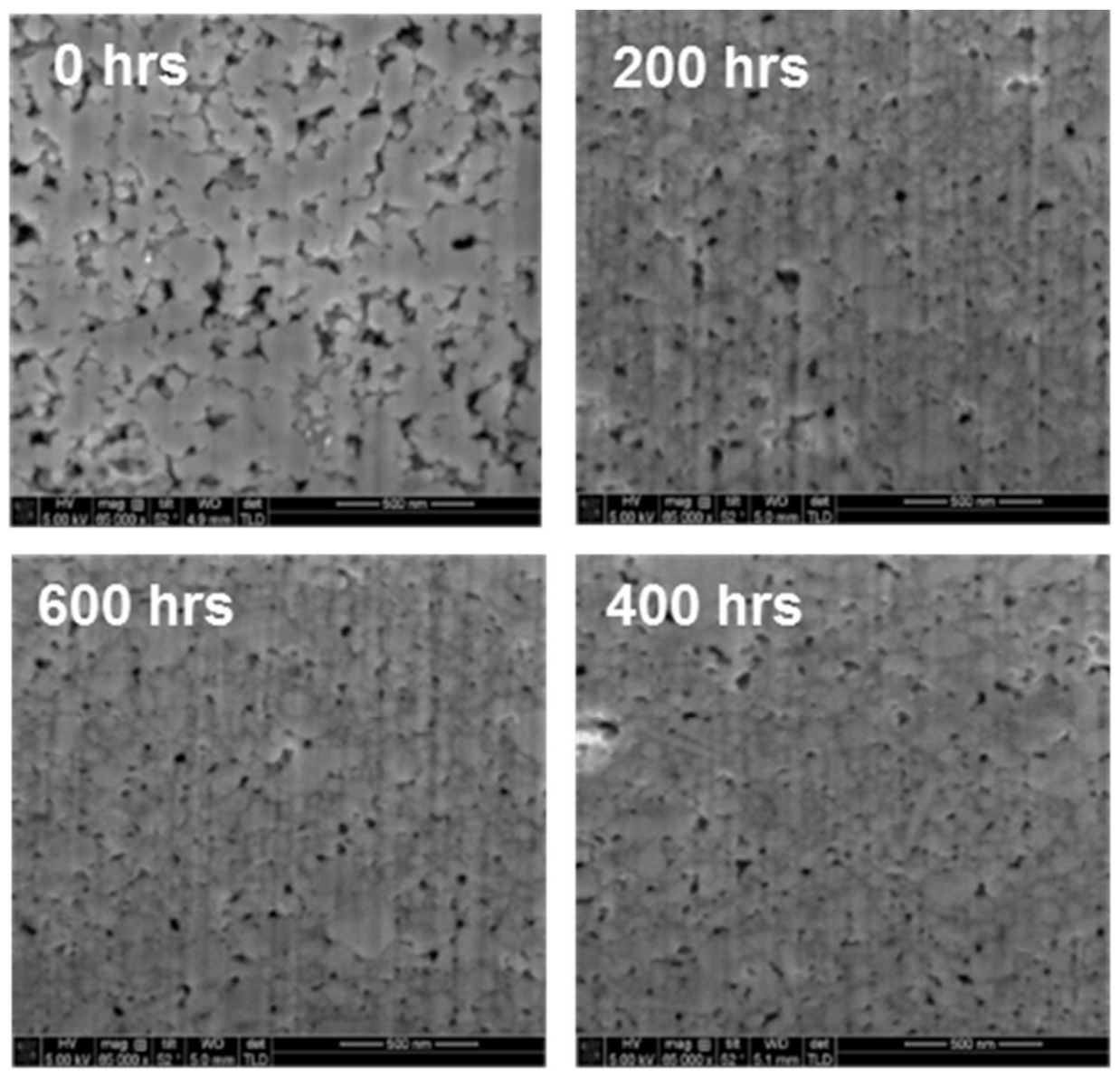
$\underline{\text { Influence of Sintering Parameters of Cu NPs \& its Structure Stability Chapter } 5}$
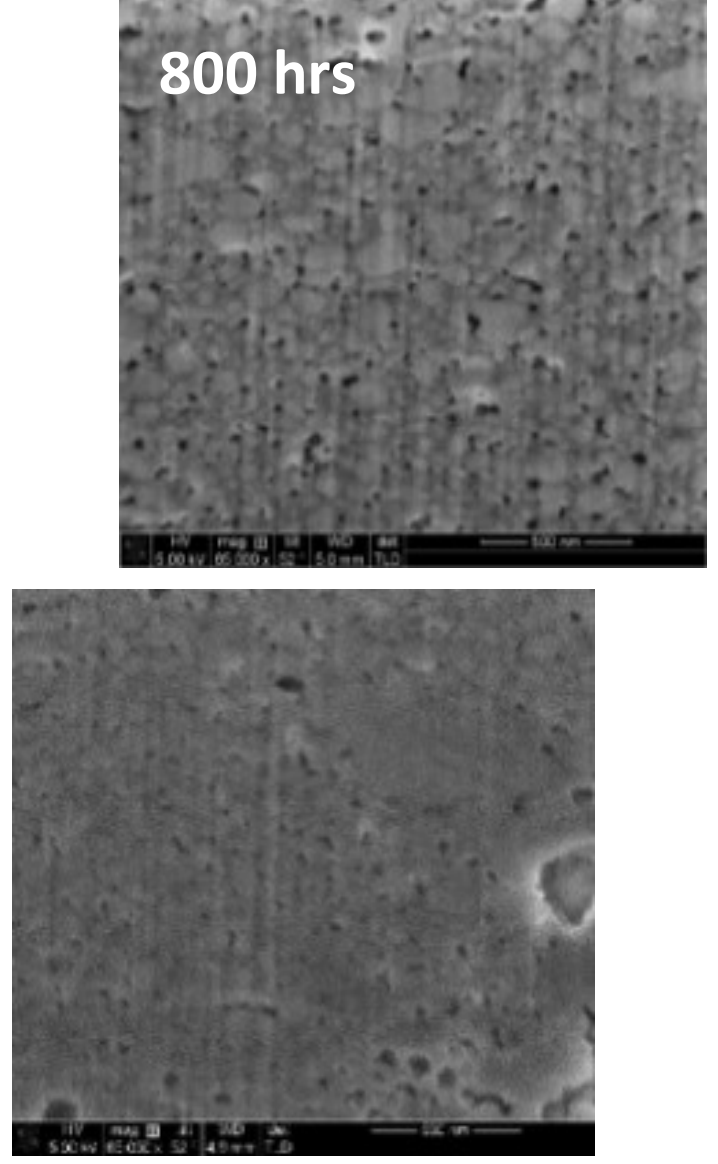

Figure 5.19 Microstructure evolutions of bonded $\mathrm{Cu}$ layers during ageing test from $0-1000$ hours (Scale bar: $500 \mathrm{~nm}$ ) The red dotted lines indicates highly fused $\mathrm{Cu}$ particles after 1000 hours of isothermal ageing

\subsubsection{Synchrotron $\mu$ XRD}

The as-sintered and aged samples show four peaks at $2 \theta$ values of $28.971^{\circ}$, $33.511^{\circ}, 48.059^{\circ}$ and $56.959^{\circ}$, corresponding to (111), (200), (220) and (311) planes of copper. The relative intensities of the first 3 orientations, (111), (200) and (220), are tabulated in Table 5.1. Relative intensities were calculated from the intensity of a peak divided by the intensity of the 'strongest' peak. Each relative intensity is an average of 3 scan areas. 
$\underline{\text { Influence of Sintering Parameters of Cu NPs \& its Structure Stability Chapter } 5}$

Table 5.1 Relative intensity of aged Cu NPs

\begin{tabular}{|c|c|c|c|}
\hline \multirow{2}{*}{ Time (hours) } & \multicolumn{3}{|c|}{ Relative Intensity (\%) } \\
\cline { 2 - 4 } & $\mathbf{( 1 1 1 )}$ & $\mathbf{( 2 0 0 )}$ & $\mathbf{( 2 2 0 )}$ \\
\hline 0 & 100 & 83.072 & 61.77 \\
\hline 200 & 100 & 71.56 & 44.31 \\
\hline 400 & 100 & 60.56 & 41.98 \\
\hline 600 & 100 & 40.87 & 37.54 \\
\hline 800 & 100 & 34.89 & 32.69 \\
\hline 1000 & 100 & 25.68 & 35.31 \\
\hline
\end{tabular}

From Table 5.1, there is no strong preferred orientation before isothermal ageing as the relative intensities are similar. This could be due to the short total processing time of 10 minutes at $200^{\circ} \mathrm{C}$ as crystallite growth is a function of time and temperature. However, after ageing for 1000 hours, the preferred growth orientation is (111) as the relative intensity as compared to (200) and (220) is much higher. In addition, as ageing proceeded, the intensities of both (200) and (220) decreased. This means that the volume fraction of (111) crystallites has increased with ageing time and is speculated to be due to grain rotation. The XRD patterns of the fused $\mathrm{Cu}$ NPs before and after 1000 hours of isothermal annealing are shown in Figure 5.20.

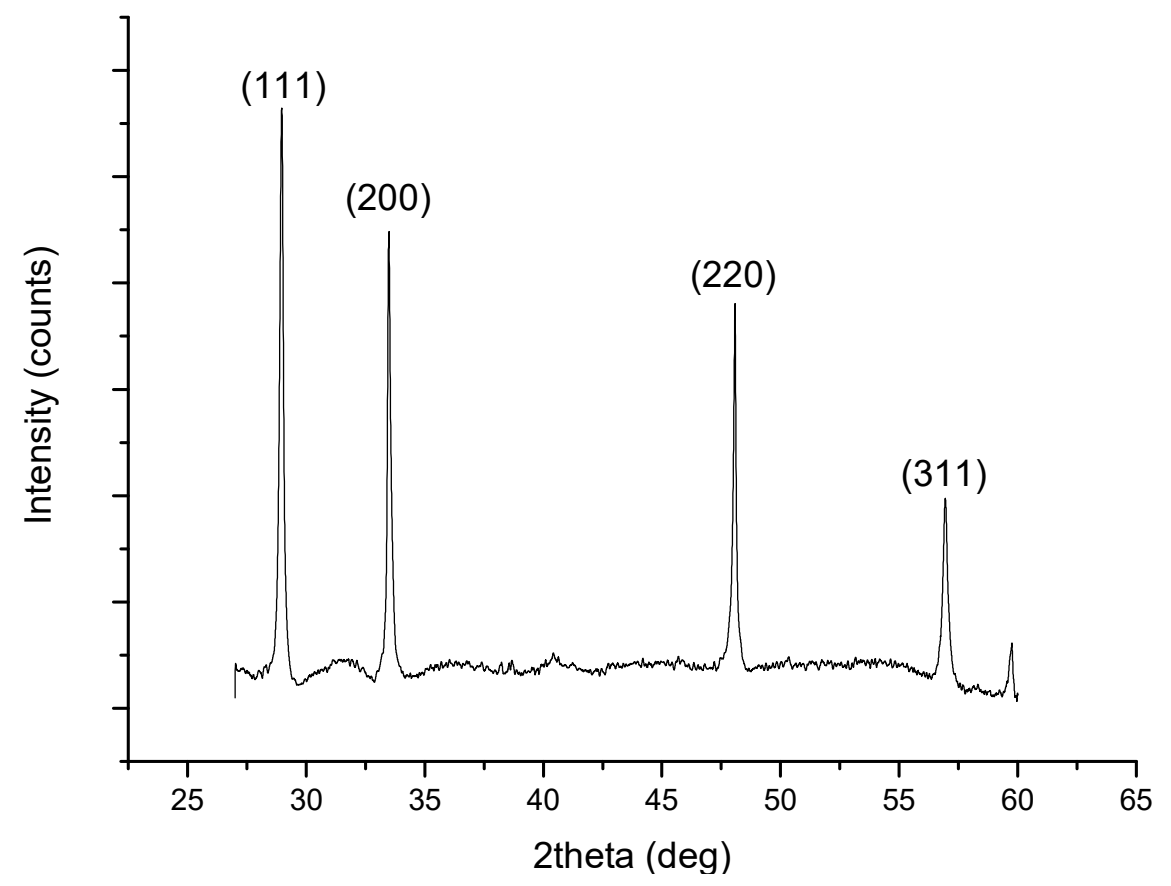


(a)

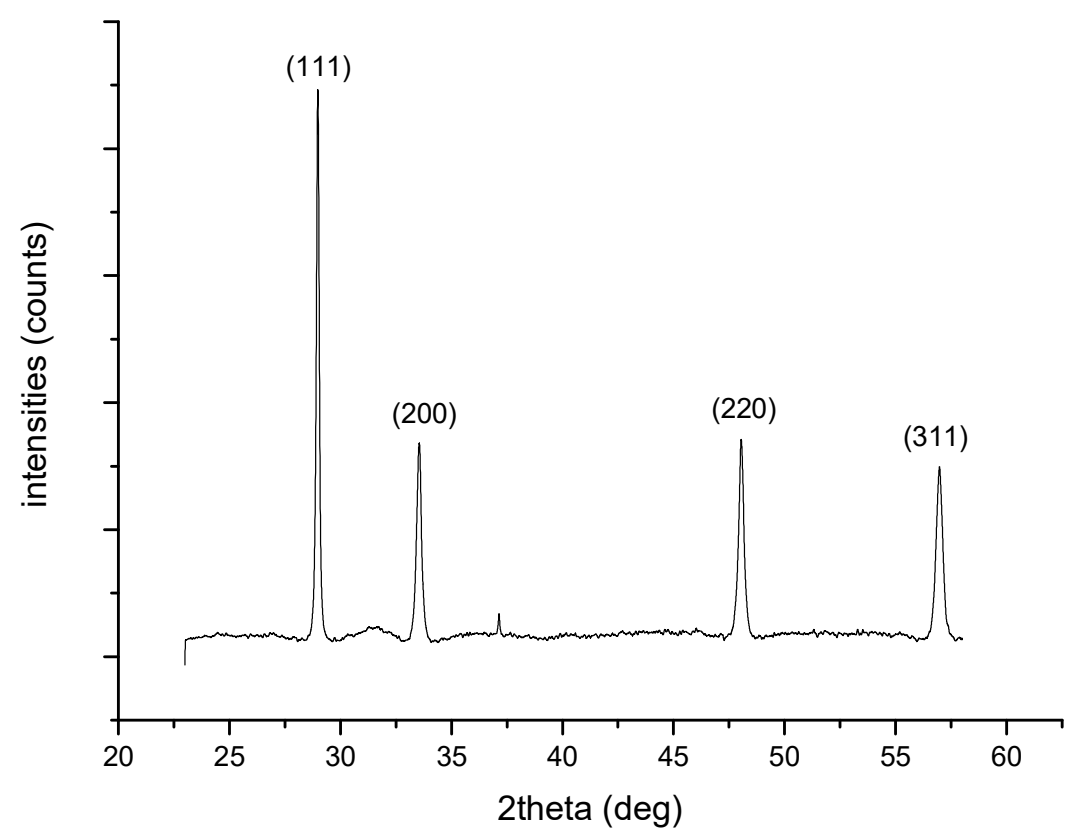

(b)

Figure 5.20 XRD patterns of Cu NPs (a) before (b) after ageing for 1000 hours

\subsubsection{Relationship of Shear strength with (111) FWHM}

Scherrer et al. showed that when the particle size of a randomly orientated mass of crystal is small, the beam of the parallel monochromatic radiation that falls onto the crystal will be broaden [37]. Therefore, the crystallite size along the $d$ spacing direction of a peak is closely related to the full-width-at-half-maximum (FWHM) of a specific diffraction peak at $2 \theta$ [38]. With this, the evolution of the FWHM of (111) diffraction peaks is used to study the growth of (111) crystallite size during isothermal annealing. From Figure 5.21, it is observed that the FWHM of (111) decreases only after 200 hours of isothermal annealing. This means that the initial decrease in porosity observed in Figure 5.21 is due to coarsening of the fused $\mathrm{Cu}$ NPs with minimum grain growth. Hence, the improvement in shear strength for the first 200 hours was suggested to be due to coarsening because the (111) crystallite size did not increase. Moreover, from the SEM images, it was observed that the size of the agglomerates increases. However, as ageing time increases to $200-800$ hours, the volume fraction and size of the (111) crystallites increase. Therefore, grain growth due to surface 
$\underline{\text { Influence of Sintering Parameters of } \mathrm{Cu} \text { NPs \& its Structure Stability Chapter } 5}$ diffusion between the fused $\mathrm{Cu}$ NPs is the likely mechanism. Though nanocrystalline materials are inherently unstable and room temperature grain growth of nano-crystalline $\mathrm{Cu}$ has been reported, grain growth of these nano-sized materials may be hindered by impurities, porosity and a narrow grain size distribution [39]. Therefore, the presence of porosities after bonding could have slowed down grain growth that led to no obvious change in the (111) FWHM during the first 200 hours. As isothermal ageing proceeded beyond 200 hours, the porosity was reduced as shown in Figure 5.19. This is accompanied by the decrease in (111) FWHM which indicates the growth of (111) crystallites that led to an increase in shear strength shown in Figure 5.21. From this observation, it shows that the (111) crystallites have grown after 1000 hours of thermal ageing even though the ageing temperature (i.e. $150^{\circ} \mathrm{C}$ ) is lower than the bonding temperature (i.e. $200^{\circ} \mathrm{C}$ ). It is reported that Lorentzian broadening of XRD peak line profiles is related to the size of the diffracting domains which can be deemed as the size of the crystallite [40]. From Figure 5.21, it is observed that the size of the (111) oriented crystallites increased after 200 hours of isothermal ageing, i.e. decrease in (111) FWHM. Hence, the narrower the FWHM, the bigger the crystallites size. As ageing time proceeded, the size of the crystallites continued to increase up till 800 hours. This is accompanied by the increase in shear strength. After 800 - 1000 hours, growth of (111) crystallites has saturated. Though the growth is minimal, a slight dip in shear strength was observed at 1000 hours. This could be due to oxidation of the $\mathrm{Cu}$ NPs that caused a slight dip in shear strength. 


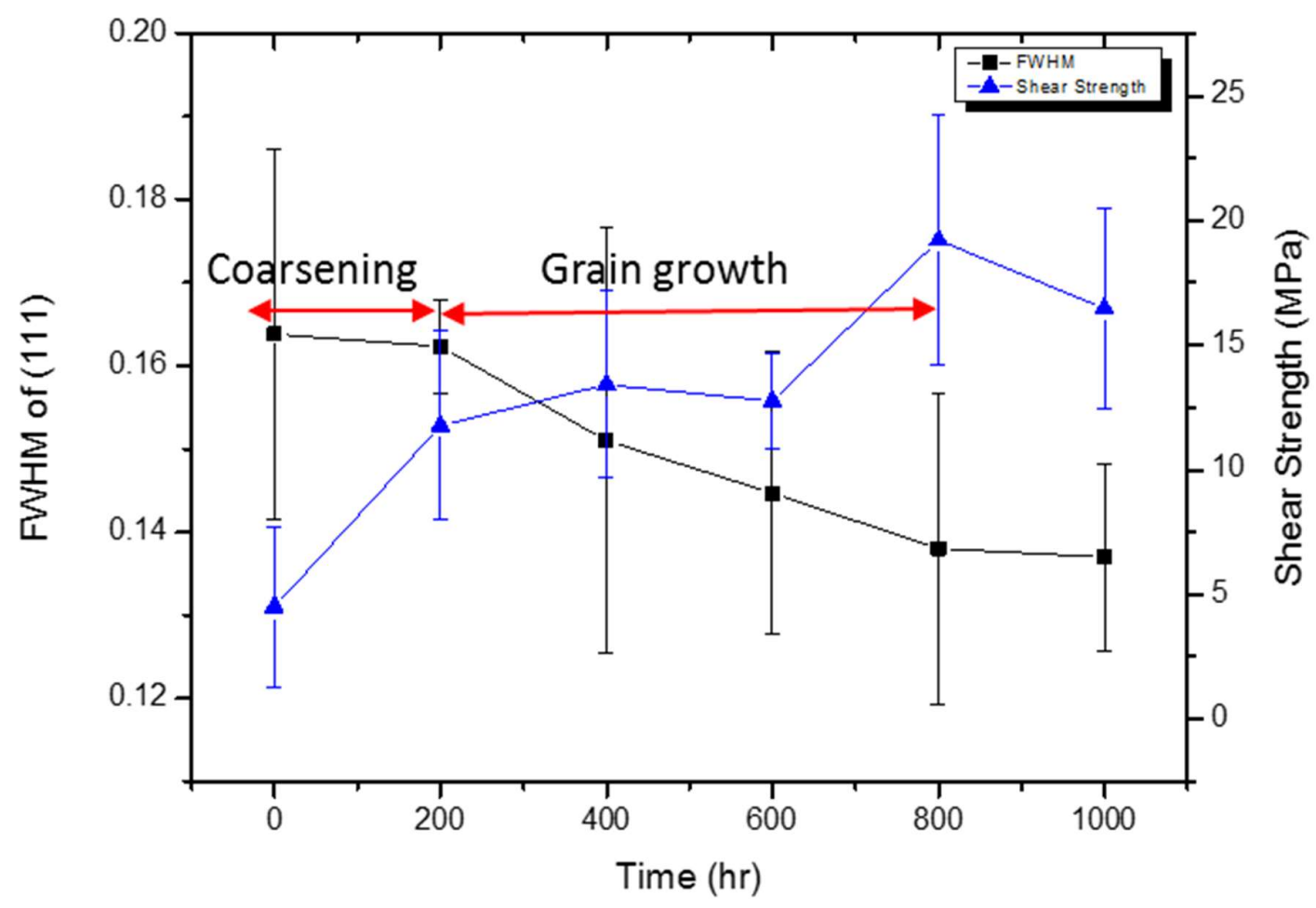

Figure 5.21 Graph of shear strength and line width (FWHM) as a function of ageing time

\subsection{Conclusion}

$\mathrm{Cu}$ NPs with a size range of $20-100 \mathrm{~nm}$ has been demonstrated to provide a feasible alternative for low temperature $\left(\sim 200^{\circ} \mathrm{C}\right)$ bonding process with good mechanical and electrical properties. Proper optimizations of process parameters can yield good mechanical properties, according to MIL-STD-883E, that can be employed in die attach and interconnect applications. From these studies, the heating rate is crucial to achieve good joint strength as it affects the rate of volatilization which in turn affects the degree of growth and densification of $\mathrm{Cu}$ NPs. Rapid volatilization should be avoided as it causes non-uniformed volatilization of organic materials which eventually affects the fusion of $\mathrm{Cu}$ NPs. However, if the heating rate is too slow, the fusion of $\mathrm{Cu}$ NPs will begin at the lower temperature regime. This leads to an increase in the effective radius of the NPs at the peak temperature which ultimately causes those NPs to lose its ability to fuse at low temperature in the later stage.

In addition, an uncovered structure will enable faster removal of organic materials as compared to a covered structure. Therefore, a suitable heating rate 
Influence of Sintering Parameters of Cu NPs \& its Structure Stability Chapter 5 and soaking duration need to be considered for different types of structures used. To establish a suitable heating rate, in-situ electrical resistance measurements can provide a quick and easy way to understand the fusion behavior of the $\mathrm{Cu}$ NPs. A measurable shear strength of $4 \mathrm{MPa}$ can be achieved at a low processing temperature of $200^{\circ} \mathrm{C}$ without any application of pressure. To improve the bonding quality, a pressure of $5 \mathrm{MPa}$ with a soak time of 10 minutes at $200^{\circ} \mathrm{C}$ can be adopted. From the microstructure studies, it is shown that the densification of the sintered layer is more noticeable with the introduction of bonding pressure. This can be attributed to the increase in the number of contact points and/or areas among $\mathrm{Cu}$ NPs and with the bonding interfaces that leads to a stronger solid neck formation among $\mathrm{Cu}$ NPs due to closer distance between $\mathrm{Cu}$ NPs and material deformation that increases the sintering rate. Strong bonding among $\mathrm{Cu}$ NPs will lead to higher bond strength as a higher energy is needed for the crack to propagate across the fused Cu network. Neck size of the fused $\mathrm{Cu}$ NPs should be used to estimate joint integrity.

With the optimum processing parameters chosen, a $150^{\circ} \mathrm{C}$ isothermal ageing test in air up till 1000 hours was carried out to study the reliability of such joints. Microstructures analysis, $\mu \mathrm{XRD}$, and shear strength were used to understand the joint reliability. No obvious cracks were observed though the ageing test was carried out in air. After ageing for 1000 hours, it has a preferred (111) texture with an increase in shear strength ( $\sim 3$ times) due to growth of crystallites and reduction in porosity. With these preliminary results, it shows that these Cu NPs can be a viable alternative as a die-attach material that is used for low temperature process applications.

\section{References}

1. Yamakawa, T., et al., Influence of Joining Conditions on Bonding Strength of Joints: Efficacy of Low-Temperature Bonding Using Cu Nanoparticle Paste. Journal of Electronic Materials, 2013. 42(6): p. 1260-1267.

2. Milhet, X., et al., Influence of the Porous Microstructure on the Elastic Properties of Sintered Ag Paste as Replacement Material for Die Attachment. Journal of Electronic Materials, 2015. 44(10): p. 3948-3956. 
Influence of Sintering Parameters of Cu NPs \& its Structure Stability Chapter 5

3. Fu, S., et al., Parametric Study on Pressureless Sintering of Nanosilver Paste to Bond Large-Area $(\geqslant 100 \mathrm{~mm} 2)$ Power Chips at Low Temperatures for Electronic Packaging. Journal of Electronic Materials, 2015. 44(10): p. 39733984.

4. Kobayashi, Y., et al., Preparation of metallic copper nanoparticles in aqueous solution and their bonding properties. Solid State Sciences, 2011. 13(3): p. 553558.

5. Couchman, P.R. and W.A. Jesser, Thermodynamic theory of size dependence of melting temperature in metals. Nature, 1977. 269(5628): p. 481-483.

6. Allen, G.L., et al., Small particle melting of pure metals. Thin Solid Films, 1986. 144(2): p. 297-308.

7. Ishizaki, T., et al., Pressure-Free Bonding of Metallic Plates with Ni Affinity Layers Using Cu Nanoparticles. Journal of Electronic Materials, 2014. 43(3): p. 774-779.

8. Krishnan, S., A.S.M.A. Haseeb, and M.R. Johan, Preparation and LowTemperature Sintering of $\mathrm{Cu}$ Nanoparticles for High-Power Devices. Components, Packaging and Manufacturing Technology, IEEE Transactions on, 2012. 2(4): p. 587-592.

9. Wang, T., et al., Shrinkage and Sintering Behavior of a Low-Temperature Sinterable Nanosilver Die-Attach Paste. Journal of Electronic Materials, 2012. 41(9): p. 2543-2552.

10. Moon, K.-S., et al., Thermal behavior of silver nanoparticles for lowtemperature interconnect applications. Journal of Electronic Materials, 2005. 34(2): p. 168-175.

11. Lei, T.G., et al., Low-Temperature Sintering of Nanoscale Silver Paste for Attaching Large-Area Chips. Components and Packaging Technologies, IEEE Transactions on, 2010. 33(1): p. 98-104.

12. Wang, T., et al., Low-Temperature Sintering with Nano-Silver Paste in DieAttached Interconnection. Journal of Electronic Materials, 2007. 36(10): p. 1333-1340.

13. Jang, S., J. Joung, and Y. Oh, Microstructure changes in nanoparticulate gold films under different thermal atmospheres and the effects on bondability. Acta Materialia, 2009. 57(18): p. 5613-5620. 
Influence of Sintering Parameters of Cu NPs \& its Structure Stability Chapter 5

14. Manikam, V.R. and C. Kuan Yew, Die Attach Materials for High Temperature Applications: A Review. Components, Packaging and Manufacturing Technology, IEEE Transactions on, 2011. 1(4): p. 457-478.

15. Bai, J.G., J.N. Calata, and L. Guo-Quan, Processing and Characterization of Nanosilver Pastes for Die-Attaching SiC Devices. Electronics Packaging Manufacturing, IEEE Transactions on, 2007. 30(4): p. 241-245.

16. Siow, K., Are Sintered Silver Joints Ready for Use as Interconnect Material in Microelectronic Packaging? Journal of Electronic Materials, 2014. 43(4): p. 947-961.

17. Watanabe, R. and T. Ishizaki, High-Strength Pressure-Free Bonding Using $\mathrm{Cu}$ and Ni-Sn Nanoparticles. Particle \& Particle Systems Characterization, 2014: p. n/a-n/a.

18. Jang, S., et al., Sintering of inkjet printed copper nanoparticles for flexible electronics. Scripta Materialia, 2010. 62(5): p. 258-261.

19. Lee, B., et al., A low-cure-temperature copper nano ink for highly conductive printed electrodes. Current Applied Physics, 2009. 9(2, Supplement): p. e157e160.

20. Park, B.K., et al., Direct writing of copper conductive patterns by ink-jet printing. Thin Solid Films, 2007. 515(19): p. 7706-7711.

21. Siow, K.S., Mechanical properties of nano-silver joints as die attach materials. Journal of Alloys and Compounds, 2012. 514(0): p. 6-19.

22. Yeadon, M., et al., In-situ observations of classical grain growth mechanisms during sintering of copper nanoparticles on (001) copper. Applied Physics Letters, 1997. 71(12): p. 1631-1633.

23. Greer, J.R. and R.A. Street, Thermal cure effects on electrical performance of nanoparticle silver inks. Acta Materialia, 2007. 55(18): p. 6345-6349.

24. Nichting, R.A., D.L. Olson, and G.R. Edwards, Low-temperature solid-state bonding of copper. Journal of Materials Engineering and Performance. 1(1): p. 35-44.

25. Zhang, Z. and L. Guo-Quan, Pressure-assisted low-temperature sintering of silver paste as an alternative die-attach solution to solder reflow. Electronics Packaging Manufacturing, IEEE Transactions on, 2002. 25(4): p. 279-283.

26. Knoerr, M. and A. Schletz. Power semiconductor joining through sintering of silver nanoparticles: Evaluation of influence of parameters time, temperature 
$\underline{\text { Influence of Sintering Parameters of } \mathrm{Cu} \text { NPs \& its Structure Stability Chapter } 5}$ and pressure on density, strength and reliability. in Integrated Power Electronics Systems (CIPS), 2010 6th International Conference on. 2010.

27. Fang, Z. and H. Wang, Densification and grain growth during sintering of nanosized particles. International Materials Reviews, 2008. 53(6): p. 326-352.

28. Skandan, G., et al., Creep Deformation of Nanocrystalline Oxides, in Plastic Deformation of Ceramics, R.C. Bradt, C.A. Brookes, and J.L. Routbort, Editors. 1995, Springer US: Boston, MA. p. 285-291.

29. Mo, Y., K.T. Turner, and I. Szlufarska, Friction laws at the nanoscale. Nature, 2009. 457(7233): p. 1116-1119.

30. Keller, R.M., S.P. Baker, and E. Arzt, Stress-temperature behavior of unpassivated thin copper films. Acta Materialia, 1999. 47(2): p. 415-426.

31. Sungchul, J. and F.B. Daniel, Adhesion mechanisms of nanoparticle silver to substrate materials: identification. Nanotechnology, 2010. 21(5): p. 055204.

32. Groza, J.R. and R.J. Dowding, Nanoparticulate materials densification. Nanostructured Materials, 1996. 7(7): p. 749-768.

33. Suk-JoongL.Kang, Sintering Densification, GrainGrowth, and Microstructure. 1 ed. 2005: Elsevier Butterworth-Heinemann

34. Morisada, Y., et al., A Low-Temperature Bonding Process Using Mixed Cu-Ag Nanoparticles. Journal of Electronic Materials, 2010. 39(8): p. 1283-1288.

35. Sasangka, W.A., et al., Influence of Bonding Parameters on the Interaction Between $\mathrm{Cu}$ and Noneutectic Sn-In Solder Thin Films. Journal of Electronic Materials, 2011. 40(11): p. 2329-2336.

36. Made, R.I., et al., Experimental characterization and modeling of the mechanical properties of $\mathrm{Cu}-\mathrm{Cu}$ thermocompression bonds for threedimensional integrated circuits. Acta Materialia, 2012. 60(2): p. 578-587.

37. Scherrer, P., Estimation of the size and internal structure of colloidal particles by means of röntgen. Nachr. Ges. Wiss. Göttingen, 1918. 2: p. 96-100.

38. Patterson, A.L., The Diffraction of X-Rays by Small Crystalline Particles. Physical Review, 1939. 56(10): p. 972-977.

39. Sanders, P.G., et al., IMPROVEMENTS IN THE SYNTHESIS AND COMPACTION OF NANOCRYSTALLINE MATERIALS. Nanostructured Materials, 1997. 8(3): p. 243252. 
$\underline{\text { Influence of Sintering Parameters of } \mathrm{Cu} \text { NPs \& its Structure Stability Chapter } 5}$ 40. Pantleon, K. and M.A.J. Somers, X-ray diffraction investigation of selfannealing in nanocrystalline copper electrodeposits. Scripta Materialia, 2006. 55(4): p. 283-286. 


\section{Chapter 6}

\section{Cu NPs as Interface Materials for High Power LEDs}

In the previous chapter, the joint stability of die - die bonding using $\mathrm{Cu} N \mathrm{~N}$ s has been demonstrated. In this chapter, the application of $\mathrm{Cu}$ NPs as a die-attach material in high power Light Emitting Diode (LED) packaging will be studied and demonstrated. To test its applicability, the process method and parameters used in the experiments follow closely with the industrial settings. These LEDs dice were coated with $\mathrm{Cu}$ NPs paste and placed onto a Ag-coated alumina substrate. These $\mathrm{Cu} N$ Ps pastes were then sintered under $\mathrm{N}_{2}$ condition in a benchtop reflow oven with a peak temperature of $280^{\circ} \mathrm{C}$. The as-bonded properties are compared directly with the conventional AuSn solder, which is commonly used for high power LEDs applications. The results are encouraging as the mechanical, electrical and optical properties are comparable to AuSn solder. To understand the long-term reliability of $\mathrm{Cu} N P$ s, reliability tests such as isothermal ageing and thermal cycling tests were carried out on these LEDs modules as well. Mechanical, electrical, optical and microstructure evolution were characterized and correlated with one another to have a better understanding of the $\mathrm{Cu} N \mathrm{~N}$ s performance as a die-attach material. From all these results, it does validate the potential of $\mathrm{Cu}$ NPs to replace current high temperature solder materials such as AuSn, though further tuning of process parameters and type of bonding interfaces should be looked into subsequently. 


\subsection{Introduction}

The number of power semiconductors applications has been increasing in the recent times. Hence, the demand for high temperature lead free solder materials is also increasing. These solders provide mechanical strength, electrical and thermal conduction between the die and the substrate. In the LED application, the interface material for die-attach plays a major role in its ability to dissipate heat and to maintain its mechanical and electrical reliability [1]. As LED lighting applications expand, new die attach material is required in LED packaging to satisfy the demanding requirement of higher thermal conductivity to achieve the desired performance and reliability of the devices. Currently, there are a few materials such as gold-tin (Au-Sn), gold-germanium (Au-Ge) and gold-silicon (Au-Si) that are being studied extensively [2]. These solders are used as dieattach for LED emitters to minimize thermal resistance between the LED die and substrate. This allows the LED to drive to higher currents and thus achieving higher light flux density reliably. However, there are some challenges such as the presence of voids from the non-wetting of solders with substrate/die and formation of IMCs within layer that will degrade the LED's mechanical, electrical, thermal and optical properties over time. Moreover, the cost of AuSn solder is high. Therefore, nano-size metallic particles $(<50 \mathrm{~nm})$ which possess good mechanical, electrical properties and high thermal conductivity have been studied extensively since it has a high possibility of replacing the current dieattach materials [3-6]. These nano-metallic particles are chosen instead of micron-scale metallic particles because of its ability to be sintered spontaneously at a lower temperature due to higher surface energy. As a result, the pressure needed for bonding can be reduced significantly. Thus, a new die-attach material with the ability to be processed at a lower temperature, has a better or comparable performance than conventional solder and has a lower price is therefore highly sought after.

Thus, the $\mathrm{Cu}$ NPs paste that was studied in the previous chapters will be investigated extensively for high power LEDs applications. The purpose of this chapter is to apply the previous understanding of this material to do a feasibility and reliability study of using $\mathrm{Cu}$ NPs as a die attach for LEDs applications. The 
characterization of the electrical, mechanical and optical performance of the LEDs after subjecting it to thermal aging will be carried out to assess its potential and possible challenges when integrating it to the current manufacturing processes.

\subsubsection{Experimental Methods}

The SiC-based LED chips from Cree, Inc. $(0.98 \mathrm{~mm} \times 0.98 \mathrm{~mm})$ used in this study are InGaN-based white LED devices that are vertically conducted with $\mathrm{Au}$ finish as the back metallization. To demonstrate the usability of $\mathrm{Cu}$ NPs, commercial Au80Sn20 solder (NC-SMQ51SC) purchased from Indium Corporation was used as a comparison. After applying the $\mathrm{Cu}$ NPs paste to bond the samples, the devices were reflowed under $\mathrm{N}_{2}$ ambient with the profile of 200$220-260-280^{\circ} \mathrm{C}$ for a total cycle time of $\sim 7 \mathrm{~min}$, with a heating duration of 1.5 min at each temperature in a 5-zone reflow oven (Sikama Falcon 5C).. For AuSn samples, $180-240-280-320^{\circ} \mathrm{C}$ with a total cycle time of $\sim 5 \mathrm{~min}$ (as recommended by the supplier), with a heating duration of $1 \mathrm{~min}$ at each temperature for AuSn samples. A higher reflow temperature of $320^{\circ} \mathrm{C}$ is needed for AuSn to ensure that the solder has fully melted during the reflow process. After bonding, mechanical strength was characterized using shear tester (similar to those explained in Chapter 3) and electrical measurements were carried out using a 2 probe method. The resistance across LED die/bonding layer (nano $\mathrm{Cu}$ )/Ag metallization on the substrate was obtained from the slope of the I-V curve measured. To examine the optical properties of the two different die attach materials, their luminescence peak wavelength of the LEDs was measured using a spectrometer (Newport OSM 100) with a 3 V voltage applied. Figure 6.1 is a typical sample of the single chip LED after reflow.

To test the long-term thermal reliability of $\mathrm{Cu}$ NPs, 1000 hours of isothermal ageing test at $200^{\circ} \mathrm{C}$ in air and 300 cycles of thermal cycling $\left(-55^{\circ} \mathrm{C}\right.$ to $\left.125^{\circ} \mathrm{C}\right)$ were carried out. Mechanical, electrical and optical properties were then correlated with the microstructure evolutions observed. 


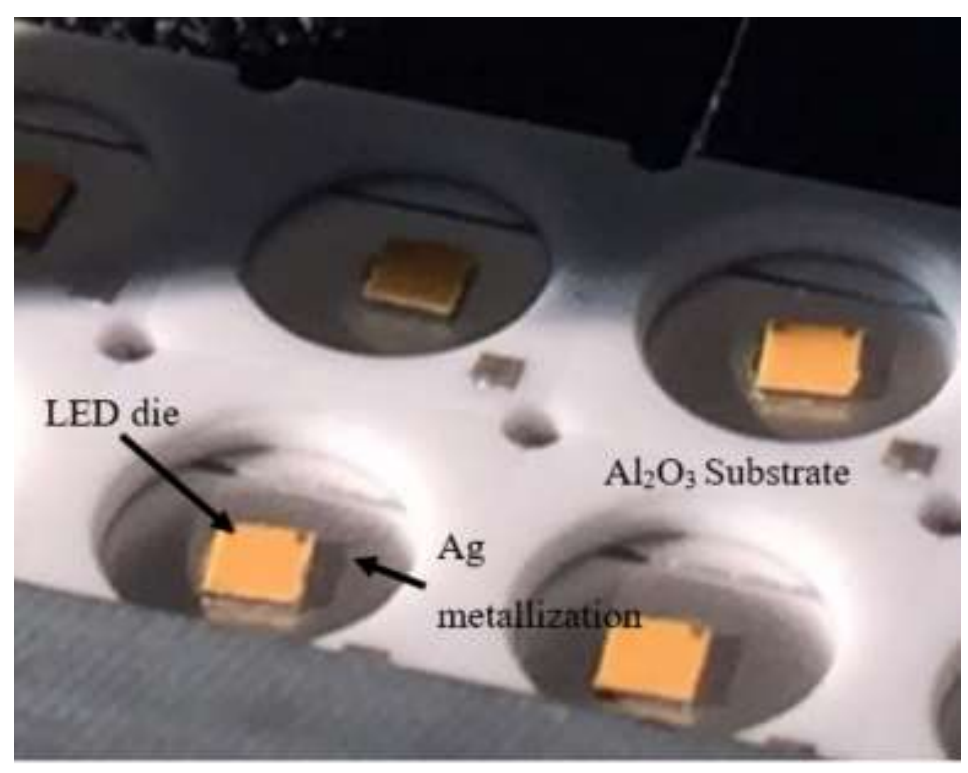

Figure 6.1 As-reflow single-chip LED module

\subsection{Principle Outcome}

\subsubsection{Overview of Cu NPs as a LEDs die attach material}

From the previous chapter, it is known that factors such as higher peak temperature, a suitable heating rate of $17^{\circ} \mathrm{C} / \mathrm{min}$ or even higher at $40^{\circ} \mathrm{C} / \mathrm{min}$ but with the aid of forming gas, can help to enhance the fusion of $\mathrm{Cu}$ NPs. Since the peak sintering temperature is $280^{\circ} \mathrm{C}$ in this study, it is likely to enhance fusion of the $\mathrm{Cu}$ NPs that can result in higher mechanical strength.

To validate the feasibility of using $\mathrm{Cu}$ NPs as a replacement for Au-Sn solder as a die attach, the LEDs modules that were bonded using $\mathrm{Cu}$ NPs paste were tested and compared with LEDs that were bonded with AuSn solder after bonding. The cross-sectioned SEM image of the as-bonded LED modules with $\mathrm{Cu}$ NPs or AuSn solder are shown in Figure 6.2. 

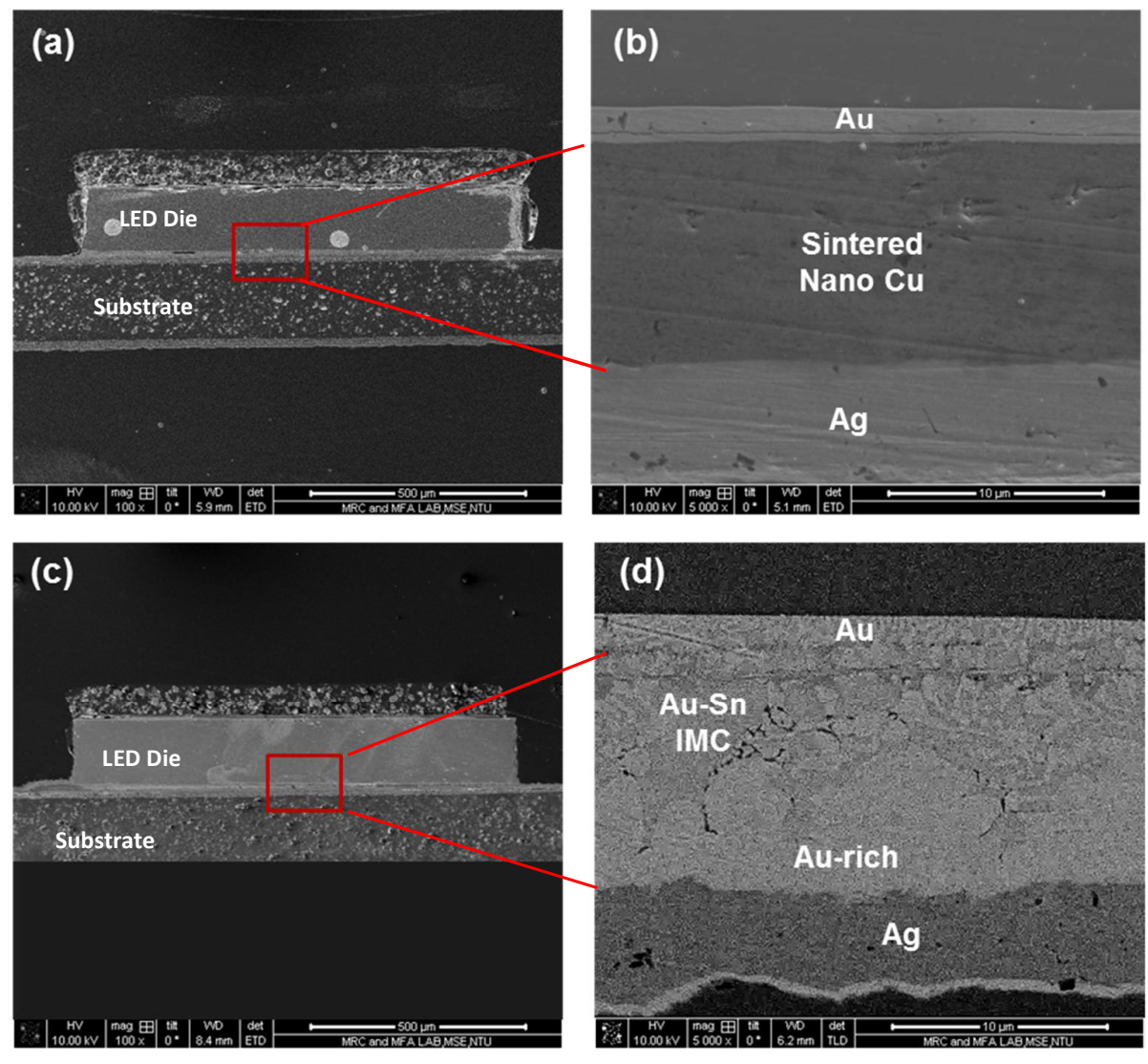

Figure 6.2(a) Overview of the LED module bonded with (a) Cu NPs paste with (b) Zoom-in view of the bonded layer; (c) AuSn solder with (d) Zoom-in view of the bonded layer (scale $10 \mu \mathrm{m}$ )

From Figure 6.2(a) and (b), it is observed that the bonded layer using Cu NPs shows uniformity across the die-attach layer. There is no sign of cracks or big pores, and no IMCs were observed. However, for AuSn solder, different color contrast can be observed in Figure 6.2(d). This possibly indicates the presence of AuSn IMC (darker contrast) and areas that are Au rich (lighter contrast) as reported in literature [7]. This difference in color contrast is commonly observed when using solder alloy as a die-attach material due to different atomic mass of materials. Based on literature, the most commonly found Au80Sn20 IMCs are AuSn, AuSn2 and AuSn4 [8,9]. The contrast in the FESEM images observed in this study is similar with those previously reported (shown in Appendix C [9]). 


\subsubsection{Mechanical Measurements}

The mechanical integrity of the LED modules was evaluated using die shear strength. The die shear strengths were measured using a Dage 4000 Multipurpose BondTester using the same parameters as what was described in Chapter3.

Table 6.1 Shear strength of LED modules bonded with Cu NPs and AuSn solder

\begin{tabular}{|c|c|c|}
\hline Materials & $\begin{array}{c}\text { Sintering/reflow temp } \\
\left({ }^{\circ} \mathbf{C}\right)\end{array}$ & Shear Strength (MPa) \\
\hline $\mathrm{Cu}$ NPs & 280 & $43.54 \pm 17.00$ \\
\hline Au80Sn20 & 320 & $50.52 \pm 0.01$ \\
\hline
\end{tabular}

From Table 6.1, the shear strength of the LED modules for both die-attach materials after sintering or reflow are comparable. This is not surprising as the bonding layer between LED die - Cu NPs - substrate as observed from the SEM images is dense and without significant voids (Figure 6.2(a) and (b)). As mentioned in Chapter 5 , to attain a shear strength of $>6 \mathrm{MPa}$, the amount and degree of necking between $\mathrm{Cu}$ NPs should be as high as possible.

Figure 6.3 shows a higher magnification cross-sectioned FESEM image of the $\mathrm{Cu}$ NPs on the LED die after shearing. Significant amount of necking between $\mathrm{Cu}$ NPs clusters can be observed. This shows that if the heating rate and peak temperature is high, though the processing time is short, good fusion between these $\mathrm{Cu}$ NPs can still be attainable. 


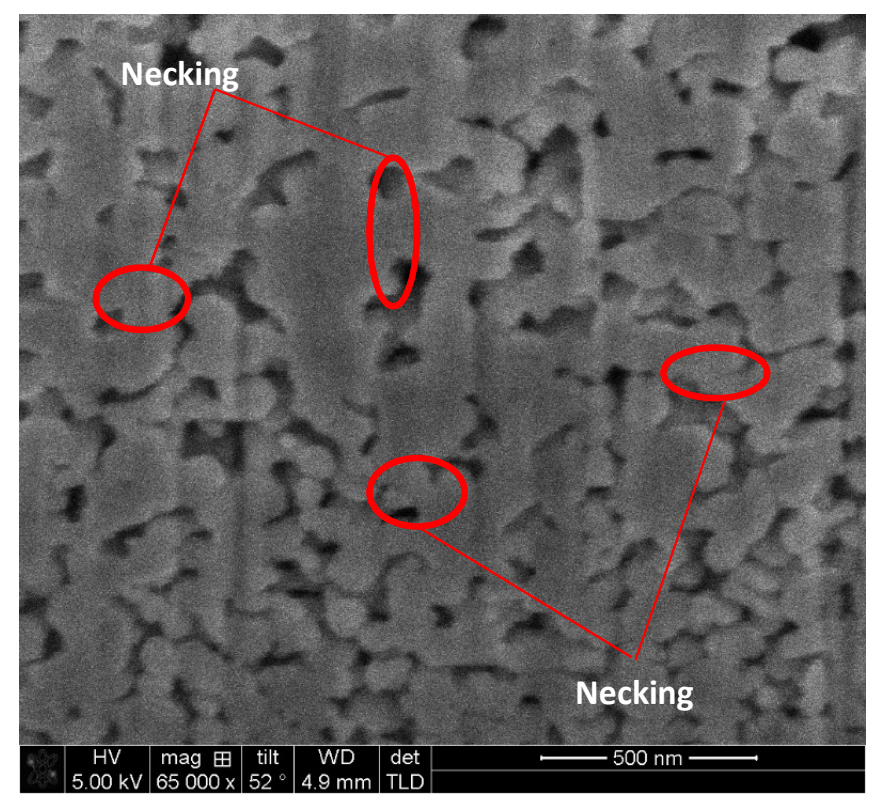

Figure 6.3 FESEM cross-sectioned image of Cu NPs on the LED die after shear test

Though the shear strength of Cu NPs samples is slightly lower than that of AuSn, the absence of applied pressure and lower processing temperature of $\mathrm{Cu}$ NPs during sintering make it compatible and attractive for this application. Besides, as the sintering of $\mathrm{Cu}$ NPs is based on solid state atomic diffusion rather than a change of state from solidus to liquidus as in Au-Sn solder reflow, the LED die will not move during the reflow process, thus enabling placement of a higher density of LED dice on the substrate. Still, the question of whether the presence of nanopores within the bonded layer will have negative effects on its electrical properties remains. Hence, electrical measurements were taken to ascertain its electrical properties after sintering.

\subsubsection{Electrical Measurements}

To measure the electrical resistance of the bonded LEDs, a two-probe method was used. The electrical resistance was obtained from the slope of the measured I-V graphs. Resistance was measured across the LED die/ die-attach material $(\mathrm{Cu}$ NPs or AuSn)/Ag metallization on the substrate. Table 6.1 shows the maximum reflow or sintering temperature of the 2 materials and their respective 
resistance. A schematic diagram of how the measurements were carried out is shown in Figure 6.4.

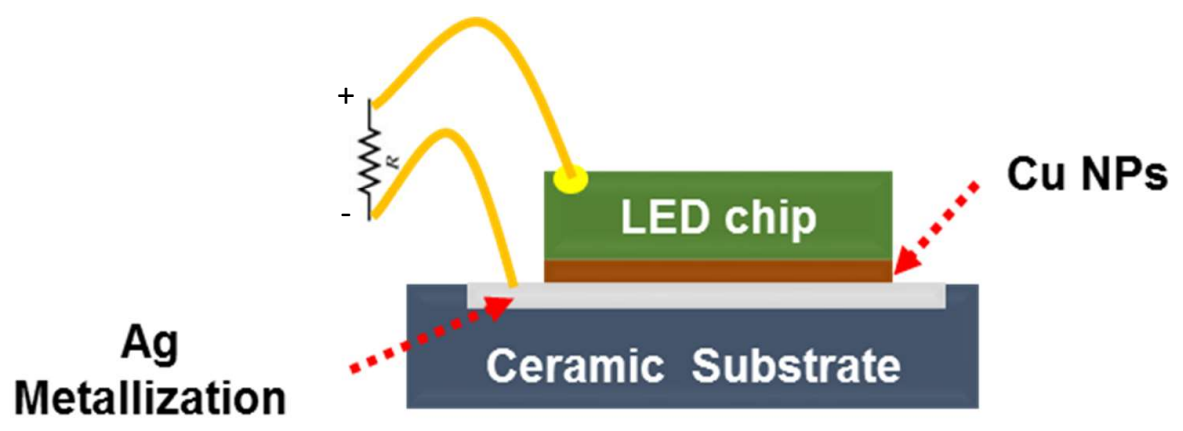

Figure 6.4 Schematic diagram of the electrical resistance measurement setup of LED module

Table 6.2 Electrical resistance of LED modules bonded with Cu NPs and AuSn solder

\begin{tabular}{|c|c|c|}
\hline Materials & $\begin{array}{l}\text { Max Fusing/Reflow } \\
\text { Temperature }\left({ }^{\circ} \mathrm{C}\right)\end{array}$ & Electrical Resistance ( $(\Omega)$ \\
\hline $\mathrm{Cu}$ NPs & 280 & $2.389 \pm 0.219$ \\
\hline Au80Sn20 & 320 & $9.117 \pm 5.969$ \\
\hline
\end{tabular}

Higher average electrical resistance from the LED modules bonded with AuSn solder was observed. The thickness for both die-attached materials is similar. Hence any thickness effect is not the main reason for the large difference in measured resistance. This means that the higher resistance is likely due to the higher electrical resistivity of $\mathrm{AuSn}\left(16.4 \times 10^{-8} \Omega \cdot \mathrm{m}\right.$ at $\left.20^{\circ} \mathrm{C}\right)$ as compared to $\mathrm{Cu}$ NPs electrical resistivity that is expected to range between $0.6 \times 10^{-8} \Omega \cdot \mathrm{m}-$ $1.68 \times 10^{-8} \Omega \cdot \mathrm{m}$ at $20^{\circ} \mathrm{C}[10]$. The expected range of electrical resistivity for $\mathrm{Cu}$ NPs is calculated based on the electrical resistivity of bulk Cu measured at $20^{\circ} \mathrm{C}$ and normalized with the amount of porosities within the sintered $\mathrm{Cu}$ NPs layer. Meanwhile, as observed in Figure 6.2(c) and (d), LED that was bonded with AuSn comprises of IMCs and alloys (represented by the different color contrast). These phases created some interfaces within the bonded layer that could possibly increase the overall electrical resistance. On the other hand, though $\mathrm{Cu}$ NPs 
bonded layer was porous, the pore sizes were all in nano-size range. In addition, there were no IMCs within the die-attach layer. Hence it does not affect the electrical properties significantly.

\subsubsection{Optical Measurements}

The optical properties of LEDs bonded with the two different types of die-attach materials, $\mathrm{Cu}$ NPs and AuSn solder, were also measured and compared to ensure its optical capabilities. The light intensity of the LED modules was measured using a spectrometer with a $3 \mathrm{~V}$ voltage supplied to the LED stack. The illumination peaks appeared at $450 \mathrm{~nm}$ and $600 \mathrm{~nm}$, which correspond to white LED. In addition, the intensity from these two die-attach materials showed a slightly higher light intensity from the Cu NPs LEDs as compared to AuSn LED samples (Figure 6.5). This might be due to the formation of micro-cracks in the intermetallic layers of the AuSn solder (Figure 6.2(d)), which affected the thermal resistance and caused a lower intensity [1]. In addition, the higher intensity could also be due to the $\mathrm{Cu}$ NPs having a lower electrical resistance as compared to AuSn since the same amount of voltage was applied.

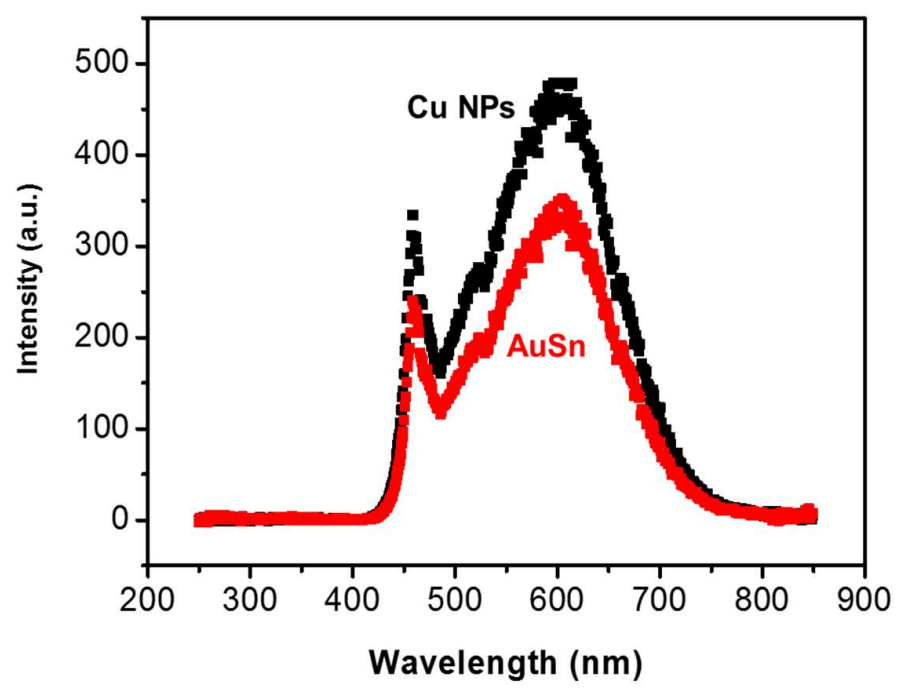

Figure 6.5 Photoluminescence spectra of Cu NPs and AuSn die-attach LEDs operated at $3 \mathrm{~V}$ at room temperature 


\subsubsection{Thermal Resistance Comparison}

From the optical intensity comparison, it is observed that when the LEDs were bonded with $\mathrm{Cu}$ NPs, it shows a higher intensity. Such an occurrence could be due to lower thermal resistance of $\mathrm{Cu}$ NPs as well. To do a relative comparison of the thermal resistance between $\mathrm{Cu}$ NPs and AuSn solder, a transient thermal analysis was carried out using T3ster ${ }^{\circledR}$ located at Nanyang Polytechnic School of Engineering [11]. For this experiment, a constant current of $100 \mathrm{~mA}$ was initially applied to the LED module until thermal equilibrium of $45^{\circ} \mathrm{C}$ was reached. Subsequently, the current was lowered to $1 \mathrm{~mA}$ so that it would not heat up the samples, yet sufficient for measurements of the change in temperature across the LED modules. The temperature of the LED modules was measured up till $1000 \mathrm{~s}$ and was used to compare the temperature dissipation response for both die-attach materials. In the measured temperature curves shown in Figure 6.6 , the $y$-axis represents the change in junction temperature measured and the sensing current used was $1 \mathrm{~mA}$. As observed in Figure 6.6, at the same given time, the decrease in junction temperature for $\mathrm{Cu}$ NPs samples is lower than the LEDs that were bonded with AuSn solder. This means that the Cu NPs is able to conduct heat better as compared to those LEDs that were bonded with AuSn solder. Such better thermal conductivity in $\mathrm{Cu}$ NPs could be due to the absence of intermetallics compounds that create multiple interfaces across bonding layer found in those LEDs samples bonded with AuSn solder. Thus, with better thermal conduction, it will have less Joule heating effect of the device which will also contribute to a lower electrical resistance as shown in Section 6.2.1.2. The lower electrical resistance and higher thermal conductivity of LED samples that were bonded with these $\mathrm{Cu}$ NPs will in turn have a higher light intensity i.e. brighter as observed in Section 6.2.1. 


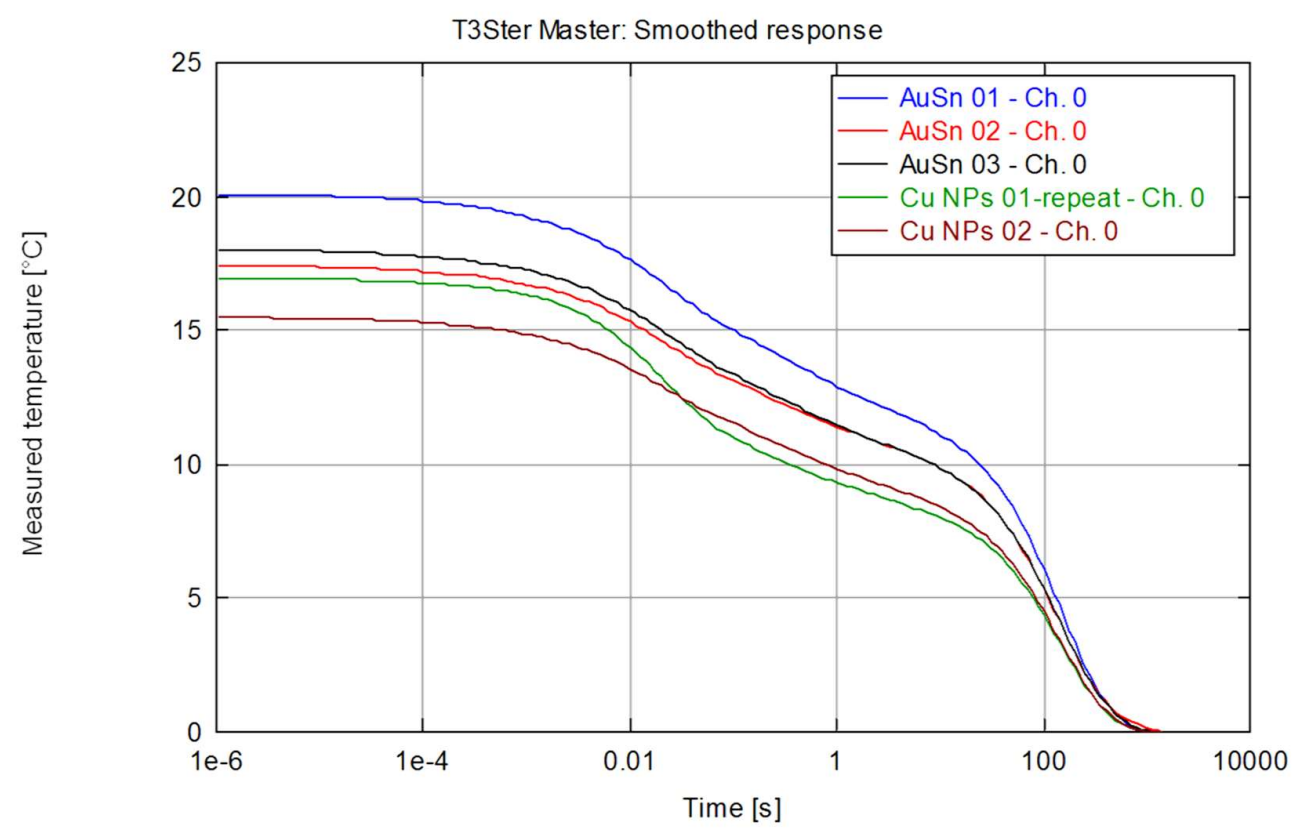

Figure 6.6 Measured temperature with time for Cu NPs and AuSn LED samples

With these mechanical, electrical, optical and thermal measurements, it further demonstrates the feasibility of using $\mathrm{Cu}$ NPs paste as a die-attach material for high power LED modules. The next step is to understand the reliability of the $\mathrm{Cu}$ NPs bonded LEDs.

\subsubsection{Reliability Tests}

In this section of reliability tests, the focus will be on joints that are formed with sintered $\mathrm{Cu}$ NPs. Hence the reliability of AuSn solder will not be included in this section. From the initial measurement data shown in Section 6.3.1, it has demonstrated the feasibility of using $\mathrm{Cu}$ NPs as a die-attach material for LEDs applications. However, nano-sized porosities were observed within the sintered $\mathrm{Cu}$ layer and at the bonding interfaces. To evaluate the long-term high temperature storage stability of sintered $\mathrm{Cu}$ NPs joint, the mechanical, electrical and optical properties were studied in detail after isothermal ageing test for a specific duration. Though similar tests have been carried out in Chapter 5, the isothermal ageing test in this section will be carried out on actual LED modules (without encapsulation) and at a higher temperature of $200^{\circ} \mathrm{C}$. This temperature was chosen based on JEDEC Standard testing for general high temperature 
storage life test (JEDEC Standard No. 22-A103E). This means that the Cu NPs are sandwiched between two different interface materials and subjected to higher thermal stress. Besides long term thermal stability examination, thermomechanical reliability test was carried out through thermal cycling as well. The joint strength (shear strength) and microstructural changes of the samples after each reliability test will be evaluated.

\subsubsection{Isothermal Ageing}

Isothermal ageing test under air condition was carried out at $200^{\circ} \mathrm{C}$ for 1000 hours. At every 250 hours, 5 LEDs samples were taken out from the oven for shear strength, electrical, optical and microstructure evaluation. The shear strengths obtained were plotted as a function of ageing time as shown in Figure 6.77 .

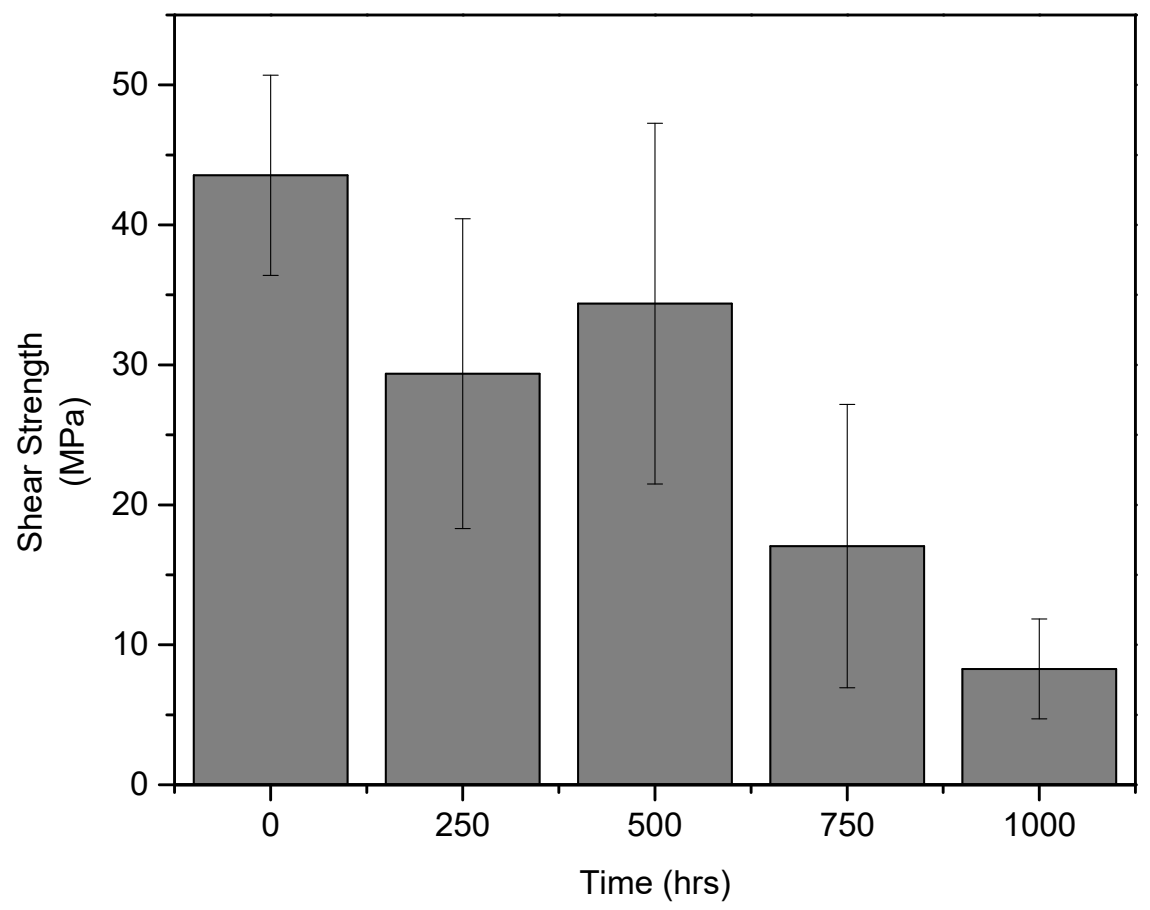

Figure 6.7 Shear Strength of Cu NPs LED die after 1000 hrs of thermal aging

From the initial shear strength (ageing time $0 \mathrm{hr}$ ), it is observed that the shear strength of the LED modules was $42 \mathrm{MPa}$. However, as ageing time proceeded to $250 \mathrm{hr}, \mathrm{a} \sim 30 \%$ drop in shear strength was observed. After $1000 \mathrm{hr}$ of ageing, 
the shear strength decreased to $9 \mathrm{MPa}$. From the previous chapter, it was shown that as ageing time increases, the overall shear strength increases. However, in this study, the opposite trend was observed. This could be due to two reasons. First, the maximum temperature for $\mathrm{Cu}$ NPs sintering was done at $280^{\circ} \mathrm{C}$, and hence the initial shear strength was in fact much higher than the previous data found in Chapter $5(\sim 4 \mathrm{MPa})$. This means that the $\mathrm{Cu}$ NPs were well-fused at time zero and further isothermal annealing would lead to more grain growth, since it was aged at $200^{\circ} \mathrm{C}$ instead of $150^{\circ} \mathrm{C}$ as studied in Chapter 5 . From Figure 6.8, the microstructure evolutions of the sintered $\mathrm{Cu}$ NPs are shown. From the images, no obvious big cracks or voids were observed after 1000 hours of ageing. Only further densification and growth, especially towards the bottom substrate, have been observed in Figure 6.9, where pores are smaller and the degree of necking among $\mathrm{Cu}$ NPs is high. However, from the fracture surfaces of the samples after annealing for $250 \mathrm{hrs}$, cracks with width $\sim 5 \mu \mathrm{m}$ were seen. At the end of $1000 \mathrm{hrs}$, the crack width grew to $9 \mu \mathrm{m}$ (Figure 6.10). This increase in the size of the cracks may be due to the continual fusion of the $\mathrm{Cu}$ NPs after sintering. As these fused $\mathrm{Cu}$ NPs continued to grow, it could further densify. This would lead to some shrinkage and may cause cracks at the bond interface and among the fused $\mathrm{Cu}$ NPs to form. Such discontinuity could not be caused by the IMCs between $\mathrm{Cu}$ and $\mathrm{Au}$ as they are completely mixable based on the $\mathrm{Cu}-\mathrm{Au}$ phase diagram as attached in Appendix B. The failure at the $\mathrm{Cu} / \mathrm{Au}$ interface may be due to capping layers of the $\mathrm{Cu}$ NPs at the interface being more difficult to volatilize because of the more closed structure.

Hence, when there are cracks among fused $\mathrm{Cu}$ NPs, the cracks can grow and propagate easily and lead to lower shear strength. From the surface fracture analysis using FESEM images, the crack propagation path is derived. Figure 6.11 shows the schematics diagram of crack propagation across the 2 bonding interfaces and within the sintered $\mathrm{Cu}$ NPs layer. 

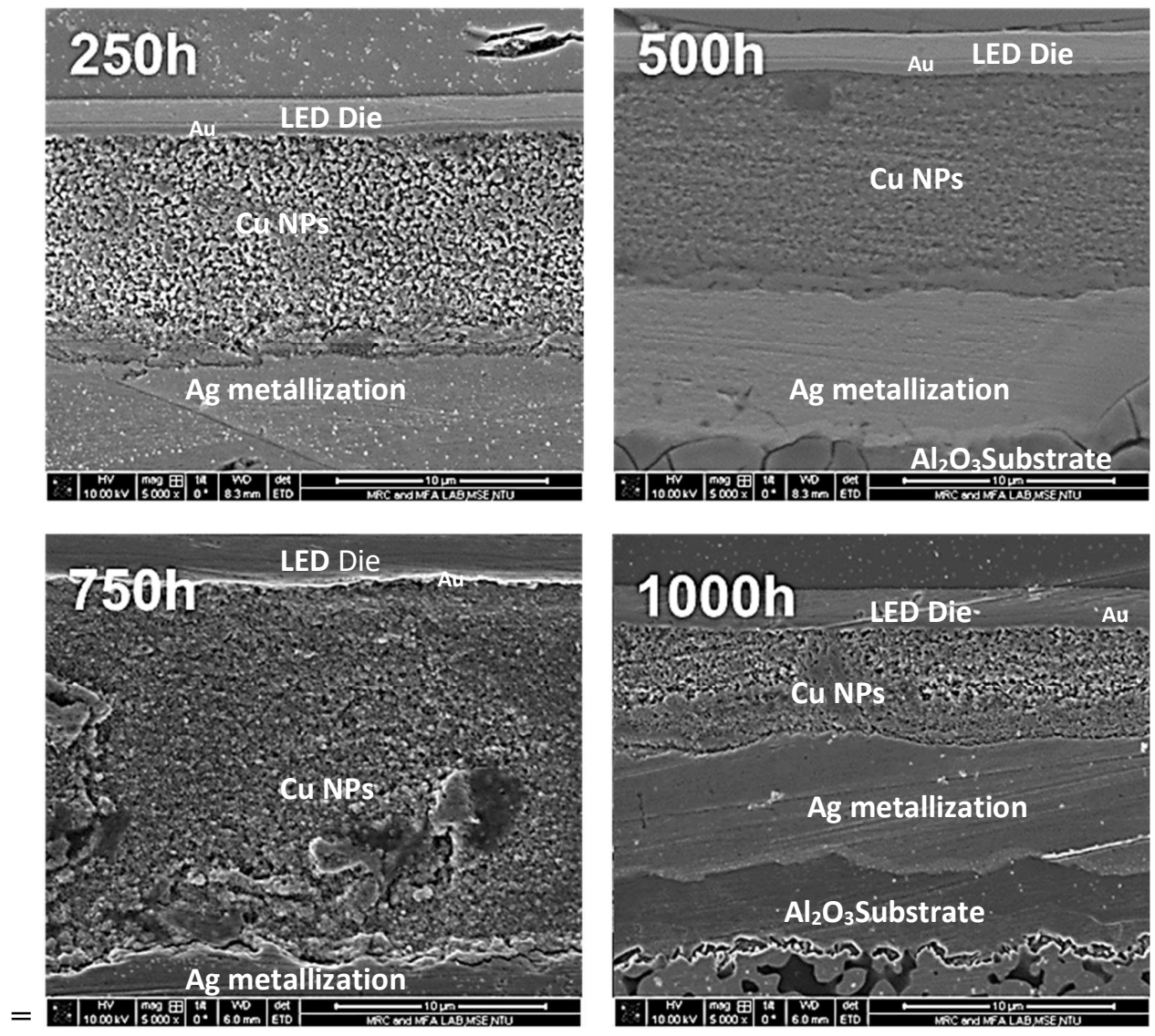

Figure 6.8 Microstructural changes of $\mathrm{Cu}$ NPs bonded onto LED
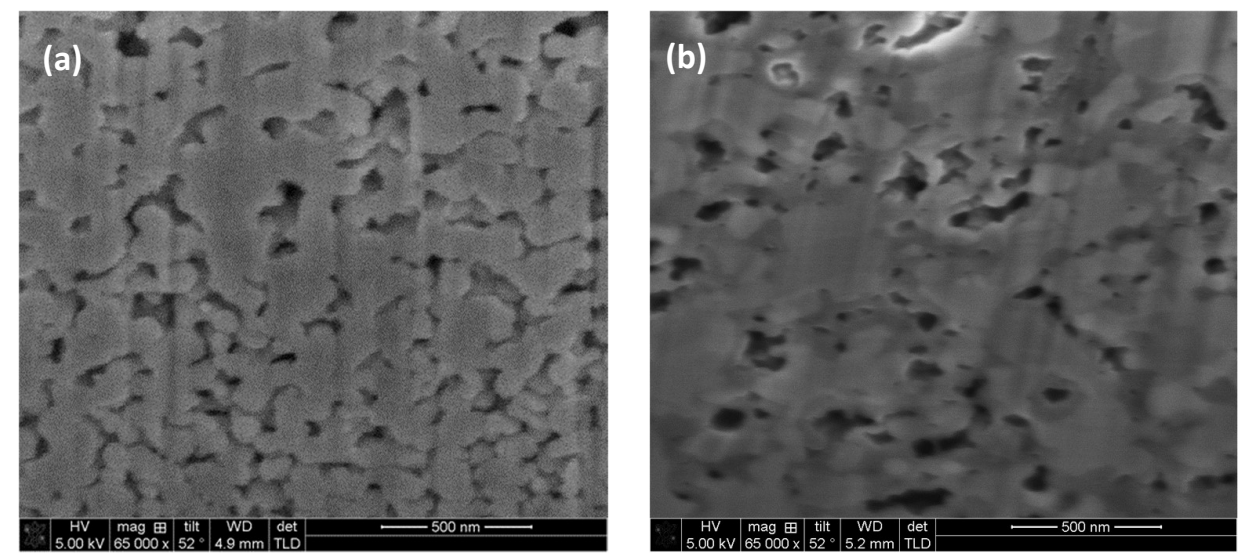

Figure 6.9 Microstructures of Cu NPs (a) just after sintering, (b) after 1000 hours at $200^{\circ} \mathrm{C}$ 
(a)

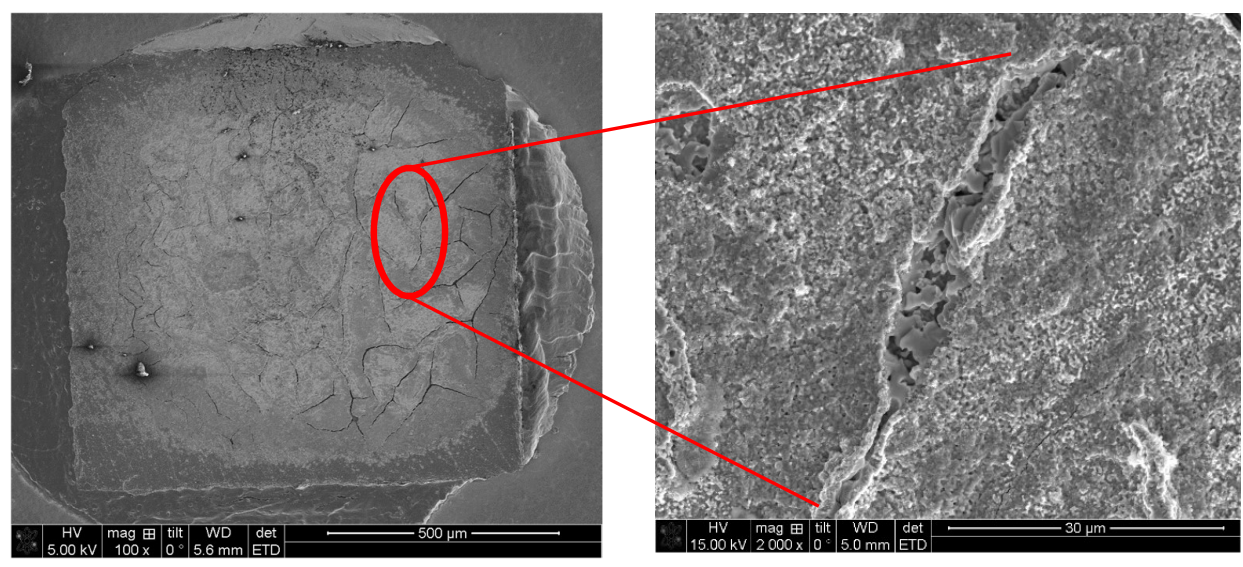

(b)
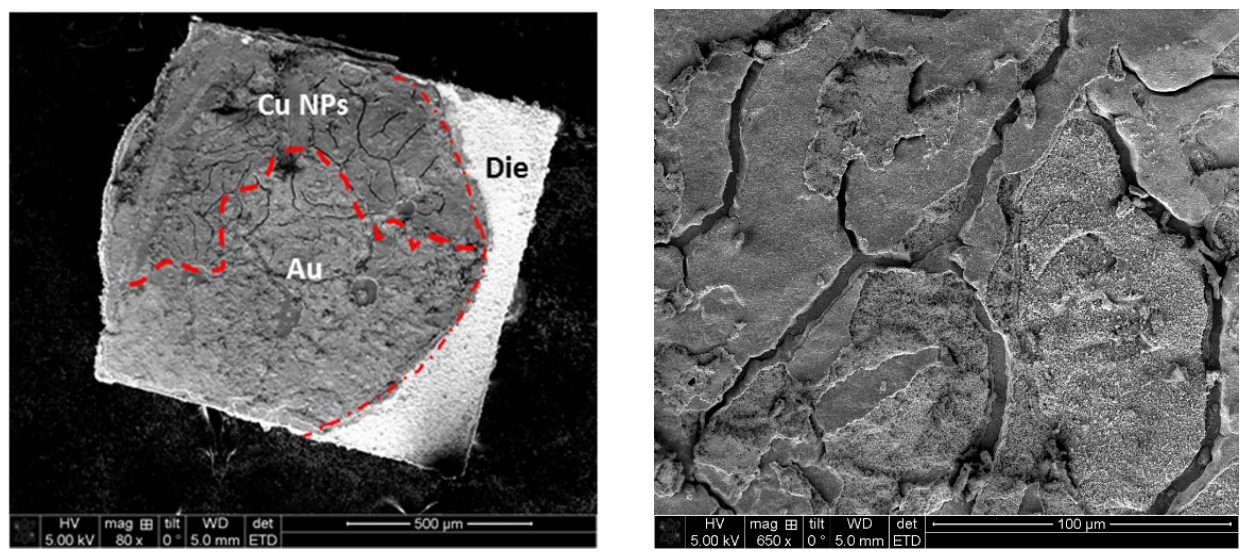

Figure 6.10 Fracture surfaces of LED dice and substrate after (a) 250 hours (30 $\mu \mathrm{m}$ scale) (b) 1000 hours of isothermal ageing at $200^{\circ} \mathrm{C}(100 \mu \mathrm{m}$ scale $)$
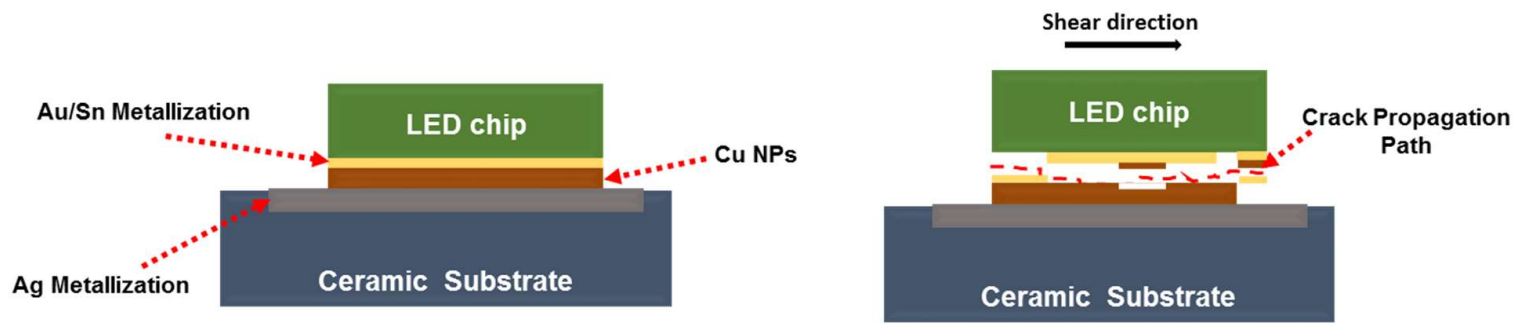

Figure 6.11 Schematic diagram of crack propagation through Cu NP layer

In terms of electrical measurements, 5 samples were measured before ageing and the same 5 samples were measured again at every 250 hours of isothermal ageing. In Figure 6.12, the electrical resistance at the start of ageing was about $2.5 \Omega$. 
However, as ageing proceeded to $250 \mathrm{hrs}$, the electrical resistance increased to $\sim 4 \Omega$ and remained relatively constant till $1000 \mathrm{hrs}$. From these electrical data results, it does appear that the electrical and mechanical properties do not share any direct co-relationship as there was no significant change in electrical resistance after $250 \mathrm{hrs}$ of ageing. This is because though there were still nanopores and/or cracks present within the bonded layer and at the bonding interfaces, electrons can still flow through the layer since majority of the $\mathrm{Cu}$ NPs had fused with one another to provide conduction paths for electrons to flow. This is shown in the FESEM images (Figure 6.8) of the sintered $\mathrm{Cu}$ NPs that even after 1000 hrs, no big voids or cracks that could cause poor joint strength was observed.

However, when the light intensity of a same LED module was measured at every $250 \mathrm{hrs}$ of isothermal ageing, it is observed that the peak intensity at $450 \mathrm{~nm}$ (corresponding to blue light) and a $2^{\text {nd }}$ broad peak which corresponds to the emission of the phosphor coating are lower and broadening of peaks are observed. The lower light output after every $250 \mathrm{hrs}$ may indicate the increase in electrical resistance at a same given voltage. This increase in electrical resistance could be due to presence of copper oxide, as the LED was not encapsulated and the ageing was done under air condition. This could result in oxidation of copper that leads to a lower light intensity as copper oxide has a higher electrical resistance than copper. In addition, the increase in the amount of small voids at the bonding interfaces that were observed in Figure 6.7 could also contribute to the increase in junction temperature that lead to lower light output. The photoluminescence spectra of the same LED module at every 250 hrs of isothermal ageing are shown in Figure 6.13. 


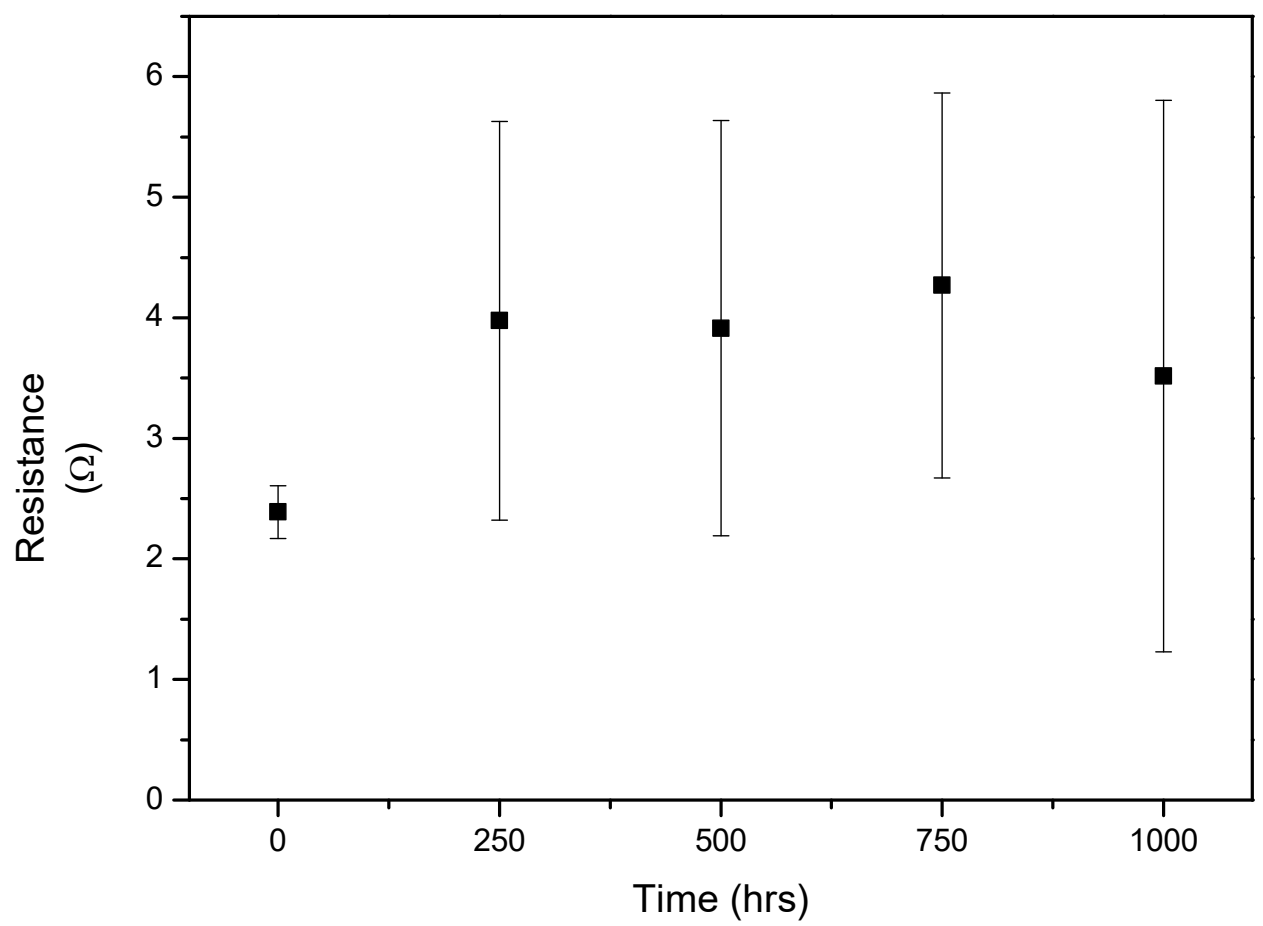

Figure 6.12 Electrical resistance of Cu NPs with Au LED from 0 - 1000 hrs of isothermal ageing test

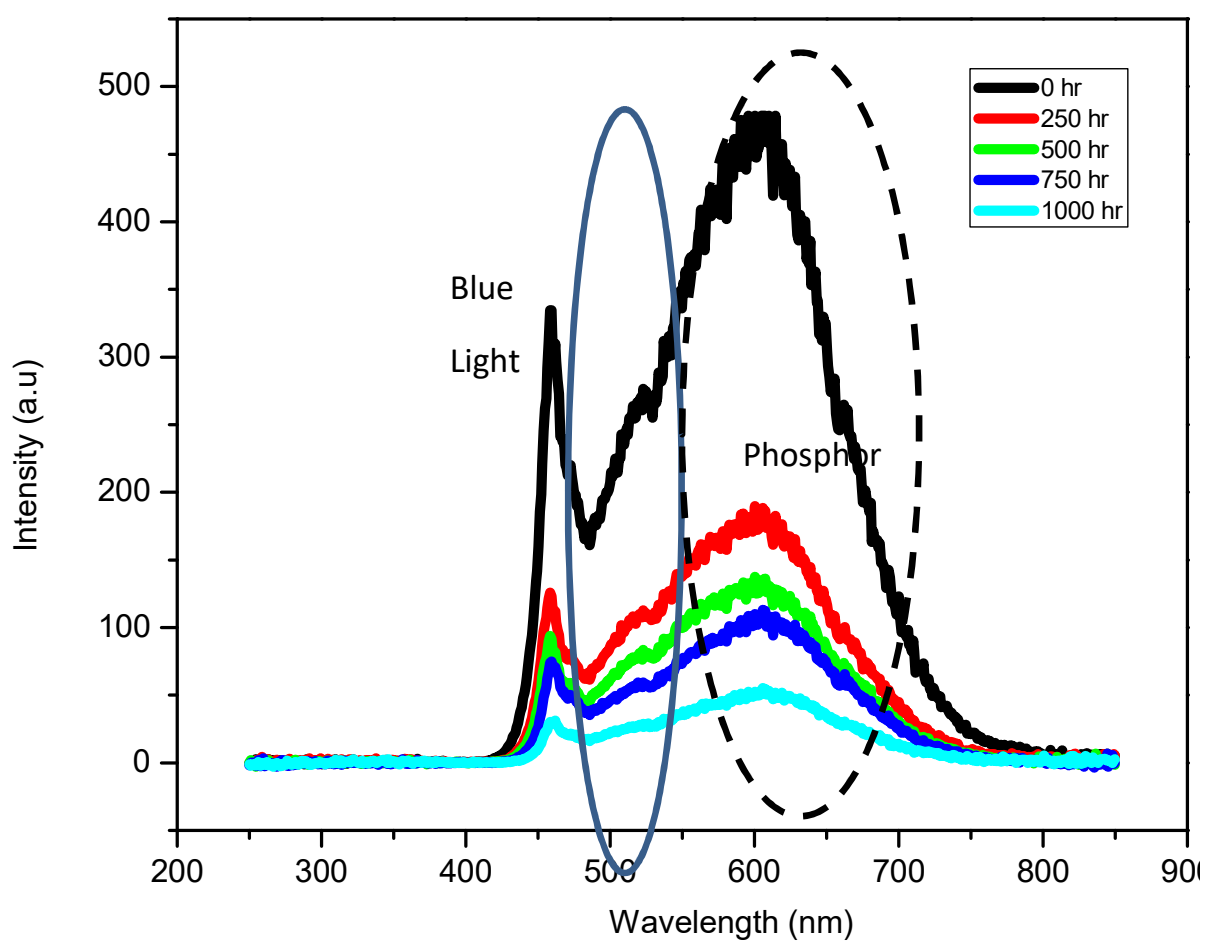

Figure 6.13 Photoluminescence spectra of Cu NPs on Au metallization of a white light LED (blue + phosphor) operated at $3 \mathrm{~V}$ at room temperature for different ageing period 


\subsubsection{Thermomechanical Reliability}

The performance of $\mathrm{Cu}$ NPs bonded on LED modules after thermal cycling was also studied. The purpose of thermal cycling test is to accelerate the effects of thermal expansion mismatch between different materials across the die and substrate. Therefore, in this study, 15 LEDs samples were subjected to a temperature cycling profile of $-55^{\circ} \mathrm{C}$ to $125^{\circ} \mathrm{C}$ with $1 \mathrm{hr} /$ cycle for 300 cycles. At every 100 cycles, 5 samples were taken for mechanical and microstructure analysis.

From the thermal cycling test results, a small decrease in shear strength was observed after 100 cycles and a drastic decrease in shear strength was observed after 200 cycles (Figure 6.14).

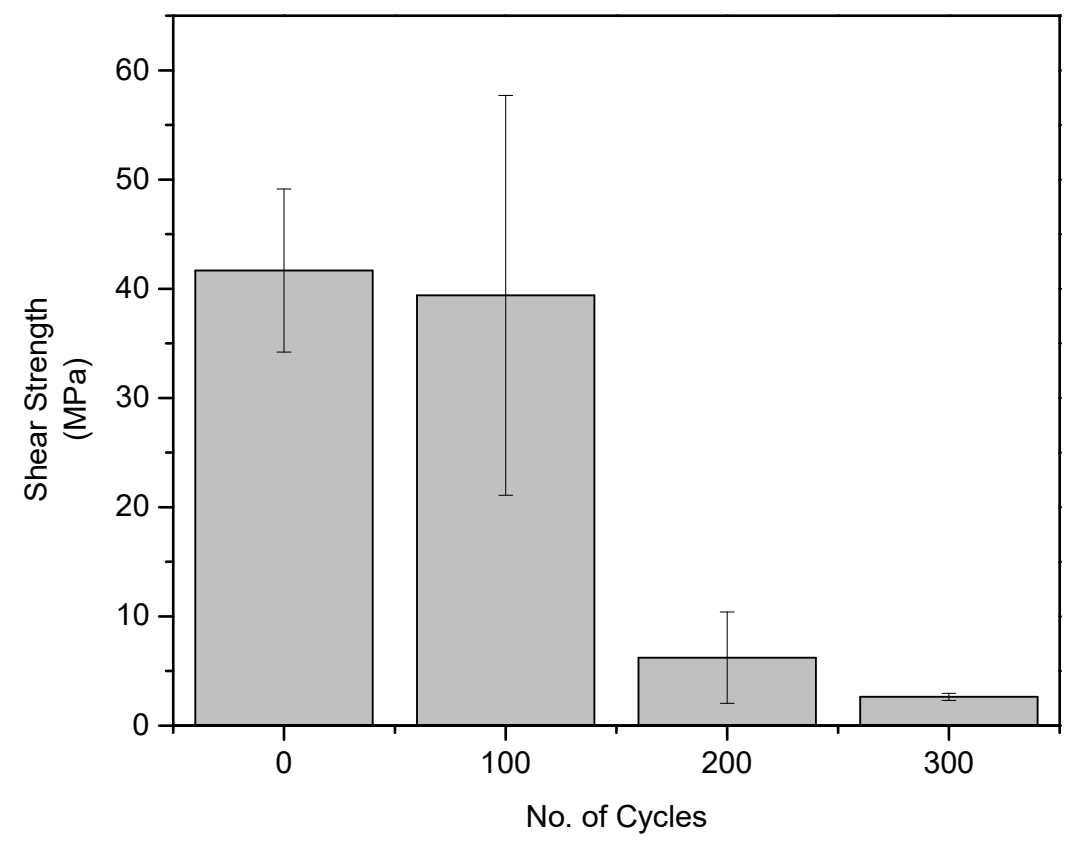

Figure 6.14 Shear strengths of Cu NPs bonded LEDs after thermal cycling

This initial small decrease in shear strength is possibly due to horizontal cracks between the $\mathrm{Cu}$ NPs and $\mathrm{Au}$ metallization of the LED substrate (6.15(a)). 
Subsequently after 200 thermal cycles, there are two distinct fracture paths: the presence of vertical cracks within the $\mathrm{Cu}$ NPs layer and more distinct horizontal cracks along the $\mathrm{Ag}$ and $\mathrm{Cu}$ NPs bonding interfaces (6.15(b)). These two occurrences could potentially give rise to a significant drop in shear strength. This is even more obvious for samples that have undergone 300 cycles where delamination between $\mathrm{Ag}$ and $\mathrm{Cu}$ was severe and the vertical cracks across the $\mathrm{Cu}$ NPs layer had grown bigger. As a result, the shear strength dropped to $\sim 3$ MPa after 300 cycles.

The delamination from the bonding interfaces as observed from the FESEM images (Figure 6.15 (b) and (c)) could be due to the different types of materials present throughout the entire LED module. The LED module consists of a silicon carbide (SiC)-based InGaN LED die with Au metallization, and Ag-plated metallization on a ceramic $\left(\mathrm{Al}_{2} \mathrm{O}_{3}\right)$ substrate.
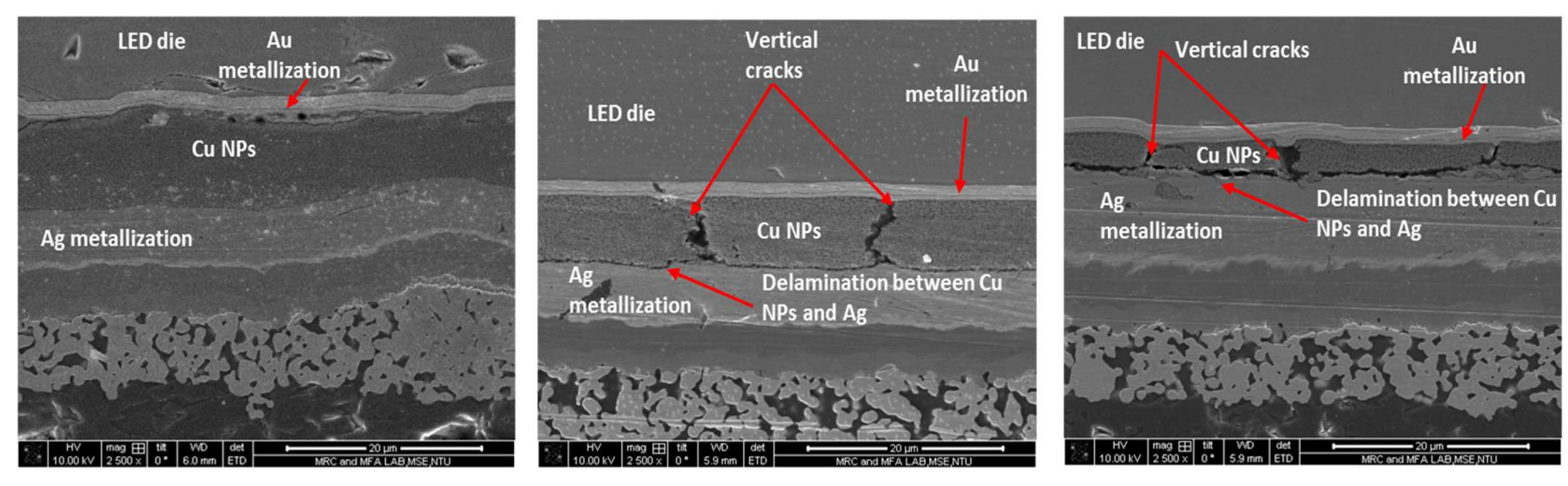

Figure 6.15 FESEM images of Cu NPs LED modules after (a) 100 cycles, (b) 200 cycles, (c) 300 cycles (Scale: $20 \mu \mathrm{m}$ )

Hence, there will be a large CTE mismatch across the entire LED module that can potentially cause thermal mismatch stresses during temperature cycling. Table 6.3 shows the CTE of the materials mentioned above. 
Table 6.3 CTE of materials across the entire LED module [12]

\begin{tabular}{|c|c|}
\hline Material & $\begin{array}{c}\text { Coefficient of Thermal Expansion at } \\
20^{\circ} \mathrm{C}\left(10^{-6} \mathrm{~K}^{-1}\right)\end{array}$ \\
\hline $\mathrm{Au}$ & 14 \\
\hline $\mathrm{Ag}$ & 18 \\
\hline $\mathrm{Cu}$ & 17 \\
\hline $\mathrm{SiC}$ & 2.77 \\
\hline $\mathrm{Al}_{2} \mathrm{O}_{3}$ & 4.5 \\
\hline
\end{tabular}

It has been reported that the thermo-mechanical properties of sintered $\mathrm{Ag}$ particles are good due to the presence of pores that lower its elastic modulus. With a lower elastic modulus, it will transfer less of the thermally induced stresses from the CTE mismatch between the LED chip and substrate [13].

However, the presence of pores and grain growth in the sintered $\mathrm{Cu}$ NPs may reduce the shear strength due to creep dislocations piling up at the grain boundaries and form microcavities [14]. This is because the thermal stresses at these pores, micrograins and interfaces between fused $\mathrm{Cu}$ NPs clusters could be sufficiently high to produce dislocation creep during thermal cycling due to stress-concentration effect [2] [14]. In addition, most studies [13-15] that have reported good thermo-mechanical properties of sintered NPs joints were based on Ag NPs bonded on Ag coated ceramic substrates. Hence, the CTE mismatch was lower, and strong and stable bonds at the bonding interfaces could be achieved as they were bonded between the same material. In the current study, the chip and substrate metallization were $\mathrm{Au}$ and $\mathrm{Ag}$, respectively, and the dieattach layer was $\mathrm{Cu}$ NPs. Moreover, the total contact area at the bonding interfaces is $<100 \%$ (Figure 6.16) since these $\mathrm{Cu}$ NPs do not melt and wet the bonding surfaces like conventional solders materials. Hence, there are nanopores at the bonding interfaces as well. This could possibly become an additional area for thermal stress accumulation that allows cracks to propagate and weaken the shear strength after cycling.

As for the vertical cracks within the sintered $\mathrm{Cu}$ NPs, they could be formed due to the occurrence of thermal stresses during the cycling process. Before the start of cycling, it is observed from Figure 6.4 and Figure 6.11(a) that not all Cu NPs were well fused. Those points where there was no or little necking between $\mathrm{Cu}$ 
NPs could become potential areas for cracks to form during the thermal cycling test. From the fracture surfaces of the as-bonded samples (Figure 6.17), it is observed that there were small "islands" on the fracture surfaces. This further proved that due to weak bonding among sintered $\mathrm{Cu}$ NPs clusters at certain regions, they allowed cracks to move through easily. Such voids or cracking could be due to fast solvent volatilization during sintering [16]. Though these voids were not big initially, they could act as stress concentration points that led to bigger voids and separation between the fused $\mathrm{Cu}$ NPs when subjected to thermal cycling. Hence, this type of failure is classified as Type 1 failure, which was explained in Chapter 5.

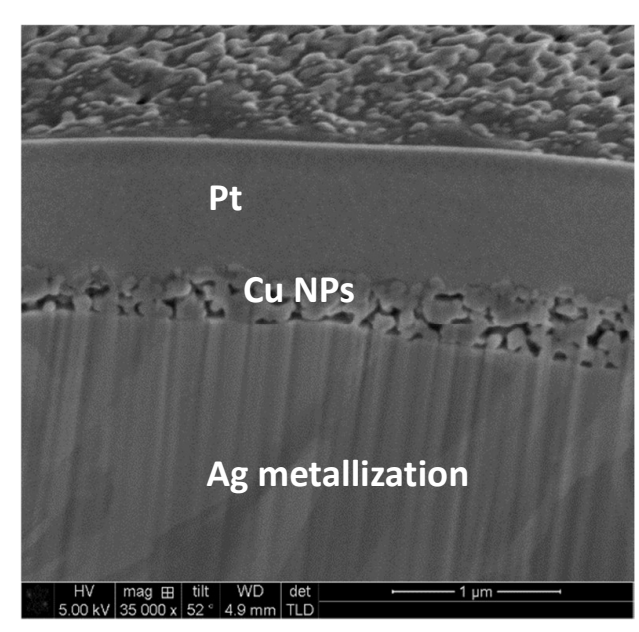

(a)

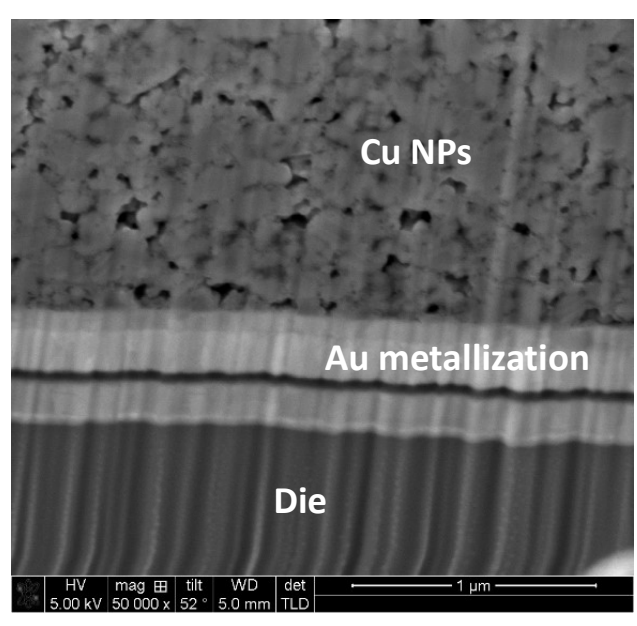

(b)

Figure 6.16 Voids were present at the bonding interface between $\mathrm{Cu}$ NPs and (a) Ag, and (b) Au metallization after sintering 


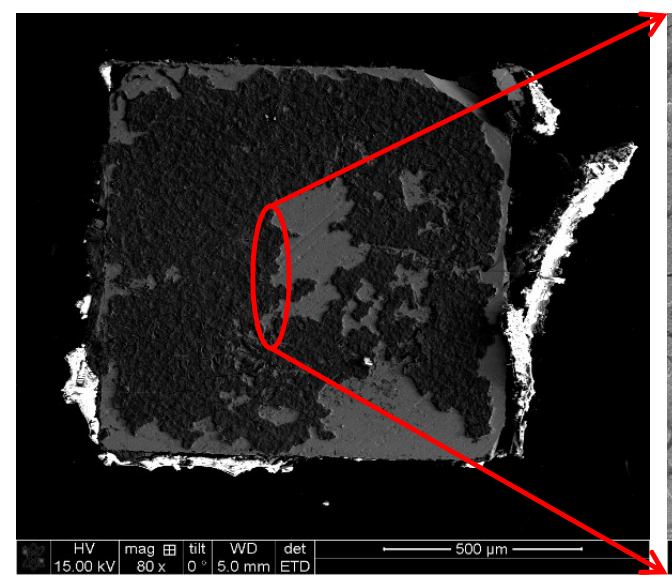

(a)

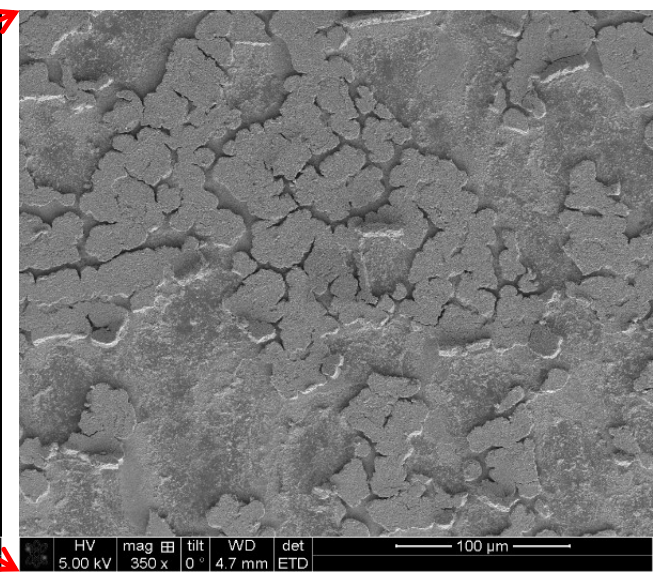

(b)

Figure 6.17 (a) FESEM image of sheared surface of an as-bonded LED chip (b) Zoomed-in on the "islands" of sintered Cu NPs clusters

\subsection{Conclusion}

In this chapter, the feasibility of using $\mathrm{Cu}$ NPs as a die-attach material for high power LEDs application is demonstrated. In the first part of the study, AuSn solder, which is the current material used in such application, was used to provide a reference for the $\mathrm{Cu}$ NPs. From the electrical, thermal and optical characterizations, it is observed that the $\mathrm{Cu}$ NPs has a lower electrical resistance than AuSn solder, which resulted in a higher light intensity when a same voltage was applied. With a higher thermal conductivity, the Cu NPs LED also has a lower junction temperature as compared to AuSn one. This was achieved even though the peak temperature for processing $\mathrm{Cu}$ NPs was only $280^{\circ} \mathrm{C}$, which is $40^{\circ} \mathrm{C}$ lower than AuSn peak reflow process. The shear strength for both materials was comparable as well.

Some reliability tests such as long-term high temperature storage and thermal cycling were carried out on the $\mathrm{Cu}$ NPs samples. From the long term high temperature storage test, a reduction in shear strength after $1000 \mathrm{hrs}$ at $200^{\circ} \mathrm{C}$ was obtained though no big voids or cracks were observed, and the LEDs dice were still intact. Such observation could be due to the further non-uniform densification of $\mathrm{Cu}$ NPs during isothermal ageing. Moreover, the contact area between the bonding interfaces ( $\mathrm{Au}$ and $\mathrm{Ag}$ ) and $\mathrm{Cu}$ NPs layer was not 
continuous as the $\mathrm{Cu}$ NPs do not melt and wet the surfaces like conventional solders. Hence, adhesion failures were observed during shear test after prolong aging.

Furthermore, due to the dissimilar bonding interfaces, it leads to thermal stress accumulation during thermal cycling. Hence delamination at the bonding interface was also observed after 300 cycles. In addition, due to the fast volatilization of solvent, the fusion between $\mathrm{Cu}$ NPs were not very strong. Therefore, vertical cracks across the sintered $\mathrm{Cu}$ NPs layers were observed after 300 cycles. With all these cracks and delamination at the interfaces, it weakened the overall shear strength. Therefore, though $\mathrm{Cu}$ NPs shows potential and feasibility to be used as a replacement for AuSn solder for high temperature solders, the processing parameters and materials used at bonding interfaces have to be optimized and designed to achieve good and reliable joints. 


\section{References}

1. Li, X., X. Chen, and G.-Q. Lu, Reliability of High-Power Light Emitting Diode Attached With Different Thermal Interface Materials. Journal of Electronic Packaging, 2010. 132(3): p. 031011-031011.

2. Manikam, V.R. and C. Kuan Yew, Die Attach Materials for High Temperature Applications: A Review. Components, Packaging and Manufacturing Technology, IEEE Transactions on, 2011. 1(4): p. 457-478.

3. Kobayashi, Y., et al., A metal-metal bonding process using metallic copper nanoparticles produced by reduction of copper oxide nanoparticles. Journal of Materials Research and Technology, 2014. 3(2): p. 114-121.

4. Knoerr, M. and A. Schletz. Power semiconductor joining through sintering of silver nanoparticles: Evaluation of influence of parameters time, temperature and pressure on density, strength and reliability. in Integrated Power Electronics Systems (CIPS), 2010 6th International Conference on. 2010.

5. Yamakawa, T., et al., Influence of Joining Conditions on Bonding Strength of Joints: Efficacy of Low-Temperature Bonding Using Cu Nanoparticle Paste. Journal of Electronic Materials, 2013. 42(6): p. 1260-1267.

6. Krishnan, S., A.S.M.A. Haseeb, and M.R. Johan, Preparation and LowTemperature Sintering of $\mathrm{Cu}$ Nanoparticles for High-Power Devices. Components, Packaging and Manufacturing Technology, IEEE Transactions on, 2012. 2(4): p. 587-592. 7. Elger, G., et al., Development of an assembly process and reliability investigations for flip-chip LEDs using the AuSn soldering. Microsystem Technologies, 2002. 7(5): p. 239-243.

8. Zhang, J., J. Zhang, and L. Yang, Effects of the Thermocompression Bonding on the Microstructure and Contact Resistance for the Ultrafine Pitch Chip-on-Glass Packaging With Nonconductive Film. Journal of Electronic Packaging, 2010. 132(4): p. 044501-044501-6

9. Lee, Teck Kheng, Sam Zhang, C. C. Wong, A. C. Tan, and Davin Hadikusuma. "Interfacial microstructures and kinetics of Au/SnAgCu." Thin Solid Films 504, no. 1 (2006): 441-445.

10. Zhou, T., et al., Au/Sn solder alloy and its applications in electronics packaging. Internal Report of Coining, Inc., 1999. 
$\underline{\mathrm{Cu} N P s \text { as Interface Materials for High Power LEDs }}$

Chapter 6

11. T3Ster $^{\circledast}$. 20 Apr 2016]; Available from: https://www.mentor.com/products/mechanical/micred/t3ster/industries.

12. Thermal expansion. [cited 201631 August]; Available from: https://en.wikipedia.org/wiki/Thermal expansion.

13. Khazaka, R., L. Mendizabal, and D. Henry, Review on Joint Shear Strength of Nano-Silver Pasteand Its Long-Term High Temperature Reliability. Journal of Electronic Materials, 2014. 43(7): p. 2459-2466.

14. Bai, J.G. and L. Guo-Quan, Thermomechanical Reliability of Low-Temperature Sintered Silver Die Attached SiC Power Device Assembly. Device and Materials Reliability, IEEE Transactions on, 2006. 6(3): p. 436-441.

15. Guo-Quan, L., et al. Low-temperature and Pressureless Sintering Technology for High-performance and High-temperature Interconnection of Semiconductor Devices. in Thermal, Mechanical and Multi-Physics Simulation Experiments in Microelectronics and Micro-Systems, 2007. EuroSime 2007. International Conference on. 2007.

16. Kuramoto, M., et al., New Silver Paste for Die-Attaching Ceramic Light-Emitting Diode Packages. Components, Packaging and Manufacturing Technology, IEEE Transactions on, 2011. 1(5): p. 653-659. 


\section{Chapter 7}

\section{Discussion and Future Work}

This chapter concludes the overall work presented in the previous chapters. Firstly, a general discussion starting from the sintering mechanism of different metallic NPs used by researchers and the challenges that needs to be addressed and overcome were mentioned. More importantly is that at the current moment, $\mathrm{Ag} N P s$ and $A u$ NPs are being mentioned more often than $\mathrm{Cu} N P s$ due to their high resistance to oxidation and ease to handle. Another area that were lacked of further research is the long-term reliability studies of $\mathrm{Cu}$ NPs. Thus further in-depth studies need to be carried out and discussions from each chapter of this thesis will be given in the following sections of this chapter. In addition, some reconnaissance work that were done but not mentioned in the main chapters of this thesis is briefly included in this chapter. After which key conclusions from this work will be identified and some outstanding questions such as the bondability of $\mathrm{Cu}$ NPs to other common metallic surfaces such and other mechanical properties such as hardness and tensile strength can be further study to understand the mechanical properties difference between $\mathrm{Cu}$ NPs and bulk copper. All these are listed as some of the recommendations for future work. 


\subsection{General Discussion}

In this study, the sintering mechanism of metallic $\mathrm{Cu}$ NPs is being studied extensively. Though many studies on metallic NPs have been carried out by various research groups, the type of metallic NPs, synthesis technique and size of NPs were largely different. This poses a huge challenge for direct comparison between studies. Moreover, these studies were more focused and developed for Ag NPs, which is much easier to handle as they do not oxidize easily and can be processed under air condition. However, $\mathrm{Ag}$ is much costlier than $\mathrm{Cu}$ and it suffers from ion migration. Therefore, $\mathrm{Cu}$ is the next alternative because it has already been used throughout the electronics industry as a trace, interconnect and pad material. This minimizes compatibility issues. Moreover, when compared to $\mathrm{Ag}$ and $\mathrm{Au}$, it is cheap and abundant. In addition, the thermal and electrical conductivity of $\mathrm{Cu}$ is relatively high, which makes it suitable for use in interconnects and die-attach applications. Though studies on $\mathrm{Cu}$ NPs have started, the long-term reliability data of $\mathrm{Cu}$ NPs is still lacking, partly due to the fact that the development of the basic understanding of $\mathrm{Cu}$ NPs is still in progress.

Hence in this thesis, it is divided into 3 main parts. The first part looks into the development of a novel and fast technique to understand the sintering mechanism and behavior of these $\mathrm{Cu}$ NPs when subjected to different sintering parameters by measuring the electrical resistance during sintering. This is important for the next 2 chapters of the thesis as the $\mathrm{Cu}$ NPs paste will be used for bonding applications and its long-term reliability will be studied. Discussions on the various chapters will be explained in the following sections with some outstanding questions to be raised.

\subsubsection{Understanding Cu NPs Sintering Mechanism Through In-Situ Electrical Resistance Measurement}

The primary objective of this work is to characterize the $\mathrm{Cu}$ NPs and evaluate its feasibility as a low temperature bonding material. In Chapter 4, the sintering mechanism and behavior of Cu NPs using a simple technique of in-situ electrical resistance measurement during sintering was investigated. The change in electrical resistance measured during sintering is used to correlate with the 
results obtained from thermal analysis techniques such as TGA and DSC that were carried out separately. Since these $\mathrm{Cu}$ NPs are capped with organic layers to prevent agglomeration, aggregation and unwanted fusion prior to thermal treatment, they are not electrically conductive. However, as it undergoes thermal treatment, these capping layers are removed from the $\mathrm{Cu}$ NPs surfaces and fusion of these particles occurs, thus forming electrically conductive paths. By studying the change in electrical resistance during sintering, the onset temperature of evaporation of the organic materials and fusion of $\mathrm{Cu}$ NPs can be known for different sintering conditions. A simple model was developed to determine the dominant sintering mechanism at the initial stage based on the resistance change with time during isothermal annealing. In addition, it is observed that the rate of change of resistance during heating up is related to the rate of removal of organic materials at different sintering conditions. Therefore, this technique is useful for designing optimal sintering conditions for all types of organic passivated metallic NPs. In addition, it can also provide a quick check on whether these NPs are fully sintered each time. In addition, with the observation in the change in electrical resistance during sintering, the ability to capture the immediate microstructure at each time step for subsequent analysis is made possible. This means that freezing the microstructure of the $\mathrm{Cu}$ NPs at certain stages based on the change in electrical resistance can be done and it is useful for microstructure evolution study for deeper understanding of the dominant sintering mechanism. For the $\mathrm{Cu}$ NPs studied, the dominant sintering mechanism when heating rate is low $\left(7^{\circ} \mathrm{C} / \mathrm{min}\right)$ is identified as surface diffusion. This related well with the FESEM images as large amount of porosities were still present after sintering.

For the heating rate of $17^{\circ} \mathrm{C} / \mathrm{min}$ samples, the proposed model with the parameters extracted suggests that the dominant sintering mechanism is due to lattice diffusion from the surface. Lattice diffusion is commonly reported to cause densification since the source of material originates from the grain boundary. However, in this study, the proposed model suggests it was lattice diffusion from the surface and no densification was observed. This could mean that the source of material during diffusion is from the nanoparticle surface, hence no densification was observed. Thus, in this thesis, it is still classified as surface diffusion. However, the model and technique are limited to the initial stage of sintering, as minimum or no shrinkage of sintered $\mathrm{Cu}$ NPs layer is 
assumed in the model and the electrical resistance does not change too much after the initial stage of sintering. Hence, an advanced model that considers resistivity instead will be useful since the thickness of the sintered $\mathrm{Cu}$ layer will have a great influence on the electrical performance.

\subsubsection{Enabling Low Temperature Bonding Using Cu NPs}

After establishing a fast and simple technique to characterize the $\mathrm{Cu}$ NPs at different sintering conditions, it shows the potential of such $\mathrm{Cu}$ NPs to be sintered at a low temperature (i.e. $200^{\circ} \mathrm{C}$ ). In Chapter 5 , based on the basic understanding of the sintering behavior of $\mathrm{Cu}$ NPs, different sintering conditions were studied for bonding. The focus here is on low temperature bonding applications and its long-term thermal stability.

In the first part of Chapter 5, a suitable heating rate was re-established since it is now a sandwich bonding structure which is different from Chapter 4 . The effects of bonding temperature, pressure and type of bonding environment were studied. A change in the mechanistic bond formation was observed when bonding was done at $300^{\circ} \mathrm{C}$. It is observed from the studies that when bonding was done at low temperature $\left(200^{\circ} \mathrm{C}\right)$, the shear strength does not increase much after prolong annealing. However, when bonding temperature increases to $250^{\circ} \mathrm{C}$ and $300^{\circ} \mathrm{C}$, longer hold time at peak temperature will cause the shear strength to increase substantially.

As the goal is to develop good fusion of Cu NPs at low temperature, applying a pressure during bonding is being investigated to improve the joint integrity. Bonding pressures between 1-5 MPa were exerted during the bonding process. It is noticed that the dominant sintering mechanism is still based on diffusion process up till $3 \mathrm{MPa}$. Ductile failure was observed on the fracture surfaces for samples that were bonded with a $5 \mathrm{MPa}$ pressure. Hence by introducing pressure, it does improve the bond strength. Though the introduction of pressure can lead to a better joint integrity at low temperature, pressureless bonding is preferred in some applications. 
Since we know that the fusion of such $\mathrm{Cu}$ NPs is dependent on the removal of passivation layers, a method to increase the rate of passivating layers' removal should be looked into. Based on the results found in Chapter 4, the removal of the passivating layers is very fast and possible when high heating rate is used under formic acid vapor environment as compared to $\mathrm{N}_{2}$ environment. Hence formic acid is only introduced at peak temperature to allow volatilization and fusion to occur only at the maximum temperature. Results show a less porous microstructure with strong necking between $\mathrm{Cu}$ NPs and good bond integrity though high heating up rate $\left(40^{\circ} \mathrm{C} / \mathrm{min}\right)$ and shorter total cycle time were used. Therefore, from this study, it is established that it is possible to sinter these $\mathrm{Cu}$ NPs at a low temperature of $200^{\circ} \mathrm{C}$ and below

The most important factor in determining the bond property is the effectiveness of passivating layer removal. Such removal will enable more uniform necking among $\mathrm{Cu}$ NPs clusters that results in higher shear strength. It is also observed from the different microstructures of various sintering conditions that porosity of the sintered layer cannot be taken solely to estimate the joint integrity. The degree of necking formed by those fused $\mathrm{Cu}$ NPs has a more direct effect on the overall joint integrity.

Lastly, long-term thermal stability of sintered $\mathrm{Cu}$ NPs joints was studied. From the results, the shear strength of the joints increases with time and porosity decreases when isothermally annealed at $150^{\circ} \mathrm{C}$ for 1000 hours in air condition. Grain growth of these $\mathrm{Cu}$ NPs after isothermal annealing was observed using exsitu $\mu$ XRD. These preliminary reliability results provide a new insight towards the stability of such sintered $\mathrm{Cu}$ joint that allows it to be tailored for different high power die-attach applications.

\subsubsection{Cu NPs Bonding Application in High Power LEDs Die Attach}

After studying the effects of sintering parameters on its microstructure and shear strength, the final objective of the thesis is to adopt this material for usage as a die-attach material for high power LEDs applications since the sintered $\mathrm{Cu}$ NPs joints show good long-term stability in Chapter 5. When the LEDs dies were bonded with $\mathrm{Cu}$ NPs or AuSn solder, the LEDs bonded with $\mathrm{Cu}$ NPs demonstrated comparable or even better mechanical, electrical and optical 
performance as the die-attach material. It is worth pointing out that the peak sintering temperature of $\mathrm{Cu}$ NPs was only $280^{\circ} \mathrm{C}$, which is $40^{\circ} \mathrm{C}$ lower than the peak reflow temperature of AuSn solder. Though the mechanical strength of the joints is slightly lower for $\mathrm{Cu}$ NPs due to the presence of small voids at the bonding interfaces, the $\mathrm{Cu}$ NPs joints outperform AuSn ones in terms of electrical and optical properties. This is likely due to the presence of IMCs in the AuSn joints that would increase the interface resistance and thus affect the overall electrical performance. On the other hand, for $\mathrm{Cu}$ NPs joint, the electrical resistance is lower due to the good electrical properties of $\mathrm{Cu}$. Moreover, the thermal conductivity for the $\mathrm{Cu}$ NP layer is higher than that of the AuSn one. Though pores were present in the sintered $\mathrm{Cu}$ joint, the optical performance of the $\mathrm{Cu}$ NPs joint is still better than that of AuSn. This could be due to the LEDs that were bonded with $\mathrm{Cu}$ NPs having a lower electrical resistance as compared to AuSn joint. In addition, it could be due to the $\mathrm{Cu}$ NPs having a higher thermal conductivity than AuSn solder.

With these preliminary data, reliability tests such as high temperature isothermal storage and thermo-mechanical reliability tests on the LEDs that were bonded with $\mathrm{Cu}$ NPs were carried out. From the isothermal ageing test, the shear strength of the $\mathrm{Cu}$ NPs joint decreases with time. This decrease in shear strength could be due to the weak interface bonding between $\mathrm{Au} / \mathrm{Cu}$ NPs and $\mathrm{Ag} / \mathrm{Cu}$ NPs. As pointed out earlier, the joining of $\mathrm{Cu}$ NPs to the bonding surfaces does not involve melting of the $\mathrm{Cu}$ NPs paste. Hence the contact area between $\mathrm{Cu}$ NPs and bonding surfaces is less than $100 \%$ after bonding. With the presence of small voids at the bonding interfaces, these voids might coalescence and form microvoids as ageing time increases. This allows cracks to propagate easily along the interfaces. The other possible reason for failure to occur at the interface is the densification of $\mathrm{Cu}$ NPs during ageing. From the FESEM images, it is observed that the amount of porosities across the sintered layer changes and the Cu NPs located near the bonding interfaces have further densified. This would cause more voids at the interfaces to form that allow cracks to propagate easily. Therefore, as ageing time increases, an increase in mixture of adhesive and cohesive fracture surface was observed. Lastly, oxidation, is a possibility in this reliability study as all these LEDs samples were not encapsulated, and signs of 
oxidation were observed in the $\mathrm{Cu}$ NPs at the edges of the die. However, in actual fully encapsulated devices, this may not be a key factor.

For the thermo-mechanical reliability tests of the sintered $\mathrm{Cu}$ NPs joints, due to the large CTE mismatch between Cu NPs, die and substrate, and the presence of voids along bonding interfaces, cracks were observed along the bonding interfaces and within the sintered layer. Though there have been reports stating that a porous sintered layer has a lower elastic modulus that will transfer less of the thermally induced stresses from the CTE mismatch between die and substrate, the contact between sintered $\mathrm{Cu}$ NPs and bonding surfaces before thermal cycling must be good. To improve the contact between $\mathrm{Cu}$ NPs and bonding interfaces, a higher peak sintering temperature of $>280^{\circ} \mathrm{C}$ is required for good sintering process between $\mathrm{Cu}$ NPs and substrate, and fusion among $\mathrm{Cu}$ NPs. In addition, other ways of improving the contact at bonding interfaces is important as the sintering of $\mathrm{Cu}$ NPs does not involve a change of solidus to liquidus state that wets the bonding surfaces.

\subsection{Reconnaissance work not included in main chapters}

When formic acid was introduced during the bonding process, one interesting observation that is not included in the main chapters is the change in color of the $\mathrm{Cu}$ NPs during bonding under different bonding environment. To correlate the change in electrical resistance with color of the $\mathrm{Cu}$ NPs paste, snapshots of the $\mathrm{Cu}$ NPs at different sintering time and ambient are shown in Figure 7.1.

(a)

(b)

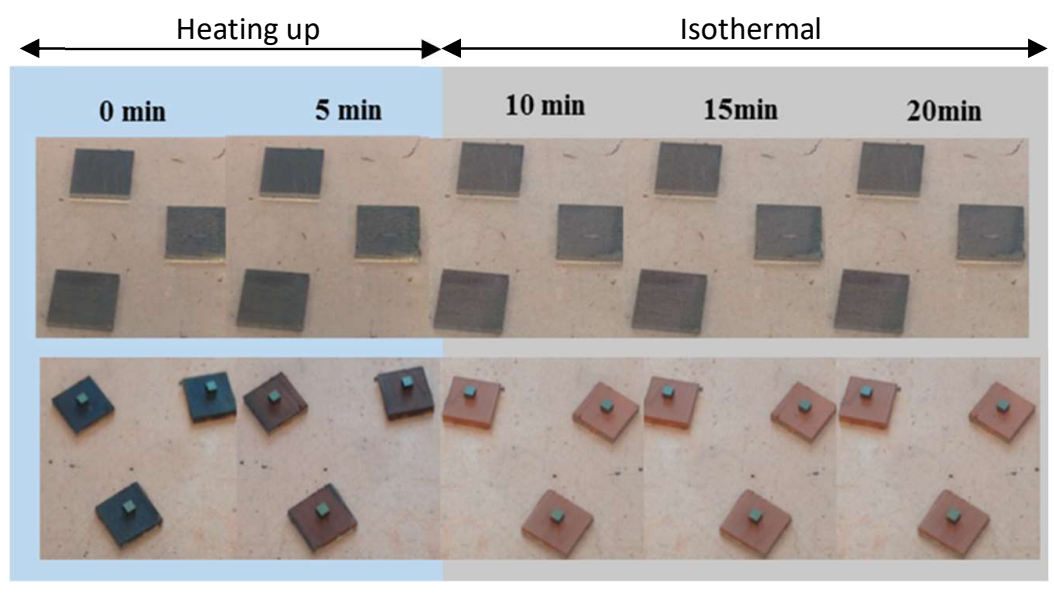

Figure 7.1 Color change during bonding under (a) N2 (b) Formic Acid 
It is observed that no significant color change was observed when bonding was done under $\mathrm{N}_{2}$ after fast heating up to $200^{\circ} \mathrm{C}$. However, under formic acid environment, color change was observed only at peak bonding temperature. This shows the effective removal of passivating layers and the onset of fusion with significant degree of necking between $\mathrm{Cu}$ NPs. Since surface plasmon resonance absorption of metallic $\mathrm{Cu}$ nanoparticles results in a red color, the reddening observed in Figure 7.1 for formic acid assisted sintering at 10 minutes implied the production of metallic $\mathrm{Cu}$ nanoparticles [5]. Hence the change in electrical resistance can be simply detected by changes in color of the $\mathrm{Cu}$ NPs and the latter can provide a quick way of gauging the final microstructure and bond strength of the sintered $\mathrm{Cu}$ layer at different bonding parameters.

\subsection{Outstanding Questions}

Through the work that was described in this thesis, we have shown the feasibility of $\mathrm{Cu}$ NPs to be used as a die-attach or for 3D interconnections. However, further studies have to be done on improving the contact area between $\mathrm{Cu}$ NPs and bonding interfaces. As sintering of metallic NPs, unlike conventional solder, does not involve melting, hence the wetting of bonding interfaces needs to study further. As shown in the results presented in Chapter 6, the degree of wetting of the bonding interfaces have a significant impact on the joint reliability. Though the mechanical strength and electrical properties of the bonds are good, after long-term high temperature storage or thermal cycling tests, these small voids along the bonding interfaces do have a negative impact on the joint integrity. Hence an in-depth focus on the bonding interfaces with $\mathrm{Cu}$ NPs would be worth studying. In addition, in most part of this work, the bonding of $\mathrm{Cu}$ NPs paste was done on $\mathrm{Cu}$ surfaces. Other metallic surfaces such as $\mathrm{Au}, \mathrm{Ag}, \mathrm{Sn}$, Ti can be looked into since they are the common materials found in electronics devices. It might be interesting to look into the bonding of Sn surfaces with $\mathrm{Cu}$ NPs. As Sn melts at $232^{\circ} \mathrm{C}$, it can flow into the pores and cracks of sintered $\mathrm{Cu}$ to form IMCs and affect the mechanical, electrical and reliability of the joint. The final microstructure might be a composite structure with fiber-like IMCs that could strengthen the overall mechanical properties of the sintered joint as they can act as crack deflection or stopping barrier. The rate of IMCs formation would also 
be an interesting area to study since the reaction of $\mathrm{Cu}$ and $\mathrm{Sn}$ has been studied widely but not the reaction of $\mathrm{Cu}$ NPs with $\mathrm{Sn}$.

In Chapter 4, the sintering and densification of $\mathrm{Cu}$ NPs is studied through a home-made test structure to provide a quick understanding of the sintering process. Based on this simple technique, the sintering mechanism was derived by studying the change in electrical resistance with temperature and time. In addition, it also provides a quick and simple method of qualifying the material in terms of the $\mathrm{Cu}$ NPs size and formulation. However, cracking of the Cu NPs paste has caused some challenges in measuring the electrical resistance during sintering. Therefore, further improvement can be made to the test structure to allow similar amount and thickness of $\mathrm{Cu}$ NPs across every test samples.

In Chapter 5, we have shown the effect of sintering parameters on the final microstructures of $\mathrm{Cu}$ NPs and proposed a sintering model. Therefore, future work can include some modelling to further investigate the sintering mechanism of $\mathrm{Cu}$ NPs under different ambient since they lead to different microstructures. More work can be done to examine the relationship between contact area at bonding interfaces with $\mathrm{Cu}$ NPs as they have a huge impact on the mechanical shear strength and reliability of the joint. The relationship between porosity and the mechanical properties of the sintered $\mathrm{Cu}$ NPs can be studied and compared with bulk copper. This includes the hardness and elastic modulus. As mention previously, change in resistivity with time for different sintering condition can be used to develop another sintering model that can predict the densification stage of $\mathrm{Cu}$ NPs sintering.

After studying the mechanical and electrical properties of $\mathrm{Cu}$ NPs, in Chapter 6, we have demonstrated the possibility of adopting these $\mathrm{Cu}$ NPs paste on actual LED modules. It does demonstrate good potential as compared to commercial AuSn solder. However, since the mechanism involved does not include melting like conventional solders, more study on increasing the contact area at bonding interfaces is needed. This may include changing the degree of roughness of the bonding surfaces, and ways to reduce the CTE mismatch such that they can be used as a die-attach material for low CTE die materials such as $\mathrm{SiC}$ and $\mathrm{GaN}$. Cracking across sintered joint is observed, especially after ageing or thermal 
cycling test. This will affect the electrical, mechanical and thermal properties. Hence further modification, enhancement and study of the formulation of $\mathrm{Cu}$ NPs paste such as adding suitable number of nanowires into the $\mathrm{Cu}$ NPs can possibly help to minimize cracks, strengthen and improve the joint reliability [6].

Last but not least, besides all the suggested areas that can be further explored based on the current studies, there are other related research works that are being pursued by others in the author's research group. This includes using the Cu NPs paste to bond tiny chips on flexible substrates as well as making $\mathrm{Cu}$ NPs ink for printing interconnects on flexible organic substrates.

\section{References}

1. Guo, W., et al., Low-Temperature Sintering Bonding Using Silver Nanoparticle Paste for Electronics Packaging. Journal of Nanomaterials, 2015. 2015: p. 7.

2. Buttay, C., et al. Die Attach of Power Devices Using Silver Sintering - Bonding Process Optimization and Characterization. in High Temperature Electronics Network (HiTEN). 2011. Oxford, United Kingdom.

3. Navarro, L., et al., Silver nano-particles sintering process for the die-attach of power devices for high temperature applications. Ingeniería mecánica, tecnología y desarrollo, 2012. 4(3): p. 97-102.

4. Khazaka, R., L. Mendizabal, and D. Henry, Review on Joint Shear Strength of Nano-Silver Pasteand Its Long-Term High Temperature Reliability. Journal of Electronic Materials, 2014. 43(7): p. 2459-2466.

5. Kobayashi, Y., et al., Preparation of metallic copper nanoparticles in aqueous solution and their bonding properties. Solid State Sciences, 2011. 13(3): p. 553558.

6. Peng, P., et al., Reinforcement of Ag nanoparticle paste with nanowires for low temperature pressureless bonding. Journal of Materials Science, 2012. 47(19): p. 6801-6811. 
Appendix

\section{Appendix A}

Based on MIL-STD-883E method 2019.5 Die shear strength Failure criteria, a device which fails any of the following criteria shall constitute a failure.

- Fails die strength requirements (1.0X) of Figure 1.

- Separation with less than 1.25 times the minimum strength (1.0X) specified in Figure 1 and evidence of less than 50 percent adhesion of the die attach medium.

- Separation with less than 2.0 times the minimum strength (1.0X) specified in Figure 1 and evidence of less than 10 percent of adhesion of the die attach medium

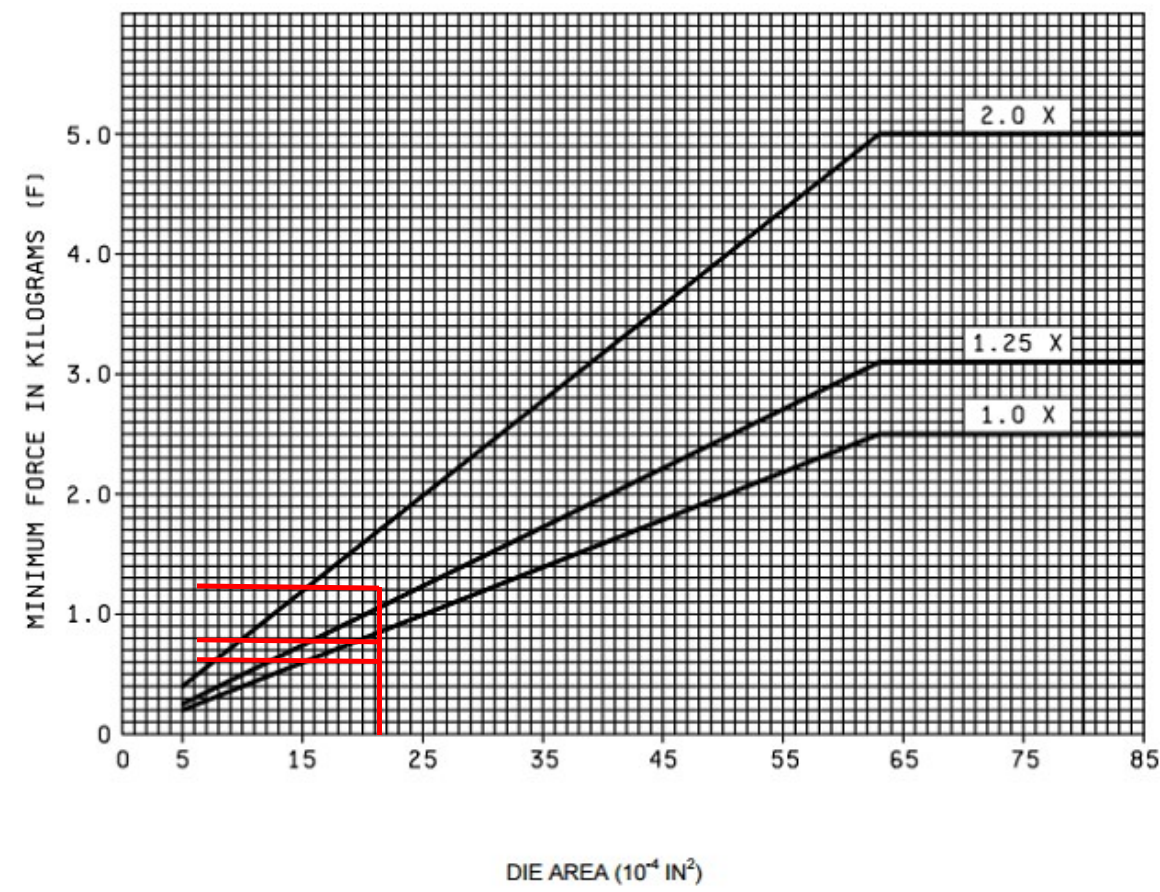

Figure 1 Die shear strength criteria (minimum force versus die attach area)

The die area used in this study is $1 \mathrm{~mm}^{2}$, which is equivalent to $15 \times 10^{-4} \mathrm{IN}^{2}$.

Based on the graph in Figure 1, the minimum force will be $0.6 \mathrm{~kg}$.

Thus, Shear strength $=0.6 \times 10^{6}=0.6 \mathrm{MPa}(1 \mathrm{X}), 0.75 \mathrm{MPa}(1.25 \mathrm{X}), 1.2 \mathrm{MPa}$ $(2 \mathrm{X})$ 


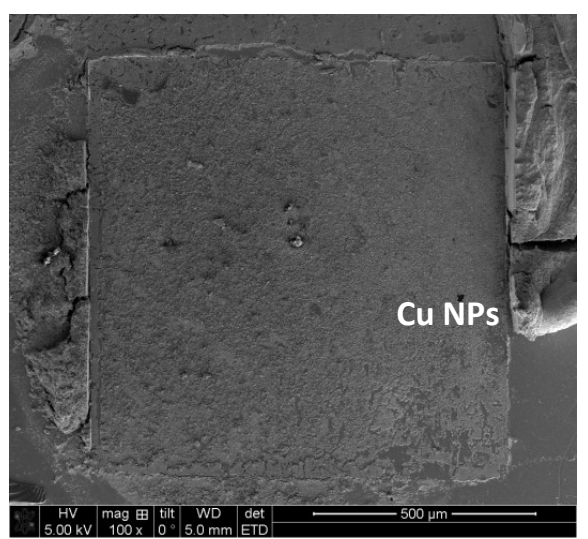

(a)

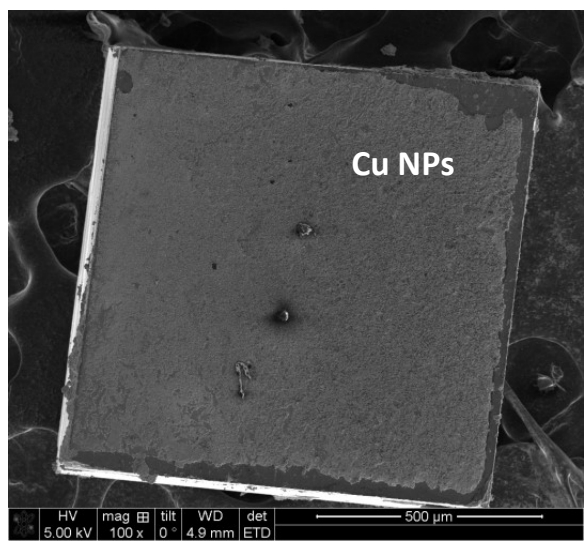

(b)

Figure 2 Failure interface of (a) Bottom Chip (b) Top Chip

All the sintered $\mathrm{Cu}$ NPs joints have a shear strength $\geq 2 \mathrm{MPa}$ and the sintered joints show cohesive failure with $>50 \%$ coverage. Thus, they have passed the MIL-STD-883E method 2019.5 failure criteria. 
Appendix

\section{Appendix B}

\section{Cu-Au plase Diagram}

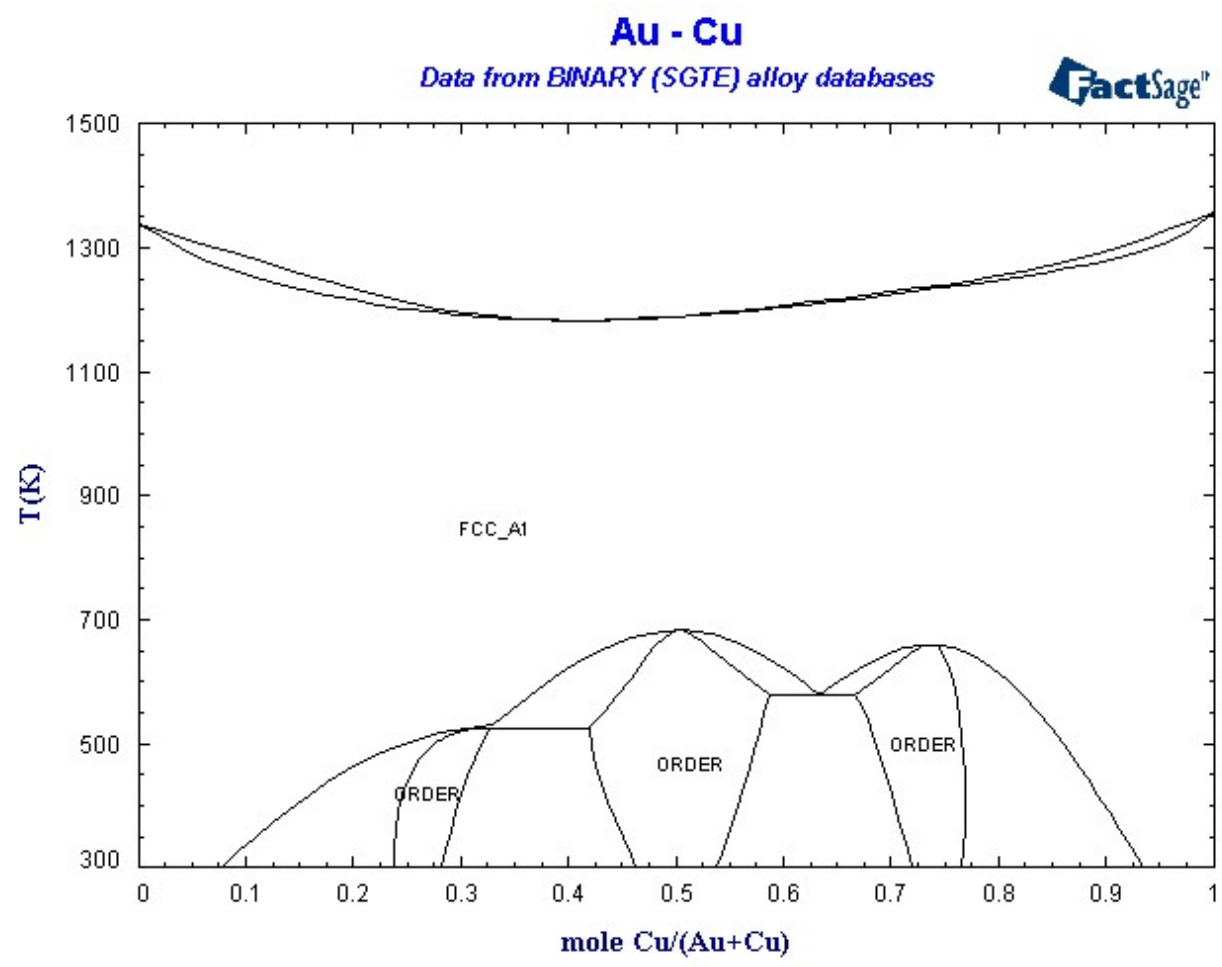

Figure 3: $\mathrm{Cu}-\mathrm{Au}$ plase Diagram

Image taken from: http://www.factsage.cn/fact/documentation/binary/binary figs.htm 
Appendix

\section{Appendix C}

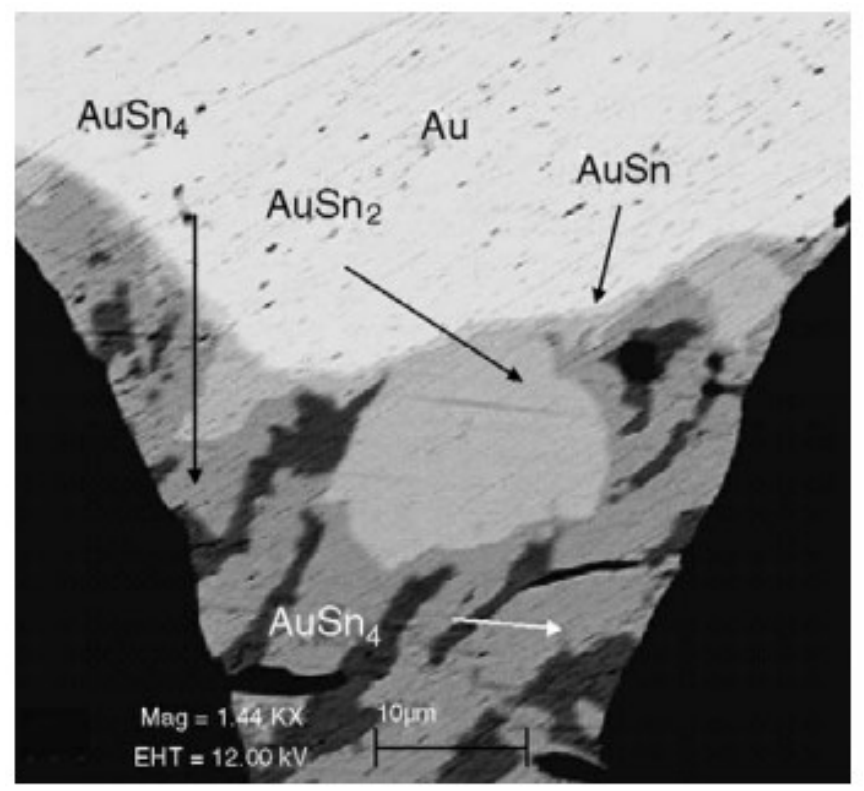

Figure 4: Different phases of AuSn IMCs

Image taken from: Lee, Teck Kheng, Sam Zhang, C. C. Wong, A. C. Tan, and Davin Hadikusuma.

"Interfacial microstructures and kinetics of Au/SnAgCu." Thin Solid Films 504, no. 1 (2006): 441-445. 